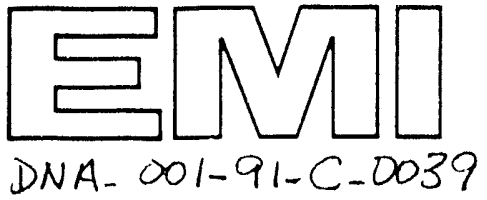

\title{
Airblast Environments From Buried HE Charges
}
H. Reichenbach
K. Behrens
A. Kuhl 


\section{DISCLAIMER}

Work performed under the auspices of the U.S. Department of Energy by Lawrence Livermore National Laboratory under contract number W-7405-ENG-48.

This document was prepared as an account of work sponsored by an agency of the United States Government. Neither the United States Government nor the University of California nor any of their employees, makes any warranty, express or implied, or assumes any legal liability or responsibility for the accuracy, completeness, or usefulness of any information, apparatus, product, or process disclosed, or represents that its use would not infringe privately owned rights. Reference herein to any specific commercial products, process, or service by trade name, trademark, manufacturer, or otherwise, does not necessarily constitute or imply its endorsement, recommendation, or favoring by the United States Government or the University of California. The views and opinions of authors expressed herein do not necessarily state or reflect those of the United States Government or the University of California, and shall not be used for advertising or product endorsement purposes. 
E $1 / 93$

\title{
Airblast Environments From Buried HE Charges
}

\author{
H. Reichenbach \\ K. Behrens \\ Fraunhofer-Institut für Kurzzeitdynamik \\ Ernst-Mach-Institut \\ Freiburg, Germany
}

A. Kuhl

Lawrence Livermore National Laboratory

El Segundo, CA, USA

January 1993

Contract No. DNA 001-91-C-0039

This work was sponsored by the Defense Nuclear Agency under RDT \& E RMSS Code B 4662 D RA RG 003524400 A AC

Work performed under the auspices of the U.S. Department of Energy by the Lawrence Livermore National Laboratory under contract number W-7405-ENG-48 and DNA IACRO number 92-824 and Work Unit 00001.

Prepared for

Director Nuclear Agency

Washington, DC 20305-1000

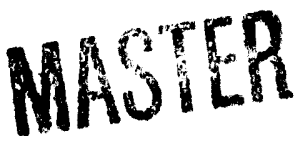

This Document consists of 167 Pages 


\section{SUMMARY}

Laboratory experiments were conducted to measure the airblast environment generated by the detonation of buried HE charges. Spherical 0.5 -g charges of Nitropenta were used as the HE source. Three ground materials were used: (1) a porous, crushable grout (YTONG, $\left.\rho=0.4 \mathrm{~g} / \mathrm{cm}^{3}\right) ;(2)$ a water-saturated grout $\left(\rho=0.7 \mathrm{~g} / \mathrm{cm}^{3}\right.$ ) to investigate the effects of density increase; and (3) a clay-loam material $\left(\rho=1.8 \mathrm{~g} / \mathrm{cm}^{3}\right)$ to simulate some of the previous field tests conducted in clay. Diagnostics consisted of 13 flush-mounted pressure gauges, and single-frame schlieren photography. A special shock isolation system was used to eliminate the acceleration effects on the gauges that were induced by the cratering process. Analysis of the pressure measurements resulted in an experimental definition of the airblast environment as a function of ground range (GR) and depth-of-burst (DOB). Synthesis of these results allowed one to construct airblast DOB curves (i.e., iso-environment curves in GR-DOB space), similar to the airblast heightof-burst curves that we published previously for Nitropenta charges. Variables analyzed were: peak pressure, arrival time, positive phase duration and impulse. As in field tesis, we found that the airblast waveforms changed character with increasing DOB: for small DOBs $\left(-0.25<\operatorname{DOB}\left(\mathrm{m} / \mathrm{kg}^{1 / 3}\right)<0.1\right)$, the waveforms had a classical blast wave character; for intermediate DOBs $\left.\left(0.1<\mathrm{DOB} \mathrm{m} / \mathrm{kg}^{1 / 3}\right)<0.25\right)$, a "front-porch" waveform was observed; while for deeper bursts (DOB $<0.35 \mathrm{~m} / \mathrm{kg}^{1 / 3}$ ), only compressional waveforms were found. The crater characteristics (e.g., depth, radius and volume) were also measured. The cube-root-scaled crater volume was in qualitative agreement with data from field tests (e.g., charge weights up to $10^{4} \mathrm{lbs}$.). Since the present scaled results compare well with data from large-scale HE tests, we conclude that the present experimental technique provides a useful tool for parametric investigations of explosion effects in the laboratory. 
TABLE OF CONTENTS

Section

Page

SUMMARY

i

FIGURES

v

TABLES

xiii

1 INTRODUCTION

2 EXPERIMENT DESIGN

2.1 SOIL MATERIAL 2

2.2 INSTALLATION OF THE CHARGE 2

2.2.1 Aerated Grout 3

2.2.2 Clay/Loam 3

2.3 INSTALLATION INTO THE EXPLOSION CHAMBER 4

3 TEST MATRIX 5

4 TEST RESULTS

4.1 CRATER , 7

4.1.1 Crater Form $\quad 7$

4.1.2 Crater Depth 11

4.1.3 Crater Volume 11

4.1.4 Crater Ejecta 12

4.1.5 Comparison with Results of Real Soil Materials 13 
iii

TABLE OF CONTENTS (Continued)

4.2 AIRBLAST ENVIRONMENTS 15

$\begin{array}{lll}\text { 4.2.1 Pressures } & 15\end{array}$

4.2.1.1 Wave Forms 15

4.2.1.2 Peak Overpressure 16

4.2.1.2.1 Fit Functions 16

4.2.1.2.2 Overpressure-Range Curves $\quad 17$

4.2.1.2.3 Estimation of Energy Absorption by Cratering Processes 18

4.2.1.2.4 Isobaric DOB-Curves $\quad 19$

$\begin{array}{lll}4.2 .2 & \text { Overpressure Impulses } & 20\end{array}$

4.2.2.1 Impulse-Range Curves 20

4.2.2.2 Fit Functions 20

4.2.2.3 Iso-Impulse DOB Curves 21

$\begin{array}{lll}\text { 4.2.3 Arrival Times } & 22\end{array}$

4.2.3.1 Arrival-Time - Range Curves 22

4.2.3.2 Fit Functions 22

4.2.3.3 Iso-Arrival Time DOB Curves 23

4.2.3.4 Independent Evaluation of Peak Overpressure 23

4.2.4 Positive Phase Durations 24

4.2.4.1 Duration-Range Curves 24

4.2.4.2 Fit Functions 25

4.2.4.3 Iso-Duration DOB Curves 26 


\section{TABLE OF CONTENTS (Concluded)}

4.2.5 Comparison with Results of Free Field Tests

4.2.5.1 Wave Forms 26

4.2.5.2 Peak Overpressures

27

4.2.5.3 Impulses of Positive Overpressure Phase

27

4.2.5.4 Arrival Times

27

4.2.5.5 Positive Phase Durations

28

$5 \quad$ CONCLUSIONS

29

6 LIST OF REFERENCES

30 


\section{FIGURES}

Figure

1 Installation of the $0.5-\mathrm{g}$ charge into aerated grout and shock-isolated mounting of the set-up into the explosion chamber.

2 General view showing the construction of the soil material holder.

3 Position of the shock-isolated pressure gauges MK 1 to MK 16.

4 Apparent crater dimensions of different charge geometries and definition of apparent and true crater depth, resp., [3]

5 Examples of craters in aerated grout (dry YTONG) at different depths of burst.

6 Examples of craters in water saturated grout (wet YTONG) at different depths of burst.

7 True crater contours in aerated grout (dry YTONG).

8 True crater contours in water saturated grout (wet YTONG).

9 True crater contours in wet clay/loam.

10 True crater depth in aerated grout (dry YTONG) vs depth of burst.

11 True crater depth in water saturated grout (wet YTONG) vs depth of burst.

12 True crater depth in wet clay/loam vs depth of burst.

13 Comparison of the crater depth approximation curves.

14 True crater volume in aerated grout (dry YTONG) vs depth of burst.

15 True crater volume in water saturated grout (wet YTONG) vs depth of burst.

16 True crater volume in wet clay/loam vs depth of burst.

17 Comparison of the crater volume approximation curves.

18 Examples of crater ejecta at different depths of burst in dry aerated grout (dry YTONG)

19 Examples of crater ejecta at different depths of burst in water saturated grout (wet YTONG)

20 Example of crater ejecta at different depths of burst in clay/loam 
vi

\section{FIGURES (Continued)}

Figure

21 Picture sequence of a high-speed film showing the movement of the crater ejecta and the shock wave formation. Test 816

Soil material: dry aerated grout (dry YTONG); DOB $=2.5 \mathrm{~cm}(0.315$ $\mathrm{m} / \mathrm{kg}^{1 / 3}$ )

22 Picture series of a high-speed film showing the movement of the crater ejecta and the shock wave formation. Test 799

Soil material: wet clay/loam; $D O B=2.5 \mathrm{~cm}\left(0.315 \mathrm{~m} / \mathrm{kg}^{1 / 3}\right)$

23 Position and velocity of crater ejecta

Soil material: wet clay/loam

$\mathrm{DOB}=2.5 \mathrm{~cm}\left(0.315 \mathrm{~m} / \mathrm{kg}^{1 / 3}\right)$. Test 799

24 True crater depth vs DOB for dry aerated grout (dry YTONG) compared with apparent crater depth of real soil materials [3].

25 True crater depth vs DOB for water-saturated grout (wet YTONG) compared with apparent crater depth of real soil materials [3].

26 True crater depth vs DOB for wet clay/loam compared with apparent crater depth of real soil materials [3].

27 Comparison of linear approximation curves for true crater depth with apparent crater depth of real soil material [3].

28 Comparison of measured true crater depth with apparent crater depth for different soil materials [Ref. 11].

29 True crater depth vs DOB for dry YTONG compared with apparent crater depth of desert alluvium [12].

30 True crater depth vs DOB for wet YTONG compared with apparent crater depth of desert alluvium [12].

31 True crater depth vs DOB for clay/loam compared with apparent crater depth of desert alluvium [12].

32 True crater volume vs DOB for dry YTONG compared with apparent crater volume of desert alluvium [12]

33 True crater volume vs DOB for wet YTONG compared with apparent crater volume of desert alluvium [12]

34 True crater volume vs DOB for clay/loam compared with apparent crater volume of desert alluvium [12] 
vii

\section{FIGURES (Continued)}

Figure

35 Example of a pressure-time record.

$\mathrm{DOB}=1.0 \mathrm{~cm} \quad$ Distance from GZ: $27 \mathrm{~cm}$

Soil material: dry aerated grout (dry YTONG). Test No.: $717 / 4$

Peak overpressure, time of arrival, positive phase duration and positive impulse resp. are recorded.

36 Comparison of pressure-time records at various distances

Soil material: dry aerated grout (dry YTONG)

Charge weight: $0.5 \mathrm{~g}$

37 Comparison of pressure-time records at different DOB

Soil material: dry aerated grout (dry YTONG)

38 Comparison of pressure-time records at various distances

Charge weight: $0.5 \mathrm{~g}$

Soil material: water-saturated grout (wet YTONG)

39 Comparison of pressure-time records at different DOB

Soil material: water saturated grout (wet YTONG)

40 Comparison of pressure-time records at various distances

Charge weight: $0.53 \mathrm{~g}$

Soil material: wet clay/loam

41 Comparison of pressure-time records at different DOB

Soil material: wet clay/loam

42 Domains of different wave forms for DOB in dry aerated grout (dry YTONG), water saturated grout (wet YTONG) and wet clay/loam.

43 Peak overpressure vs ground range at different DOB

Soil materiai: dry aerated grout (dry YTONG)

$\begin{array}{lll}D O B=-1.0 \mathrm{~cm} & \text { DOB }=0.0 \mathrm{~cm} & \text { DOB }=1.0 \mathrm{~cm} \\ D O B=2.0 \mathrm{~cm} & \text { DOB }=3.0 \mathrm{~cm} & \text { DOB }=4.0 \mathrm{~cm}\end{array}$

44 Peak overpressure vs ground range at different DOB

Soil material: water saturated grout (wet YTONG)
$\mathrm{DOB}=-1.0 \mathrm{~cm}$
$\mathrm{DOB}=0.0 \mathrm{~cm}$
$\mathrm{DOB}=1.0 \mathrm{~cm}$
$\mathrm{DOB}=2.0 \mathrm{~cm}$
$\mathrm{DOB}=3.0 \mathrm{~cm}$
$\mathrm{DOB}=4.0 \mathrm{~cm}$

45 Peak overpressure vs ground range at different DOB

Soil material: clay/loam
$\mathrm{DOB}=-1.0 \mathrm{~cm}$
$\mathrm{DOB}=0.0 \mathrm{~cm}$
$\mathrm{DOB}=1.0 \mathrm{~cm}$
$\mathrm{DOB}=2.0 \mathrm{~cm}$
$\mathrm{DOB}=3.0 \mathrm{~cm}$
$\mathrm{DOB}=4.0 \mathrm{~cm}$

46 Coefficients $a_{i}$ vs DOB of the approximation function $\log \mathrm{p}=\sum_{0}^{2} \alpha_{\mathrm{i}}(\log \mathrm{GR})^{\mathrm{i}}$ for dry YTONG. 
viii

\section{FIGURES (Continued)}

Figure

47 Coefficients $a_{i}$ vs DOB of the approximation function $\log p=\sum_{0}^{2} \alpha_{i}(\log G R)^{i}$ for wet YTONG.

48 Coefficients $a_{i}$ vs DOB of the approximation function $\log \mathrm{p}=\sum_{0}^{2} \alpha_{\mathrm{i}}(\log \mathrm{GR})^{\mathrm{i}}$ for clay/loam.

49 Peak Overpressure vs Ground Range (Logarithmic plot with domains of different wave forms).

Soil material: dry aerated grout (dry YTONG)

50 Peak Overpressure vs Ground Range (Logarithmic plot with domains of different wave forms).

Soil material: water saturated grout (wet YTONG)

51 Peak Overpressure vs Ground Range (Logarithmic plot with domains of different wave forms).

Soil material: wet clay/loam

52 Percentage of Energy Losses vs Ground Range

Soil material: dry aerated grout (dry YTONG)

53 Percentage of Energy Losses vs Ground Range

Soil material: water saturated grout (wet YTONG)

54 Percentage of Energy Losses vs Ground Range Soil material: clay/loam

55 Percentage of Energy Losses vs DOB at GR $=2\left[\mathrm{~m} / \mathrm{kg}^{1 / 3}\right]$

56 Percentage of Energy' Losses vs DOB at GR $=6\left[\mathrm{~m} / \mathrm{kg}^{1 / 3}\right]$

57 Percentage of Energy Losses vs DOB at GR $=10\left[\mathrm{~m} / \mathrm{kg}^{1 / 3}\right]$

58 Isobaric HOB-curves for a hydrodynamically-smooth surface completed with DOB-curves for dry aerated grout [Ref. 2]. Specially marked is the region in which the isobaric DOB data are presented in the following figures.

59 Isobaric DOB-curves for dry aerated grout (dry YTONG)

Intermediate-pressure regime

60 Isobaric DOB-curves for water saturated grout (wet YTONG)

Intermediate-pressure regime

61 Isobaric DOB-curves for clay/loam

Intermediate-pressure regime 


\section{FIGURES (Continued)}

Figure

62 Isobaric DOB-curves for dry aerated grout (dry YTONG) Low-pressure regime

63 Isobaric DOB-curves for water saturated grout (wet YTONG)

Low-pressure regime

64 Isobaric DOB-curves for clay/loam

Low-pressure regime

65 Comparison of isobaric DOB-curves for the three soil materials in the low-pressure regime.

Black curves are valid for "hydrodynamically smooth surface".

Pressure parameter: 1 psi; 3 psi; 6 psi; 10 psi; 15 psi

66 Comparison of isobaric DOB-curves for the three soil materials in the low-pressure regime.

Black curves are valid for "hydrodynamically smooth surface".

Pressure parameter: 2 psi; 4 psi; 8 psi; 15 psi

67 Comparison of isobaric DOB-curves for the three soil materials in the intermediate-pressure regime.

Black curves are valid for "hydrodynamically smooth surface".

Pressure parameter: 8 psi; 15 psi; 30 psi; 70 psi; 150 psi

68 Comparison of isobaric DOB-curves for the three soil materials in the intermediate-pressure regime.

Black curves are valid for "hydrodynamically smooth surface".

Pressure parameter: 10 psi; 20 psi; 50 psi; 100 psi; 200 psi

69 Positive phase impulse vs ground range at different DOB. Soil material: dry aerated grout (dry YTONG)
$\mathrm{DOB}=-1.0 \mathrm{~cm}$
$\mathrm{DOB}=0 \mathrm{~cm}$
$\mathrm{DOB}=1.0 \mathrm{~cm}$
$\mathrm{DOB}=2.0 \mathrm{~cm}$
$\mathrm{DOB}=3.0 \mathrm{~cm}$
$\mathrm{DOB}=4.0 \mathrm{~cm}$

70 Positive phase impulse vs ground range at different DOB. Soil material: water saturated grout (wet YTONG)
$\mathrm{DOB}=-1.0 \mathrm{~cm}$;
$\mathrm{DOB}=0 \mathrm{~cm}$;
$\mathrm{DOB}=1.0 \mathrm{~cm}$
$\mathrm{DOB}=2.0 \mathrm{~cm}$;
$\mathrm{DOB}=3.0 \mathrm{~cm}$
$\mathrm{DOB}=4.0 \mathrm{~cm}$

71 Positive phase impulse vs ground range at different DOB. Soil material: clay/loam
$\mathrm{DOB}=-1.0 \mathrm{~cm}$
$\mathrm{DOB}=0 \mathrm{~cm}$
DOB $=1.0 \mathrm{~cm}$
$\mathrm{DOB}=2.0 \mathrm{~cm}$;
$\mathrm{DOB}=3.0 \mathrm{~cm}$
$\mathrm{DOB}=4.0 \mathrm{~cm}$

72 Logarithmic plot for impulse-range curves.

Soil material: aerated grout (dry YTONG)

73 Logarithmic plots for impulse-range curves

Soil material: water saturated grout (wet YTONG) 


\section{FIGURES (Continued)}

Figure

74 Logarithmic plots for impulse-range curves

Soil material: clay/loam

75 Iso-impulse DOB curves for aerated grout (dry YTONG)

76 Iso-impulse DOB curves for water saturated grout (wet YTONG)

77 Iso-impulse DOB curves for clay/loam

78 Time of arrival vs ground range at different DOB. Soil material: dry aerated grout (dry YTONG)
$\mathrm{DOB}=-1.0 \mathrm{~cm}$;
$\mathrm{DOB}=0 \mathrm{~cm}$
$\mathrm{DOB}=1.0 \mathrm{~cm}$
$\mathrm{DOB}=2.0 \mathrm{~cm}$
$\mathrm{DOB}=3.0 \mathrm{~cm}$;
$\mathrm{DOB}=4.0 \mathrm{~cm}$

79 Time of arrival vs ground range at different DOB. Soil material: water saturated grout (wet YTONG)

$\mathrm{DOB}=-1.0 \mathrm{~cm} ; \quad \mathrm{DOB}=0 \mathrm{~cm} ; \quad \mathrm{DOB}=1.0 \mathrm{~cm}$

$\mathrm{DOB}=2.0 \mathrm{~cm} ; \quad \mathrm{DOB}=3.0 \mathrm{~cm} ; \quad \mathrm{DOB}=4.0 \mathrm{~cm}$

80 Time of arrival vs ground range at different DOB. Soil material: clay/loam
$\mathrm{DOB}=-1.0 \mathrm{~cm}$;
$\mathrm{DOB}=0 \mathrm{~cm}$;
$\mathrm{DOB}=1.0 \mathrm{~cm}$
$\mathrm{DOB}=2.0 \mathrm{~cm}$;
$\mathrm{DOB}=3.0 \mathrm{~cm}$;
$\mathrm{DOB}=4.0 \mathrm{~cm}$

81 Logarithmic plots of arrival-time range curves.

Soil material: aerated grout (dry YTONG)

82 Logarithmic plots of arrival-time range curves.

Soil material: water saturated grout (wet YTONG)

83 Logarithmic plots of arrival-time range curves.

Soil material: clay/loam

84 Constant arrival time DOB-curves for dry aerated grout (dry YTONG).

85 Constant arrival time DOB-curves for water saturated grout (wet YTONG).

86 Constant arrival time DOB-curves for clay/loam.

87 Determination of peak overpressure by using time-of-arrival data upper diagrams: ground range vs arrival time with approximation curve and deduced shock front velocity

lower diagrams: calculated pressure-range curve compared with measured peak pressure values

soil material: dry aerated grout (dry YTONG)

$\mathrm{DOB}=-1.0 \mathrm{~cm} ; \mathrm{DOB}=0 \mathrm{~cm} ; \mathrm{DOB}=1.0 \mathrm{~cm}$ 


\section{FIGURES (Continued)}

Figure

88 Determination of peak overpressure by using time-of-arrival data upper diagrams: ground range vs arrival time with approximation curve and deduced shock front velocity

lower diagrams: calculated pressure-range curve compared with measured peak pressure values

soil material: water saturated grout (wet YTONG)

$\mathrm{DOB}=-1.0 \mathrm{~cm} ; \mathrm{DOB}=0 \mathrm{~cm} ; \mathrm{DOB}=1.0 \mathrm{~cm}$

89 Determination of peak overpressure by using time-of-arrival data

upper diagrams: ground range vs arrival time with approximation curve and deduced shock front velocity

lower diagrams: calculated pressure-range curve compared with measured peak pressure values

soil material: clay/loam

$\mathrm{DOB}=-1.0 \mathrm{~cm} ; \mathrm{DOB}=0 \mathrm{~cm} ; \mathrm{DOB}=1.0 \mathrm{~cm}$

90 Time duration of positive overpressure phase vs ground range at different DOB

soil material: dry aerated grout

$\mathrm{DOB}=-1.0 \mathrm{~cm} \quad \mathrm{DOB}=0 \mathrm{~cm} \quad \mathrm{DOB}=1.0 \mathrm{~cm}$

$\mathrm{DOB}=2.0 \mathrm{~cm} \quad \mathrm{DOB}=3.0 \mathrm{~cm} \quad \mathrm{DOB}=4.0 \mathrm{~cm}$

91 Time duration of positive overpressure phase vs ground range at different DOB

soil material: water saturated grout (wet YTONG)

$\mathrm{DOB}=-1.0 \mathrm{~cm} \quad \mathrm{DOB}=0 \mathrm{~cm} \quad \mathrm{DOB}=1.0 \mathrm{~cm}$

$\mathrm{DOB}=2.0 \mathrm{~cm} \quad \mathrm{DOB}=3.0 \mathrm{~cm} \quad \mathrm{DOB}=4.0 \mathrm{~cm}$

92 Time duration of positive overpressure phase vs ground range at different DOB

soil material: clay/loam

$\begin{array}{lll}\mathrm{DOB}=-1.0 \mathrm{~cm} & \text { DOB }=0 \mathrm{~cm} & \mathrm{DOB}=1.0 \mathrm{~cm} \\ \mathrm{DOB}=2.0 \mathrm{~cm} & \mathrm{DOB}=3.0 \mathrm{~cm} & \mathrm{DOB}=4.0 \mathrm{~cm}\end{array}$

93 Logarithmic plots of positive phase duration range curves.

Soil material: aerated grout (dry YTONG)

94 Logarithmic plots of positive phase duration range curves.

Soil material: water saturated grout (wet YTONG)

95 Logarithmic plots of positive phase duration range curves.

Soil material: clay/loam

96 Constant duration DOB-curves for dry aerated grout (dry YTONG).

97 Constant duration DOB-curves for water saturated grout (wet YTONG). 
Figure

98 Constant duration DOB-curves for clay/loam.

99 Comparison with wave forms from Ref. [12].

100 Comparison of wave form transitions for úesert alluvium [from Ref. 12] and dry aerated grout (dry YTONG).

101 Peak overpressure vs ground range for desert alluvium [Ref. 12] compared with results for aerated grout, water saturated grout and clay/loam.

102 Peak overpressure suppression as function of DOB for desert alluvium [Ref.12] compared with results for aerated grout, water saturated grout and clay/loam.

103 Impulse vs ground range for all charges fired in NTS desert alluvium [Ref. 12] compared with results for aerated grout and water saturated grout.

104 Suppression of blast impulse as function of DOB for desert alluvium [Ref. 12] compared with results for water saturated grout.

105 Arrival time vs ground range for desert alluvium [Ref. 12] compared with results for aerated grout and water saturated gout, resp.

106 Arrival time vs ground range for DOB $=0.5\left[\mathrm{ft} / \mathrm{lbs}^{1 / 3}\right](=17 \mathrm{ft})$ and DOB $=1.0\left[\mathrm{ft} / \mathrm{lbs}^{1 / 3}\right](=34 \mathrm{ft})$ [Ref. 12] compared with results for aerated grout and water saturated grout, resp.

107 Effect of charge burial in desert alluvium on positive phase duration [Ref. 12] compared with results for aerated grout and water saturated grout.

108 Positive phase duration vs ground range for all charges fired in desert alluvium [Ref. 12] compared with results for aerated grout and water saturated grout. 



\section{SECTION 1}

\section{INTRODUCTION}

While much airblast data were available for height-of burst (HOB) effects (e.g., References [1] to [4] systematic airblast data for depth-of-burst (DOB) effects are much more limited (e.g., References [5] to [13]). The regitimate question has therefore been asked whether the 0.5-g NP charges that proved to be successful for HOB tests are also suitable for DOB tests. As demonstrated in exploratory DOB experiments (Ref. [13]) airblast DOB tests can be performed at laboratory scale. Of course, not all physical quantities (e.g., gravity) can, on a model scale, be chosen in accordance with requirements of the similarity laws. This is true especially for the study of crater formation processes.

It was decided to use our laboratory test equipment to investigate blast wave data in order to be able to extend the isobaric $\mathrm{HOB}$ curves to cover DOB cases. The main interest was therefore to measure the airblast environment generated by the detonation of buried and aboveground HE-charges. The data recording concerning crater depth and crater volume are of secondary importance.

In the present report, the test setup will be described and results for three different simulated soil materials will be presented. 


\section{SECTION 2}

\section{EXPERIMENT DESIGN}

Because the exploratory DOB experiments (Ref. [13]) produced remarkably good results, the previous experimental setup was maintained. In particular, the measuring system installed in the roof plate of the explosion chamber remained basically the same as used for our HOB tests. That means the DOB experiments were carried out upside down. For a more detailed description of the explosion chamber see Ref. [1].

\subsection{SOIL MATERIAL.}

Because of the geometrical arrangement, the simulated soil had to be cohesive. Three soil materials were used:

(1) a porous, crushable aerated grout (German trade name: YTONG) specific weight: $\rho=0.40 \mathrm{~g} / \mathrm{cm}^{3}\left(25 \mathrm{lbs} / \mathrm{ft}^{3}\right)$

(2) a water saturated grout (wet YTONG)

specific weight: $\rho=0.73 \mathrm{~g} / \mathrm{cm}^{3}\left(45 \mathrm{lbs} / \mathrm{ft}^{3}\right)$

(3) a clay/loam material

specific weight: $\rho=1.8 \mathrm{~g} / \mathrm{cm}^{3}\left(113 \mathrm{lbs} / \mathrm{ft}^{3}\right)$

These materials were chosen to investigate the effects of density increase and to simulate some previous field tests.

\subsection{INSTALLATION OF THE CHARGE.}

The installation of the $0.5 \mathrm{~g}$ charge is sketched in Figure 1. The soil material was embedded in a steel tube (length: $300 \mathrm{~mm}$; inner diameter: $100 \mathrm{~mm}$ ). Different procedures were applied: 


\subsubsection{Aerated Grout (YTONG; materials (1) and (2)).}

With the help of a core drill, cylinders were bored out of YTONG-blocks and finished on a lathe. Thus the aerated grout, despite its granular structure, achieves a relatively smooth surface. During the drilling and turning water is added. YTONG absorbs the moisture. To achieve reproducible results, for tests with dry YTONG, the cylinders were stored and dried in the laboratory for several days. For tests with wet YTONG the cylinders were saturated in water for several hours. They were only used when there were no further changes in the weight checks in both cases.

To install the charge (diameter: $10 \mathrm{~mm}$ ), a hole with a diameter of $10.4 \mathrm{~mm}$ is drilled concentrically into the YTONG cylinder. The bore depth is chosen in such a way that the required overburden remains undisturbed. With the help of a special tool, a hemispherical deepening with a radius of $5 \mathrm{~mm}$ is made at the end of the bore. The charge is inserted through the bore channel and the correct position of the charge is controlled with the length of the supply wires. The remaining hollow space in the bore channel is filled with pulverized aerated grout to obtain the necessary backfilling. Finally, the bore opening is closed with an adhesive.

This procedure guarantees that the overburden remains in the original material condition and is not altered, as it is generally the case with iree field DOB experiments. There the charge is usually sunk into the soil from the earth surface.

After the YTONG cylinder was prepared as described, it was inserted into the steel tube so that the plane face ends flush with the rim of the tube.

\subsubsection{Clay/Loam (material (3)) .}

It was not possible to apply the same procedure as with YTONG. Therefore the steel tube containing the simulated soil material was direct filled with the clay/loam mixture to such a height that the charge could be placed in the desired position. Then the overburden was filled in so that the clay/loam soil ends flush with the rim of the tube. The material was carefully and slightly compacted to achieve a cohesive connection between overburden and the first filled-in material. The supply wires of the charge led sideways through the overburden. 


\subsection{INSTALLATION INTO THE EXPLOSION CHAMBER.}

To reduce the transmission of acceleration pulses created by the detonation of the charge and the cratering processes, the steel tube containing the soil material was installed with shock isolation mechanism to decouple it from the explosion chamber (see Figure 1). A shock isolation system was also used on the gauge to eliminate the acceleration effects.

Figure 2 gives a general view showing not only the construction of the steel cylinder but also of the shielding of the high-voltage ignition circuit that runs in a type of Faraday cage. This isolation technique was necessary to keep the electromagnetic interferences, coming from the ignition circuit, as far away from the pressure gauges and their supplies as possible.

The position of the pressure gauges in relation to ground zero (GZ) is depicted in Figure 3. Gauge MK1 is $90 \mathrm{~mm}$ away from GZ. The distance between gauges MK1 to MK13 is $60 \mathrm{~mm}$ each. Gauges MK14, MK15, MK16 are arranged in a distance of $85 \mathrm{~mm}, 99.4 \mathrm{~mm}$ and 150 $\mathrm{mm}$, respectively, but they are not on the same radial as gauges MK1 to MK13.

The recording equipment and the optical arrangement for shadow and schlieren single photographs are the same as described in Reference [1]. 


\section{SECTION 3}

\section{TEST MATRIX}

The test matrix is presented in Table 1. Included are also the tests documented in Reference [13]. We found that experiments with $\mathrm{DOB}>5 \mathrm{~cm}\left(=0.63 \mathrm{~m} / \mathrm{kg}^{1 / 3}\right)$ did not create significant pressure pulses in air. Note that $\mathrm{DOB}$ is counted positive from the surface to the installation point (center of charge), so that $\mathrm{DOB}=-0.5 \mathrm{~cm}$ (at a charge diameter of $\mathrm{D}=$ $1.0 \mathrm{~cm}$ ) indicates a charge tangent above surface, which is identical with $\mathrm{HOB}=+0.5 \mathrm{~cm}$.

Table 1. Test Matrix

\begin{tabular}{|c|c|c|c|c|c|c|}
\hline \multirow{3}{*}{$\begin{array}{l}\mathrm{DOB} / \mathrm{D} \\
-2.0\end{array}$} & \multirow{2}{*}{\multicolumn{2}{|c|}{ dry YTONG }} & \multicolumn{3}{|c|}{ Test Number } & \multirow{2}{*}{ Remarks } \\
\hline & & & wet $Y$ & TONG & Clay/Loam & \\
\hline & 814 & & 768 & 783 & 813 & $\mathrm{HOB} / \mathrm{D}=+2.0$ \\
\hline-1.0 & 815 & & 769 & & 781 & \\
\hline-0.5 & $\begin{array}{l}723 \\
747\end{array}$ & $\begin{array}{l}726 \\
802\end{array}$ & 800 & 801 & 780 & $\begin{array}{l}\text { tangent above } \\
\text { surface }\end{array}$ \\
\hline-0.25 & 804 & & 807 & & 812 & \\
\hline 0.0 & 722 & 803 & 805 & & 777 & half buried \\
\hline 0.15 & 736 & & & & & \\
\hline 0.25 & 73.5 & & 784 & 808 & & \\
\hline 0.5 & $\begin{array}{l}737 \\
809\end{array}$ & 738 & 806 & - & 767776 & $\begin{array}{l}\text { tangent below } \\
\text { surface }\end{array}$ \\
\hline 1.0 & 717 & & 758 & 785 & 762811 & \\
\hline 1.5 & 740 & & 786 & 787 & 766796 & \\
\hline 2.0 & $\begin{array}{l}712 \\
719\end{array}$ & 713 & 788 & 789 & $\begin{array}{ll}761 & 773 \\
774 & 775 \\
810 & \end{array}$ & \\
\hline 2.5 & $\begin{array}{l}741 \\
816\end{array}$ & 742 & 790 & 791 & $\begin{array}{ll}765 & 797 \\
798 & 799\end{array}$ & \\
\hline 3.0 & 718 & 720 & 792 & 793 & 763 & \\
\hline 3.5 & & & & & 771 & \\
\hline 4.0 & 721 & & 794 & 795 & 764 & \\
\hline 5.0 & 724 & 725 & 759 & 760 & 772 & \\
\hline
\end{tabular}


To get a better idea about how the measuring data fit in with previous full scale experiments, Table 2 presents some DOB tests, for which airblast data were determined. The charge weights were between 8 and 20 tons, i.e., about 7 orders of magnitude higher than for our $0.5-\mathrm{g}$ charges. The EMI experiments have also been inserted in Table 2. The scaling was $\mathrm{W}^{1 / 3}$.

Table 2. HE Events with Airblast Data

\begin{tabular}{|c|c|c|c|c|c|}
\hline $\begin{array}{l}\text { SDOB } \\
{\left[f^{\prime} / k^{1 / 3}{ }^{1 / 3}\right.}\end{array}$ & HE Event & Yield & Soil & $\begin{array}{l}\text { EMI Exp } \\
\text { SDOB } \\
{\left[\mathrm{fD}^{\left.\mathrm{k} / \mathrm{k}^{1 / 3}\right]}\right.}\end{array}$ & $\begin{array}{l}\text { its } \\
\text { Depth } \\
\text { (Charge Dia.) }\end{array}$ \\
\hline \multirow{3}{*}{$\begin{array}{l}36.4 \\
39.2\end{array}$} & \multirow{3}{*}{$\begin{array}{l}\text { Essex-I-3MS } \\
\text { Essex-I-3MU }\end{array}$} & \multirow{2}{*}{$\begin{array}{l}11.5-\mathrm{T} \\
9-\mathrm{T}\end{array}$} & \multirow{2}{*}{$\begin{array}{l}\text { LMD* } \\
\text { LMD }\end{array}$} & $\begin{array}{r}-56 \\
-28 \\
-14 \\
-7 \\
0 \\
4 \\
7 \\
14 \\
28\end{array}$ & $\begin{array}{l}-2.0-D \\
-1.0-D \\
-0.5-D \\
-0.25-D \\
0-D \\
0.15-D \\
0.25-D \\
0.5-D \\
1.0-D\end{array}$ \\
\hline & & & & & \\
\hline & & $9-T$ & LMD & 42 & $1.5-\mathrm{D}$ \\
\hline 54 & Stagecoach-2 & $20-\mathrm{T}$ & Alluvium & $\begin{array}{l}56 \\
70\end{array}$ & $\begin{array}{l}2.0-\mathrm{D} \\
2.5-\mathrm{D}\end{array}$ \\
\hline 73.3 & Essex-I-6MWS & $10-\mathrm{T}$ & LMD & & \\
\hline 74.4 & Essex-I-6MU & $10 \cdot \mathrm{T}$ & LMD & & \\
\hline 81 & Buckboard-11 & 20- $\mathrm{T}$ & Basalt & & \\
\hline 81.5 & Essex-I-6MU & 8-T & LMD & 84 & 3.0-D \\
\hline 108 & Stagecoach-3 & $20-\mathrm{T}$ & Alluvium & & 4.0-D \\
\hline 135 & Buckboard-12 & $20-\mathrm{T}$ & Basalt & 140 & 5.0-D \\
\hline $\begin{array}{l}152.7 \\
152.7\end{array}$ & $\begin{array}{l}\text { Essex-I-12MS } \\
\text { Essex-I.12MPS }\end{array}$ & 10-T & LMD & & \\
\hline $\begin{array}{l}152.7 \\
186\end{array}$ & $\begin{array}{l}\text { Essex-I 12MPS } \\
\text { Buckboard-13 }\end{array}$ & $\begin{array}{l}10-T \\
20-T\end{array}$ & $\begin{array}{l}\text { LMD } \\
\text { Basalt }\end{array}$ & & \\
\hline 253 & Stagecoach-1 & $20-\mathrm{T}$ & Alluvium & & \\
\hline
\end{tabular}

"LMD = Layered Marine Deposits 


\section{SECTION 4}

\section{TEST RESUITS}

\subsection{CRATER.}

The depth of the crater, $d_{k}$, which is formed at the detonation of the charge has been measured with a caliper rule. Note that, with our test set-up, the true crater depth is measured, because the loose crater material can no longer fall back into the crater, as it is the case with free field tests. A definition of apparent and true crater depths, respectively, is given in Figure 4 (Ref. [3]). The crater volume, $V_{k}$, was determined by several methods: (1) by difference in weight of the soil material before and after the experiment, (2) by weight of soil material found after the test in the explosion chamber, (3) by filling the crater with fine grained sand and determining its weight, $\Delta G$. The last method proved to be the most accurate and was applied in most cases. Since the specific weight of the used sand, $\gamma_{\text {sand, was }}$ determined before, we find:

$$
\mathrm{V}_{\mathrm{k}}=\Delta \mathrm{G} / \gamma_{\mathrm{sand}}
$$

In Tables 3 to 5 the crater depth and crater volume are given for the three soil materials under consideration.

\subsubsection{Crater Form.}

Some photographs of craters at differen $i$ DOB have been compiled in Figure 5 for the porous, crushable aerated grout (dry YTONG) and in Figure 6 for the water-saturated grout (wet YTONG), respectively. It was not possible to extricate the clay/loam material from the steel tube without destruction of the form.

Figures 7 to 9 depict some typical crater cross sections, measured mostly according to eye judgement. The crater form turned out to be axially symmetrical in all experiments. It is remarkable that in about one third of the DOB an edge exists that is more or less distinct for dry YTONG and wet YTONG. For clay/loam material the crater is more trough-shaped. In contrast to the crushable YTONG the clay/loam material shows a more viscous behavior. It also has to be pointed out that the experiments at the same DOB show relative small scatter in the crater dimensions. 
Table 3 Crater Depth and Crater Volume for dry YTONG

\begin{tabular}{|l|l|l|l|l|l|l|}
\hline $\begin{array}{l}\text { Test } \\
\text { No. }\end{array}$ & $\begin{array}{c}\text { DOB } \\
{[\mathrm{cm}]}\end{array}$ & $\begin{array}{c}\mathrm{dk} \\
{[\mathrm{cm}]}\end{array}$ & $\begin{array}{c}\mathrm{Vk} \\
{\left[\mathrm{m} \mathrm{m}^{3}\right]}\end{array}$ & $\begin{array}{c}\mathrm{SDOB} \\
{\left[\mathrm{m} / \mathrm{kg}^{1 / 3}\right]}\end{array}$ & $\begin{array}{c}\mathrm{Sdk} \\
{\left[\mathrm{m} / \mathrm{kg}^{1 / 3}\right]}\end{array}$ & $\begin{array}{c}\mathrm{SVk} \\
{\left[\mathrm{m}^{3} / \mathrm{kg}\right]}\end{array}$ \\
\hline 814 & -2.0 & 0.6 & 4.26 & -0.252 & 0.0756 & 0.0085 \\
\hline 815 & -1.0 & 1.2 & 8.33 & -0.126 & 0.151 & 0.0167 \\
\hline 723 & -0.5 & 1.8 & 14.3 & -0.063 & 0.227 & 0.0286 \\
726 & & 1.8 & 16.3 & & 0.227 & 0.0326 \\
747 & & 1.95 & 15.6 & & 0.246 & 0.0312 \\
802 & & 1.9 & 12.5 & & 0.239 & 0.0250 \\
\hline 804 & -0.25 & 2.4 & 33.8 & -0.0315 & 0.302 & 0.0683 \\
\hline 722 & 0 & 2.7 & 32.2 & 0 & 0.340 & 0.0644 \\
803 & & 2.6 & 34.6 & & 0.328 & 0.0692 \\
\hline 736 & 0.15 & 2.9 & 70.9 & 0.0189 & 0.365 & 0.142 \\
\hline 735 & 0.25 & 2.7 & 83.7 & 0.0315 & 0.340 & 0.167 \\
\hline 737 & 0.5 & 3.1 & 76.7 & 0.063 & 0.391 & 0.153 \\
738 & & 3.0 & 85.7 & & 0.378 & 0.171 \\
809 & & 3.2 & 85.1 & & 0.403 & 0.170 \\
\hline 717 & 1.0 & 4.0 & - & 0.126 & 0.504 & - \\
\hline 740 & 1.5 & 5.0 & 163.1 & 0.189 & 0.630 & 0.326 \\
\hline 712 & 2.0 & 5.3 & - & 0.252 & 0.668 & - \\
\hline 713 & & 5.3 & - & & 0.668 & - \\
\hline 719 & & 5.0 & 177.1 & & 0.630 & 0.354 \\
\hline 741 & 2.5 & 5.9 & 179.1 & 0.315 & 0.743 & 0.358 \\
742 & & 6.0 & 194.9 & & 0.756 & 0.390 \\
816 & & 4.9 & 165.4 & & 0.617 & 0.331 \\
\hline 718 & 3.0 & 6.4 & 197.1 & 0.378 & 0.806 & 0.394 \\
720 & & 6.2 & 193.0 & & 0.781 & 0.386 \\
\hline 721 & 4.0 & 7.2 & 223.2 & 0.504 & 0.907 & 0.446 \\
\hline 724 & 5.0 & 8.5 & 307.4 & 0.630 & 1.071 & 0.615 \\
725 & & 9.0 & 315.8 & & 1.134 & 0.632 \\
\hline
\end{tabular}




\begin{tabular}{|c|c|c|c|c|c|c|c|c|c|c|c|c|c|c|}
\hline รีర్ష & 웅ㅎํㅇ & ర్యిర్లి & 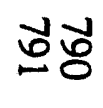 & $\infty$ & ర్రంది & 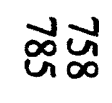 & ઠ̊ำ & 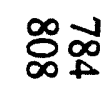 & 总 & 串 & : & ชั & ๖ోప్రి & Z \\
\hline$\ddot{0}$ & $\dot{0}$ & ou & i & $\stackrel{N}{O}$ & in & $\dot{0}$ & in & 怘 & 0 & 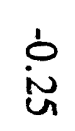 & in & $\dot{\circ}$ & $\stackrel{\grave{~}}{\circ}$ & 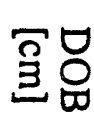 \\
\hline$\stackrel{\infty}{\infty}$ & $\vec{\forall} \vec{N}$ & $\ddot{\omega} \vec{a}$ & unu & $\begin{array}{l}\text { un } \\
\text { on }\end{array}$ & $\begin{array}{l}\overrightarrow{a u} \\
\dot{a u}\end{array}$ & 满萑 & $\underset{i r}{\omega}$ & $\begin{array}{l}W N \\
\rightarrow \infty\end{array}$ & $\stackrel{\sim}{a}$ & $\stackrel{\sim}{\sim}$ & 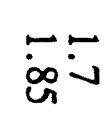 & in & 品 & 惡只 \\
\hline $\begin{array}{l}\omega \\
\text { w. } \\
0 \\
0\end{array}$ & $\begin{array}{l}\text { Nu } \\
\text { wo } \\
\text { s. }\end{array}$ & 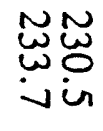 & $\begin{array}{l}\vec{\infty} \\
0.0 \\
0 \%\end{array}$ & $\begin{array}{l}\text { जo } \\
\text { i0 }\end{array}$ & $\begin{array}{l}\text { के } \\
\text { के } \\
\text { ina }\end{array}$ & $\begin{array}{l}\text { 岕 } \\
\text { 点 } \\
00\end{array}$ & 总 & 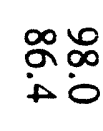 & $\stackrel{t}{\vec{A}}$ & $\begin{array}{l}\text { O } \\
\text { : }\end{array}$ & 훙 & $\stackrel{\vec{\omega}}{\omega}$ & $\begin{array}{l}\omega \infty \\
+\infty\end{array}$ & 总 \\
\hline : & 옹 & 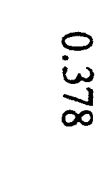 & $\stackrel{0}{\dot{\omega}}$ & 宓 & $\stackrel{\circ}{\circ}$ & $\stackrel{0}{\stackrel{0}{\alpha}}$ & $\begin{array}{l}\text { 영 } \\
\text { }\end{array}$ & $\stackrel{\stackrel{\circ}{\omega}}{\stackrel{\leftrightarrow}{u}}$ & 0 & 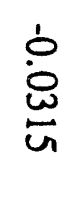 & $\begin{array}{l}\dot{0} \\
\dot{\alpha}\end{array}$ & $\begin{array}{l}\dot{0} \\
\frac{N}{0}\end{array}$ & 宓 & 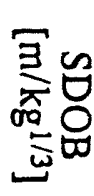 \\
\hline ㅎㅇㅇㅇㅇ & 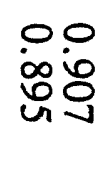 & 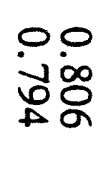 & 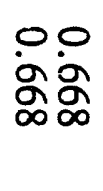 & 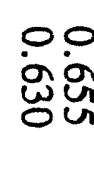 & $\begin{array}{l}\text { io } \\
\text { un un } \\
\text { og }\end{array}$ & $\begin{array}{l}\text { in } \\
\text { unin } \\
\text { Nig }\end{array}$ & $\begin{array}{l}\circ \\
\dot{E}\end{array}$ & 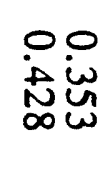 & 見 & $\begin{array}{l}\dot{i} \\
\dot{\omega} \\
\Delta\end{array}$ & 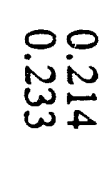 & $\stackrel{\circ}{\stackrel{0}{\circ}}$ & $\begin{array}{l}\text { 이 } \\
\text { ì이 }\end{array}$ & 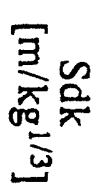 \\
\hline 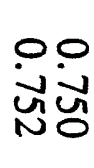 & $\begin{array}{l}\text { 우 } \\
\text { ing } \\
\text { fio }\end{array}$ & 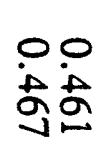 & $\begin{array}{l}\text { 이 } \\
\text { W. } \\
\text { ô. }\end{array}$ & 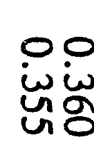 & 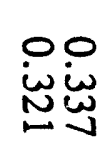 & 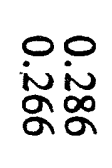 & 芫 & 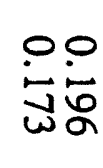 & $\begin{array}{l}\stackrel{\circ}{\circ} \\
\stackrel{0}{\infty}\end{array}$ & $\begin{array}{l}\text { 영 } \\
\text { g. }\end{array}$ & $\begin{array}{l}\text { 음 } \\
\text { 섬워 }\end{array}$ & $\begin{array}{l}0 \\
\text { 엄 }\end{array}$ & 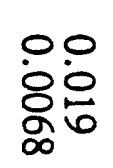 & 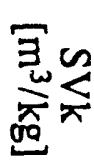 \\
\hline
\end{tabular}


Table 5 Crater Depth and Crater Volume for Clay/Loam

\begin{tabular}{|l|l|l|l|l|l|l|}
\hline $\begin{array}{l}\text { Test } \\
\text { No. }\end{array}$ & $\begin{array}{c}\mathrm{DOB} \\
{[\mathrm{cm}]}\end{array}$ & $\begin{array}{c}\mathrm{dk} \\
{[\mathrm{cm}]}\end{array}$ & $\begin{array}{c}\mathrm{Vk} \\
{\left[\mathrm{cm}^{3}\right]}\end{array}$ & $\begin{array}{c}\mathrm{SDOB} \\
{\left[\mathrm{m} / \mathrm{kg}^{1 / 3}\right]}\end{array}$ & $\begin{array}{c}\mathrm{Sdk} \\
{[\mathrm{m} / \mathrm{kg} / 3]}\end{array}$ & $\begin{array}{c}\mathrm{SVk} \\
{\left[\mathrm{m}^{3} / \mathrm{kg}\right]}\end{array}$ \\
\hline 813 & -2.0 & 1.3 & 9.4 & -0.240 & 0.156 & 0.016 \\
\hline 781 & -1.0 & 2.6 & 40.2 & -0.119 & 0.308 & 0.067 \\
\hline 780 & -0.5 & 3.0 & 73.7 & -0.060 & 0.358 & 0.125 \\
\hline 812 & -0.25 & 3.1 & 115.5 & -0.0303 & 0.376 & 0.206 \\
\hline 777 & 0 & 3.3 & 145.3 & 0 & 0.416 & 0.291 \\
\hline 767 & 0.5 & 3.6 & 165.8 & 0.062 & 0.445 & 0.313 \\
776 & & 3.5 & 162.0 & 0.063 & 0.444 & 0.331 \\
\hline 762 & 1.0 & 3.9 & 155.1 & 0.126 & 0.491 & 0.310 \\
811 & & 3.8 & 171.8 & 0.124 & 0.470 & 0.324 \\
\hline 766 & 1.5 & 4.0 & 190.6 & 0.188 & 0.501 & 0.374 \\
796 & & 5.0 & 223.0 & 0.199 & 0.662 & 0.519 \\
\hline 761 & 2.0 & 4.0 & 230.0 & 0.237 & 0.474 & 0.383 \\
773 & & 4.7 & 207.9 & 0.254 & 0.596 & 0.424 \\
774 & & 4.6 & 188.4 & 0.252 & 0.580 & 0.377 \\
775 & & 3.8 & 248.6 & 0.252 & 0.479 & 0.497 \\
810 & & 4.8 & 217.6 & 0.247 & 0.593 & 0.411 \\
\hline 765 & 2.5 & 5.2 & 228.2 & 0.315 & 0.655 & 0.456 \\
797 & & 4.8 & 285.0 & 0.262 & 0.503 & 0.328 \\
798 & & 4.6 & 229.0 & 0.313 & 0.576 & 0.449 \\
799 & & 4.6 & 207.0 & 0.321 & 0.591 & 0.440 \\
\hline 763 & 3.0 & 6.0 & 261.2 & 0.368 & 0.737 & 0.484 \\
771 & 3.5 & 6.2 & 301.2 & 0.441 & 0.781 & 0.602 \\
\hline 764 & 4.0 & 6.6 & 279.0 & 0.494 & 0.816 & 0.526 \\
\hline 772 & 5.0 & 6.9 & 335.2 & 0.630 & 0.869 & 0.670 \\
\hline
\end{tabular}




\subsubsection{Crater Depth.}

Figures 10 to 12 show the crater depth for the three different soil materials as function of depth-of-burst. At linear approximation, the relation between crater depth, $d_{k}$, and DOB is described in scaled dimensions by:

(Eq. 2)

$$
\text { dry YTONG }
$$$$
\mathrm{d}_{\mathrm{k}}=0.328+1.226 * \mathrm{DOB}
$$

wet YTONG

$$
d_{k}=0.347+1.137 * D O B
$$

Clay/Loam

$$
d_{k}=0.382+0.789 * \text { DOB }
$$

where $\left[d_{k}\right]=m / \mathrm{kg}^{1 / 3}$ and $[D O B]=\mathrm{m} / \mathrm{kg}^{1 / 3}$. In the Figures are also scales for $\left[\mathrm{d}_{\mathrm{k}}\right]=\mathrm{cm}$ and $[D O B]=\mathrm{cm}$, valid for $0.5-\mathrm{g}$ NP charges.

Figure 13 indicates that the crater depth curves for dry YTONG and wet YTONG respectively, are nearly identical, whereas the curve for clay/loam differs and shows a flatter course.

\subsubsection{Crater Volume.}

The diagrams, Figure 14 to 16 , depict the crater volume for the three different soil materials as function of DOB. A linear approximation seems to be adapted to describe the material behavior. In scaled dimensions we get the following linear functions:

(Eq. 5)

dry YTONG

$\mathrm{V}_{\mathrm{k}}=0.110+0.782 * \mathrm{DOB}$ wet YTONG

$\grave{V}_{\mathrm{k}}=0.141+0.882 * \mathrm{DOB}$

(Eq. 7)

Clay/Loam

$V_{k}=0.227+0.738 * D O B$

where $\left[\mathrm{V}_{\mathrm{k}}\right]=\mathrm{m}^{3} / \mathrm{kg}$ and $[\mathrm{DOB}]=\mathrm{m} / \mathrm{kg}^{1 / 3}$. In addition also scales $\left[\mathrm{V}_{\mathrm{k}}\right]=\mathrm{cm}^{3}$ and $[D O B]$ $=\mathrm{cm}$ for $0.5-\mathrm{g}$ NP charges are given.

In Figure 17 the results are summarized for the three different soil materials. The slope of the curves for dry YTONG and clay/loam are quite similar whereas wet YTONG shows a steeper slope. 
$V_{k}(D O B)$ and $d_{k}(D O B)$ are approximated by linear functions. Normally one would expect a proportion $V_{k}(D O B)-\left(d_{k}(D O B)^{3}\right)$, but in view of change of crater form with DOB and in view of the data scatter of crater depth and crater volume it seems to be acceptable to describe the DOB dependence to be linear for both quantities. It would seem also reasonable that the amount of charge energy absorbed by the cratering process would be linearly related to the crater volume. But one has also to consider that possibly the confinement of the soil by the steel tube influences the amount of crater volume. Hence Figure 17 indicates that the amount of charge energy, available to drive the airblast wave decreases with DOB. This is certainly born out by pressure measurements.

\subsubsection{Crater Ejecta.}

A single shadow-picture has been made for each DOB-test. In these photographs, the shock front is usually visible and also the crater ejecta can be seen as a black cone. Some typical cases for the three soil materials under consideration are given in Figures 18 to 20. For large DOB ( $\leq 3 \mathrm{~cm} ; 0.38 \mathrm{~m} / \mathrm{kg}^{1 / 3}$ ) it is noticeable that big lumps of soil material are thrown out of the crater and gas jets appear between the lumps. In these cases, no shock front is visible. This leads one to assume that the pressure propagates in form of randomly distributed compression waves.

To get a better idea of the crater ejecta kinematics and of the shock wave formation, some cinematographic pictures were taken with a Cordin framing camera (type 330). Compared with single-picture photographs (e.g., Figures 18 to 20), the quality of the individual frames of the film is worse. The spacial resolution power is substantially smaller and the exposure time is somewhat longer. Nevertheless the two picture series, Figures 21 and 22, give interesting information. Both tests were made at $\mathrm{DOB}=2.5 \mathrm{~cm}\left(=0.315 \mathrm{~m} / \mathrm{kg}^{1 / 3}\right)$, one in dry YTONG, the other in clay/loam. In these examples two shock fronts are clearly visible. For the dry aerated grout case (dry YTONG) the two shock fronts combine after a while ( see pictures $b$ to $f$ of Figure 21), while for the clay/loam case the two wave fronts remain separated. To evaluate the speed of the crater ejecta, the height of the ejecta vs time was measured vertical above surface zero. Time zero was assumed to be the first analysed picture of the film. In Figure 23 the distance-time curve is shown for clay/loam. The approximation was made with a curve of second order. Differentiation gives the approximation function of the ejecta velocity. Although the speed is somewhat sensitive to the chosen approximation function for distance-time data, one nevertheless finds a maximum speed of $250-300 \mathrm{~m} / \mathrm{s}$. In the first $200 \mu \mathrm{s}$, the ejecta velocity increases; later the speed decays, because of decreasing of the pushing force. This is evident. The gas cloud of the HE-charge penetrates the crater ejecta and therefore their overpressure is reduced considerably. In the time interval shown in 
Figure 23 the influence of gravity is negligible. In $500 \mu$ s a mass would reach a speed of about $5 \mathrm{~mm} / \mathrm{s}$. Therefore, the influence of gravity (due to the fact that the tests are made upside down) is negligible for the data reported here.

\subsubsection{Comparison with Results of Real Soil Materials.}

To investigate how the measured values fit in with the results for real soil, data were used from Reference [3]. Figure 24 shows a comparison of the crater depth in dry aerated grout with other soil materials. In [3] the crater depths are scaled with $\mathrm{W}^{5 / 16}$, so that this scale was chosen for the conversion of our data. Of all the soil materials given in [3], sand or perhaps also alluvium have the closest resemblance to aerated grout although the density of both materials is higher.

Considering that the EMI experiments determine the true crater depth and not the apparent one, the deviation from the real sand curve is absolutely plausible. As expected, for the same DOB, dry YTONG has a larger crater depth. It is also apparent that the slope of the two curves are similar.

As shown in Figure 13, the crater depth data of wet YTONG do not differ significantly from dry YTONG. Therefore, also the comparison with real soil material, Figure 25, shows the same trend as mentioned for dry YTONG.

The slope of the crater depth curve vs DOB for wet clay/loam differs from the YTONG curves (see Figure 13) and runs as shown in Figure 26, more parallel to dry clay soil or playa, which are most similar to the material we used. As mentioned earlier, our clay/loam material was wet. So it makes sense that the experiments give a smaller crater depth than the data of Reference [3] for dry clay at the same scaled DOB. In Figure 27 the linear approximation curves of crater depth vs DOB for the three materials are combined and shown together with real soil curves. We cannot expect complete agreement between the presented values and the curves of Reference [3] because of the different definition of crater depth (true versus apparent crater respectively) and because of the different soil materials used. But even real soil of the same kind can differ noticeably from one location to another.

Comparison of true crater depth with apparent crater depth curves of different real soil materials from Reference [11] is made in Figure 28. The linear approximation functions are used. Also here the deviations are as discussed above. 
Extended DOB experiments (Stagecoach Project) with different charge weights for a single soil material are presented in Reference [12]. Charges of $216 \mathrm{lbs} ; 256 \mathrm{lbs} ; 2560 \mathrm{lbs} ; 3000$ lbs; $40000 \mathrm{lbs} ; 2.4^{*} 10^{6} \mathrm{lbs}$ (nuclear) were used. Our charge of $0.5 \mathrm{-g}$ corresponds to $1.1^{*} 10^{-3}$ lbs. The soil is described as Nevada desert alluvium. Different scalings of crater dimensions are used in [12], namely $W^{1 / 4}$ and $W^{0.3}$. Moreover, we have added $W^{5 / 16}$ (as applied in [3]) and $\mathrm{W}^{1 / 3}$ scaling (as used mostly in explosion modelling).

Of primary interest in the Stagecoach experiments was the critical examination of scaling laws for crater dimensions resulting from buried explosions. Examination of cratering phenomena by means of dimensional analysis and by model experiments produced the result that crater dimensions from explosions were proportional to the $1 / 3$ power of the explosion energy. Experiments with large chemical explosives and large nuclear explosions gave some indications that cube root scaling is not strictly valid over wide ranges of explosion energy. If lithostatic pressure is much greater than atmospheric pressure, forth root scaling prevails. For certain ranges of explosion energies $W^{m}$-scaling is expected, where $1 / 4 \leq m \leq 1 / 3$.

In Figures 29 to 34, a comparison is made with the data of Reference [12] and our data. Compared are crater depth and crater volume using the aforementioned four different scaling procedures. Concerning the slope, the dry aerated grout data for crater depth agree best with the desert alluvium values. Also water saturated aerated grout data show quite a good agreement with the slope of desert alluvium curves. As expected, the slope for clay/loam differs significantly.

The crater volume data may be influenced by the steel tube used to hold the soil material (see Figure 1). But one must also take into account that the data of our experiments are related to the true crater. It is not to be expected that the volumes of true and apparent craters are related proportionally. Then, the slope of the corresponding curves will be different.

We conclude that the small charge DOB test data of the true crater give the right order of magnitude, compared with real soil material. They show the same slope as actual soil materials used in tests with much larger charges. $\mathrm{W}^{1 / 3}$-scaling is adequate to compare the crater dimensions of different tests. 


\subsection{Airblast Environments.}

The airblast was measured at 16 different places on the surface (see Figure 3). Figure 35 gives an example of a pressure-time record and demonstrates that not only the positive overpressure impulse, It $=\int$ pdt is recorded, but also the time of arrival of the shock front. The positive phase duration of the blast can also be inferred from the records.

\subsubsection{Pressures.}

4.2.1.1 Wave Forms. Several pressure-time records of the three different soil materials are presented in Figures 36 to 41 . Figures 36, 38, and 40 demonstrate the decay of peak overpressure as function of distance from ground zero (GZ) at three different depths of burst (DOB). The influence of DOB onto the blast overpressure is shown in Figures 37, 39, 41 respectively. Note that the scale of the different recording curves changes, because the peak overpressure varies strongly with distance and DOB.

For small DOB $(0 \leq \mathrm{DOB}[\mathrm{cm}]<1.5)$, the pressure-time curves are similar to an ideal Friedlander function and shows no disturbances. The shock front is steep. There are no signs of compression waves running ahead of the main wave.

With increasing DOB, the character of the curves changes. One notes two phases of the pressure increase. The first plateau is created by the upward motion of the soil that acts like a piston. This fast moving piston (see Figure 23) creates a bow wave. Also cracks are formed through which some compressed smoke can escape. Depending on DOB, lumps are formed and are partly perforated with cracks and are finally hurled out of the crater clearing the way for a propagation of the main compression wave. This wave steepens up in a short time to a shock (second phase of pressure rise). The resulting shock front shape can be described as "porched shock front". It is a question of time when the main shock reaches the porch front. It is said in the literature that the first phase of the pressure rise is created also due to ground shock waves. In our case this explanation is unrealistic. The soil specimen is embedded in a steel tube. This tube is shock isolated from the plate containing the pressure gauges. Also these gauges are shock isolated (see Figure 1). Under these circumstances, no significant ground shock signal can be measured by the pressure gauges.

At DOB $>3 \mathrm{~cm}\left(=0.378 \mathrm{~m} / \mathrm{kg}^{1 / 3}\right)$ the lumps of the rater material keep increasingly prevent an uninterrupted propagation of the compressed smoke, so that no uniform shock front can be formed. An accumulation of compression waves propagates. 
This explanation of the three typical wave-forms is not only based on the pressure-time records, but also on the crater ejecta pictures (e.g., Figures 18 to 20) and high-speed film analyses (Figures 21 to 23).

Figure 42 shows domains of the different wave forms. They differ from material to material. The borders between the different domains are not precisely defined. They depend to a certain degree on judgement.

4.2.1.2 Peak Overpressures. The dependence of the peak overpressure on DOB and ground range is shown in scaled form in Figures 43 to 45 . The data of different tests at the same DOB are included in these diagrams. So one can make sure of the reproducibility of different tests under same conditions.

4.2.1.2.1 Fit Functions. For each data set, fit functions in form of:

(Eq. 8)

$$
\begin{gathered}
\log p=a_{0}+a_{1} * \log (G R)+a_{2} *(\log (G R))^{2} \\
1 \leq G R\left[m / \mathrm{kg}^{1 / 3}\right] \leq 10
\end{gathered}
$$

have been determined from the measured values according to the least square method. The solid lines in Figures 43 to 45 correspond to these functions. While the agreement of different experiments at the same DOB (DOB $<3 \mathrm{~cm} ;\left(0.378 \mathrm{~m} / \mathrm{kg}^{1 / 3}\right)$ ) is excellent, there are major deviations at larger DOB's. We assign this to the formation of crater ejecta which has a strong influence on the pressure curve due to the numerous compression waves. In addition, it is very problematic to compare the well defined peak overpressure of a blast wave with the more random maximum pressure of a porched shock front or of the sum of compression waves (see e.g., Figures 36 to 41 ).

Another reason for deviations for the clay/loam experiments might be that the charge position cannot be controlled as precisely as at YTONG tests. But small variations in DOB strongly influence the peak overpressure values.

The coefficients of the approximation function ( $\mathrm{Eq} .8$ ) as function of DOB are shown in Figures 46 to 48 . This dependency can be described by the following fit functions where third order polynomials in most cases are sufficient for estimation purposes. They are valid within the limits:

$$
-0.25 \leq \mathrm{DOB}\left(\mathrm{m} / \mathrm{kg}^{1 / 3}\right) \leq 0.63
$$


Aerated Grout (dry YTONG):

(Eq. 9)

$$
a_{0}=0.9516-3.9002 * D O B-5.7415 * D^{2} B^{2}+10.060 * D^{2} B^{3}
$$

(Eq. 10)

$$
\mathrm{a}_{1}=-2.3816+5.5376 * \mathrm{DOB}+6.4823 * \mathrm{DOB}^{2}-18.950 * \mathrm{DOB}^{3}
$$

(Eq. 11)

$$
\mathrm{a}_{2}=0.5881-2.5779 * \mathrm{DOB}-3.2815 * \mathrm{DOB}^{2}+8.3900 * \mathrm{DOB}^{3}
$$

Water saturated Grout (wet YTONG):

(Eq. 12)

$$
a_{0}=0.8596-4.8773 * \text { DOB }-6.4067 * \mathrm{DOB}^{2}+13.000 * \mathrm{DOB}^{3}
$$

(Eq. 13)

$$
a_{1}=-2.1271+5.8440 * D O B+3.4900 * \mathrm{DOB}^{2}-14.700 * \mathrm{DOB}^{3}
$$

(Eq. 14)

$$
a_{2}=0.4339-2.5637 * D O B-1.6757 * \mathrm{DOB}^{2}+6.8500 * \mathrm{DOB}^{3}
$$

\section{Wet Clay/Loam:}

(Eq. 15)

$$
a_{0}=0.7386-5.1257 * \mathrm{DOB}-4.8570 * \mathrm{DOB}^{2}+14.650 * \mathrm{DOB}^{3}
$$

(Eq. 16)

$$
a_{1}=-1.7355+6.0377 * \text { DOB }-2.9671 * D^{2} B^{2}-11.750 * D^{2} B^{3}
$$

(Eq. 17)

$$
\mathrm{a}_{2}=0.1833-2.7668 * \mathrm{DOB}+2.3120 * \mathrm{DOB}^{2}+5.1300 * \mathrm{DOB}^{3}
$$

where DOB is given in scaled values; $\left(\mathrm{m} / \mathrm{kg}^{1 / 3}\right)$

4.2.1.2.2 Overpressure-Range Curves. The equations (Eq. 8) to (Eq. 17) allow one to evaluate the overpressure-range curve for any DOB in the given range. But one has to taken into account that the character of the curves changes within the range. In Figures 49 to 51 overpressure-range curves are presented together with the transition lines of the different pressure domains.

Strictly speaking, only peak overpressures of the DOB-blastwave regime can be compared with $\mathrm{HOB}$ results. The range of such comparisons remains limited. One should therefore not be surprised, if in other domains overpressure-range curves of different DOB come close together (see e.g. Figure 51). The term peak overpressure has a different meaning in the other regimes (i.e., front porch regime and compression wave regime). 
4.2.1.2.3 Estimation of Energy Absorption by Cratering Processes. In Reference [2], a free-air overpressure curve was given for the 0.5 -g NP charges:

(Eq. 18)

$$
\begin{aligned}
\log p & =1.047-2.289 * \log R & & \text { for } 0.9<R \leq 2.45 \\
& =0.954-2.253 * \log R+0.427 *(\log R)^{2} & & \text { for } 2.45<R \leq 9.8
\end{aligned}
$$

For an ideal surface burst the so-called $2 \mathrm{~W}$-assumption is made. This means, in a given distance, GR, from ground zero of an ideal surface burst, the same peak overpressure exists as in the same distance, $R$, of a free air explosion of the double charge weight (i.e., double the energy content). Or, related to the same charge weight: $G R=\left(2^{1 / 3}\right) R$. If the peak overpressure at the soil surface of a DOB test is compared with the result of a corresponding ideal surface experiment, the energy portion can be estimated, needed for the cratering processes and other energy absorbing mechanisms.

The Cranz- or Hopkinson-similarity law for explosions says:

"The ground range distances $\mathrm{GR}_{1}$ and $\mathrm{GR}_{2}$ with the same overpressure in a geometrical similar arrangement of two different explosions are proportional to the cube root of the corresponding charge weight".

$$
\mathrm{GR}_{1} / \mathrm{W}_{1}{ }^{1 / 3}=\mathrm{GR}_{2} / \mathrm{W}_{2}{ }^{1 / 3}
$$

For a given distance $R$ the peak overpressure $p_{1}$ for ideal surface condition is calculated, applying equation Eq. 18. Then, for a given $D O B$ test, the distance $G_{2}$ is determined by applying Eq. 8, where the same pressure $p_{2}=p_{1}$ exists. The corresponding charge weight is evaluated by the similarity law, (Eq. 19). Under the assumption that the effective charge weight $W_{2}$ is reduced by energy absorbing processes such as cratering, we find:

(Eq. 20)

$$
\frac{G R_{1}}{W_{1}{ }^{1 / 3}}=\frac{2^{1 / 3} \cdot R}{W_{1}{ }^{1 / 3}}=\frac{G R_{2}}{\left(W_{1}-\Delta W\right)^{1 / 3}}
$$

or

(Eq. 21)

$$
\frac{\Delta W}{W}=1-0.5\left(\frac{G R_{2}}{R}\right)^{3}
$$


For the three soil materials, the evaluated energy loss vs ground range is shown in Figures 52 to 54 .

We conclude that the energy loss, based on the peak blast wave pressure is not constant; it varies with ground range. All the curves have a tendency to decrease with increasing ground range. This indicates that the peak pressure is not uniformly distributed in space. As demonstrated by photographs in section 4.1 .4 , the shock strength at DOB tests is favoured in vertical direction in the first phase of blast propagation. At later times an equalizing process takes place. As a consequence, the pressure near surface increases relatively with ground range, reducing the apparent energy loss.

At $\mathrm{HOB}$ tests $(\mathrm{DOB} \leq 0)$, the energy loss increases with ground range at short distances from GZ. Due to cratering processes energy is transmitted to the soil; rarefaction waves are created and follow the shock front. The peak overpressure is reduced and the evaluated energy loss is increased.

Differences for dry and wet YTONG in the HOB-region are caused by the porosity. The pores of wet YTONG are water-filled and can only absorb a small amount of compressed gas of the blast wave. This may explain the fact that energy losses for dry YTONG are higher than in wet YTONG. Differences in the DOB-region of this two materials may be also be influenced by the higher density or by the weight of the overburden layer. The same tendency can be noticed for wet clay/loam.

For different ground range positions, the percentage of energy losses is given in Figures 55 to 57 as function of DOB. The curves are relatively close together and indicate that for these soil materials the energy loss at $D O B=0\left[\mathrm{~m} / \mathrm{kg}^{1 / 3}\right]$ is about $50 \%$. Also note that for small heights of burst (e.g., HOB $=1 \mathrm{D})$, a significant amount of the charge energy (20 - 30 per cent) is lost from the blast wave and absorbed in the soil material. The ideal-surface assumption is not a good approximation in this regime.

4.2.1.2.4 Isobaric DOB-Curves. Figure 58 shows isobaric height-of-burst curves for a hydrodynamically smooth surface, completed with DOB-curves for dry aerated grout in the intermediate-pressure regime (taken from Reference [2], Figure 27). With increasing DOB, the extremely strong attenuation of the blast wave is clearly visible. In Figure 58 an area is also marked $\left(0.3 \leq \mathrm{HOB}\left(\mathrm{m} / \mathrm{kg}^{1 / 3}\right) \leq-0.2 ; 0 \leq \mathrm{GR}\left(\mathrm{m} / \mathrm{kg}^{1 / 3}\right) \leq 5\right)$ indicating the range where the isobaric DOB data in the intermediate-pressure regime are presented in the following diagrams. 
The isobaric DOB diagrams are given in Figures 59 to 61 in the intermediate-pressure regime, whereas Figures 62 to 64 show these curves in the low-pressure regime. In the diagrams the scales for $\mathrm{HOB}$ and GR are not the same. The correlated data points are linked with fit curves.

In Figures 65 to 68 the isobaric DOB curves of the three soil materials are compared. In addition, in Figures 65 and 66 also the isobaric HOB curves for a hydrodynamically smooth surface are shown. All isobaric curves for the three soil materials deviate from the smooth surface results below HOB $\leq 0.25\left(\mathrm{~m} / \mathrm{kg}^{1 / 3}\right)$. This value is also about the limit where crater formation in the soil material is observed. The most significant deviation is found in the range $0<\mathrm{HOB}\left(\mathrm{m} / \mathrm{kg}^{1 / 3}\right)<0.1$. Here the isobaric curves - especially of dry aerated grout show a bulge, compared to the other materials. We believe that the porosity of the material is the reason. Gas is pressed into the pores, reducing the remaining energy to drive the shock wave. Also at the estimation of the energy losses (section 4.2.1.2.3), the tendency of highest energy losses at aerated grout in this region was noticed.

In the diagrams of Figures 65 to 68 also the transition lines are indicated between regions of different wave forms. Strictly speaking, the isobaric DOB curves can only be compared in the blast wave regime.

\subsubsection{Overpressure Impulses.}

4.2.2.1 Impulse-Range Curves. As demonstrated in Figure 35, not only the pressure time history was recorded, but also the overpressure impulse and the positive phase duration was measured. In Figure 69 to 71 diagrams of impulse vs. ground range for several DOB are shown. In general, the scatter of the data increase with DOB. This is not surprising if one recalls the complicated interactions between cratering processes and formation of the different wave systems in air. One should also remember that the pressure at the soil surface is used to determine the impulse of the positive overpressure phase.

4.2.2.2 Fit Functions. For each set of impulse-ground range data, fit functions of the form:

$$
\begin{aligned}
\log I+= & b_{0}+b_{1} * \log G R+b_{2} *(\log G R)^{2} \\
& 1 \leq G R\left[\mathrm{~m} / \mathrm{kg}^{1 / 3}\right] \leq 10
\end{aligned}
$$


have been determined, according to the least square method. The coefficients of the fit functions depend on DOB. Using a third order polynomial approximation, they can be depicted by the following functions, where

$$
-0.25 \leq \mathrm{DOB}\left[\mathrm{m} / \mathrm{kg}^{1 / 3}\right] \leq 0.63
$$

Dry Aerated Grout (dry YTONG)

(Eq. 23)

$$
b_{0}=0.1765-1.9620 * D O B-1.7172 * D^{2} B^{2}+4.9040 * D^{2} B^{3}
$$

(Eq. 24)

$$
b_{1}=-0.5949+2.0708 * \mathrm{DOB}-1.6700 * \mathrm{DOB}^{2}-6.4450 * \mathrm{DOB}^{3}
$$

(Eq. 25)

$$
b_{2}=-0.2009-1.2159 * D O B+1.0193 * \mathrm{DOB}^{2}+2.4320 * \mathrm{DOB}^{3}
$$

Water Saturated Grout (wet YTONG)

(Eq. 26)

$$
b_{0}=0.0951-2.3065 * \mathrm{DOB}-0.7824 * \mathrm{DOB}^{2}+3.0855 * \mathrm{DOB}^{3}
$$

(Eq. 27)

$$
b_{1}=-0.4737+1.8461 * D O B-3.6947 * D^{2} B^{2}+0.5210 * D^{2} B^{3}
$$

(Eq. 28)

$$
b_{2}=-0.2726-1.0104 * D O B+1.5717 * \mathrm{DOB}^{2}+1.3135 * \mathrm{DOB}^{3}
$$

\section{Wet Clay/Loam}

(Eq. 29)

$$
b_{0}=0.0974-2.2366 * \mathrm{DOB}-1.0388 * \mathrm{DOB}^{2}+4.0740 * \mathrm{DOB}^{3}
$$

(Eq. 30)

$$
b_{1}=-0.3835+1.9128 * D O B-4.1936 * \mathrm{DOB}^{2}+2.3850 * \mathrm{DOB}^{3}
$$

(Eq. 31)

$$
b_{2}=-0.3514-0.9747 * D O B+3.3949 * \mathrm{DOB}^{2}-4.1055 * \mathrm{DOB}^{3}
$$

DOB is given in scaled values; $\left[\mathrm{m} / \mathrm{kg}^{1 / 3}\right]$

Logarithmic plots of impulse-range curves for different DOB are presented in Figures 72 to 74 .

4.2.2.3 Iso-Impulse DOB Curves. By means of fit functions for the impulse of the positive overpressure phase, the distances to a given impulse value can be determined. Some scaled iso-impulse DOB curves are arranged in Figures 75 to 77 for the three soil materials. 


\subsubsection{Arrival Times.}

4.2.3.1 Arrival-Time - Range Curves. Zero time is defined as time of charge ignition. In the pressure records (see Figure 35 ) the arrival of the shock front can easily be detected in the blast wave regime. More uncertainty exists in the compression wave regime.

Arrival-time-range curves are shown in Figures 78 to 80 . It is evident that the curves start with a delay, depending on DOB. This time delay is mainly caused by the clearing time needed before the cloud of the detonated charge can escape and expand and drive the blast wave.

4.2.3.2 Fit Functions. For each set of time of arrival data, fit functions of the form:

(Eq. 32)

$$
\begin{array}{rl}
\mathrm{ta}=\mathrm{c}_{1} & * \log \mathrm{GR}+\mathrm{c}_{2} / \mathrm{GR}+\mathrm{GR} / \mathrm{c}_{0}+\mathrm{c}_{3} \\
1 & \leq \mathrm{GR}\left[\mathrm{m} / \mathrm{kg}^{1 / 3}\right] \leq 10
\end{array}
$$

have been determined, according to the least square method, where $c_{0}$ means sound speed in air and ta and GR are given in cube-root scaled values. The coefficients depend on DOB. Using a third order polynomial approximation, they can be represented by the following functions in the interval, where

$$
-0.25 \leq \mathrm{DOB}\left[\mathrm{m} / \mathrm{kg}^{1 / 3}\right] \leq 0.63
$$

Dry Aerated Grout (dry YTONG)

(Eq. 33) $\quad c_{1}=-3.807 \mathrm{E}-3+6.132 \mathrm{E}-3 * \mathrm{DOB}+3.462 \mathrm{E}-3 * \mathrm{DOB}^{2}+1.891 \mathrm{E}-2 * \mathrm{DOB}^{3}$

(Eq. 34) $\quad \mathrm{C}_{2}=1.242 \mathrm{E}-3-6.820 \mathrm{E}-3 * \mathrm{DOB}-1.457 \mathrm{E}-2 * \mathrm{DOB}^{2}+6.289 \mathrm{E}-2 * \mathrm{DOB}^{3}$

(Eq. 35) $\quad c_{3}=-3.360 \mathrm{E}-3+1.018 \mathrm{E}-2 * \mathrm{DOB}+2.461 \mathrm{E}-2 * \mathrm{DOB}^{2}-5.461 \mathrm{E}-2 * \mathrm{DOB}^{3}$ 
Water Saturated Grout (wet YTONG)

(Eq. 36)

$$
c_{1}=-4.204 \mathrm{E}-3+1.166 \mathrm{E}-2 * \mathrm{DOB}+2.190 \mathrm{E}-2 * \mathrm{DOB}^{2}-5.648 \mathrm{E}-2 * \mathrm{DOB}^{3}
$$

(Eq. 37)

$$
c_{2}=7.017 \mathrm{E}-4-2.751 \mathrm{E}-3 * \mathrm{DOB}+6.626 \mathrm{E}-3 * \mathrm{DOB}^{2}-1.503 \mathrm{E}-2 * \mathrm{DOB}^{3}
$$

(Eq. 38)

$$
c_{3}=-2.677 \mathrm{E}-3+8.172 \mathrm{E}-3 * \mathrm{DOB}+1.478 \mathrm{E}-3 * \mathrm{DOB}^{2}-9.124 \mathrm{E}-2 * \mathrm{DOB}^{3}
$$

Wet Clay/Loam

(Eq. 39)

$$
c_{1}=-4.333 \mathrm{E}-3+9.811 \mathrm{E}-3 * \mathrm{DOB}+1.475 \mathrm{E}-2 * \mathrm{DOB}^{2}-3.127 \mathrm{E}-2 * \mathrm{DOB}^{3}
$$

(Eq. 40)

$$
c_{2}=6.023 \mathrm{E}-4-4.668 \mathrm{E}-3 * \text { DOB }-3.999 \mathrm{E}-4 * \mathrm{DOB}^{2}+1.211 \mathrm{E}-2 * \mathrm{DOB}^{3}
$$

(Eq. 41)

$$
c_{3}=-8.024 \mathrm{E}-4+6.186 \mathrm{E}-3 * \text { DOB }-2.409 \mathrm{E}-2 * \mathrm{DOB}^{2}+2.300 \mathrm{E}-2 * \mathrm{DOB}^{3}
$$

where DOB is given in scaled values; $\left[\mathrm{m} / \mathrm{kg}^{1 / 3}\right]$

Logarithmic plots of arrival time - range curves are presented in Figures 81 to 83.

4.2.3.3 Iso-Arrival Time DOB Curves. By means of fit functions for time of arrival curves, the ground range for a constant arrival time can be determined. Constant arrival time DOB curves are shown in Figures 84 to 86 for the three soil materials.

4.2.3.4 Independent Evaluation of Peak Overpressure. Arrival time data can be used to evaluate, independently from pressure measurements, peak overpressure range curves. The propagation speed of the shock front is obtained by time differentiation of the function GR = $\mathrm{GR}(\mathrm{ta})$. This speed is directly related to the peak overpressure of the shock front. It is evident that this method works properly only in the blast wave regime.

As approximation function is used:

(Eq. 42)

$$
\mathrm{GR}=\mathrm{d}_{1} * \log \mathrm{ta}+\mathrm{d}_{2} / \mathrm{ta}+\mathrm{c}_{0} * \operatorname{ta}+\mathrm{d}_{3}
$$

where $c_{0}=$ sound speed and ta and GR are given in cube-root scaled values. The propagation speed of the shock front is then: 
.نq. 43)

$$
\mathrm{dGR} / \mathrm{dta}=\mathrm{c}_{0}+\mathrm{d}_{1} /(\mathrm{ta} * \ln 10)-\mathrm{d}_{2} / \mathrm{ta}^{2}
$$

If ideal gas conditions are assumed, the shock Mach number is

$$
\mathrm{Ms}=\mathrm{W} / \mathrm{c}_{0}
$$$$
(\mathrm{W}=\text { shock front speed })
$$

and the shock strength

$$
\begin{aligned}
& P_{10}=\left(7 * M s^{2}-1\right) / 6=\left(p+p_{n}\right) / p_{0} \\
& \left(p=\text { overpressure; } p_{0}=\text { ambient pressure }\right)
\end{aligned}
$$

Or the peak overpressure

$$
\mathrm{p}=\mathrm{p}_{0} *\left(\mathrm{Ms}^{2}-1\right) * 7 / 6
$$

This procedure was applied to the arrival time data. Some results are presented in the diagrams of Figures 87 to 89 . The upper diagrams show the measured ta values at different ground ranges, approximated by the function (Eq. 42). from this specific function, the velocity of the shock front is determined, applying (Eq. 43). In the lower diagrams, the calculated overpressure-range function (Eq. 44 to Eq. 46 ) is plotted. The peak overpressures are also given, measured by pressure gauges.

We conclude that the calculated pressure-range curves, based on the arrival time data, approximate very well the measured peak overpressures in the blast wave region. Both independent methods give the same values and prove that our gauges are able to accurately measure these blastwave pressures.

\subsubsection{Positive Phase Durations.}

4.2.4.1 Duration-Range Curves. The duration of the positive overpressure phase of a blast wave is a quantity that cannot be measured very precisely. The intersection of overpressure curve and zero pressure line (abscissa of pressure time record) is often very flat. Small shifts of the zero line have a great influence on the intersection point and therefore on the time duration. Also the crater ejecta formation with the different compression and rarefaction waves influence strongly the measured duration values. 
Measured time duration-range results are presented in Figures 90 to 92 . As expected, the scatter of the data larger than for other quantities of the blast wave. Especially at large DOB, the mcasured values vary considerably. But on the other side, the interval of the time data is comparably limited. At $D O B \geq 3 \mathrm{~cm}\left(0.378 \mathrm{~m} / \mathrm{kg}^{1 / 3}\right)$ the duration of the positive overpressure phase is practically constant.

4.2.4.2 Fit Functions. For each set of time duration-range data, fit functions of the type:

(Eq. 47)

$$
\begin{aligned}
\log t+= & e_{0}+e_{1} * \log G R+e_{2}^{*}(\log G R)^{2} \\
& 1 \leq G R\left[m / \mathrm{kg}^{1 / 3}\right] \leq 10
\end{aligned}
$$

have been determined, according to the least square method. Using a third order polynomial as fit function for the coefficient of equation (Eq. 47), the following functions were obtained in the interval:

$$
-0.25 \leq \mathrm{DOB}\left[\mathrm{m} / \mathrm{kg}^{1 / 3}\right] \leq 0.63
$$

Dry Aerated Grout (dry YTONG)

(Eq. 48)

$$
e_{0}=-3.030+0.8294 * D O B+1.9510 * D^{2} B^{2}-1.6230 * D^{2} B^{3}
$$

(Eq. 49)

$$
e_{1}=0.9863-0.3838 * D O B-7.5028 * D^{2} B^{2}+10.295 * D^{2} B^{3}
$$

(Eq. 50)

$$
e_{2}=-0.3326-0.59361 * \mathrm{DOB}+4.7449 * \mathrm{DOB}^{2}-6.7200 * \mathrm{DOB}^{3}
$$

Saturated Aerated Grout (wet YTO Ni $)$

(Eq. 51)

$$
e_{0}=-3.14 .92+1.2350 * D O B+4.9975 * D^{2} B^{2}-5.4100 * D^{2} B^{3}
$$

(Eq. 52)

$$
\mathrm{e}_{1}=1.2532-1.8612 * \mathrm{DOB}-7.8808 * \mathrm{DOB}^{2}+12.890 * \mathrm{DOB}^{3}
$$

(Eq. 53)

$$
e_{2}=-0.5343+0.2599 * \mathrm{DOB}+4.1609 * \mathrm{DOB}^{2}-5.2500 * \mathrm{DOB}^{3}
$$


Wet Clay/Loam

(Eq. 54)

$$
e_{0}=-3.0175+1.4429 * \mathrm{DOB}+3.5410 * \mathrm{DOB}^{2}-5.3650 * \mathrm{DOB}^{3}
$$

$$
\mathrm{e}_{1}=0.9166-1.4064 * \mathrm{DOB}-3.2040 * \mathrm{DOB}^{2}+6.5600 * \mathrm{DOB}^{3}
$$

(Eq. 56)

$$
e_{2}=-0.2958+0.0122 * \mathrm{DOB}+0.8082 * \mathrm{DOB}^{2}-1.5151 * \mathrm{DOB}^{3}
$$

where DOB, GR, $t+$ resp. are given in scaled values.

Logarithmic plots of duration-range curves are presented in Figures 93 to 95.

4.2.4.3 Iso-Duration DOB Curves. By means of fit functions for the duration curves, the ground range for a constant value of positive phase were determined. Scaled constant duration DOB curves are shown in Figures 96 to 98 for the three soil materials.

\subsubsection{Comparison with Results of Free Field Tests.}

To investigate how the laboratory data agree with free field measurements, some comparisons were made with results presented in Reference [12]. Extensive test results are very well presented there. The soil material was desert alluvium. Therefore it cannot be expected that complete agreement exists between the model tests with different soil materials and the free field experiments. In Reference [12] charges between $256 \mathrm{lbs}(116 \mathrm{~kg}$ ) and $40000 \mathrm{lbs}$ (18400 $\mathrm{kg}$ ) were used; also some nuclear explosion data are included, whereas in our experiments only 0.5 -g charges were applied. What can be demonstrated by this comparison, we believe, is the consistency of the data sets and at least the agreement of the individual values in the right order of magnitude. A good indication for correct results of the model tests is the same tendency or the slope of the different curves.

4.2.5.1 Wave Forms. In Figure 99 results of two institutions, namely Ballistic Research Lab. Aberdeen Proving Ground (BRL), and Naval Ordnance Lab., Silver Spring, (NOL) are compared with our registration curves for two different $\mathrm{DOB}$ and ground ranges, resp. $W^{1 / 3}$ scaling was applied. Figure 99 demonstrates that also in laboratory small scale tests, depending on DOB, different wave forms exist. Not in detail, but in general the character of the wave shape is quite similar. At DOB $=3 \mathrm{~cm}\left(=0.38 \mathrm{~m} / \mathrm{kg}^{1 / 3}\right)$ front porch blast waves exist but not at $\mathrm{DOB}=1.5 \mathrm{~cm}\left(=0.19 \mathrm{~m} / \mathrm{kg}^{1 / 3}\right)$. The same result is discovered at the free field tests. More examples for different wave forms are given in Figures 36 to 41 . 
Transition from one wave form to another is compared in Figure 100 for desert alluvium (Reference [12]) and dry aerated grout. The curves differ of course but the small scale values deviate in the whole range less than a factor of two. They show beyond it the same trend of dependency on ground range.

4.2.5.2 Peak Overpressures. For free field tests at two different $D O B$ in desert alluvium, a diagram of peak overpressure vs ground range is shown in Figure 101, taken from [12]. Included are scaled curves for tests in aerated grout, water saturated grout and clay/loam, resp. Altogether, the conformity is acceptable, considering the different test conditions. Water saturated grout shows the closest agreement with desert alluvium. Also clay/loam differs not too much. This behavior can be noticed just so in Figure 102, where the overpressure suppression vs DOB of the different soil materials is shown. At aerated grout the weight of the overburden has the smallest value. So it is reasonable that the overpressure suppression is smaller compared with the other materials.

4.2.5.3 Impulses of Positive Overpressure Phase. A comparison of scaled overpressure impulse vs scaled ground range is made in Figure 103. The data of the free field tests are taken from Reference [12]. At and near the surface the curves for aerated grout and especially for water saturated grout are in a good agreement with the desert alluvium values. This is not so surprising because the influence of the soil for near-surface bursts is not so strongly pronounced. But even at $\mathrm{DOB}=1\left[\mathrm{ft} / \mathrm{bs}^{1 / 3}\right]$ the wet YTONG data are within the scatter of the desert alluvium values. It it noteworthy that the slopes of the impulse curves for the different soil materials are nearly identical. Also the suppression of the blast impulse as function of DOB agrees very well, as shown in Figure 104 for water saturated grout (wet YTONG).

4.2.5.4 Arrival Times. Arrival time curves vs ground range are expected to be parallel at great distances because the shock strength of the blast is small and the propagation velocity approaches the sound speed. The influence of the soil material and of DOB are noticeable only near ground zero. In Figures 105 and 106 arrival time vs ground range curves for dry YTONG and wet, resp. are compared with $40000 \mathrm{lbs}$ results at DOB $=17 \mathrm{ft}$ and $34 \mathrm{ft}$ for desert alluvium. The curves behave as expected. Due to the test conditions for YTONG experiments, direct ground-shock induced air shocks are not present. 
4.2.5.5 Positive Phase Durations. As discussed earlier, the evaluation of the positive phase duration is not very accurate, especially in the region of porched shocks and compression waves. Nevertheless the comparison with desert alluvium results demonstrates that even for this quantity the results are quite similar as shown in Figures 107 and 108. Typically, the positive phase duration of dry aerated grout is smaller than for water saturated grout and clay/loam. The reason might be the smaller overburden mass at the same DOB. The clearing time of the crater is therefore shorter. The model tests show that at large DOB the positive phase duration is practically constant, which is in full agreement with the observations at free field experiments. 


\section{SECTION 5}

\section{CONCLUSIONS}

1.) The tests have demonstrated the feasibility of performing airblast DOB experiments at laboratory scale.

2.) The data sets of airblast environments from buried HE charges for the three applied different materials are self consistent.

3.) The transition effects from $\mathrm{HOB}$ to $\mathrm{DOB}$ are documented for peak overpressure, overpressure impulse, arrival time and positive phase duration. Corresponding fit functions are given.

4.) Different mechanisms for airblast creation at DOB tests were demonstrated photographically. At small $D O B$ the crater ejecta do not significantly influence the expansion of the explosion smoke. As a consequence, a blast wave is formed with a shape of a Friedlander function. At intermediate DOB the ejecta material acts like a moving piston. A bow wave is created before the detonation products can expand in free air. Then, a porched waveform is observed. At large DOB numerous randomly distributed compression waves are observed. These different regions are also found in free field tests.

5.) An estimate of the energy absorption due to cratering processes and specific material behavior is given. The energy losses, based on overpressure measurements, depend on $\mathrm{DOB}$ and ground range. At $\mathrm{DOB}=0$ about $50 \%$ of the total energy are lost as driver for the blast wave.

6.) The comparison with numerous tests in desert alluvium shows that the data sets are self consistent. The deviations due to different soil materials and different charge weights are plausible and are self consistent.

7.) The laboratury-scale test method for $D O B$ investigations is especially useful for parameter studies. 


\section{SECTION 6}

\section{LIST OF REFERENCES}

1. Reichenbach, H., Laboratory-Scale Airblast Precursor Experiments, Volume III - HOB Studies Micro-Mach Experiments, Defense Nuclear Agency, DNA-TR-85-352-V3 (March 1989).

2. Reichenbach, H., Scheklinski-Glück, G., and Kuhl, A.L., Comparison of HOB Curves for 0.5-g NP Charges with Field Test Data and Calculations, R and D Associates, RDA-TR-0263229003-001 (August 1991).

3. Petes, J., Handbook of HE Explosive Effects, DASIAC-TN-86-15 (April 1986).

4. Swisdak, M.M., Explosion Effects and Properties; Part I - Explosion Effects in Air, NSWC/WOL/TR 75-116 (October 1975).

5. Teller, E., Talley, W.K., Higgins, G.H., and Johnson, C.W., The Constructive Uses of Nuclear Explosives, McGraw-Hill (1968).

6. Harvey, W.T., ESSEX - DIAMOND ORE Research Program, Preliminary Results Report - Essex-I, Phase 1: Nuclear Cratering Device Simulation (Project ESSEX). DNA PR 0002 (WES PR E-74-1), (Apr. 1974).

7. Reisler, R.E., Dettit, B.A., Air Blast From Shallow-Buried Charges. ESSEX I, Phase 2, BRL MR 2656, (Aiug. 1976).

8. Vortman, L.J.; Dickinson, J.R., and Fastle, D.L.; Results of Airblast and Temperature Measurements, Project ESSEX I, Phase 3, SAND76-0531, Sandia Laboratories (Jan. 1977).

9. Rooke, A.D., Jr., ESSEX-DIAMOND ORE Research Program: Apparent Crater Measurements for Simulated Low Yield Nuclear Explosions, Project ESSEX I, Phases 1 and 2. WES MP N-78-3 (Mar. 1978).

10. Reed, J.W., "Air Blast Cratering Explosions," Proc. of the Third Plowshare Symposium, TID-7695, pp. 169-180, U.S. Atomic Energy Commission (1964). 


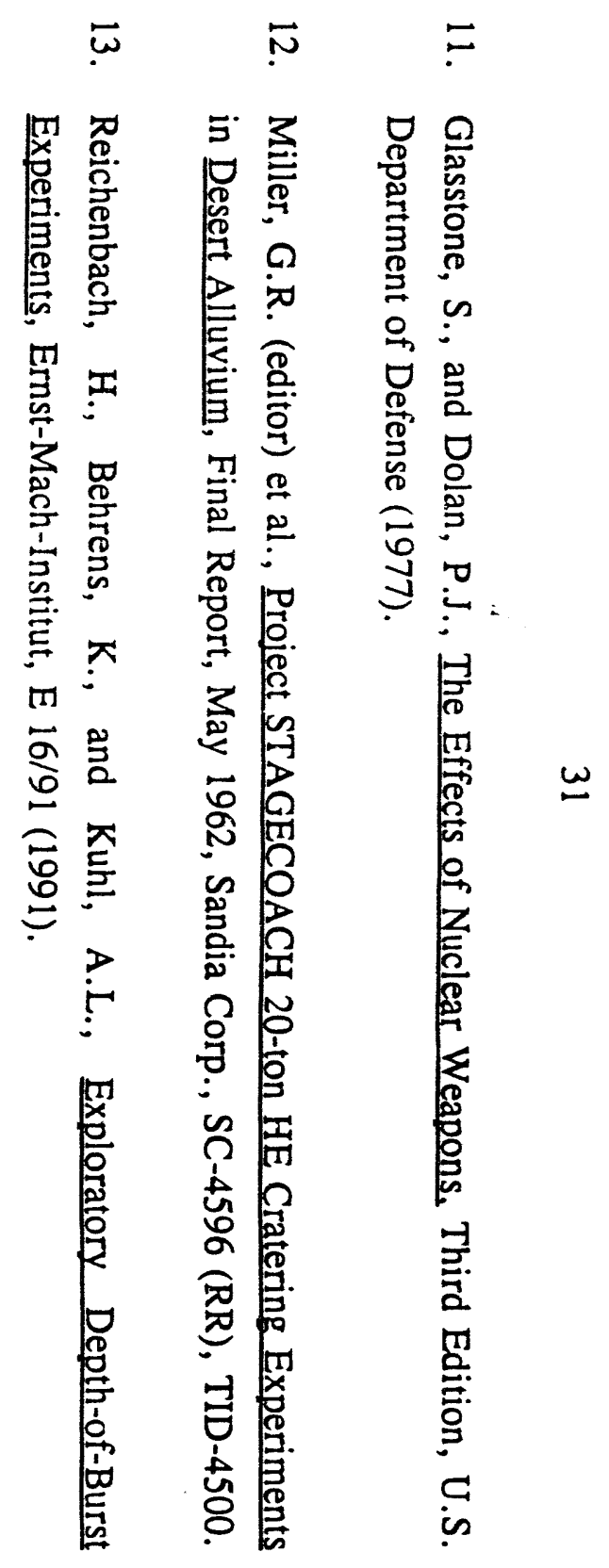




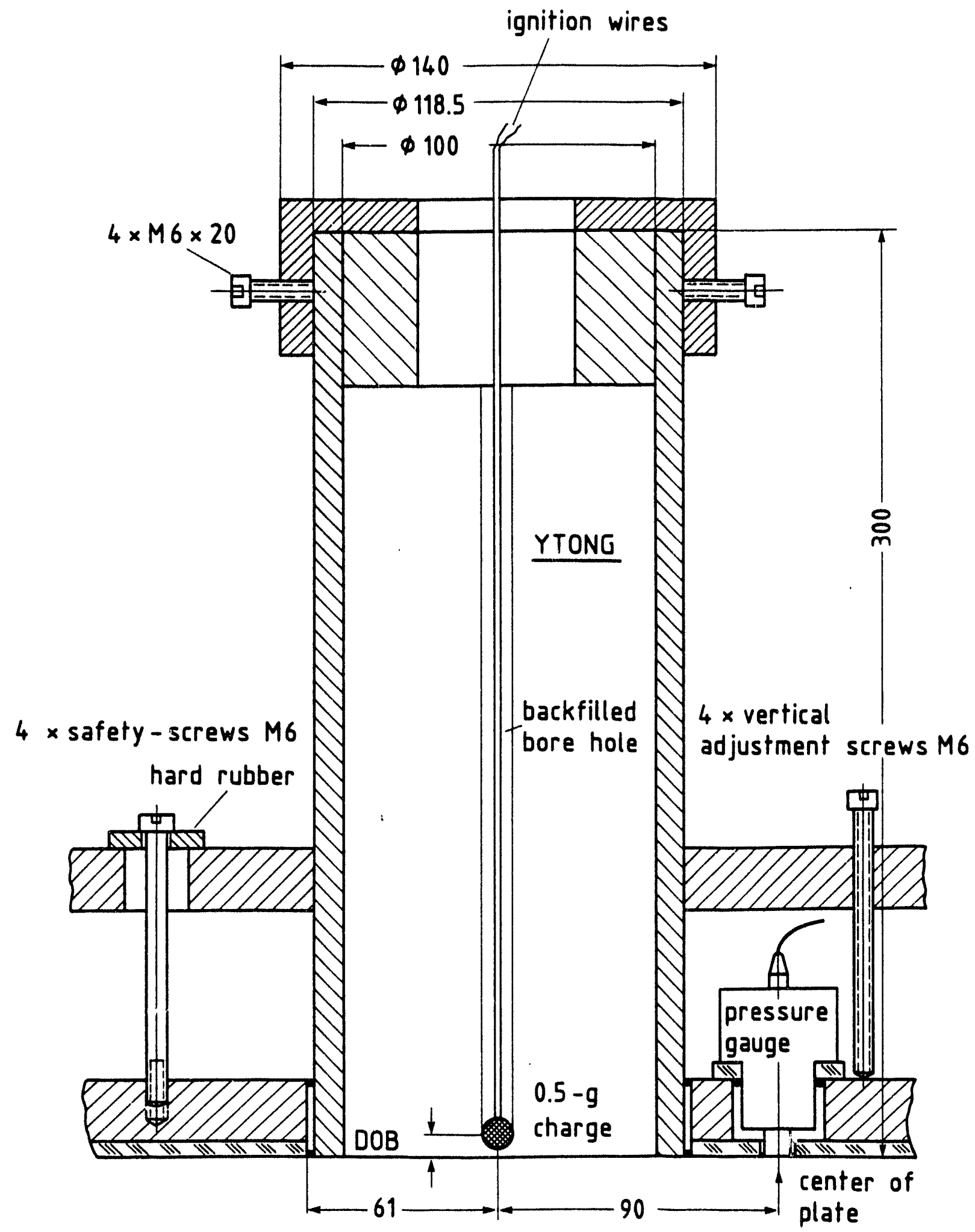

Figure 1 Installation of the $0.5-\mathrm{g}$ charge into aerated grout and shockisolated mounting of the set-up into the explosion chamber. 


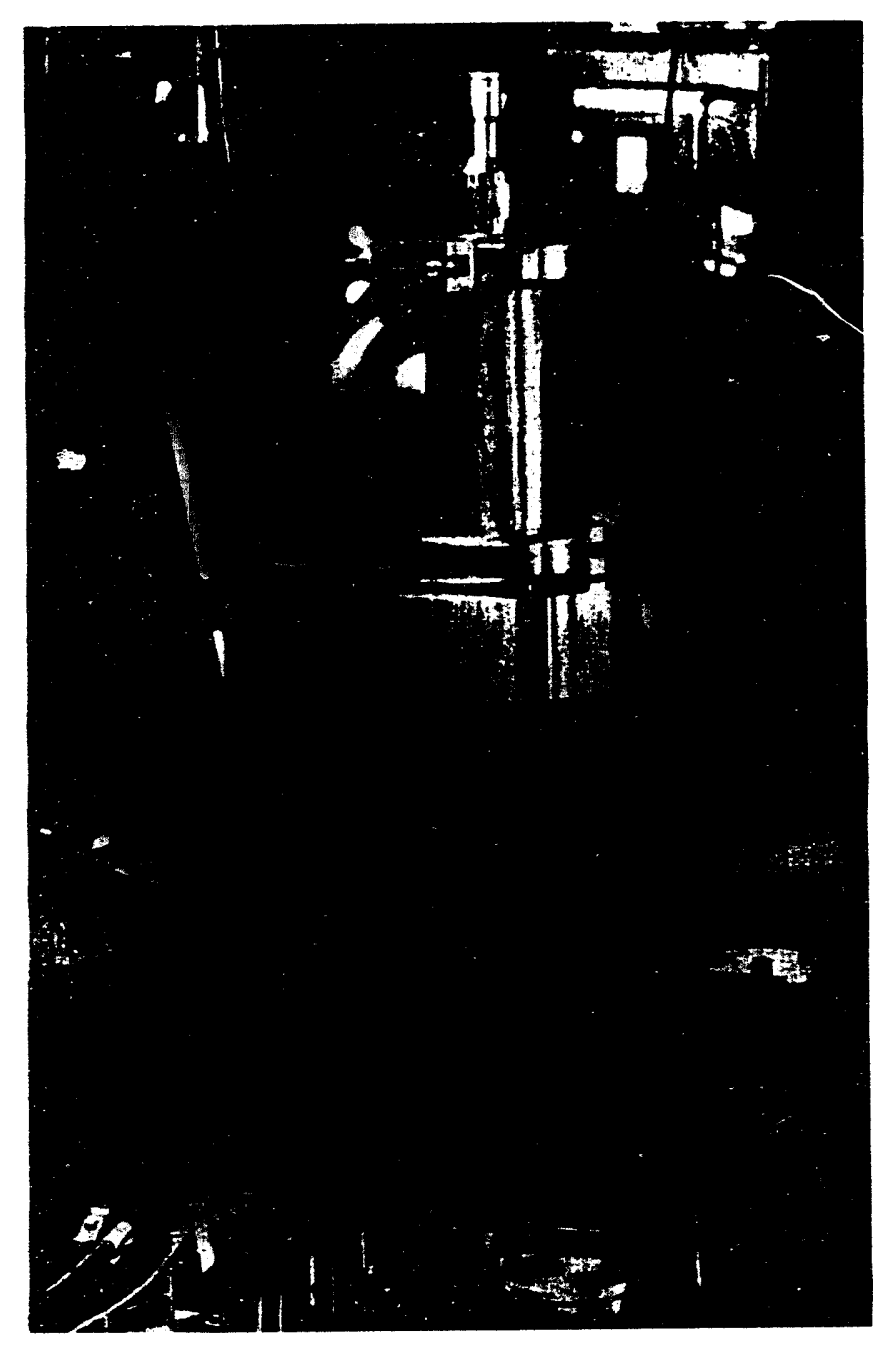

Figure 2 General view showing the construction of the soil material holder.

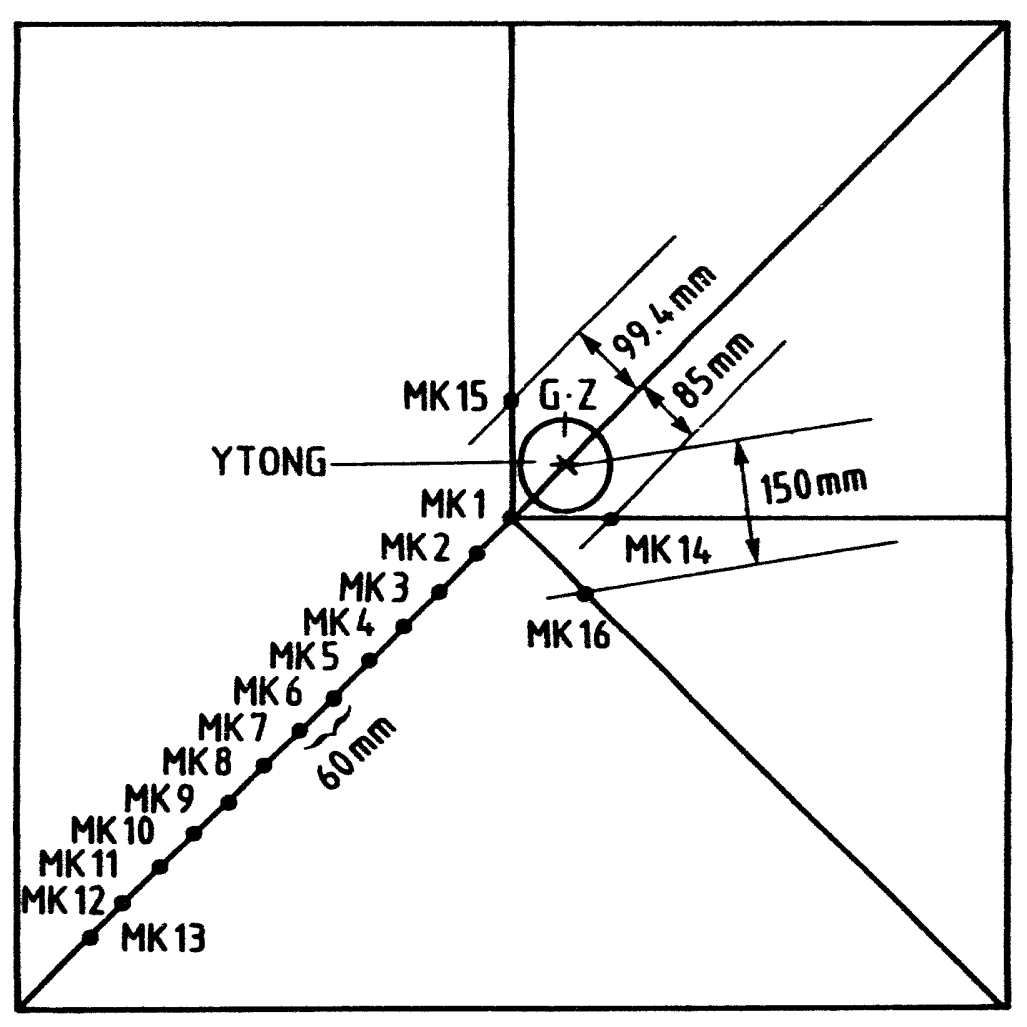

Figure 3 Position of the shock-isolated pressure gauges MK 1 to MK 16. 
CHARGE GEOMETRY

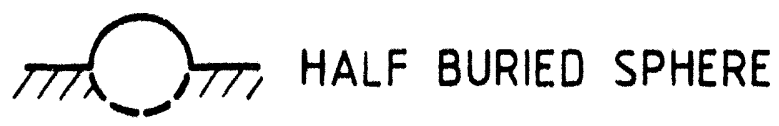

T77777777, SURFACE TANGENT SPHERE

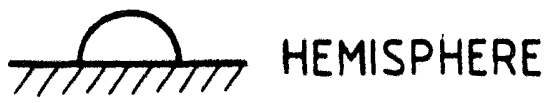

RADIUS DEPTH

1.0

1.0

0.74

0.61

0.97

1.08

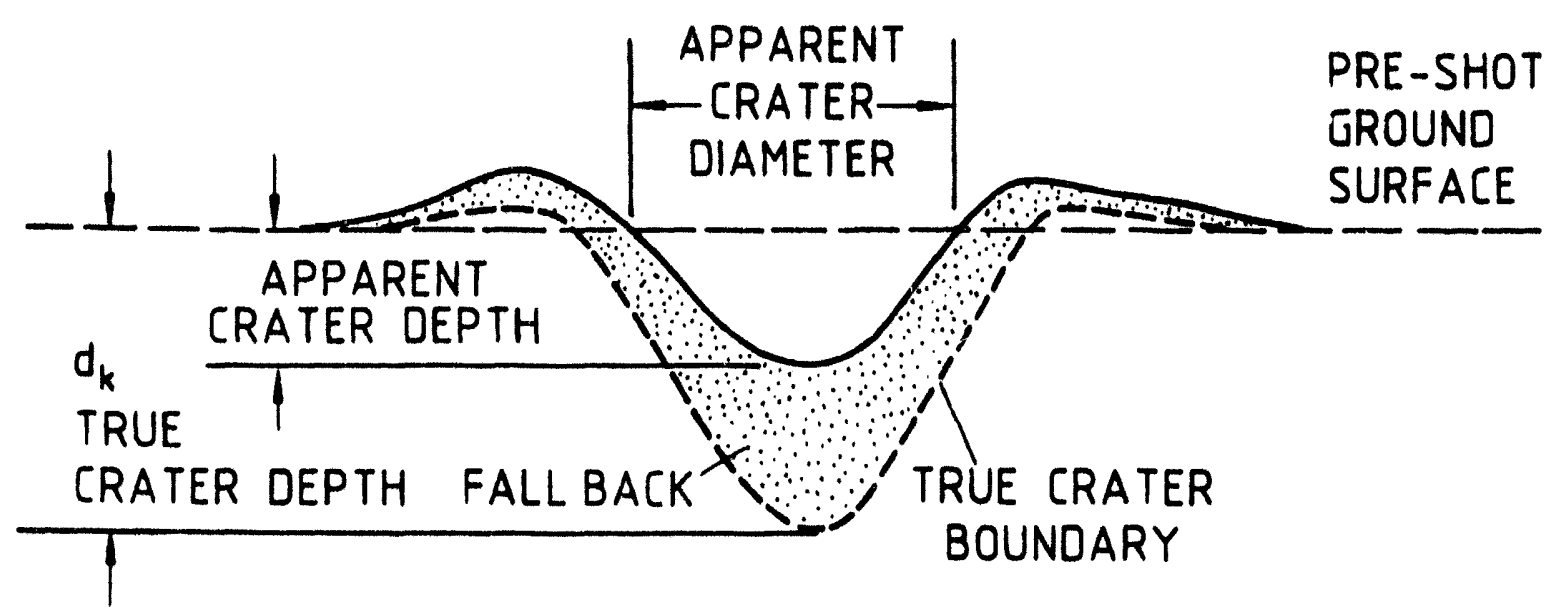

Figure 4 Apparent crater dimensions of different charge geometries and definition of apparent and true crater depth, resp., [3] 


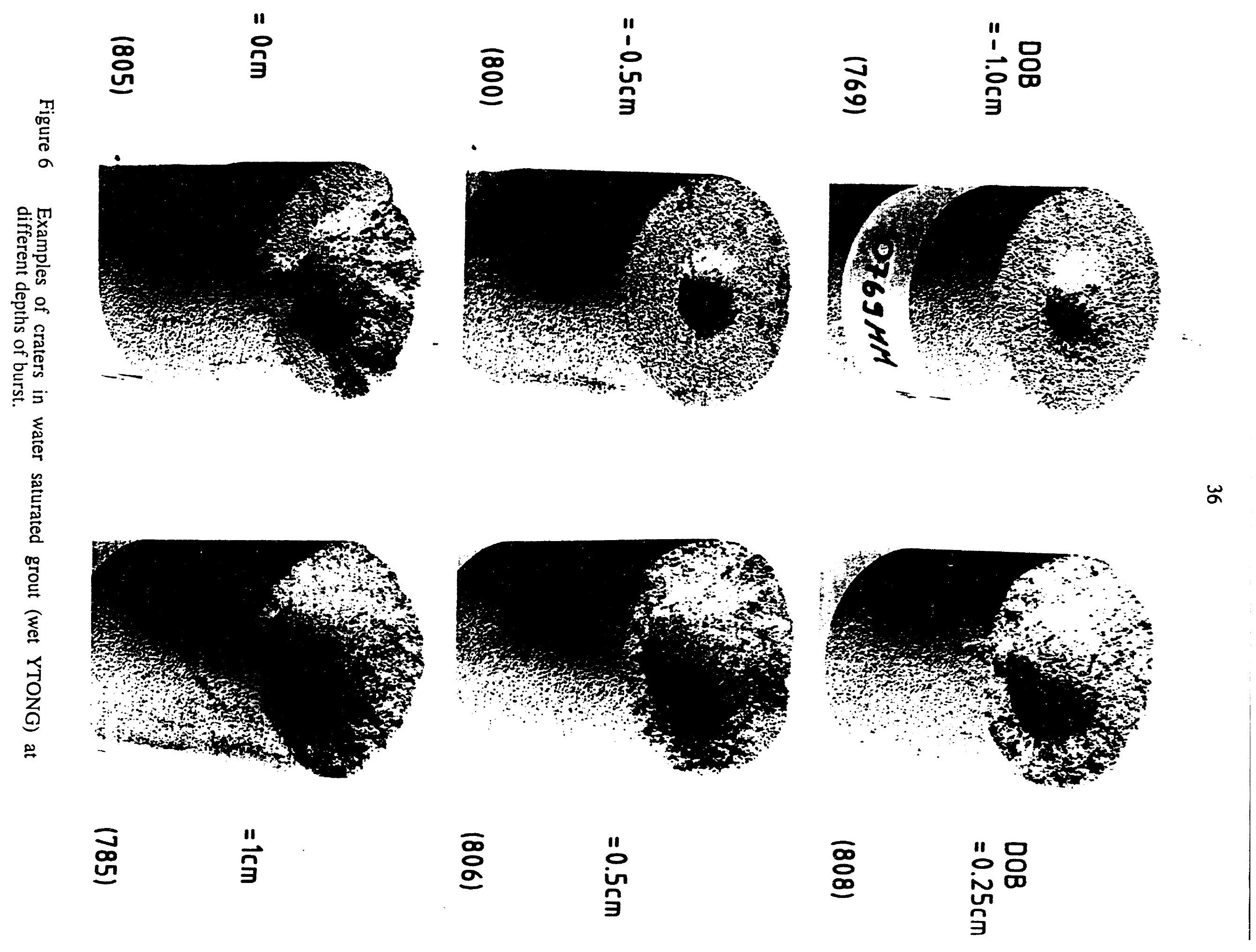



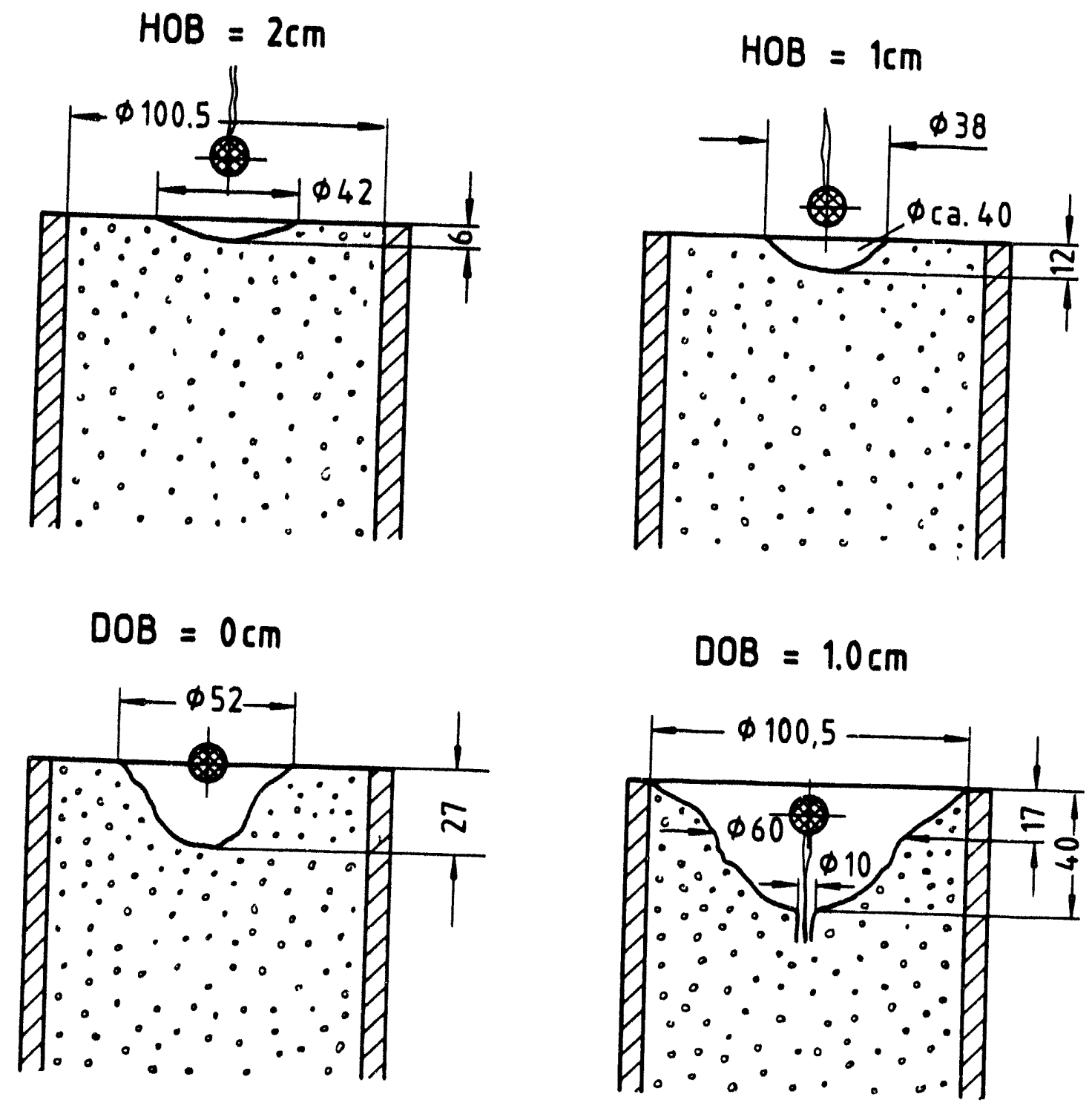

Figure 7 True crater contours in aerated grout (dry YTONG). 
38

$D O B=1,5 \mathrm{~cm}$
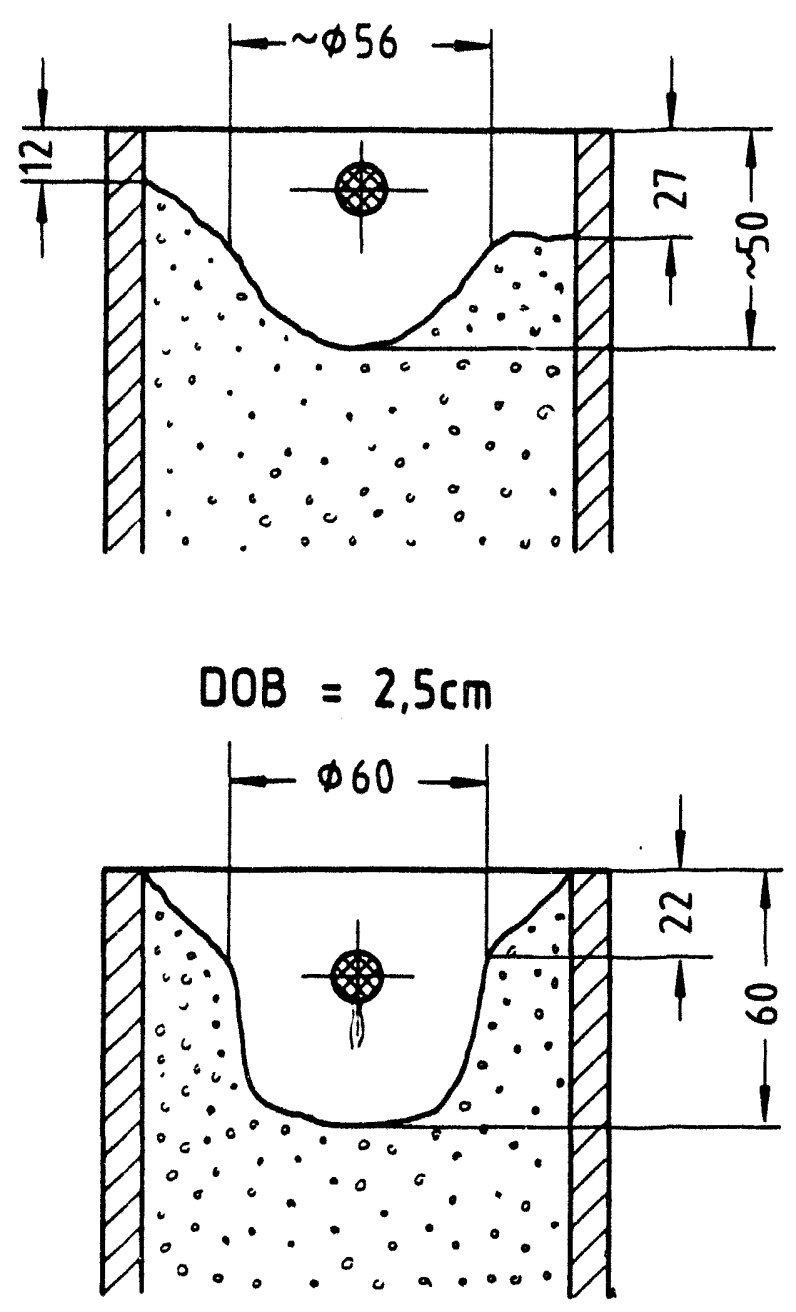

$D O B=2.0 \mathrm{~cm}$

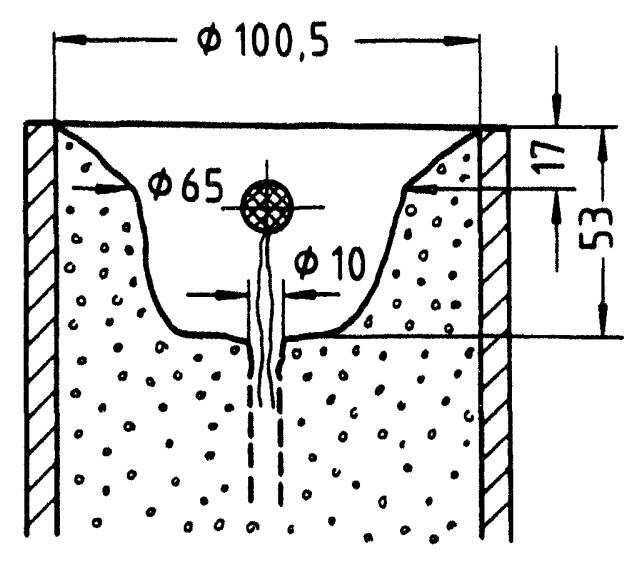

$D O B=3.0 \mathrm{~cm}$

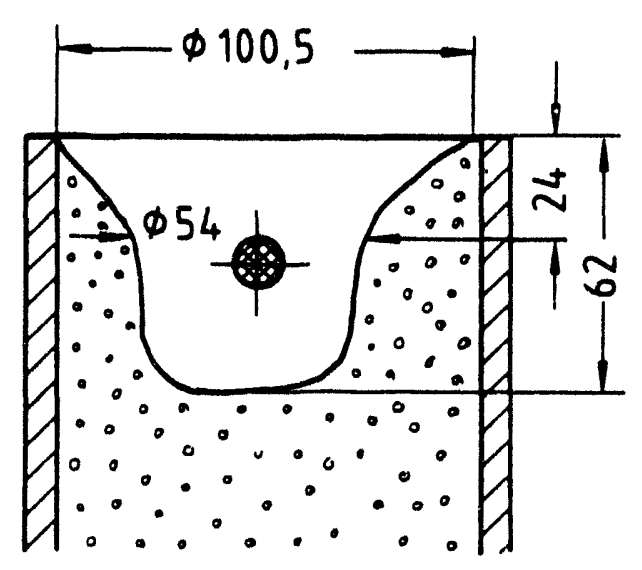

$D O B=4.0 \mathrm{~cm}$

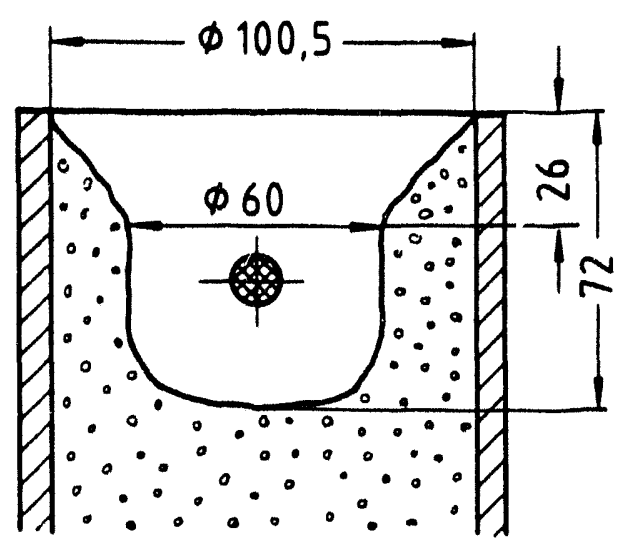

$D O B=5,0 \mathrm{~cm}$

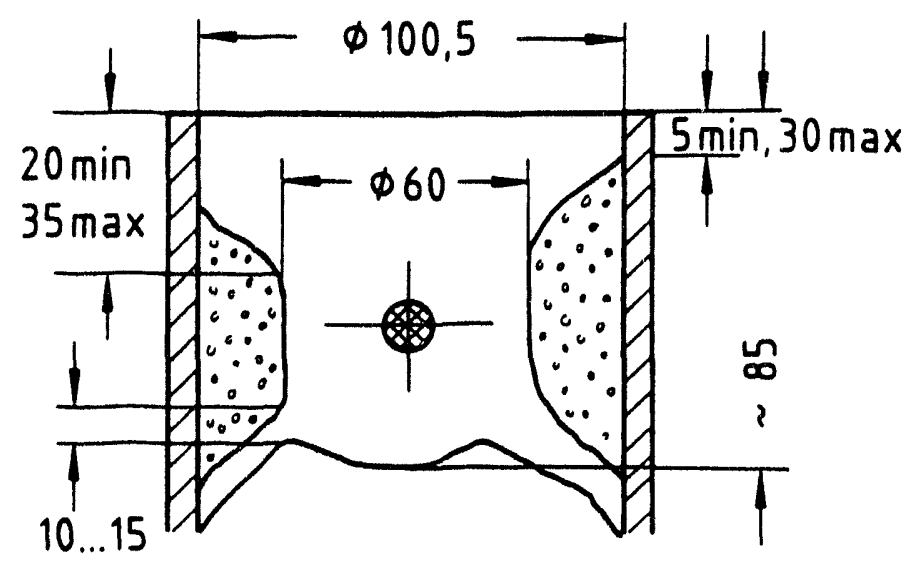

Figure 7 Continued. 

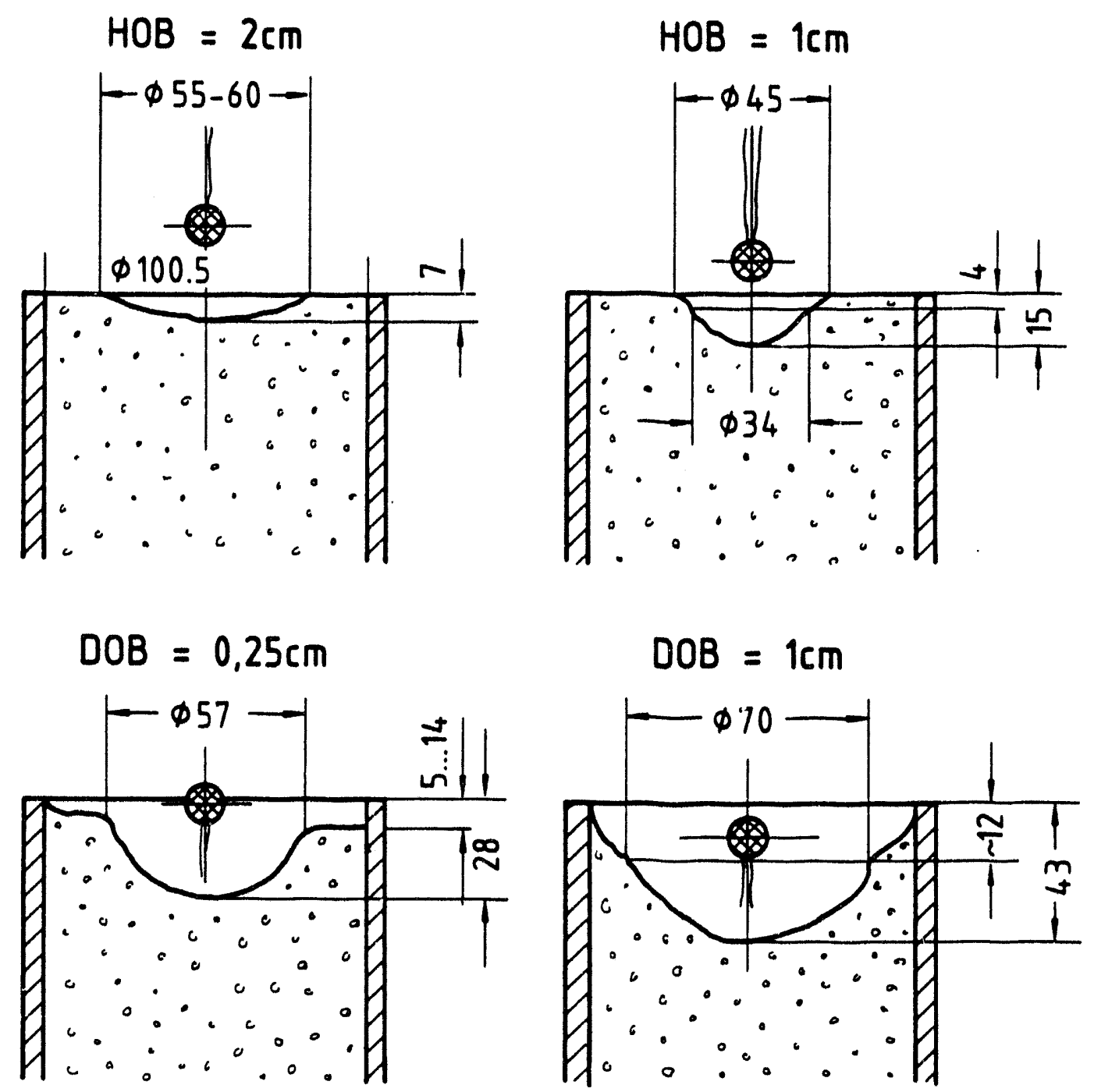

Figure 8 True crater contours in water saturated grout (wet YTONG). 

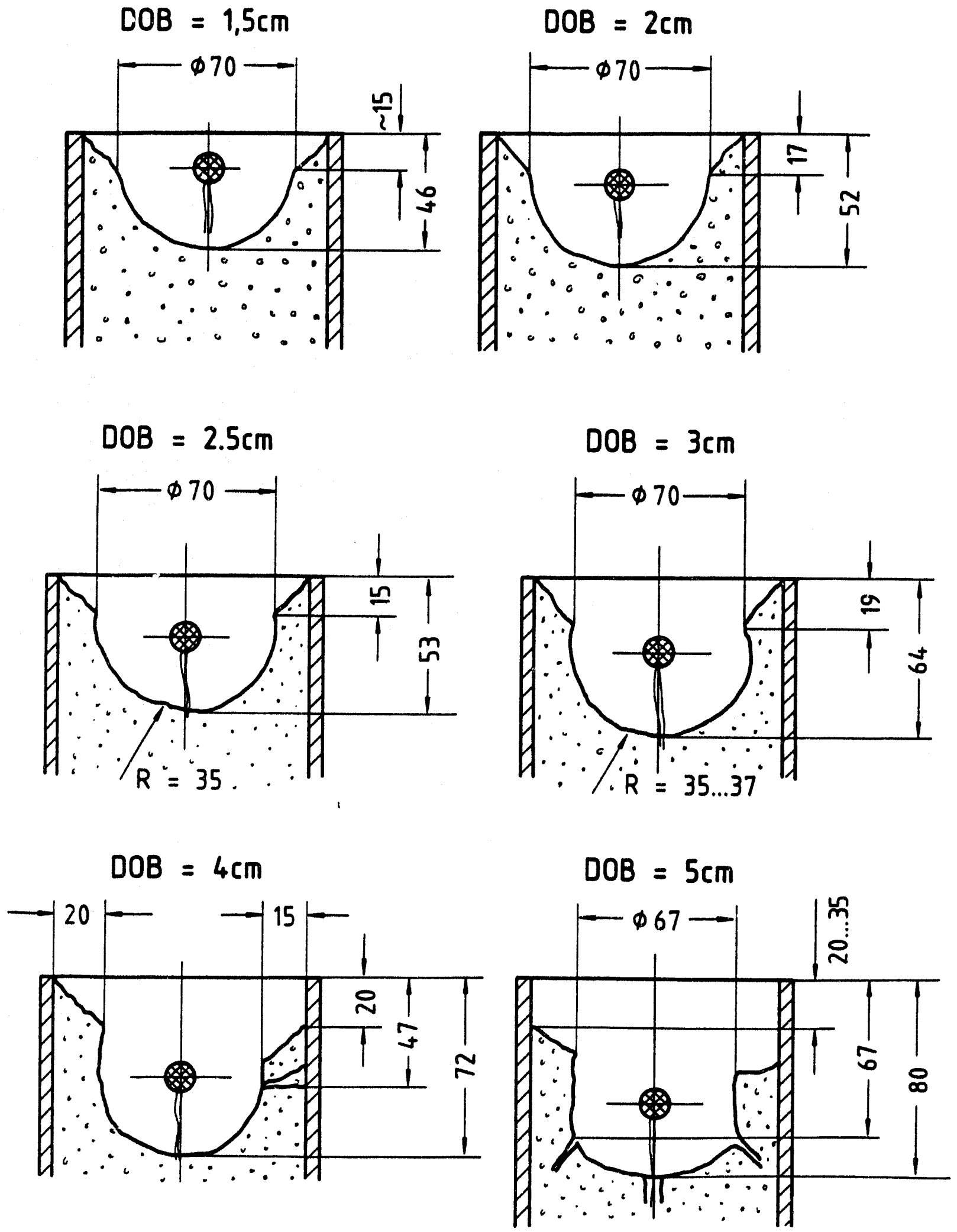

Figure 8 Continued. 

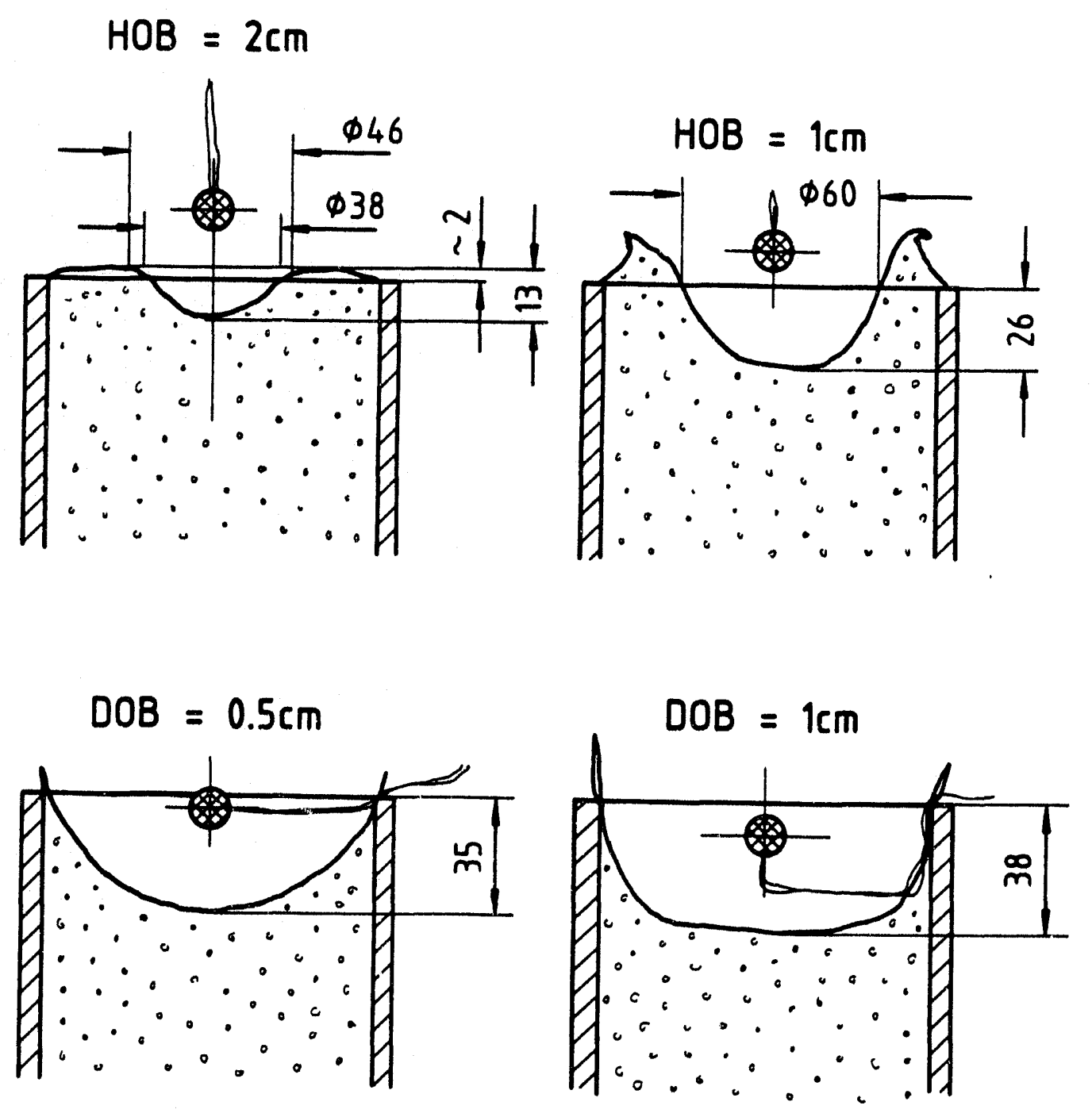

Figure 9 True crater contours in wet clay/loam. 
'panụฺนuoว 6 อมกริ!ส
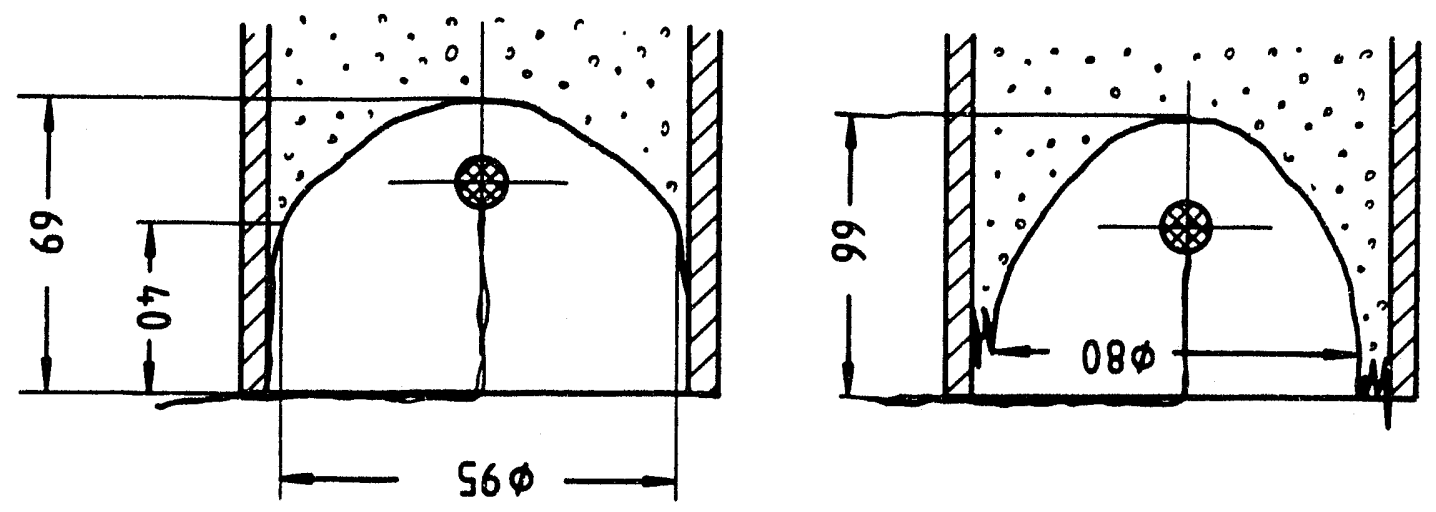

$$
\text { WJS }=800
$$

$$
\text { யग† = } 800
$$
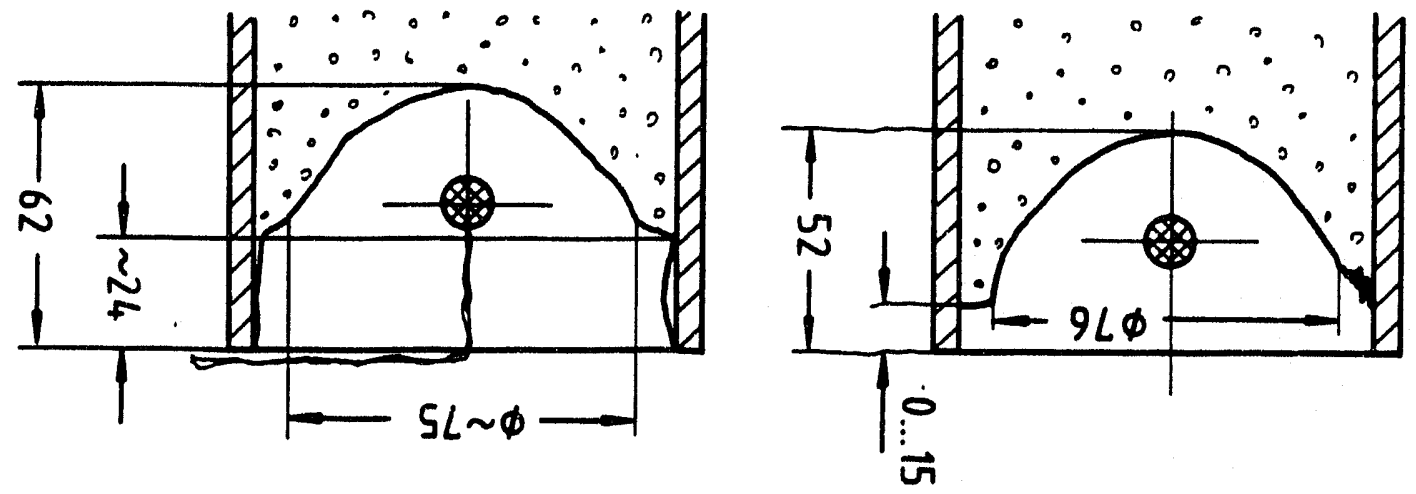

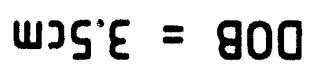

$\omega J S^{\prime} \tau=800$
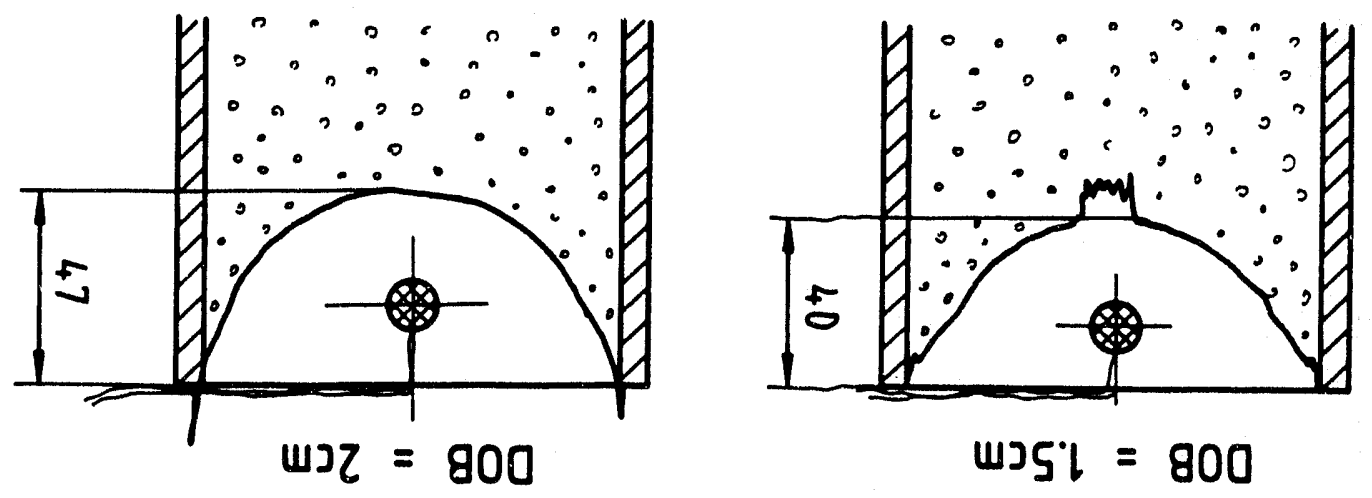


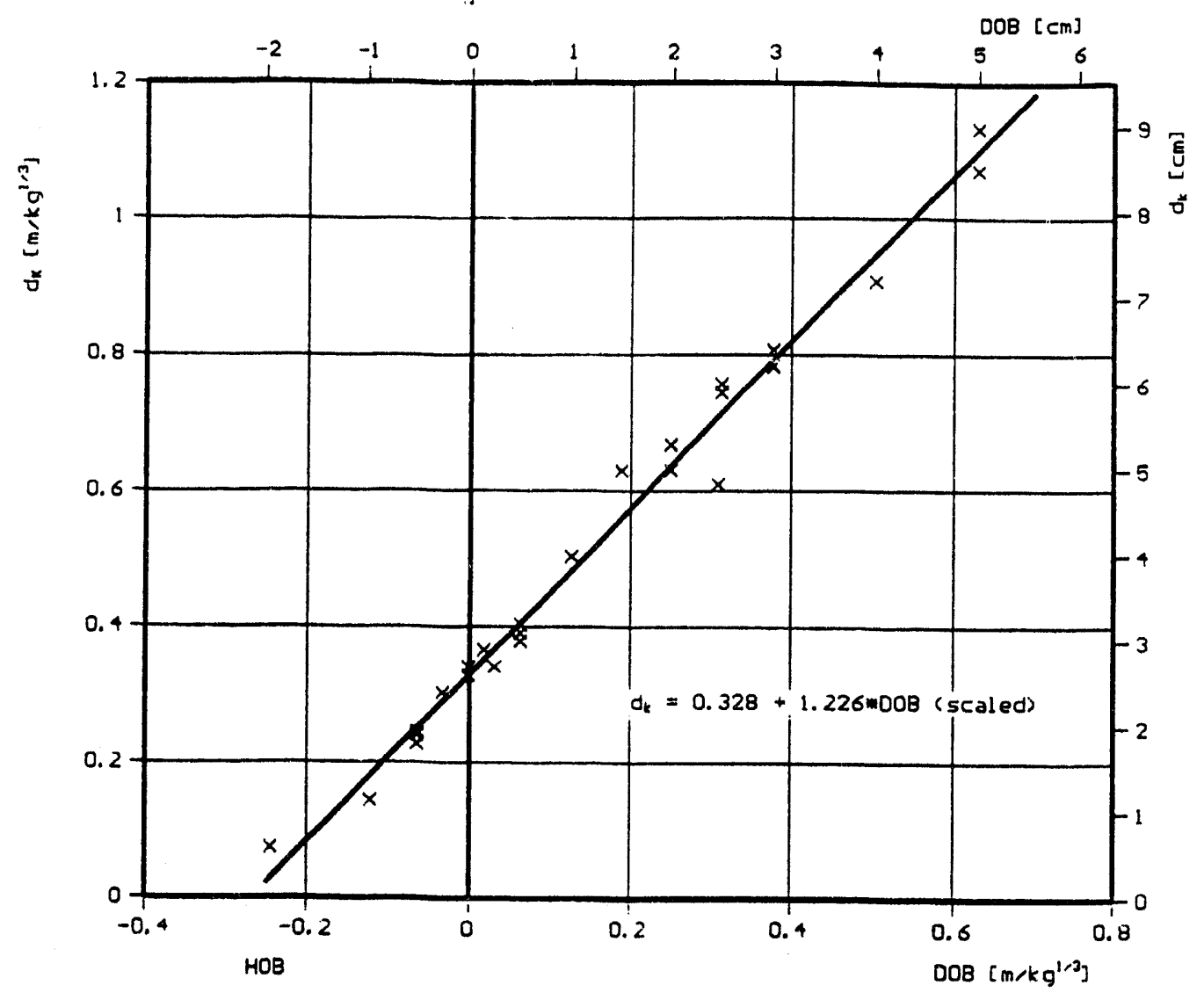

Figure 10 True crater depth in aerated grout (dry YTONG) vs depth of burst.

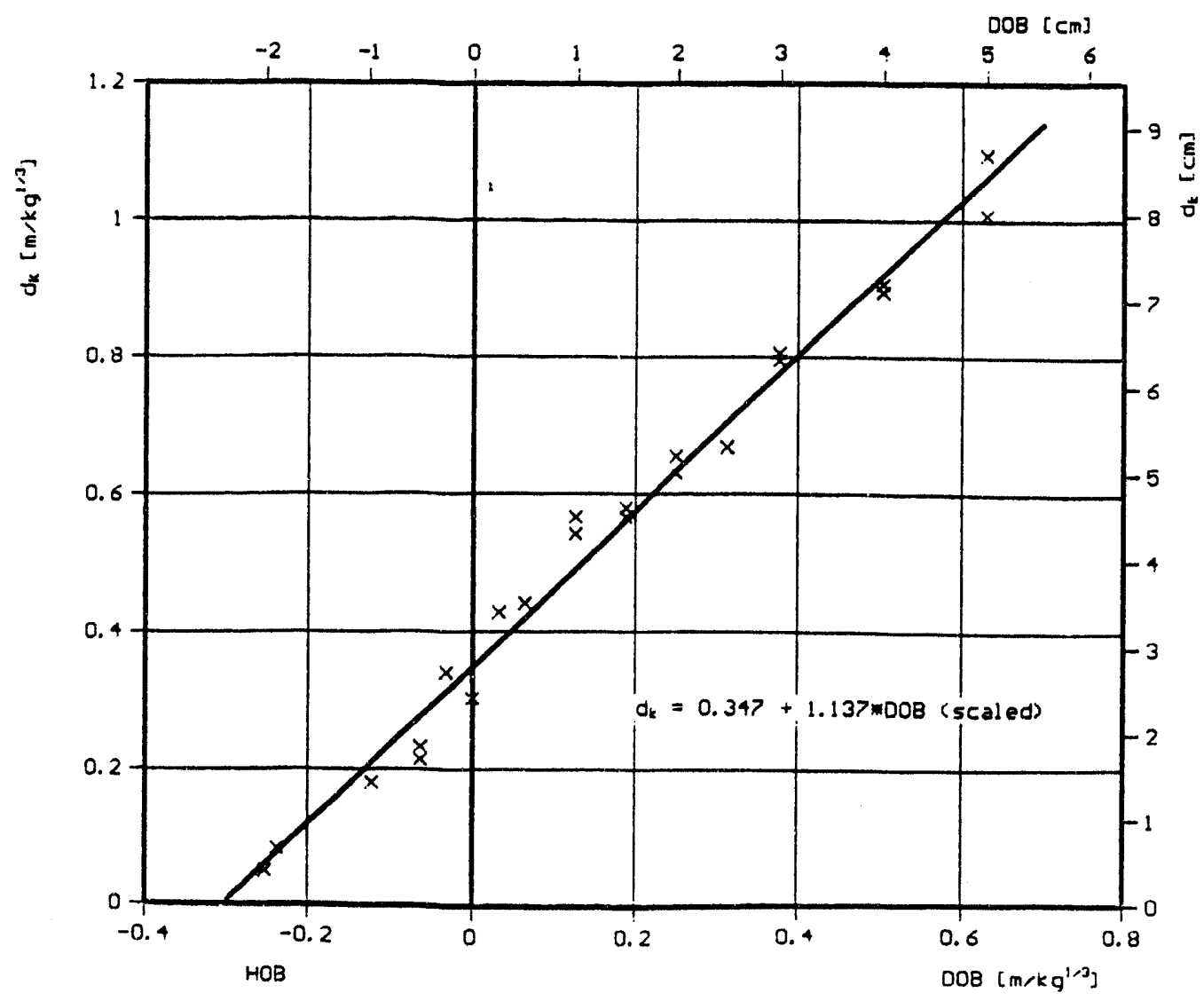

Figure 11 True crater depth in water saturated grout (wet YTONG) 


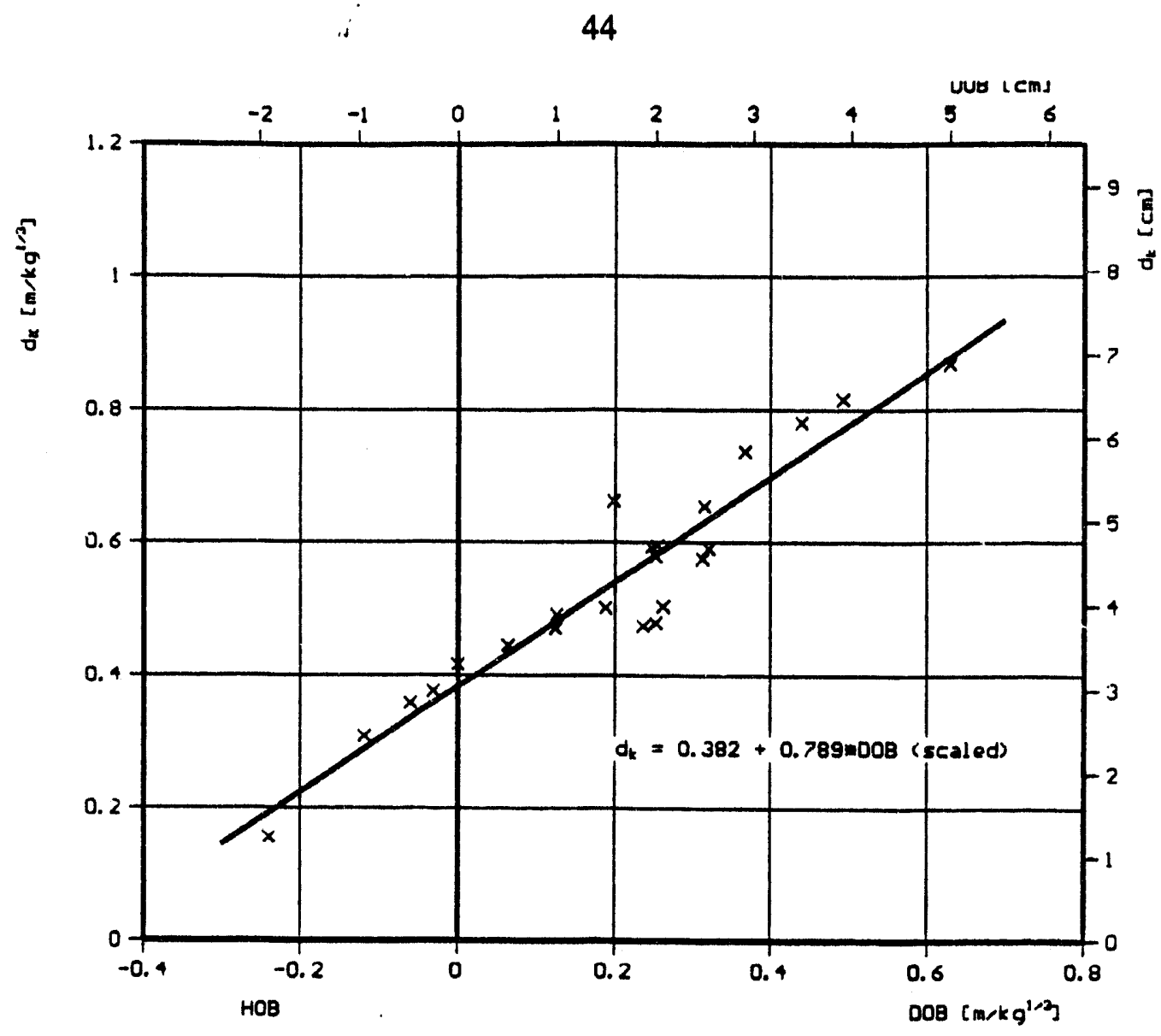

Figure 12 True crater depth in wet clay/loam vs depth of burst.

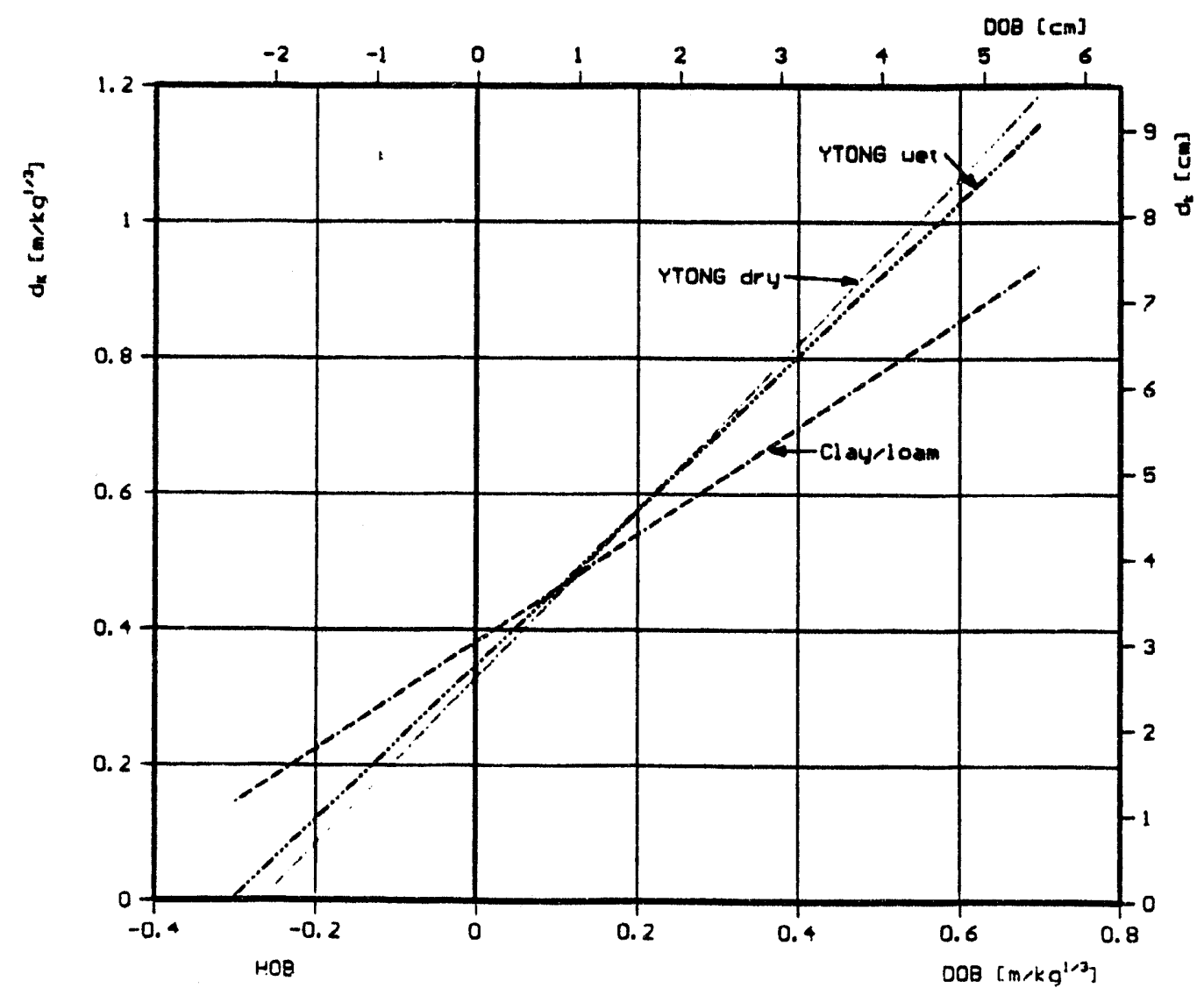




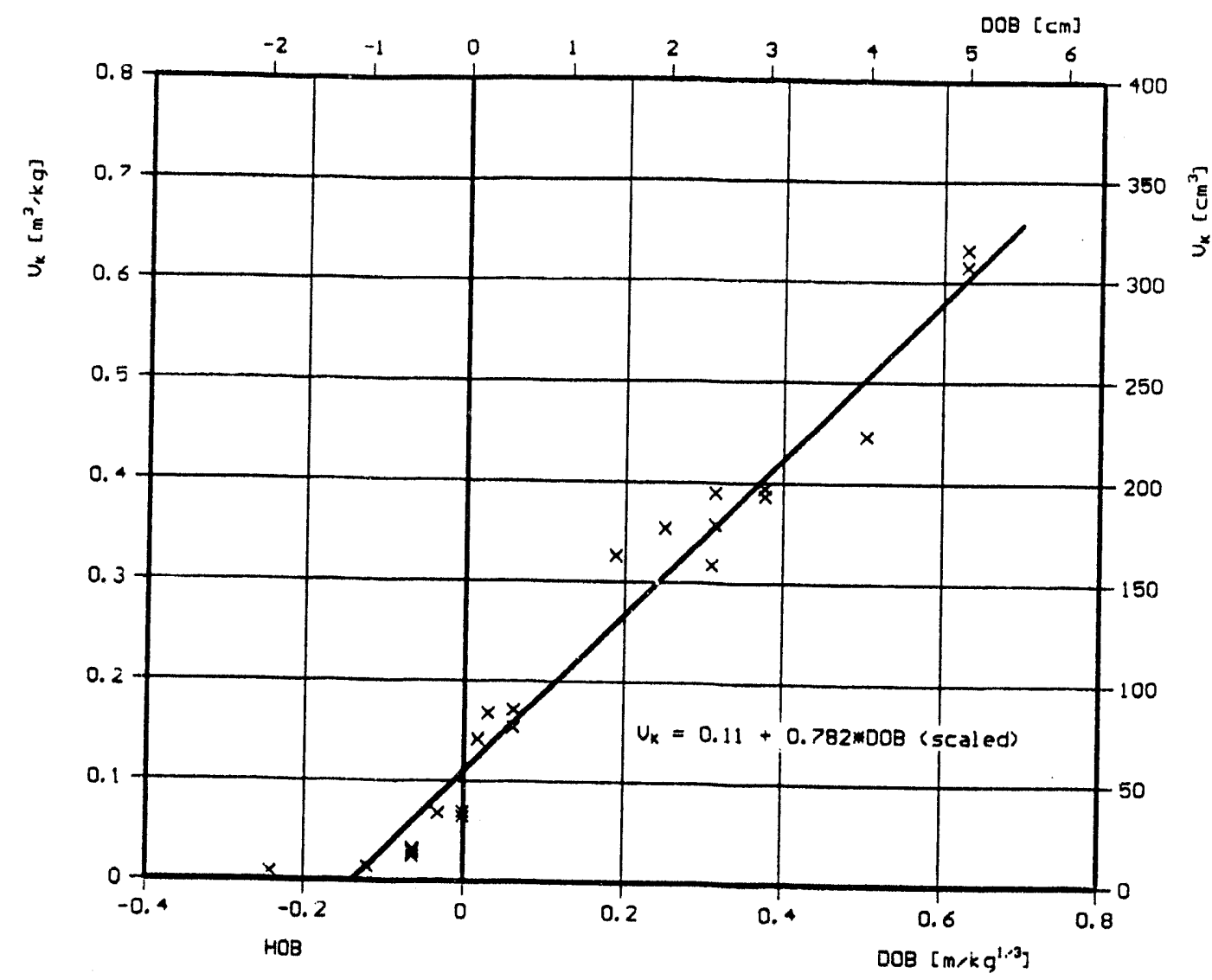

Figure 14 True crater volume in aerated grout (dry YTONG) vs
depth of burst.

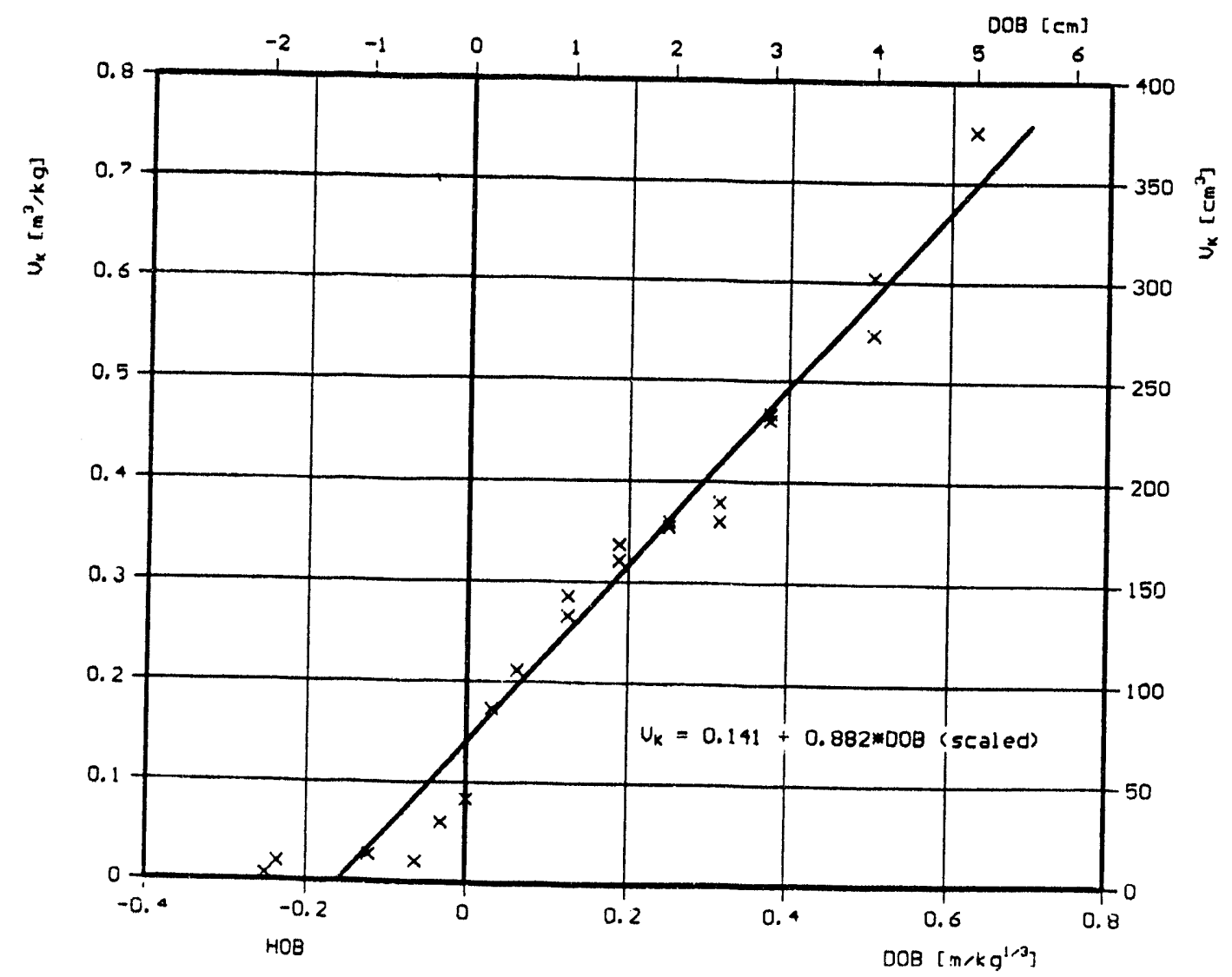

Figure 15 True crater volume in water saturated grout (wet YTONG) 


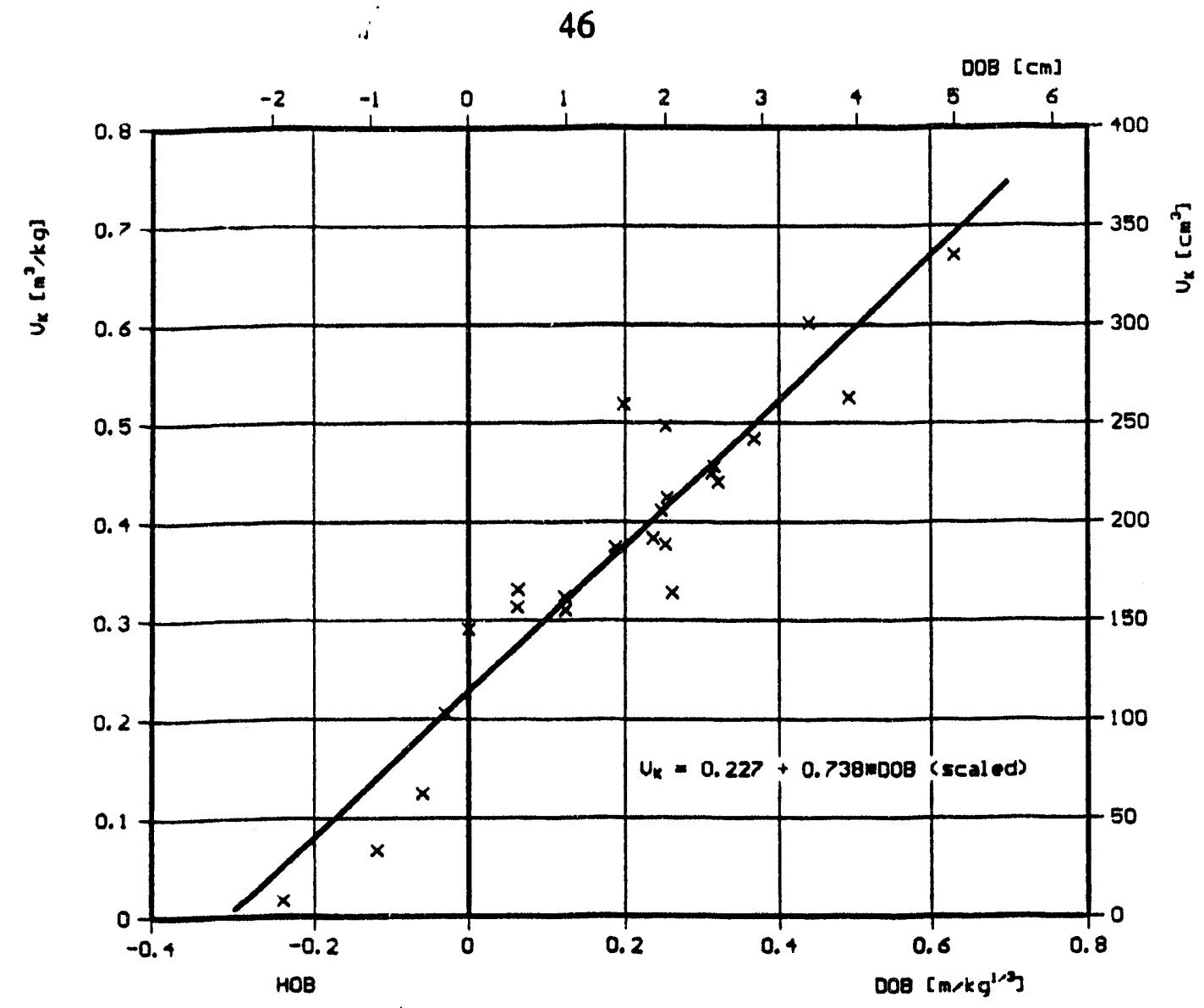

Figure 16 True srater volume in wet clay/loam vs depth of burst.

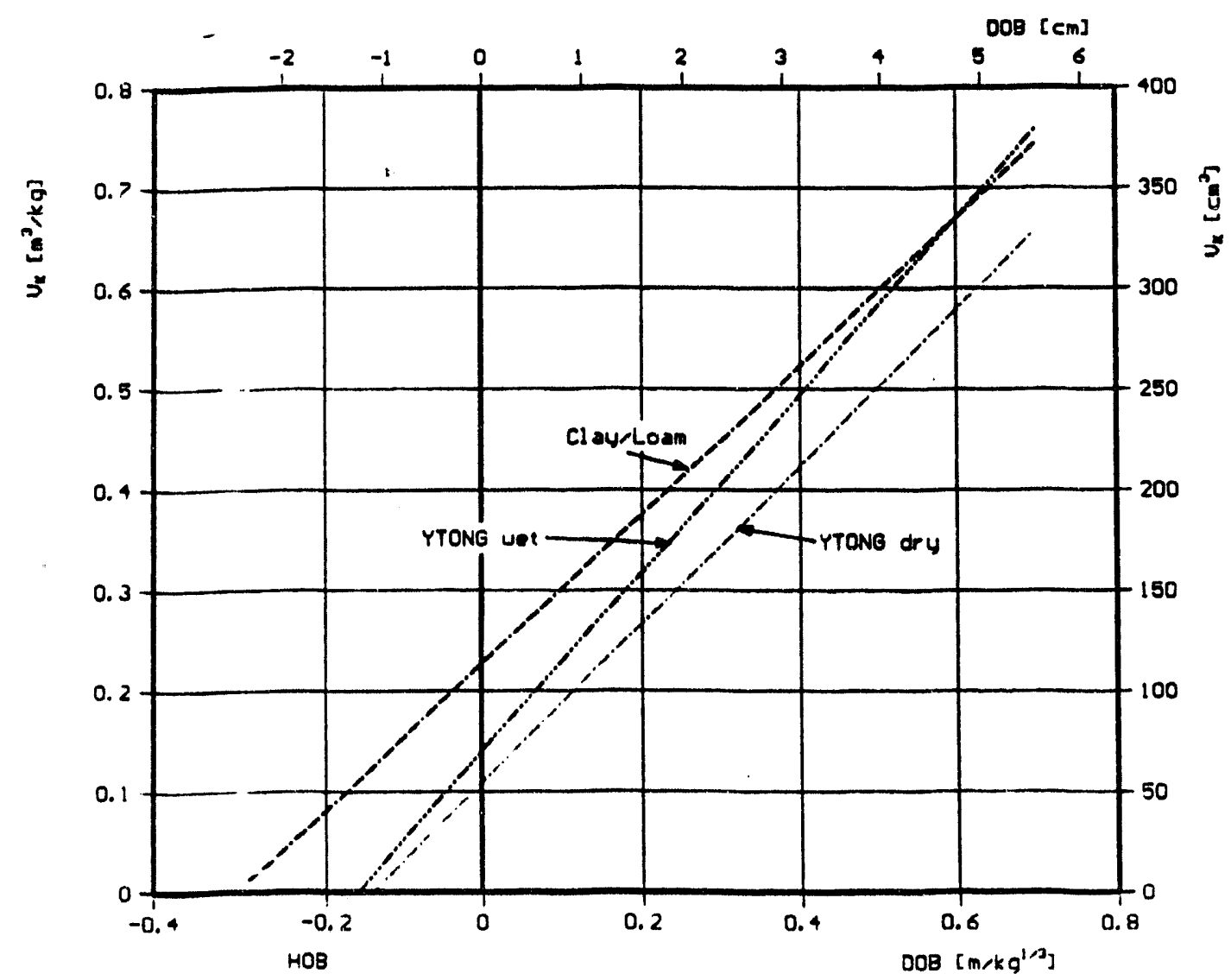

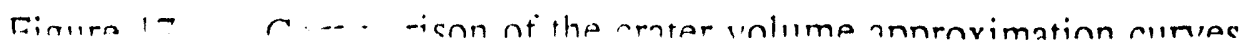




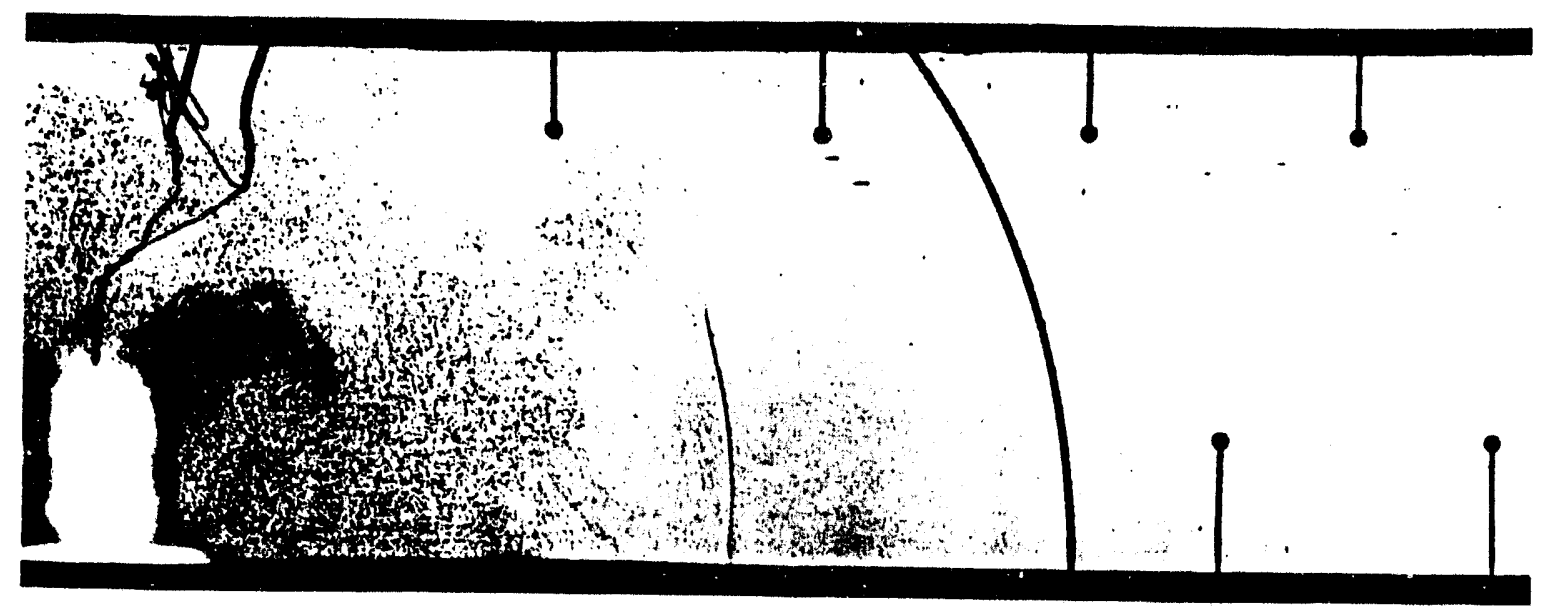

a)

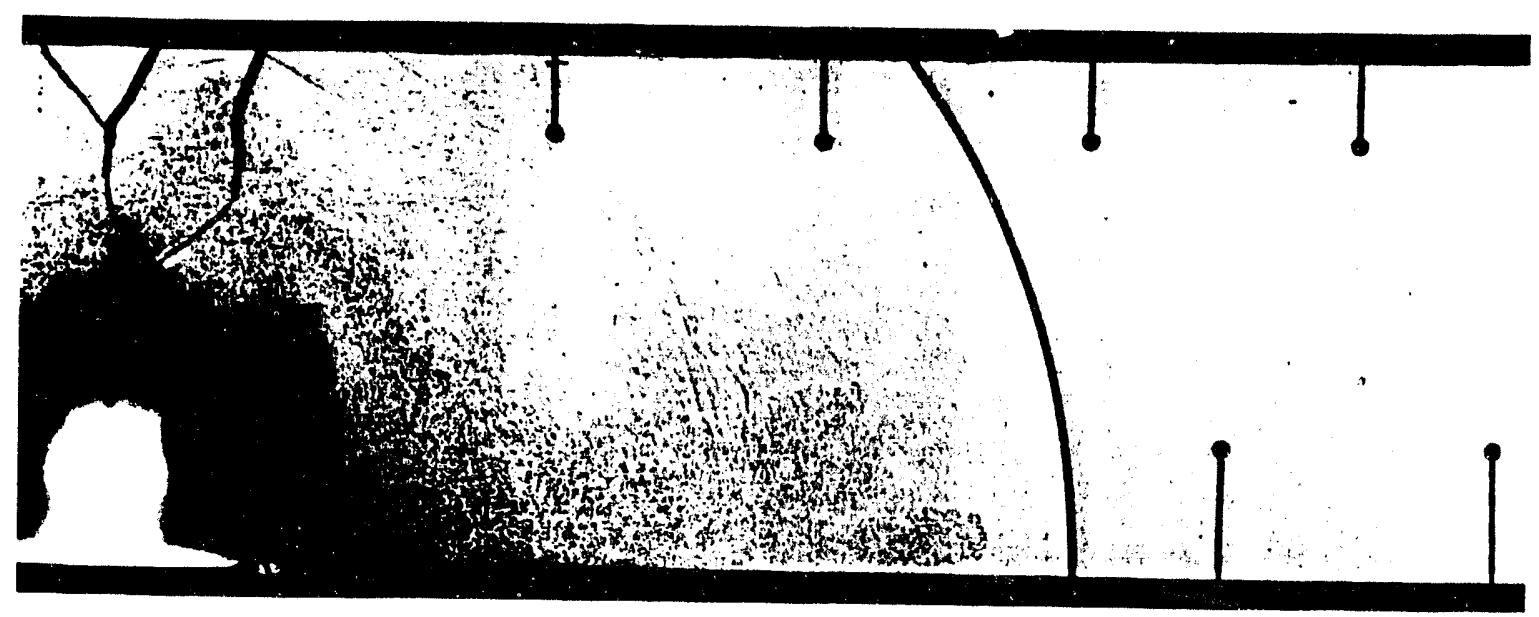

b)

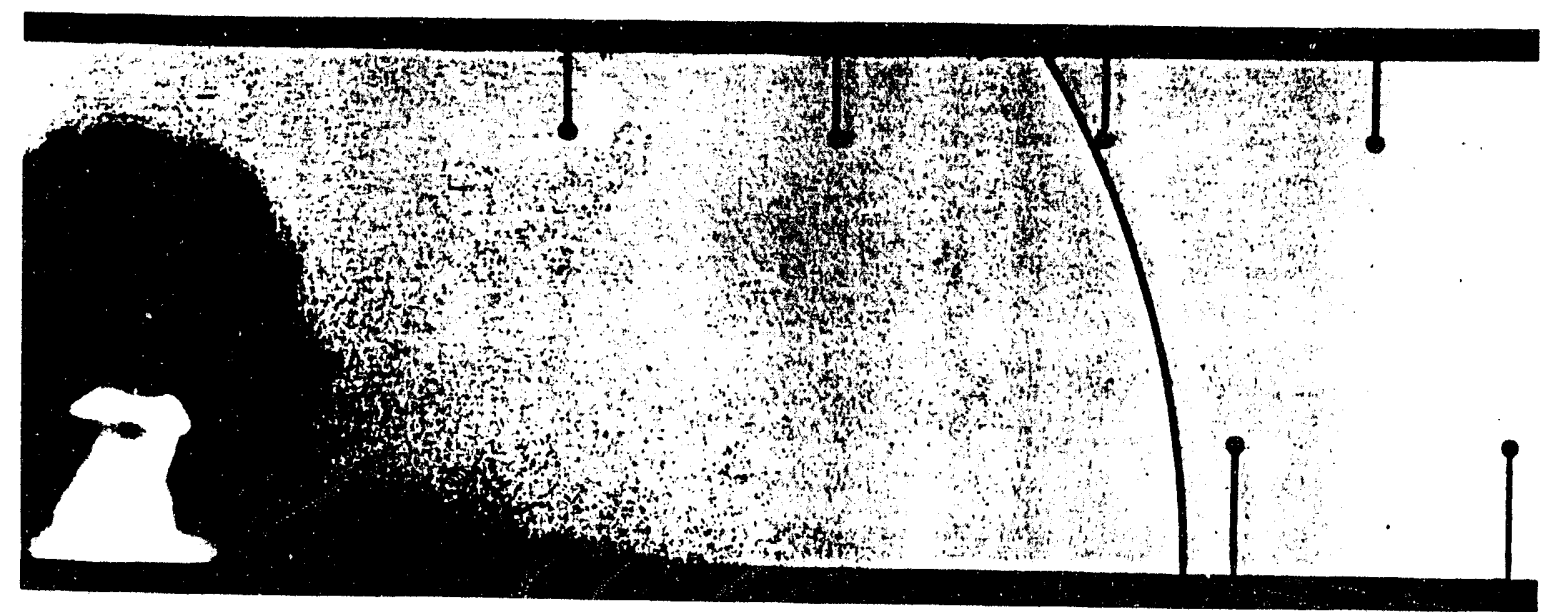

c)

Figure 18 Examples of crater ejecta at different depths of burst in dry $(\Delta t=$ time difference between ignition and exposure)

a) $\mathrm{HOB}=2.0 \mathrm{~cm}\left(-0.252 \mathrm{~m} / \mathrm{kg}^{1 / 3}\right) ; \Delta \mathrm{t}=500 \mu \mathrm{s}$; Test 814

b) $\mathrm{HOB}=1.0 \mathrm{~cm}\left(-0.126 \mathrm{~m} / \mathrm{kg}^{1 / 3}\right) ; \Delta \mathrm{t}=500 \mu \mathrm{s}$; Test 815

c) $\mathrm{HOB}=0.5 \mathrm{~cm}\left(-0.063 \mathrm{~m} / \mathrm{kg}^{1 / 3}\right) ; \Delta \mathrm{t}=600 \mu \mathrm{s}$; Test 802 


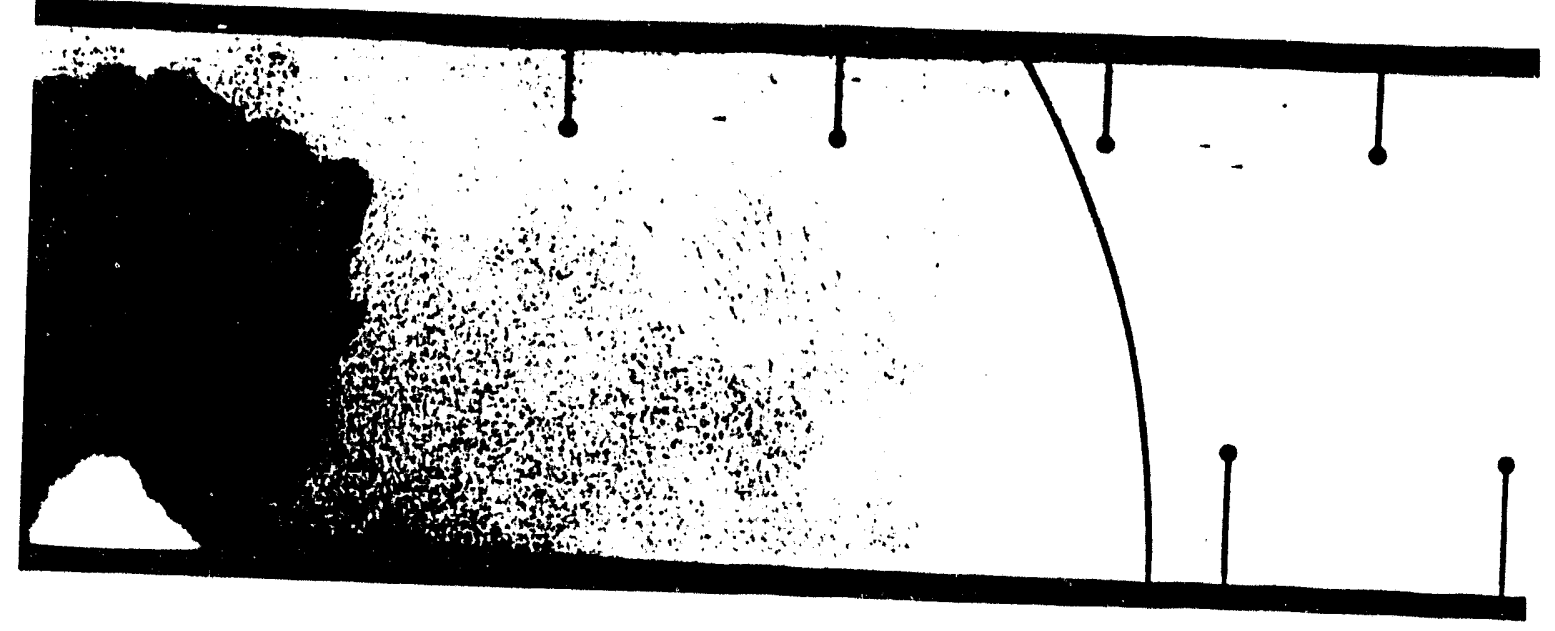

d)

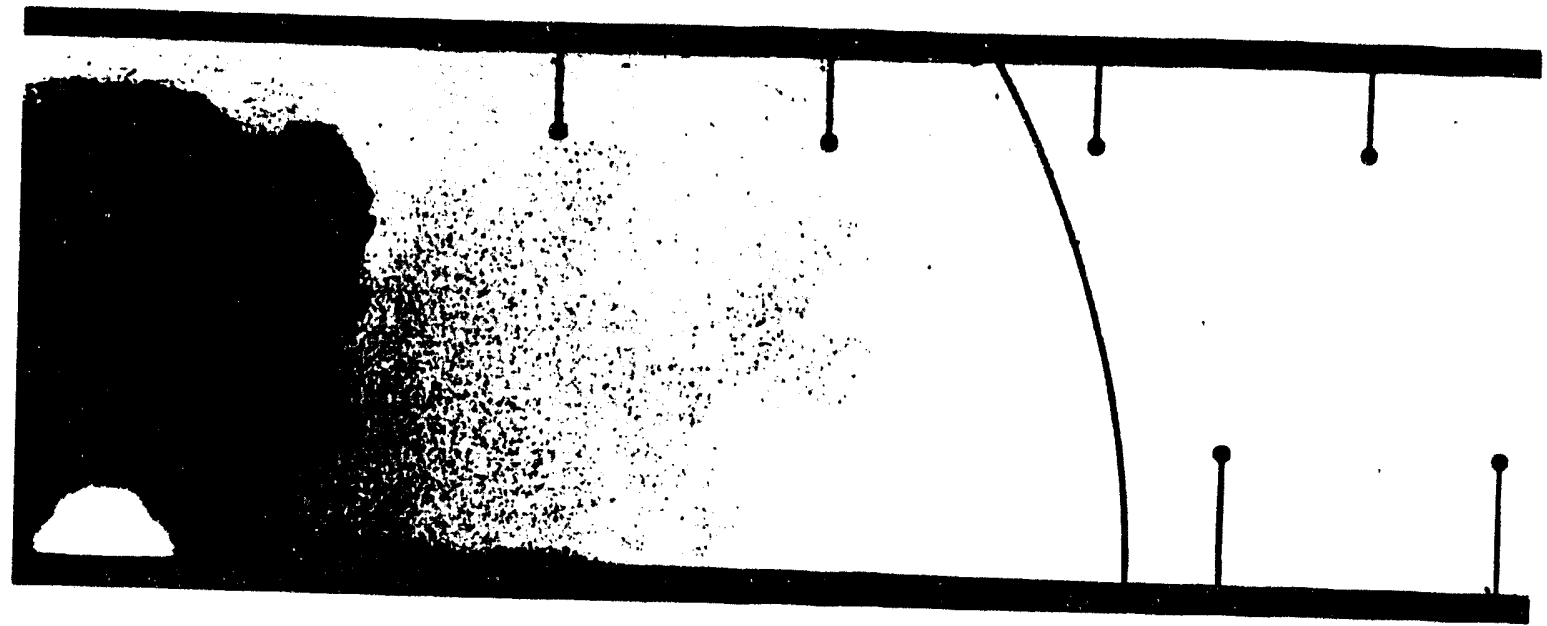

e)

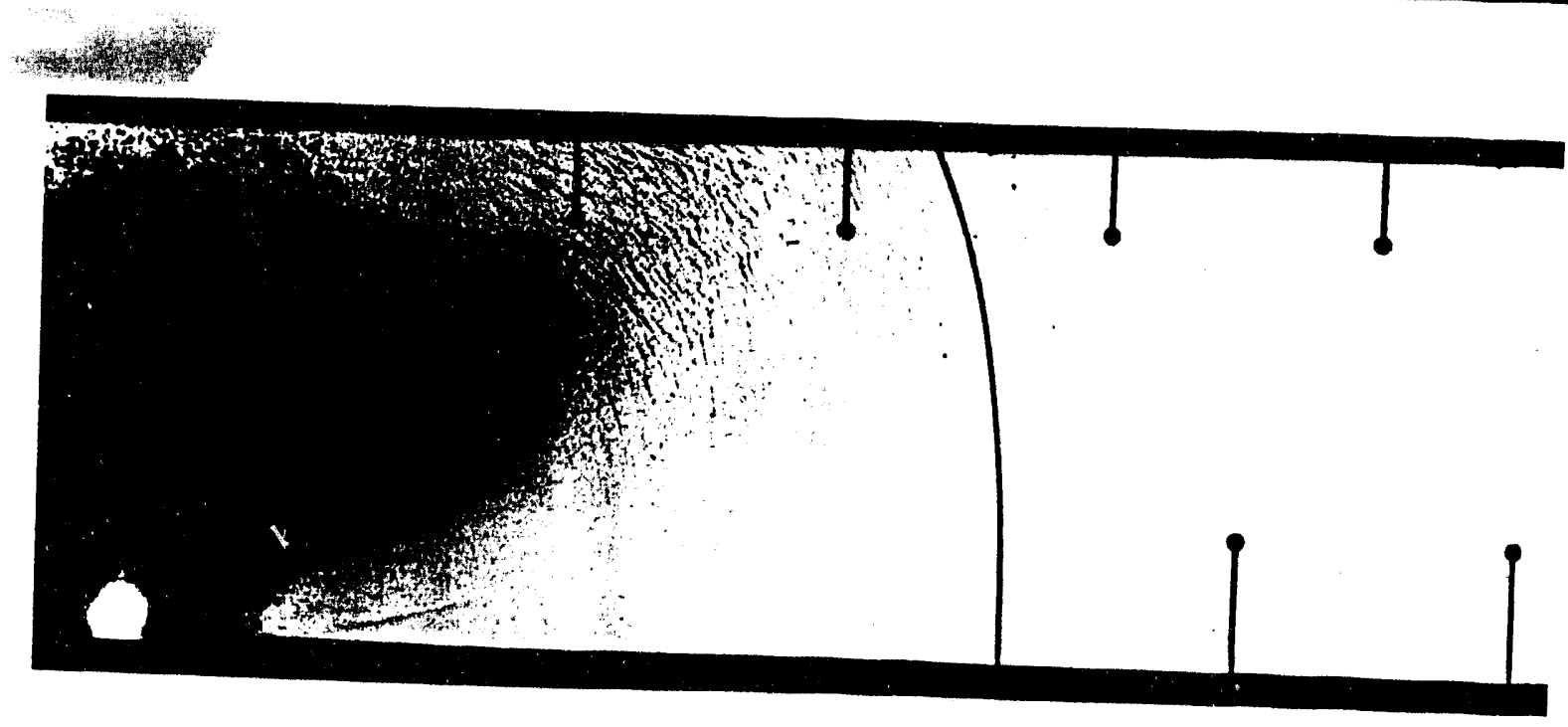

f)

Figure 18 Continued.

d) $\mathrm{HOB}=0.25 \mathrm{~cm}\left(-0.032 \mathrm{~m} / \mathrm{kg}^{1 / 3}\right) ; \Delta \mathrm{t}=600 \mu \mathrm{s}$; Test 804

e) DOB $=0.0 \mathrm{~cm}\left(0.0 \mathrm{~m} / \mathrm{kg}^{1 / 3}\right) ; \Delta \mathrm{t}=600 \mu \mathrm{s}$; Test 803

f) $\mathrm{DOB}=0.5 \mathrm{~cm}\left(0.063 \mathrm{~m} / \mathrm{kg}^{1 / 3}\right) ; \Delta \mathrm{t}=600 \mu \mathrm{s} ;$ Test 809 


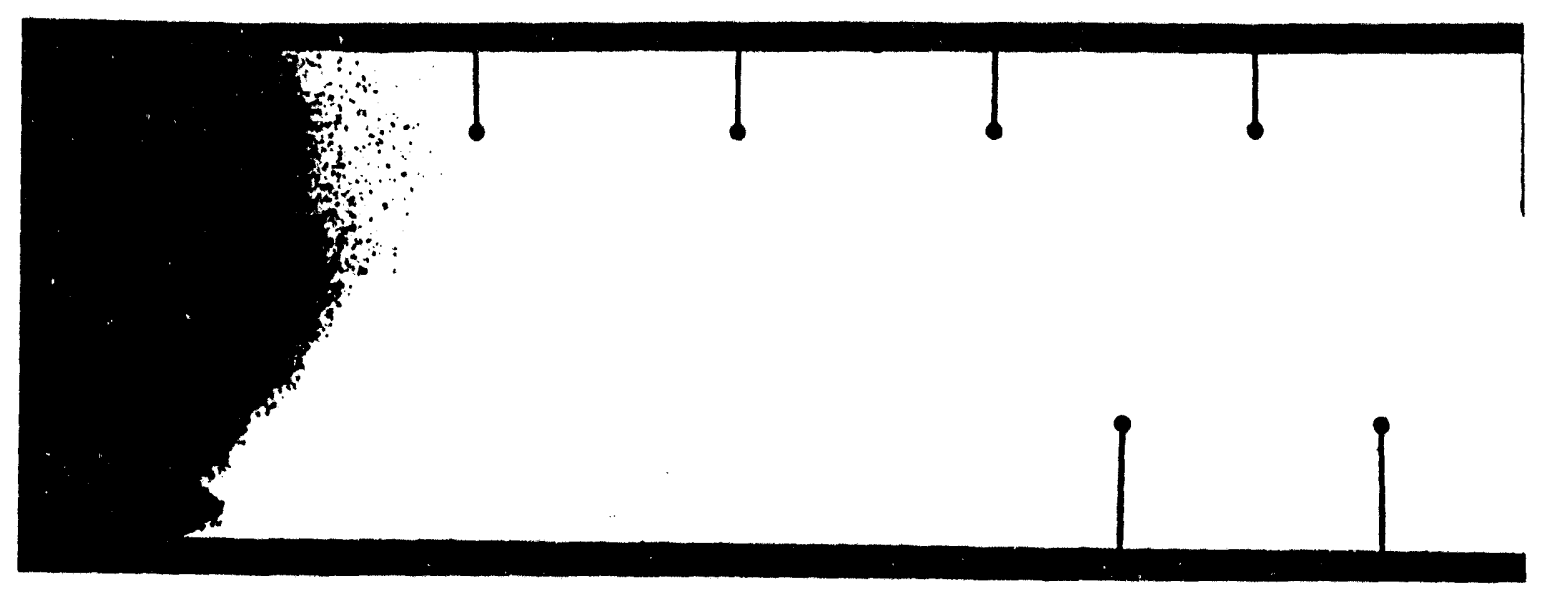

g)

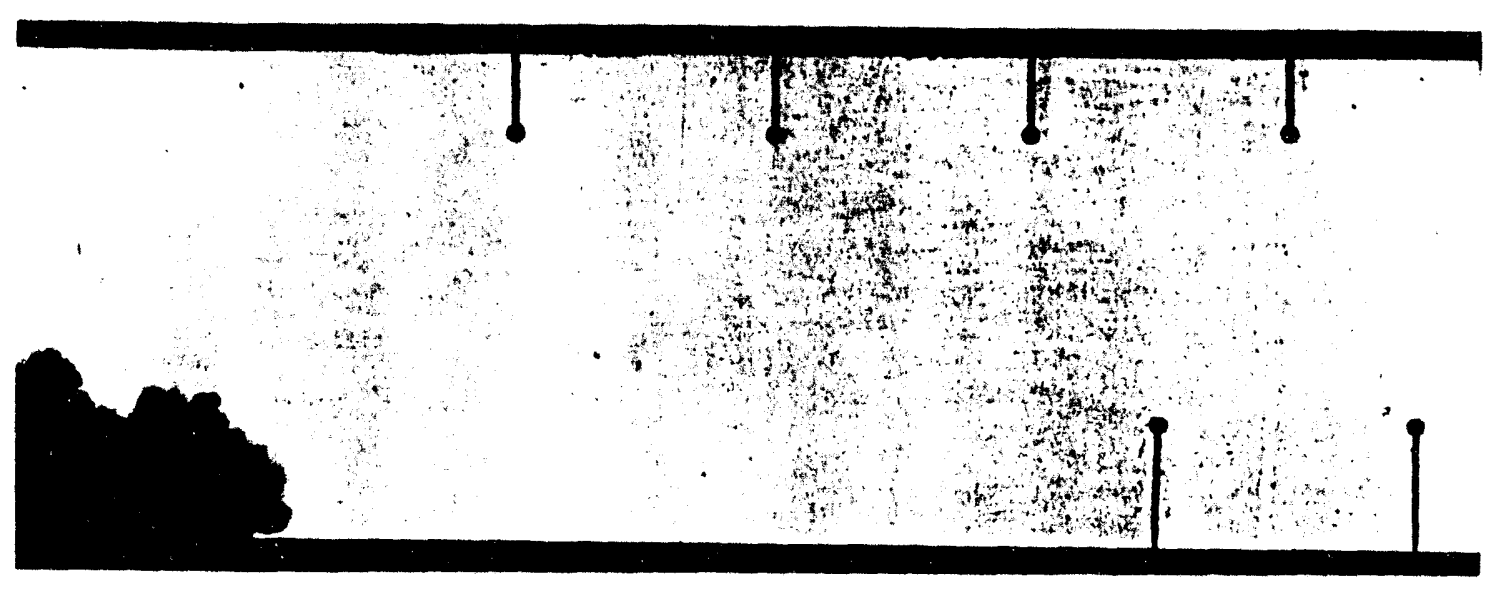

h)

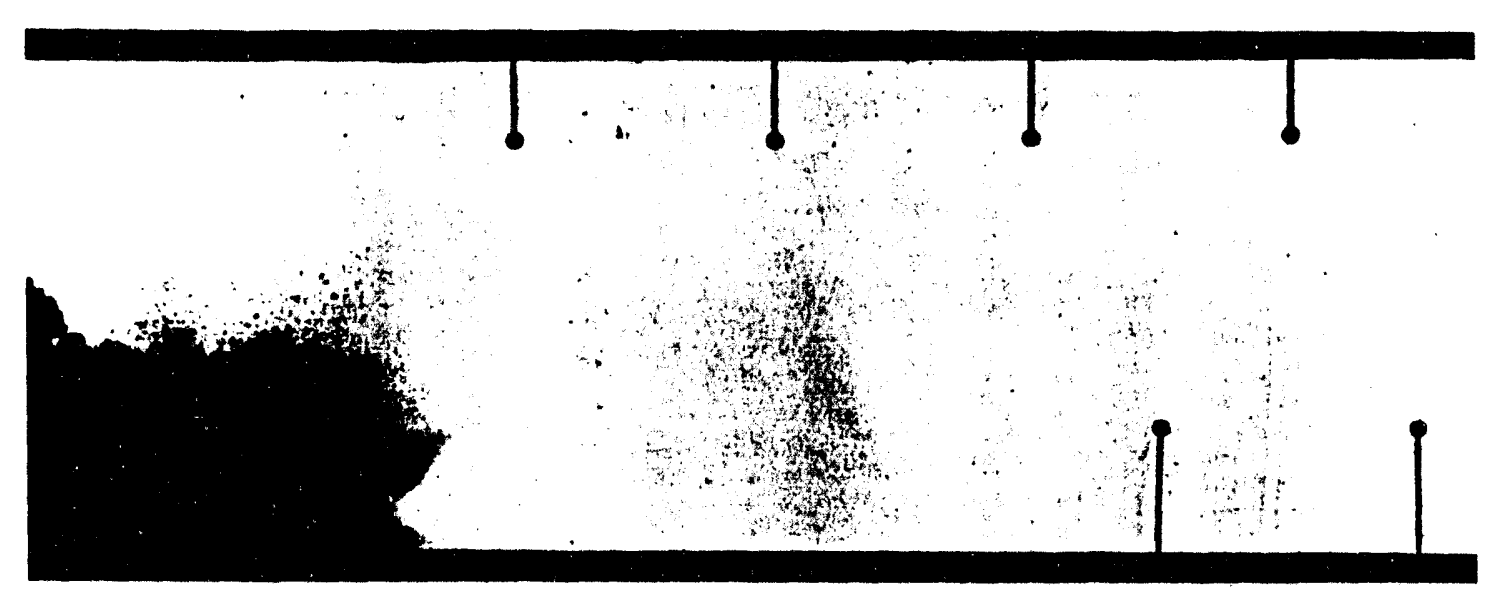

i)

Figure 18 Concluded.

g) $\mathrm{DOB}=2.0 \mathrm{~cm}\left(0.252 \mathrm{~m} / \mathrm{kg}^{1 / 3}\right) ; \Delta \mathrm{t}=1000 \mu \mathrm{s}$; Test 713

h) $\mathrm{DOB}=4.0 \mathrm{~cm}\left(0.504 \mathrm{~m} / \mathrm{kg}^{1 / 3}\right) ; \Delta \mathrm{t}=700 \mu \mathrm{s}$; Test 721

i) $\mathrm{DOB}=5.0 \mathrm{~cm}\left(0.630 \mathrm{~m} / \mathrm{kg}^{1 / 3}\right) ; \Delta \mathrm{t}=2000 \mu \mathrm{s}$; Test 725 


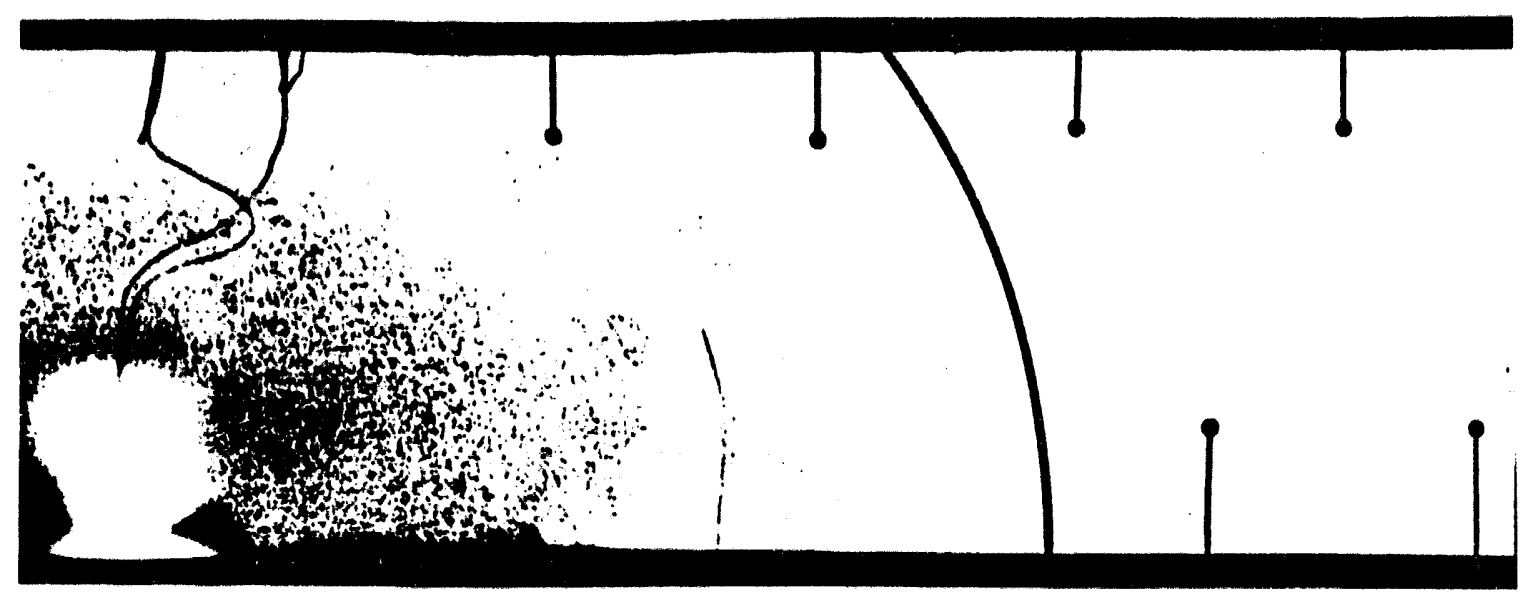

a)

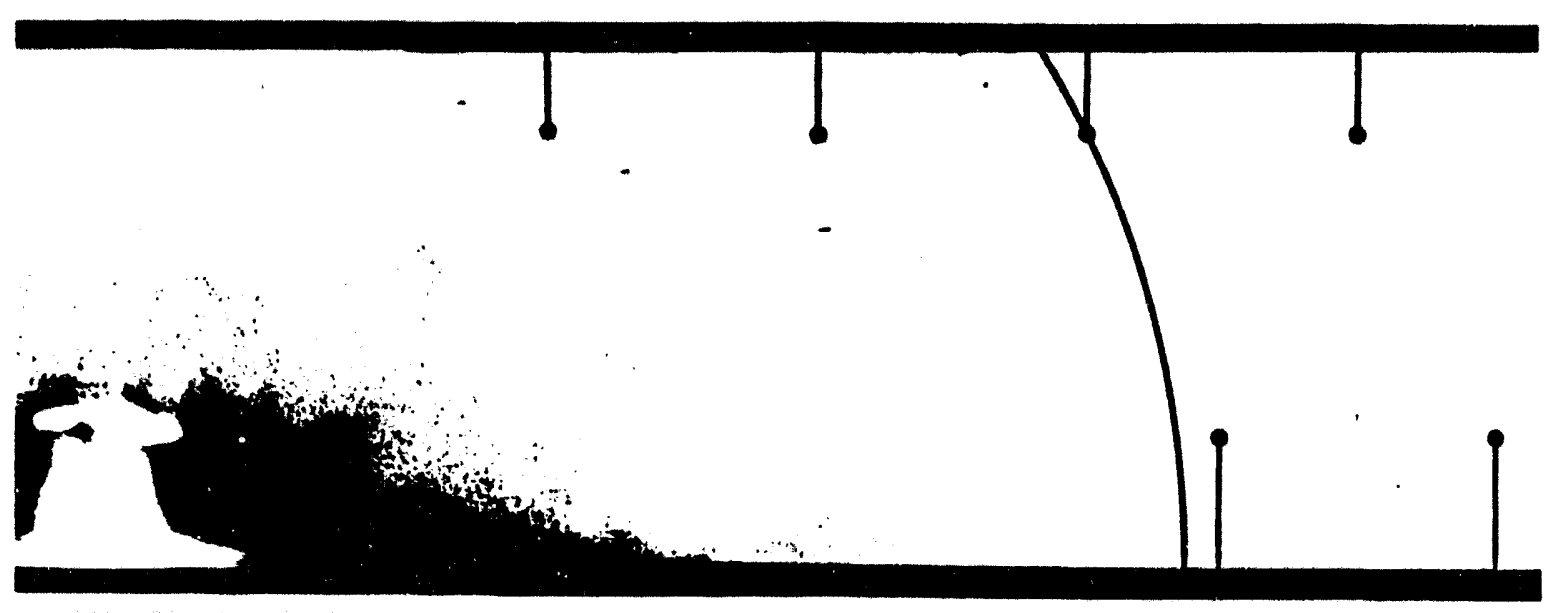

b)

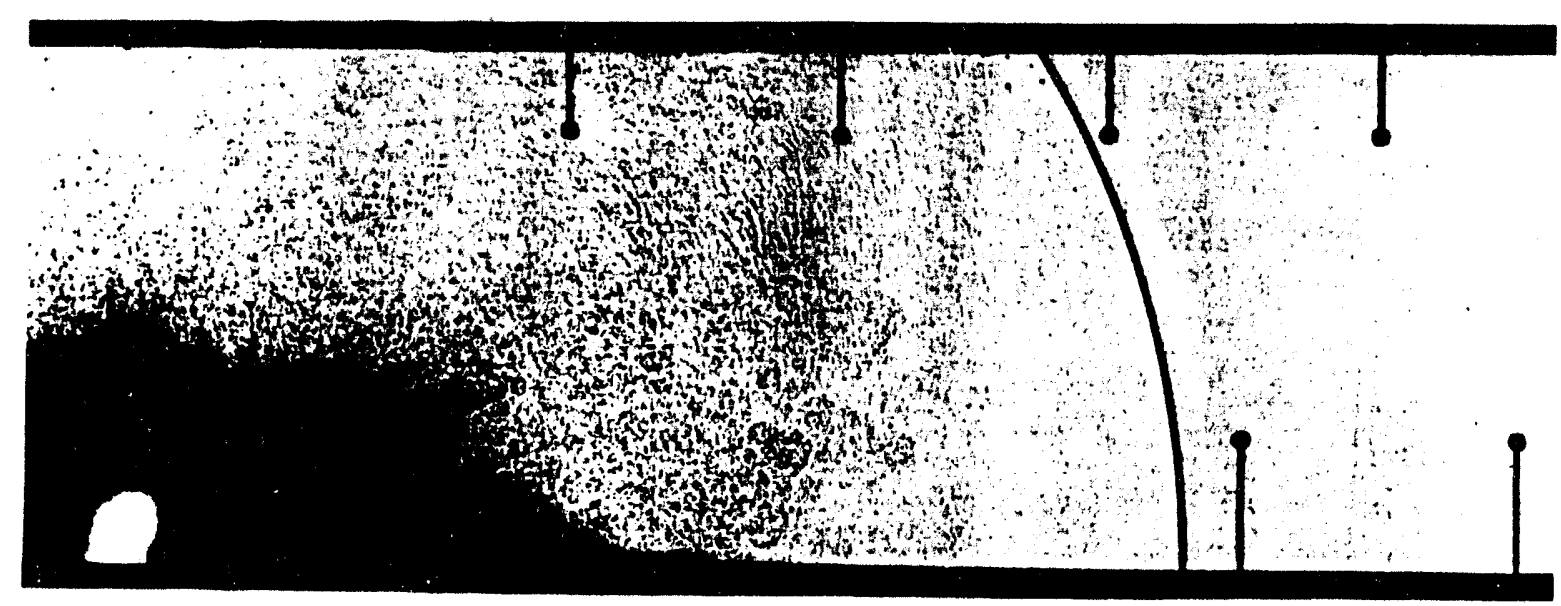

C)

Figure 19 Examples of crater ejecta at different depths of burst in water saturated grout (wet YTONG)

$(\Delta t=$ time difference between ignition and exposure)

a) $\mathrm{HOB}=2.0 \mathrm{~cm}\left(-0.252 \mathrm{~m} / \mathrm{kg}^{\mathrm{l} / 3}\right) ; \Delta \mathrm{t}=500 \mu \mathrm{s} ;$ Test 783

b) $\mathrm{HOB}=0.5 \mathrm{~cm}\left(-0.063 \mathrm{~m} / \mathrm{kg}^{1 / 3}\right) ; \Delta \mathrm{t}=600 \mu \mathrm{s}$; Test 801

c) $\mathrm{HOB}=0.25 \mathrm{~cm}\left(-0.032 \mathrm{~m} / \mathrm{kg}^{1 / 3}\right) ; \Delta \mathrm{t}=600 \mu \mathrm{s}$; Test 807 


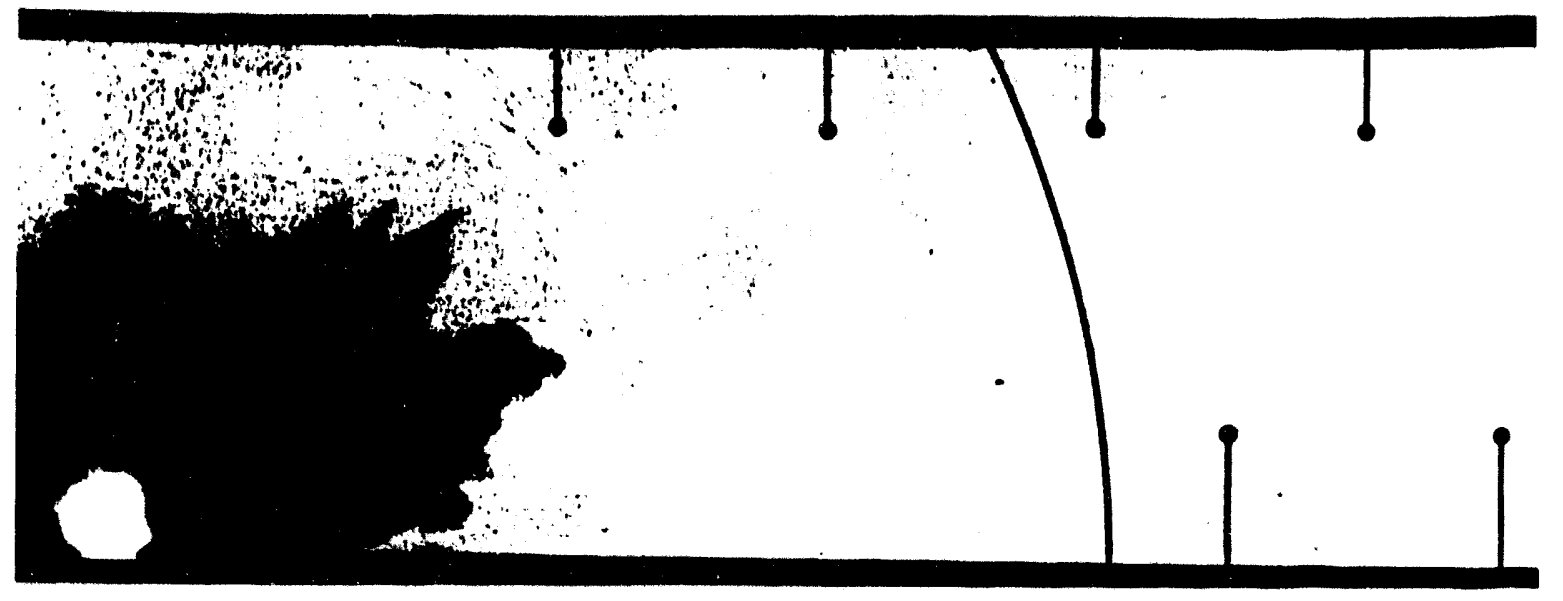

d)

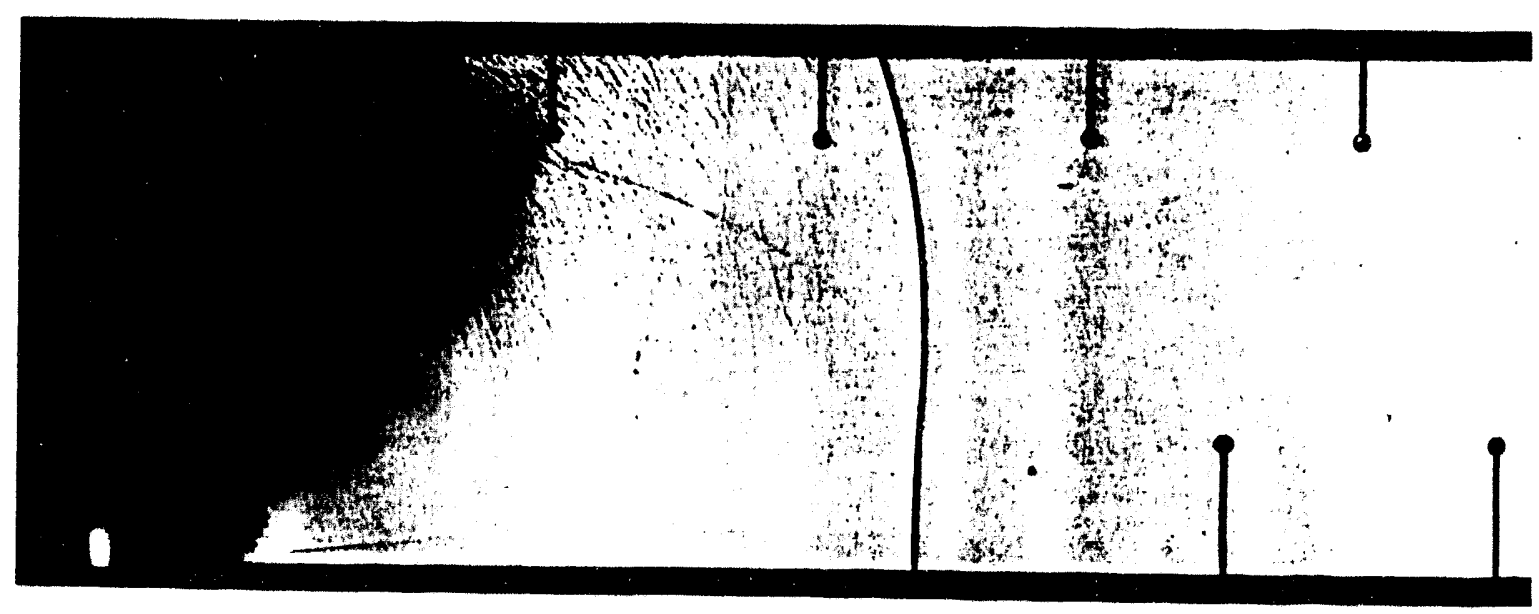

e)

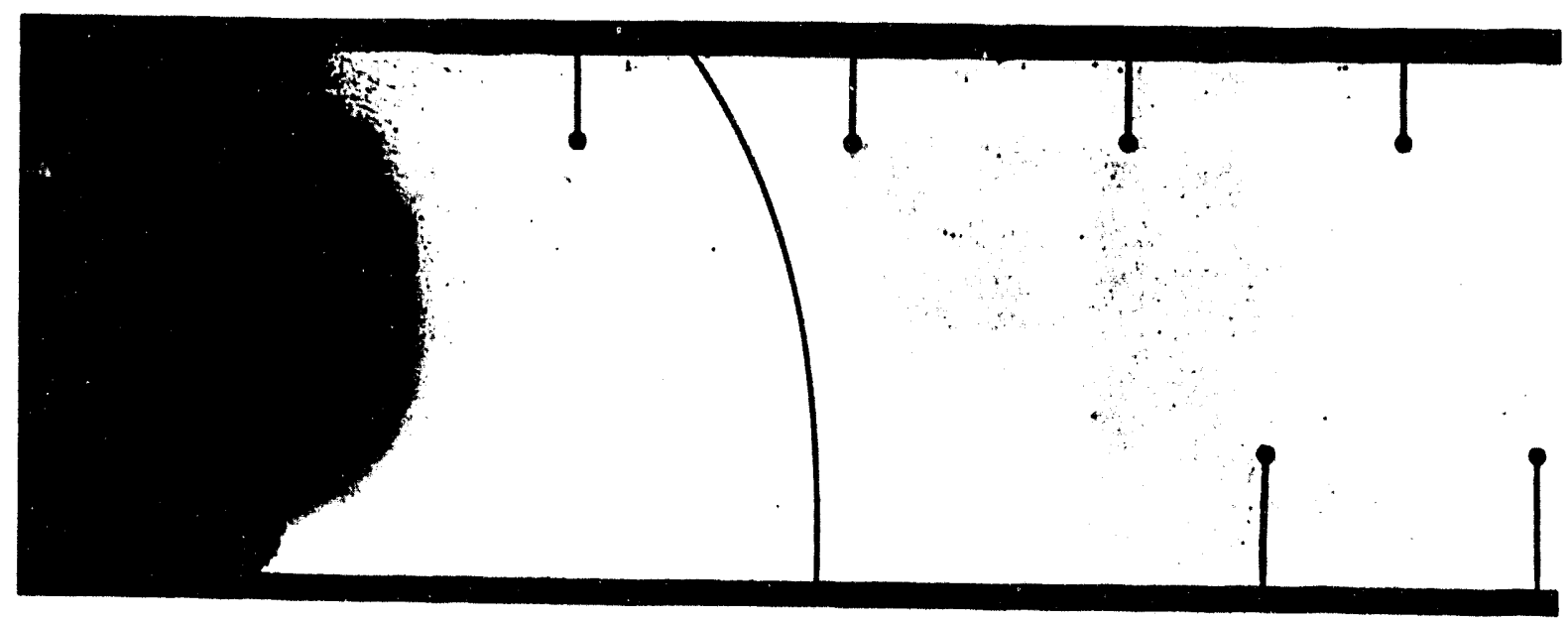

f)

Figure 19 Continued.

d) $\mathrm{DOB}=0 \mathrm{~cm}\left(0 \mathrm{~m} / \mathrm{kg}^{1 / 3}\right) ; \Delta \mathrm{t}=600 \mu \mathrm{s} ;$ Test 805

e) $\mathrm{DOB}=0.5 \mathrm{~cm}\left(0.063 \mathrm{~m} / \mathrm{kg}^{1 / 3}\right) ; \Delta \mathrm{t}=600 \mu \mathrm{s}$; Test 806

f) $\mathrm{DOB}=1.0 \mathrm{~cm}\left(0.126 \mathrm{~m} / \mathrm{kg}^{1 / 3}\right) ; \Delta \mathrm{t}=550 \mu \mathrm{s}$; Test 758 


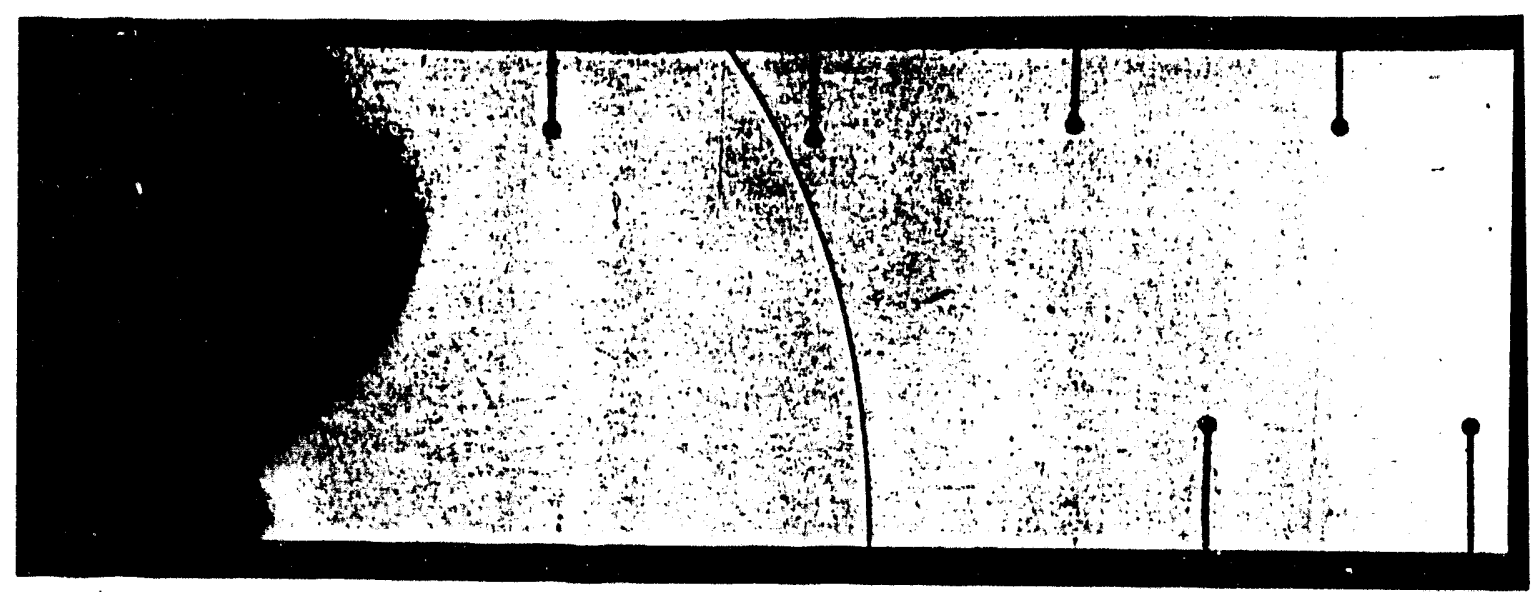

g)

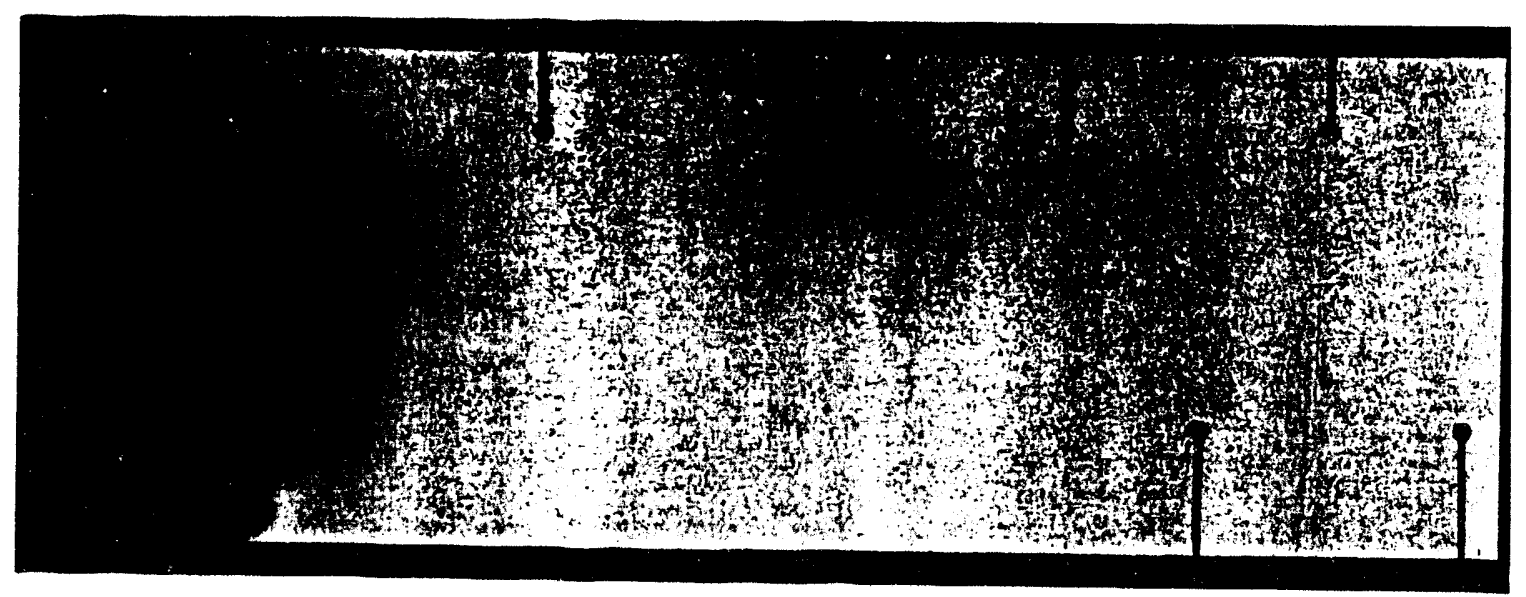

h)

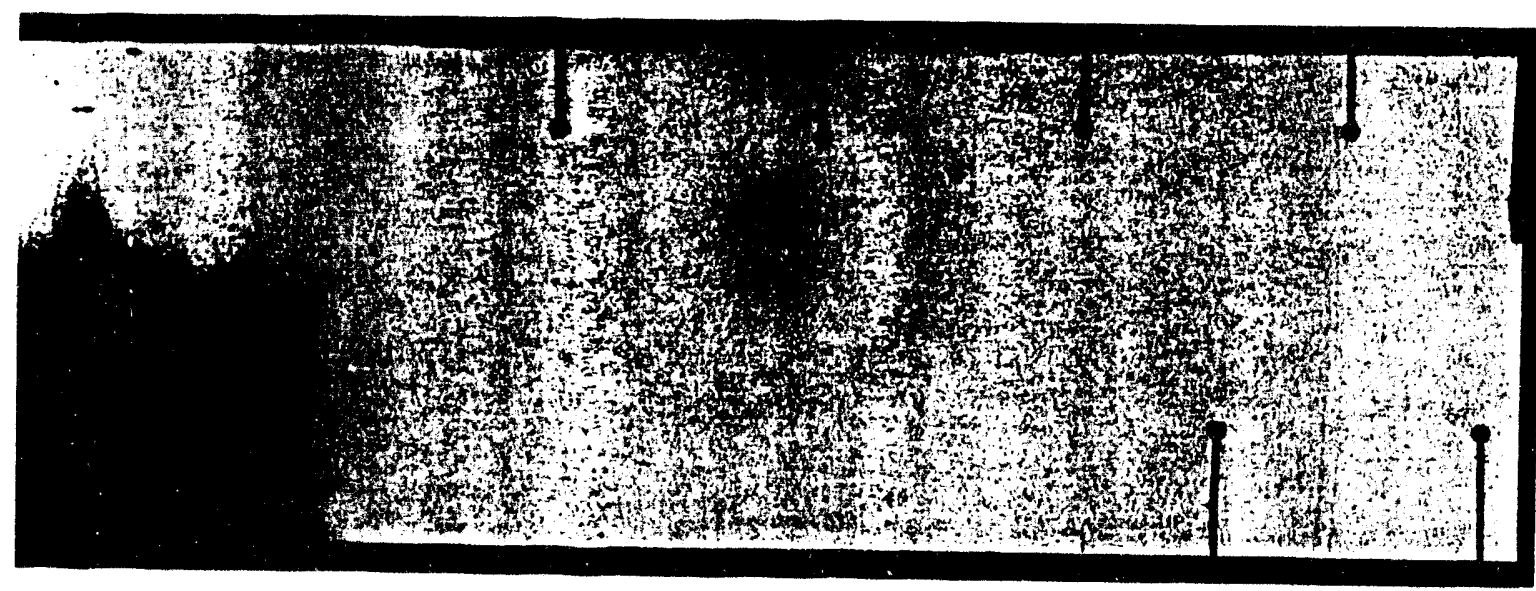

Figure 19 Concluded.

g) $\mathrm{DOB}=2.0 \mathrm{~cm}\left(0.252 \mathrm{~m} / \mathrm{kg}^{1 / 3}\right) ; \Delta \mathrm{t}=800 \mu \mathrm{s} ;$ Test 788

h) $\mathrm{DOB}=3.0 \mathrm{~cm}\left(0.378 \mathrm{~m} / \mathrm{kg}^{1 / 3}\right) ; \Delta \mathrm{t}=1500 \mu \mathrm{s} ;$ Test 793

i) DOB $=4.0 \mathrm{~cm}\left(0.504 \mathrm{~m} / \mathrm{kg}^{1 / 3}\right) ; \Delta \mathrm{t}=1700 \mu \mathrm{s} ;$ Test 795 


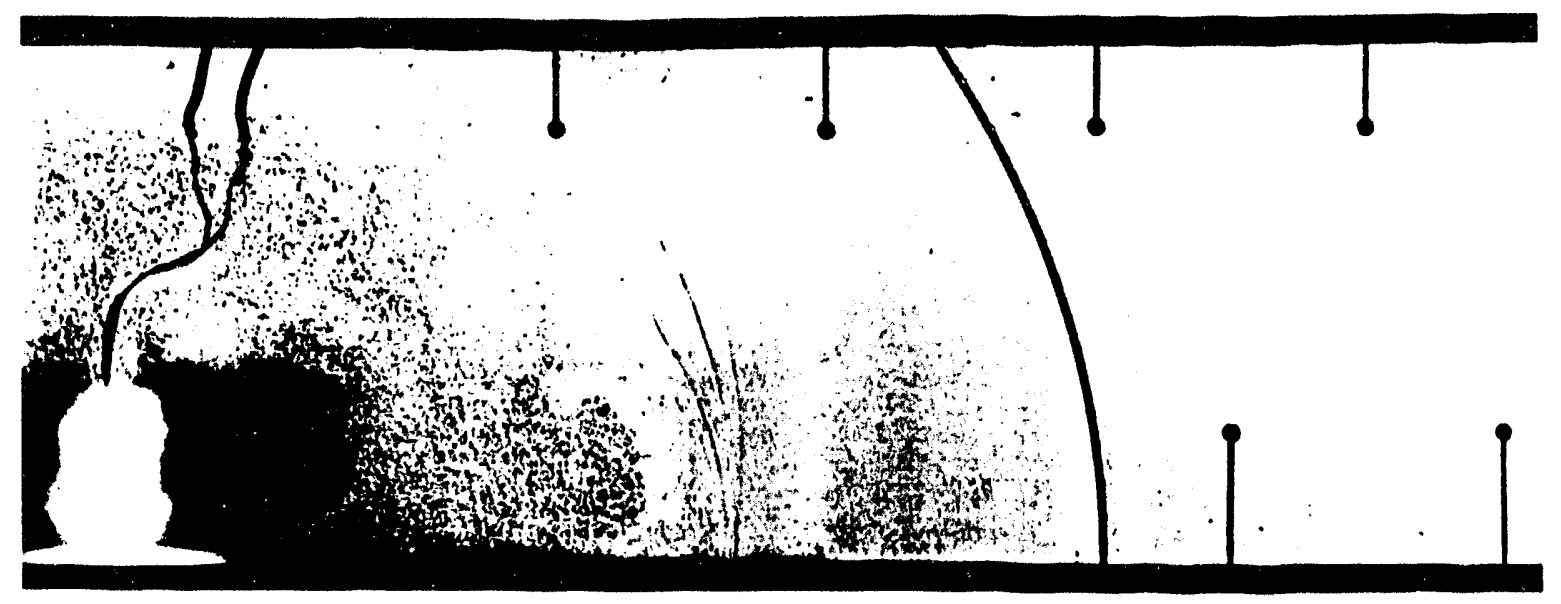

a)

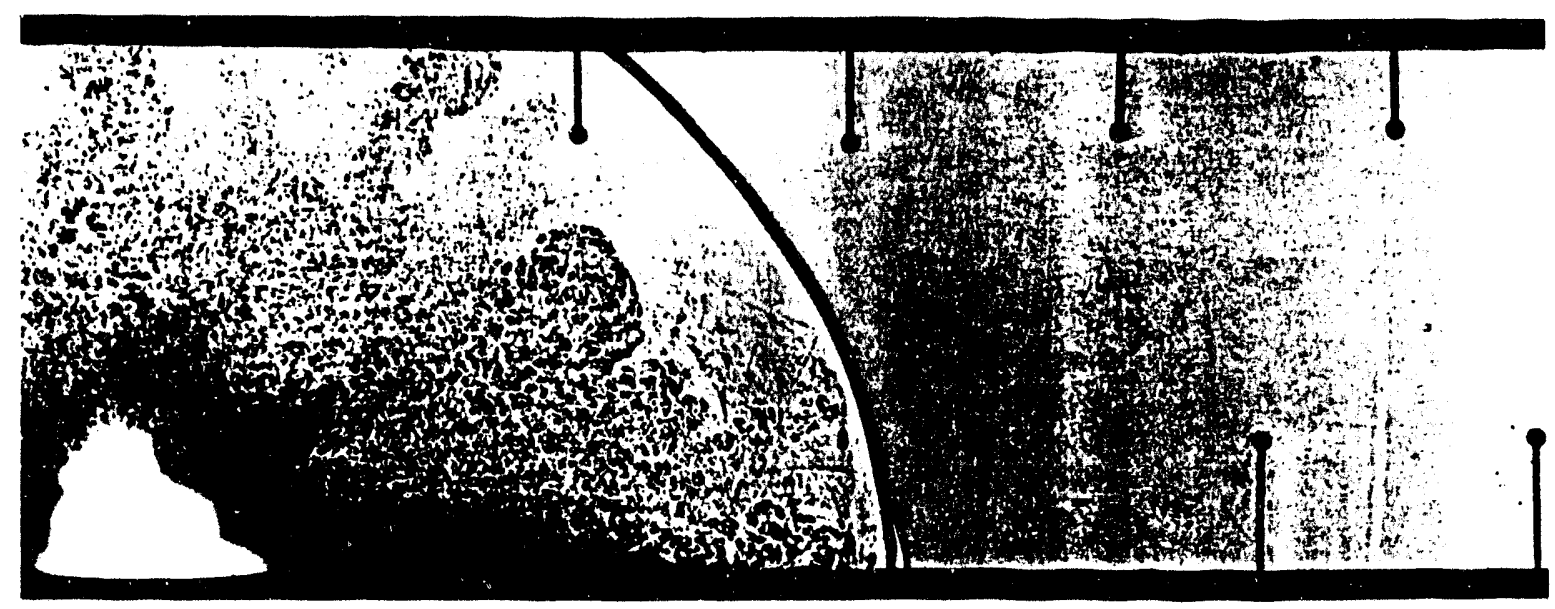

b)

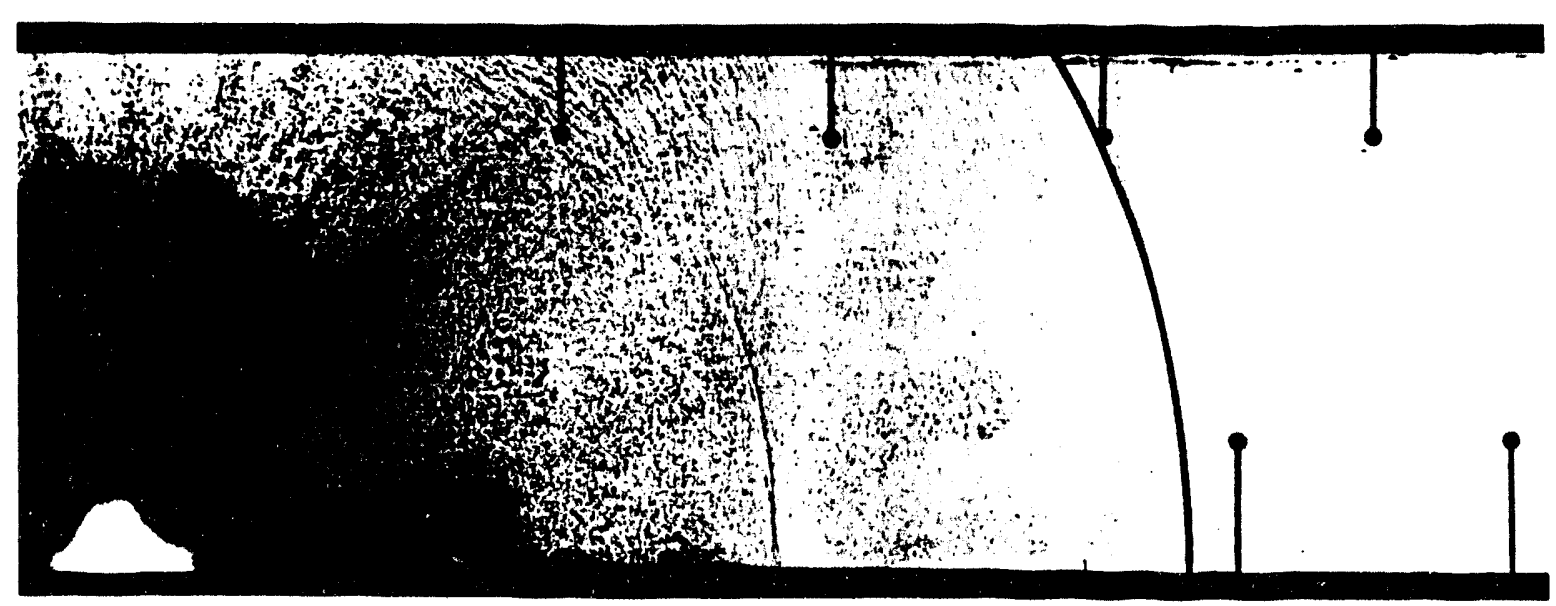

c)

Figure 20 Examples of crater ejecta at different depths of burst in clay/loam $(\Delta t=$ time difference between ignition and exposure).
a) $\mathrm{HOB}=2.0 \mathrm{~cm}\left(-0.240 \mathrm{~m} / \mathrm{kg}^{1 / 3}\right) ; \Delta \mathrm{t}=500 \mu \mathrm{s}$; Test 813
b) $\mathrm{HOB}=0.5 \mathrm{~cm}\left(-0.060 \mathrm{~m} / \mathrm{kg}^{1 / 3}\right) ; \Delta \mathrm{t}=300 \mu \mathrm{s} ;$ Test 780
c) $\mathrm{HOB}=0.25 \mathrm{~cm}\left(-0.030 \mathrm{~m} / \mathrm{kg}^{1 / 3}\right) ; \Delta \mathrm{t}=600 \mu \mathrm{s}$; Test 812 


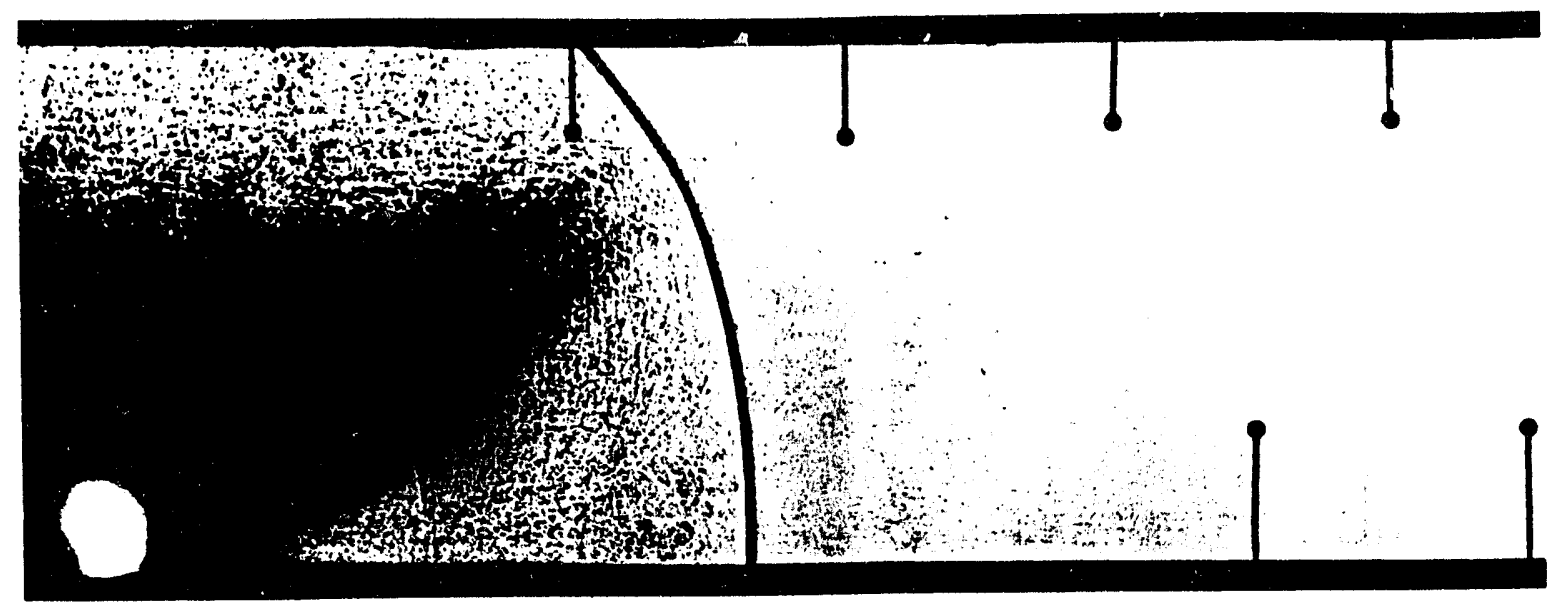

d)

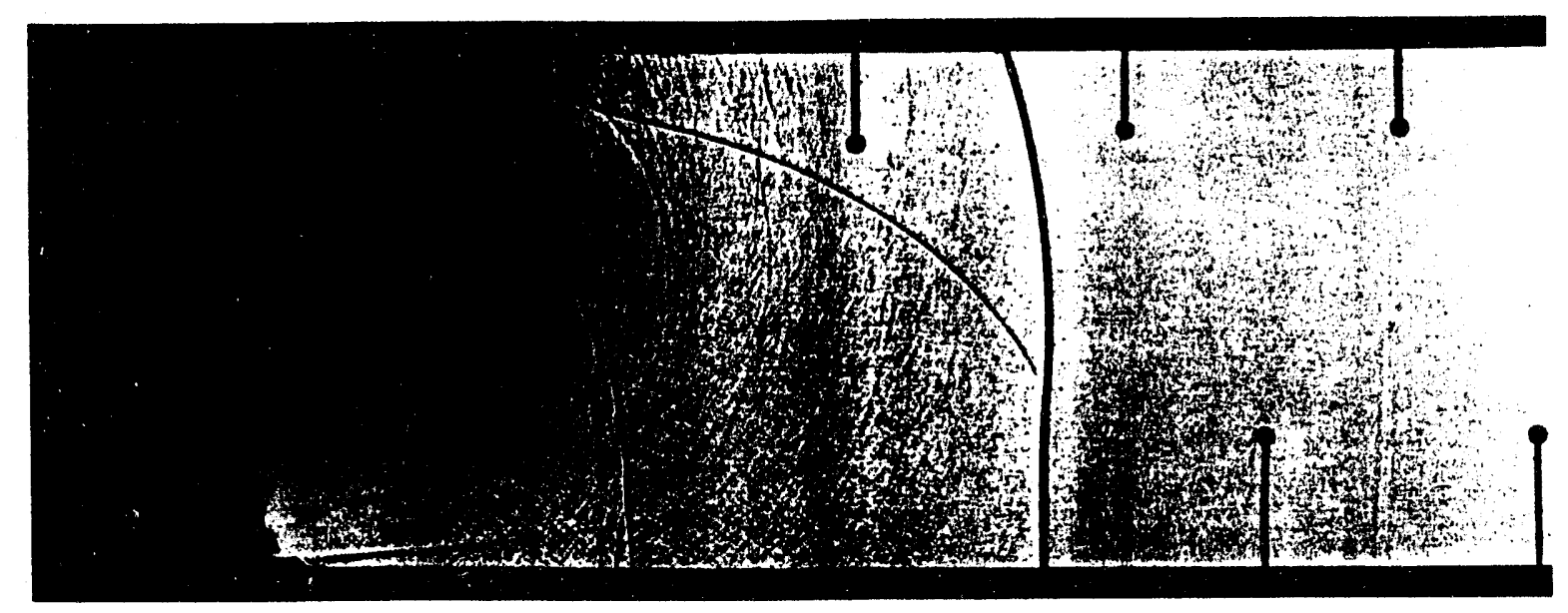

e)

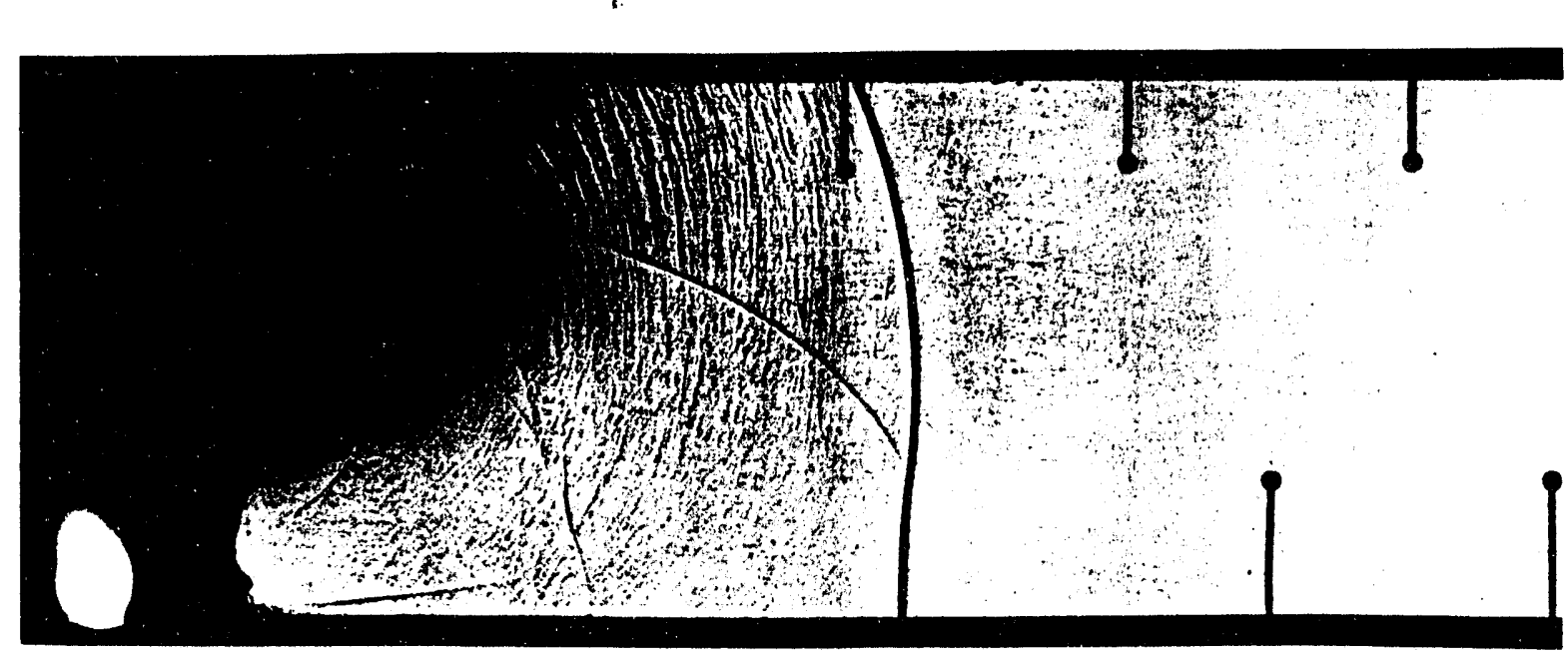

Figure 20 Continued.

d) $\mathrm{DOB}=0 \mathrm{~cm}\left(0 \mathrm{~m} / \mathrm{kg}^{1 / 3}\right) ; \Delta \mathrm{t}=300 \mu \mathrm{s} ;$ Test 777

e) $\mathrm{DOB}=0.5 \mathrm{~cm}\left(0.063 \mathrm{~m} / \mathrm{kg}^{1 / 3}\right) ; \Delta \mathrm{t}=650 \mu \mathrm{s} ;$ Test 776

f) $\mathrm{DOB}=1.0 \mathrm{~cm}\left(0.126 \mathrm{~m} / \mathrm{kg}^{1 / 3}\right) ; \Delta \mathrm{t}=550 \mu \mathrm{s} ;$ Test 762 


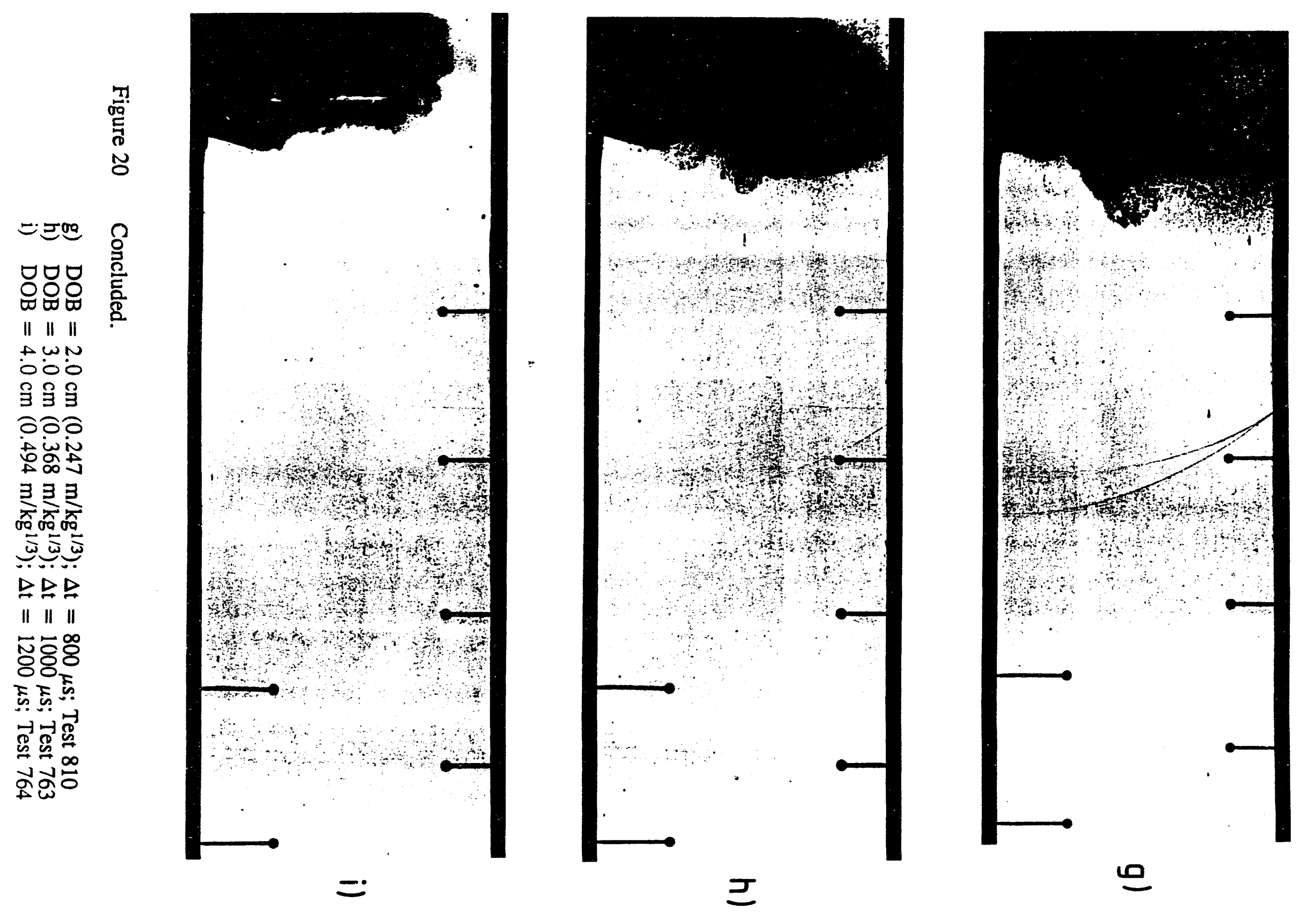



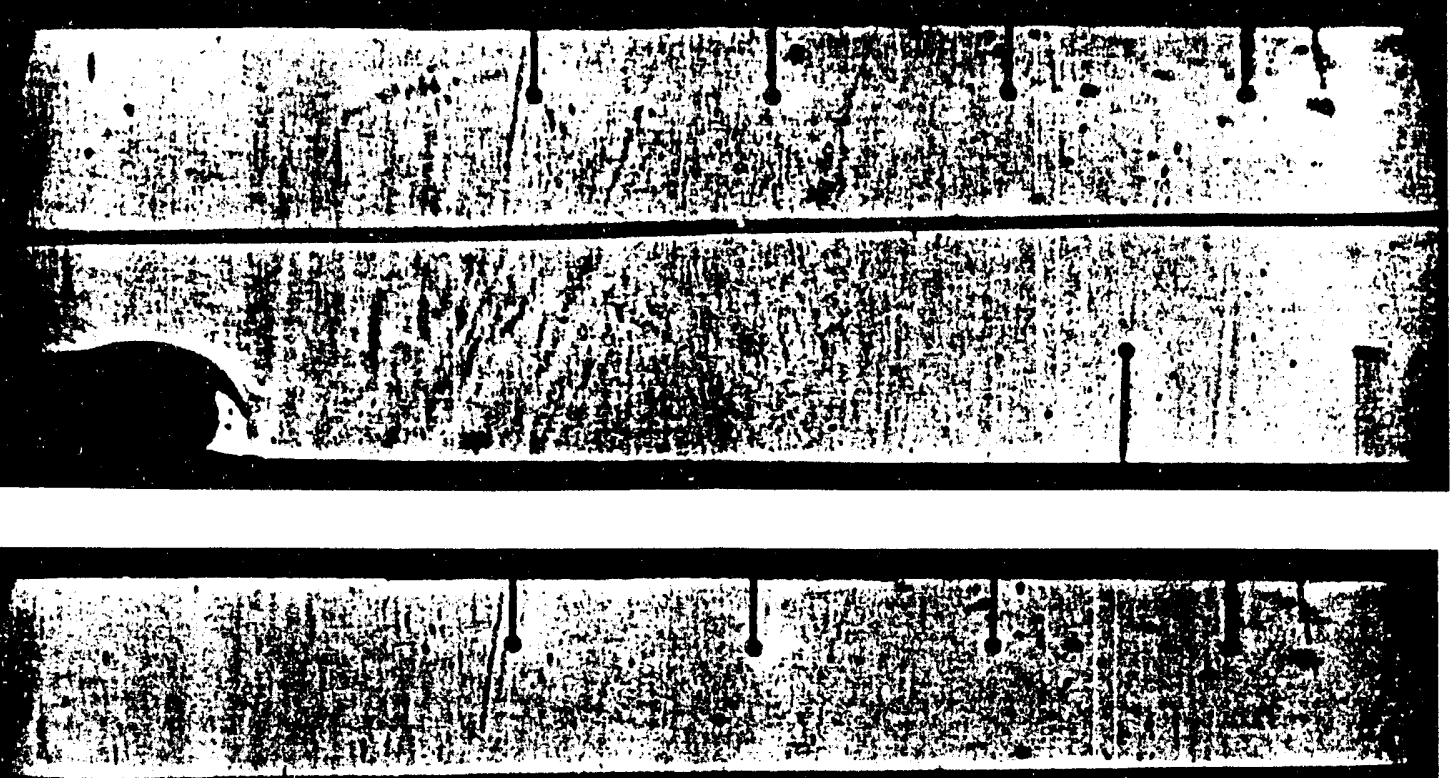

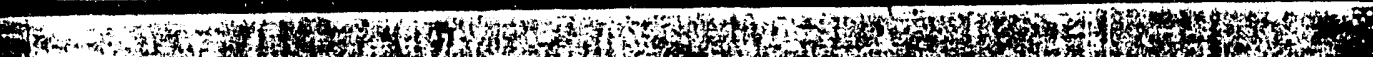

b)
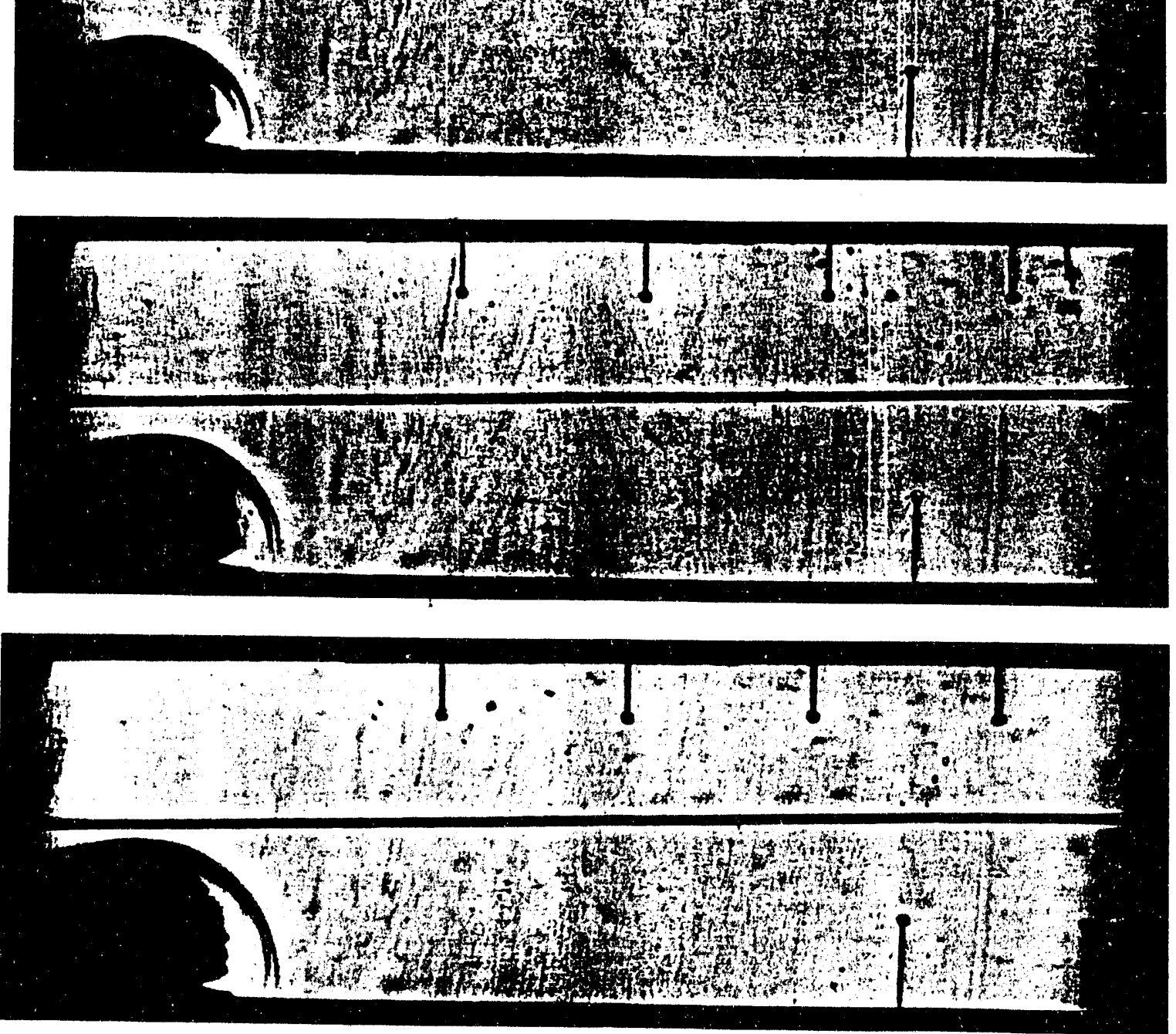

Figure 21 Picture sequence of a high-speed film showing the movement of the crater ejecta and the shock wave formation. Test 816 Soil material: dry aerated grout (dry YTONG); DOB $=2.5 \mathrm{~cm}(0.315$ $\mathrm{m} / \mathrm{kg}^{1 / 3}$ )

a) $\mathrm{t}=0 \mu \mathrm{s} ; \mathrm{b}) \mathrm{t}=30 \mu \mathrm{s} ; \mathrm{c}) \mathrm{t}=60 \mu \mathrm{s} ; \mathrm{d}) \mathrm{t}=90 \mu \mathrm{s}$ 


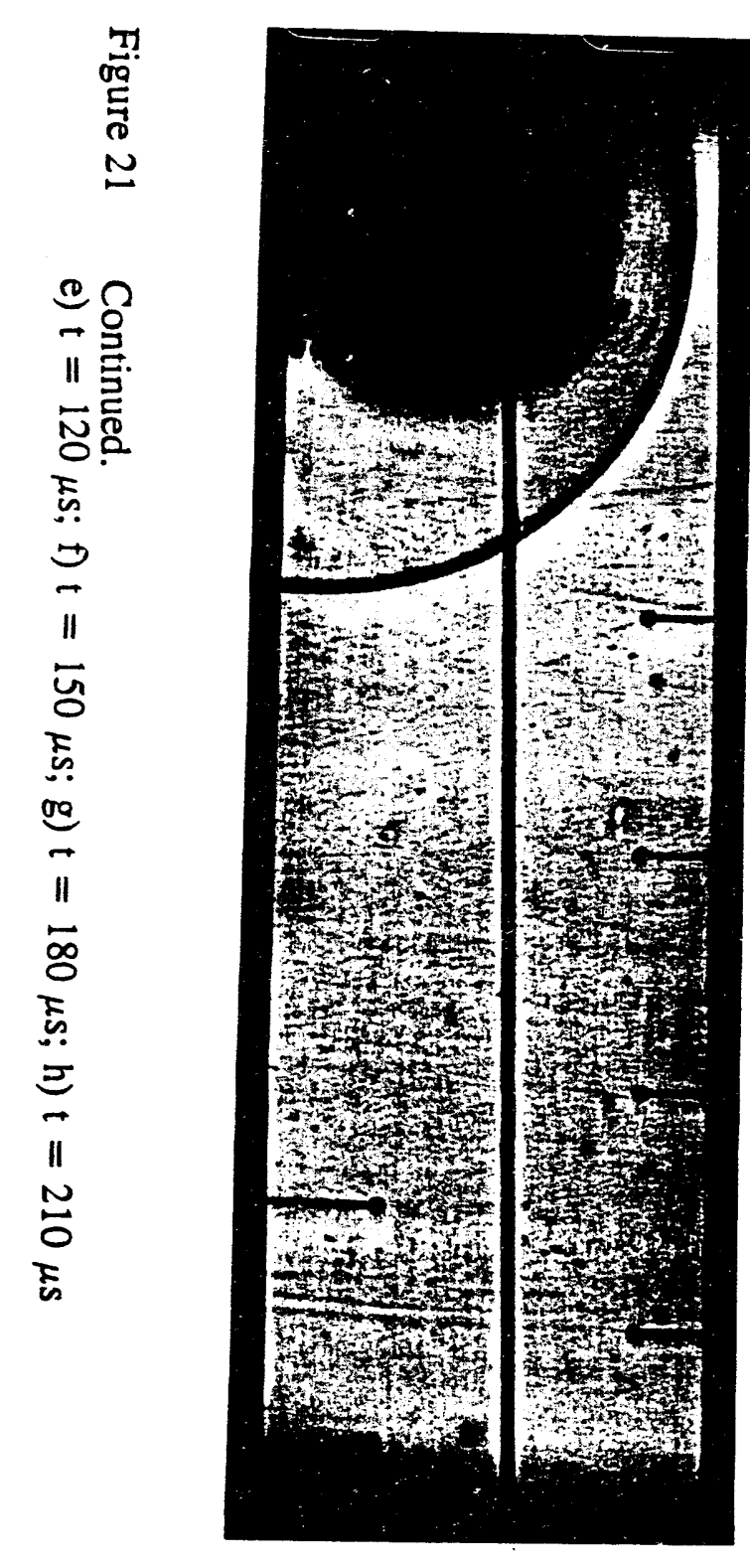

$\Xi$

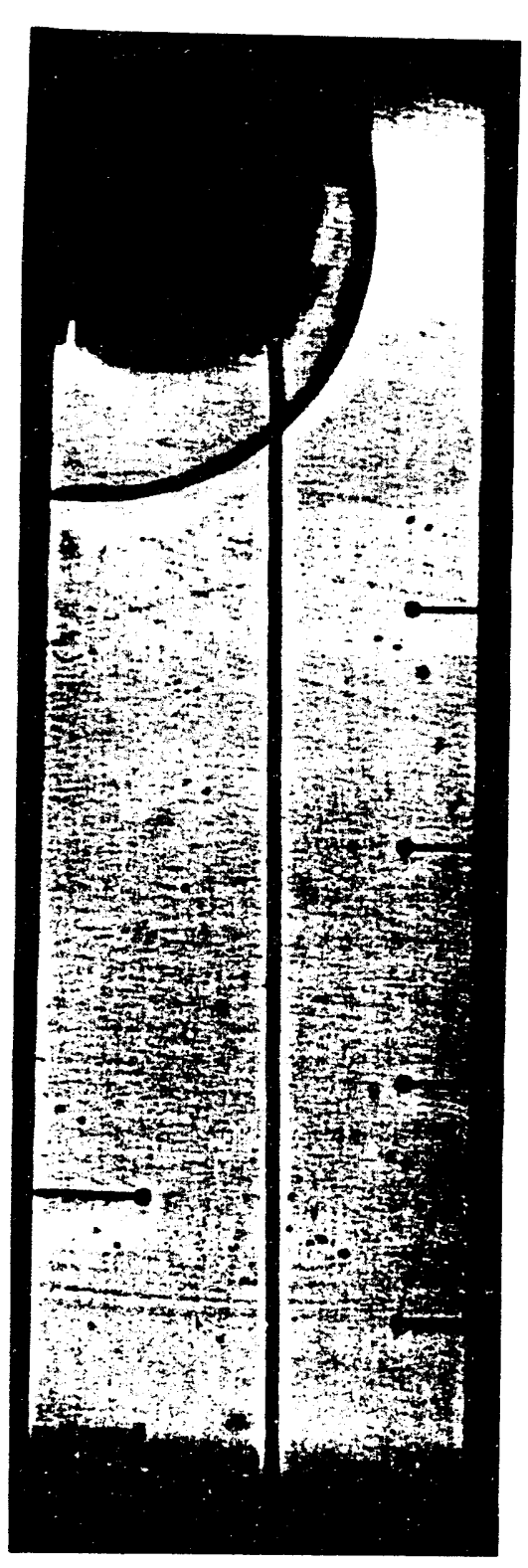

$\underline{0}$

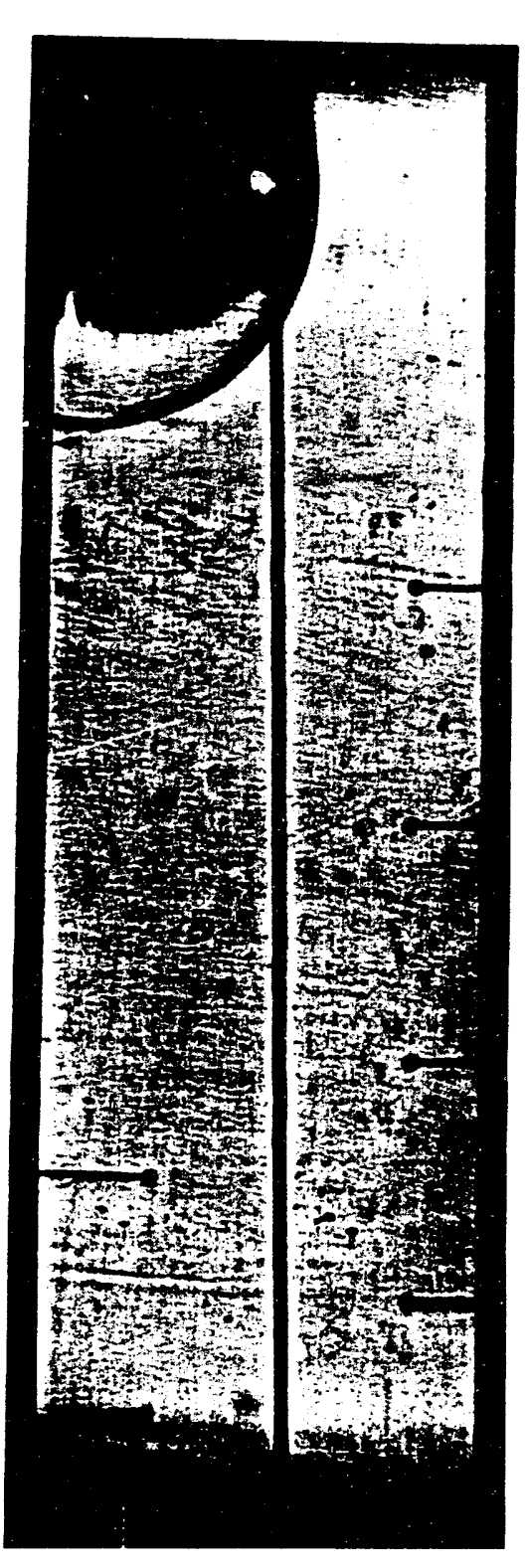

$\Rightarrow$

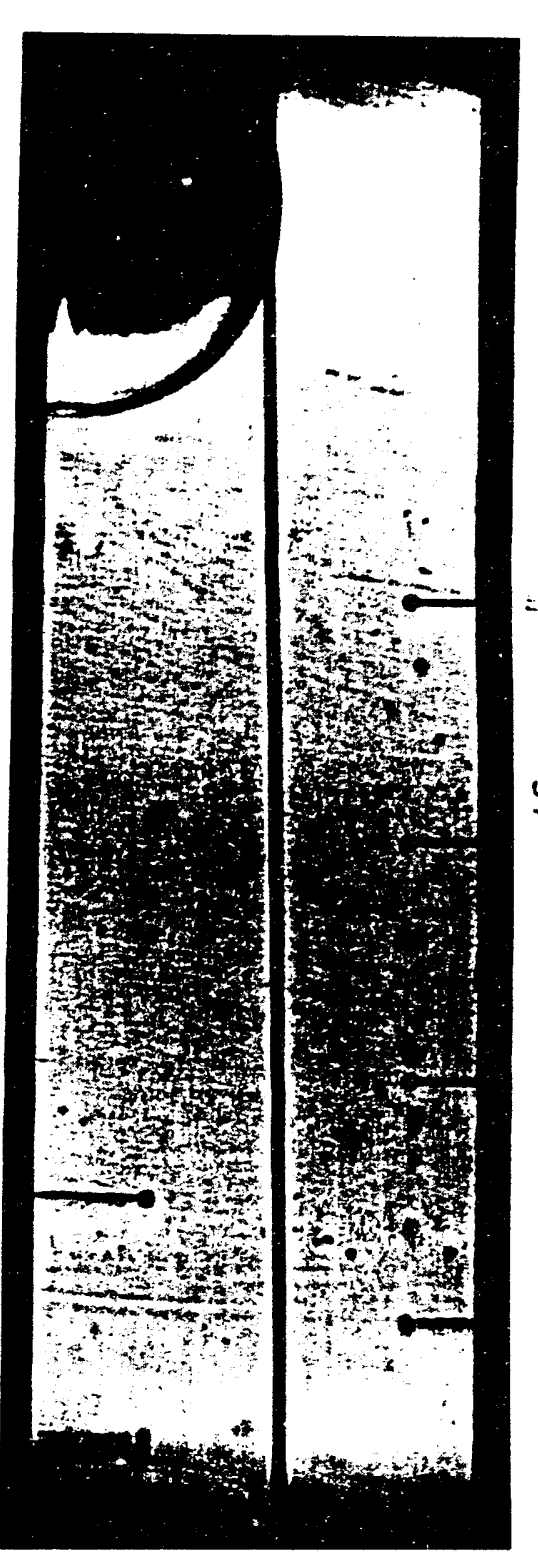

ㄴ 


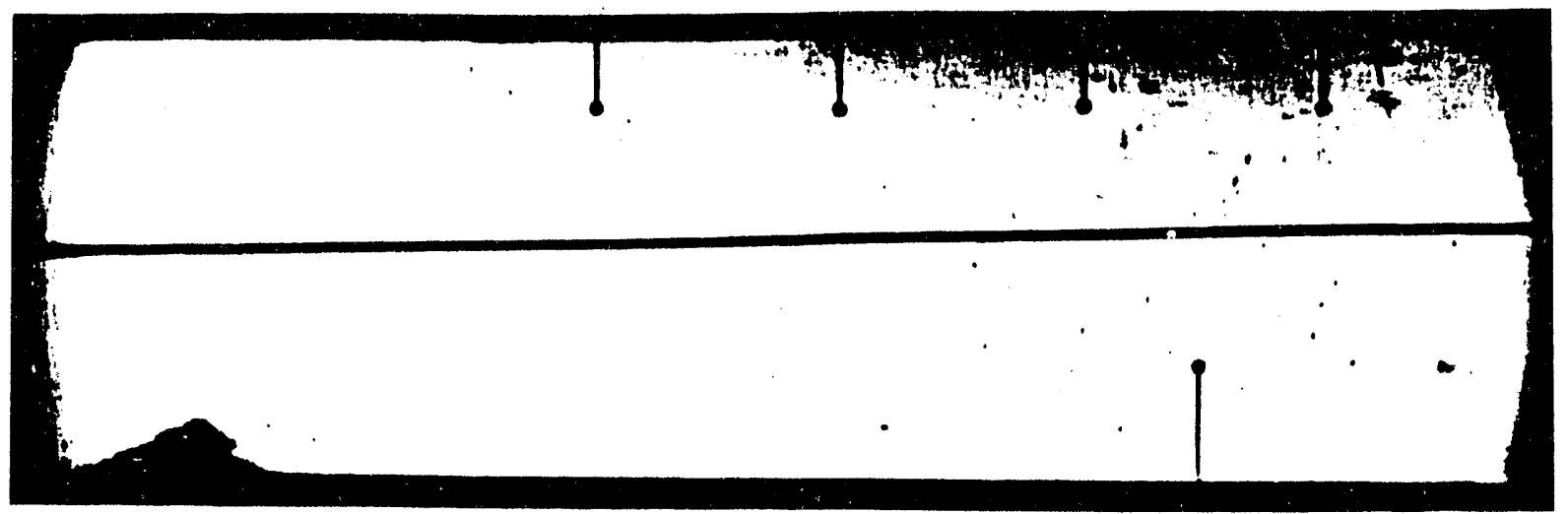

a)

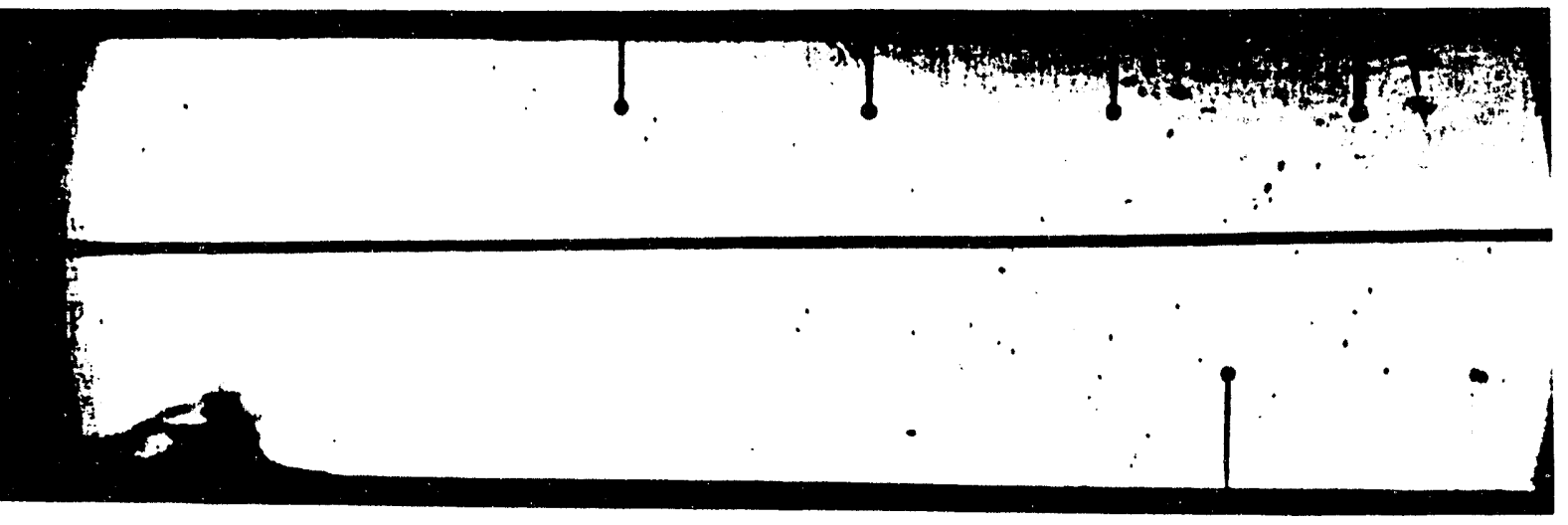

b)

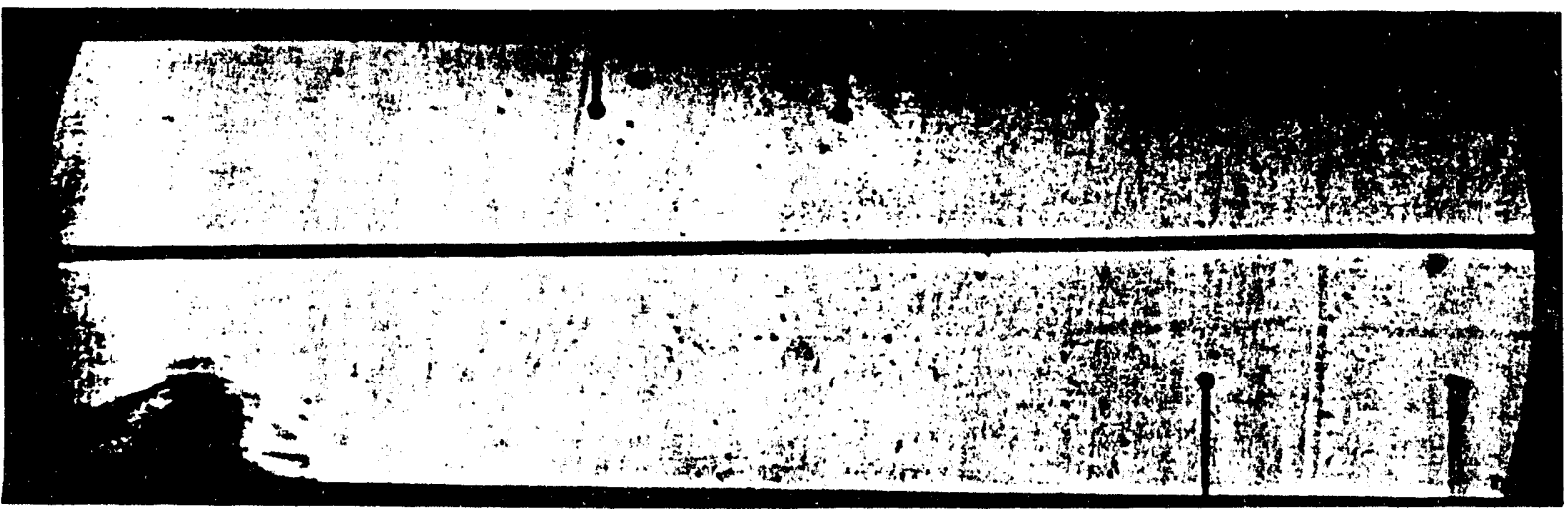

c)

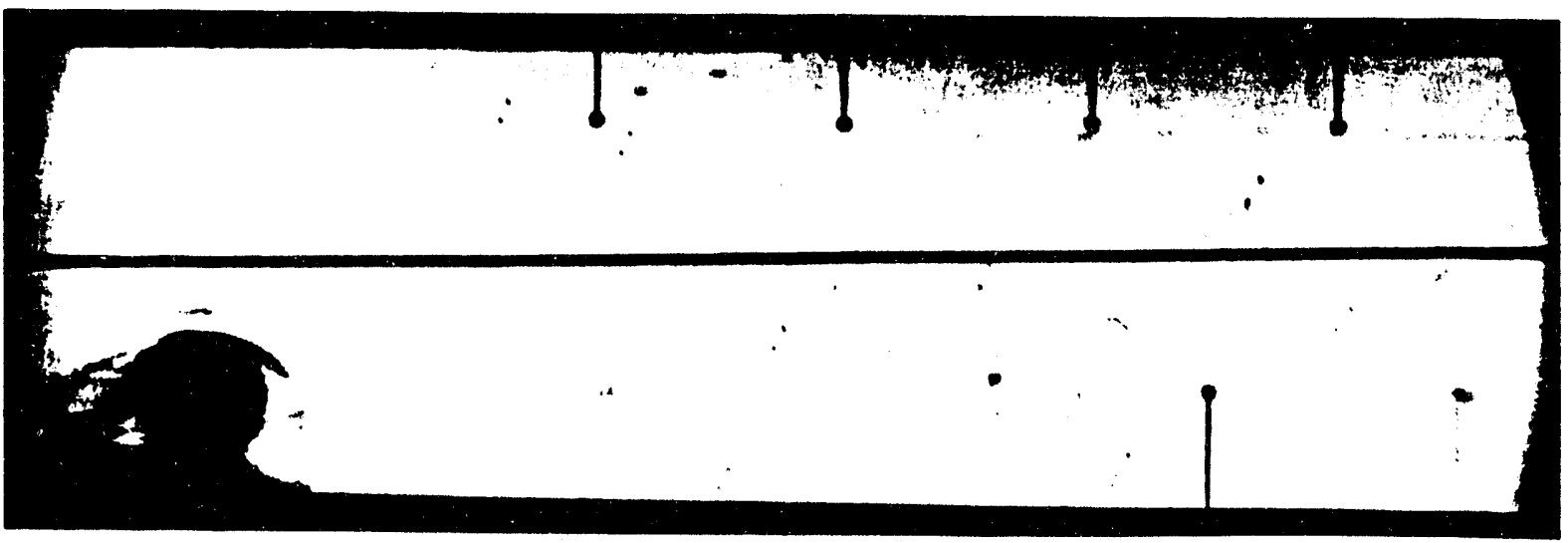

d)

Figure 22 Picture series of a high-speed film showing the movement of the crater ejecta and the shock wave formation. Test: 799

Soil material: wet clay/loam; $\mathrm{DOB}=2.5 \mathrm{~cm}\left(0.315 \mathrm{~m} / \mathrm{kg}^{1 / 3}\right)$
a) $\mathrm{t}=0 \mu \mathrm{s}$;
b) $\mathrm{t}=30 \mu \mathrm{s}$;
c) $\mathrm{t}=60 \mu \mathrm{s}$
d) $\mathrm{t}=120 \mu \mathrm{s}$ 


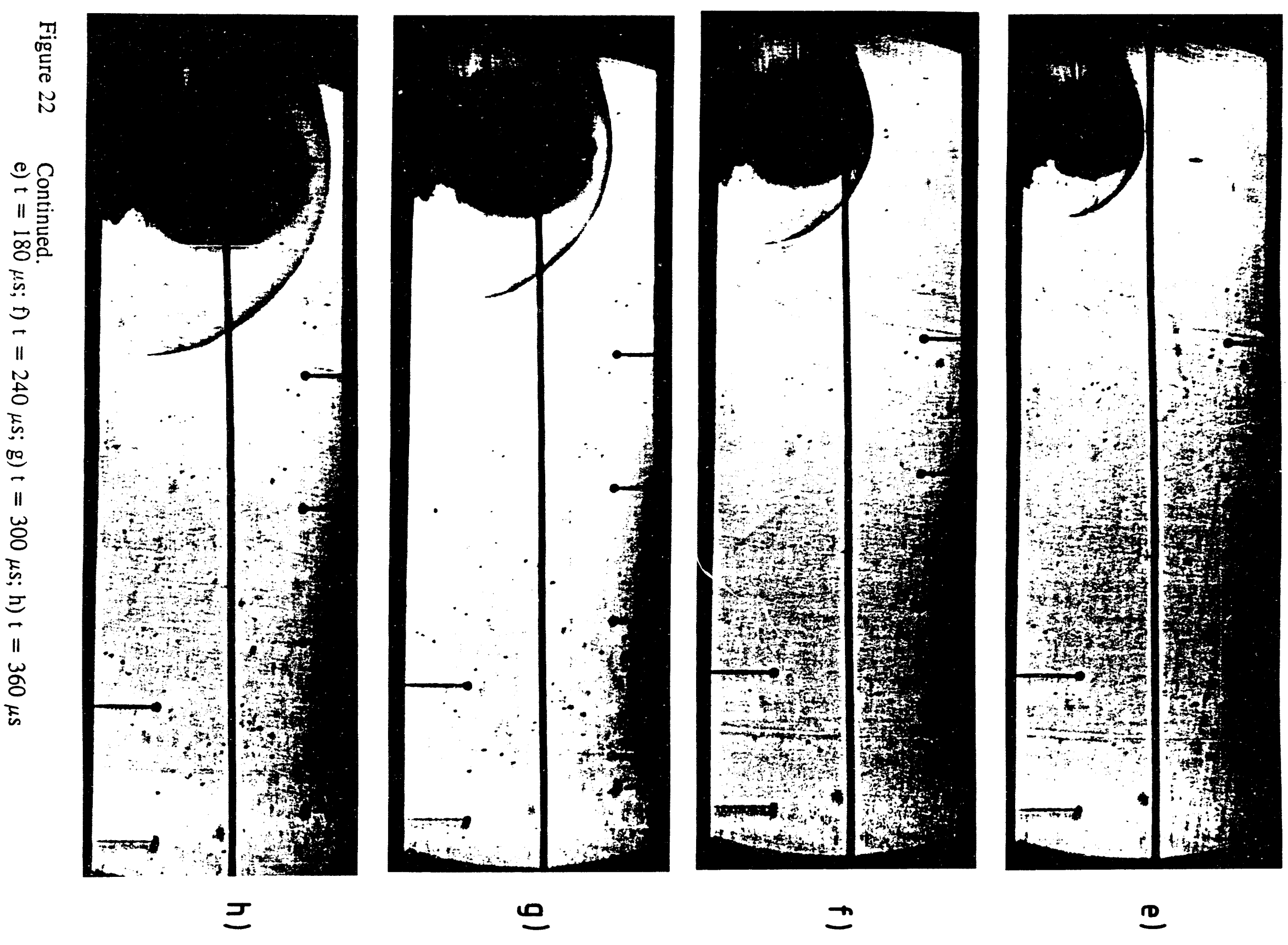




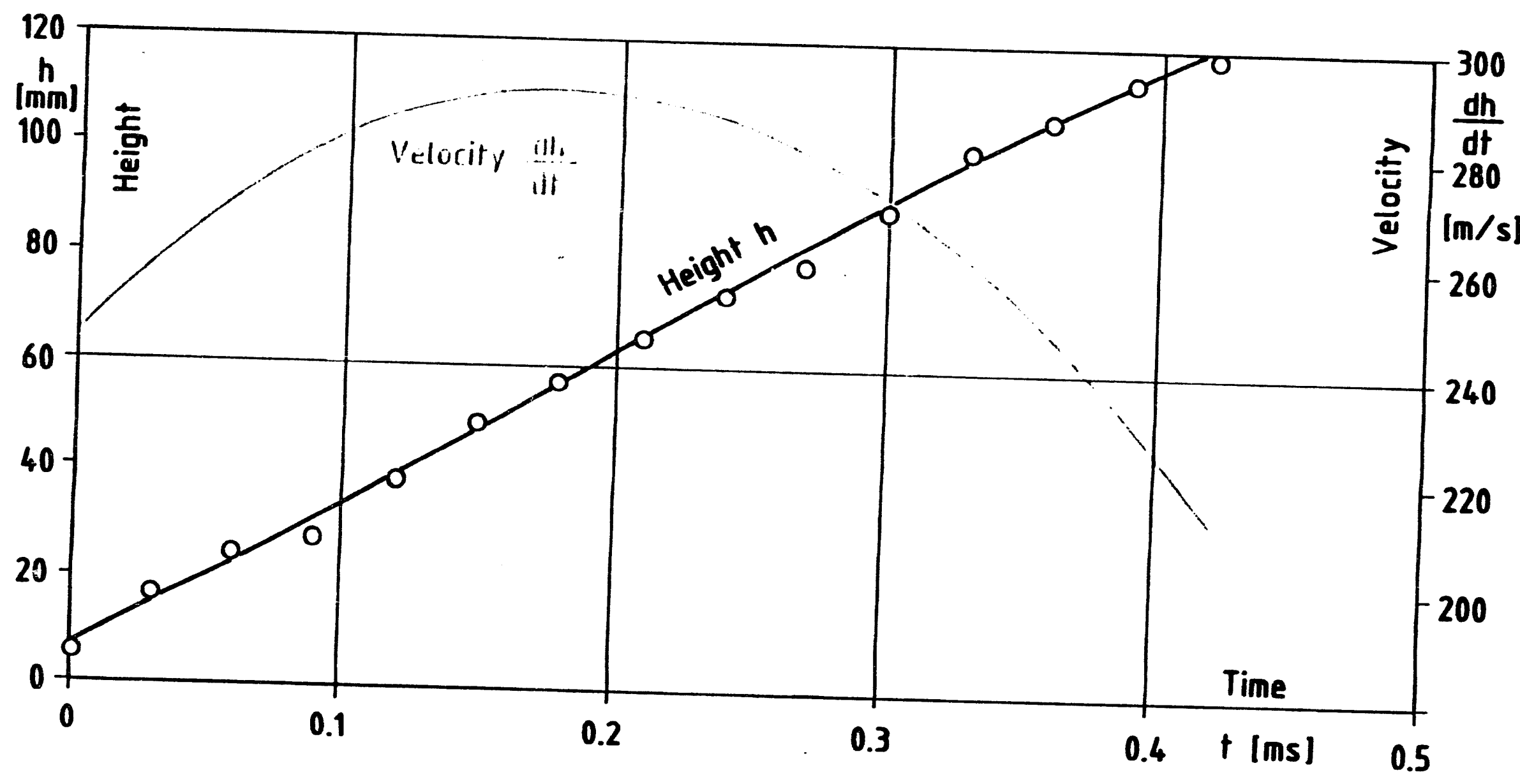

Figure 23 Position and velocity of crater ejecta

Soil material: wet clay/loam

DOB $=2.5 \mathrm{~cm}\left(0.315 \mathrm{~m} / \mathrm{kg}^{1 / 3}\right)$. Test 799 


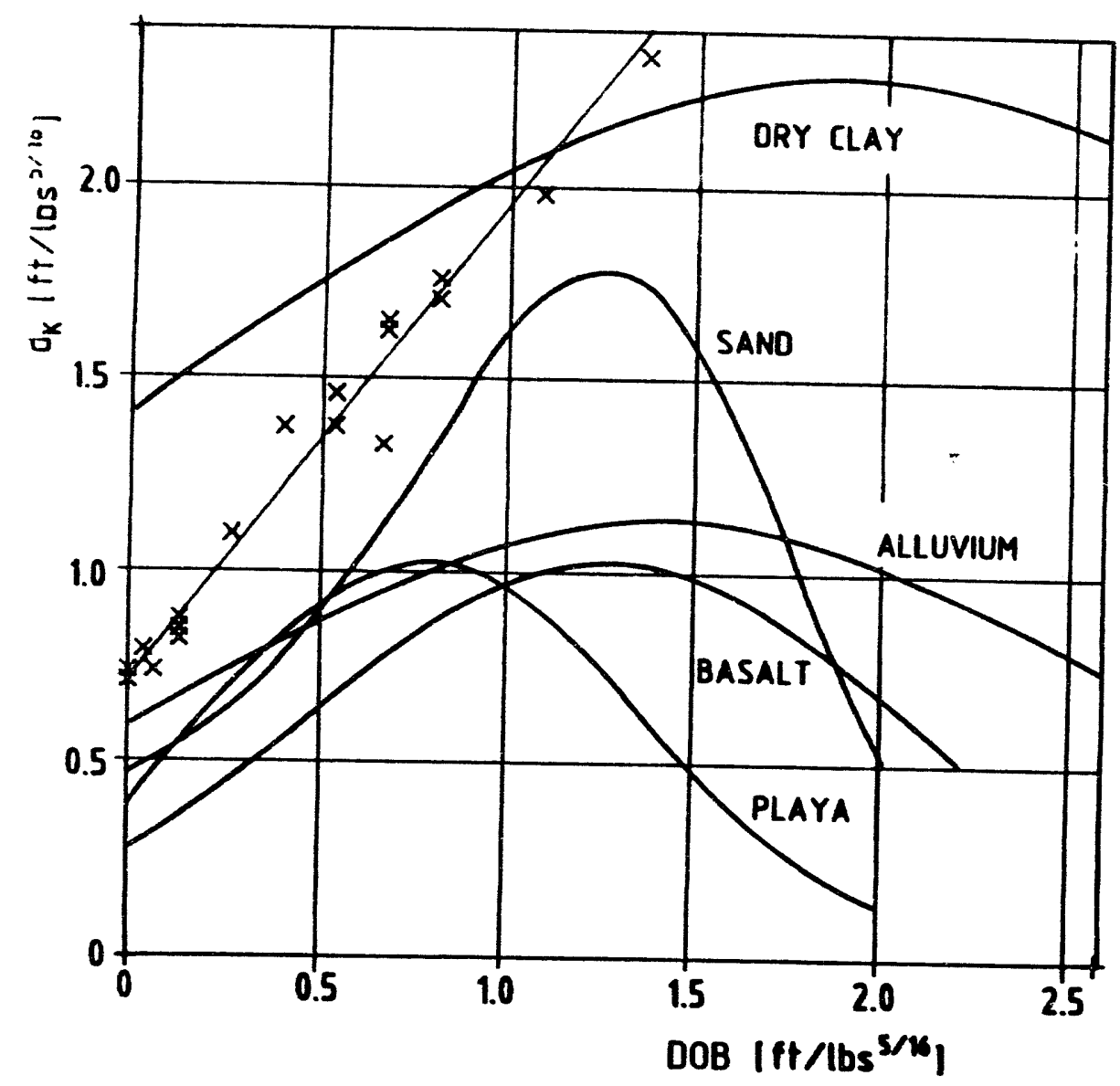

Figure 24

True crater depth vs DOB for dry aerated grout (dry YTONG) compared with apparent crater depth of real soil materials [3].

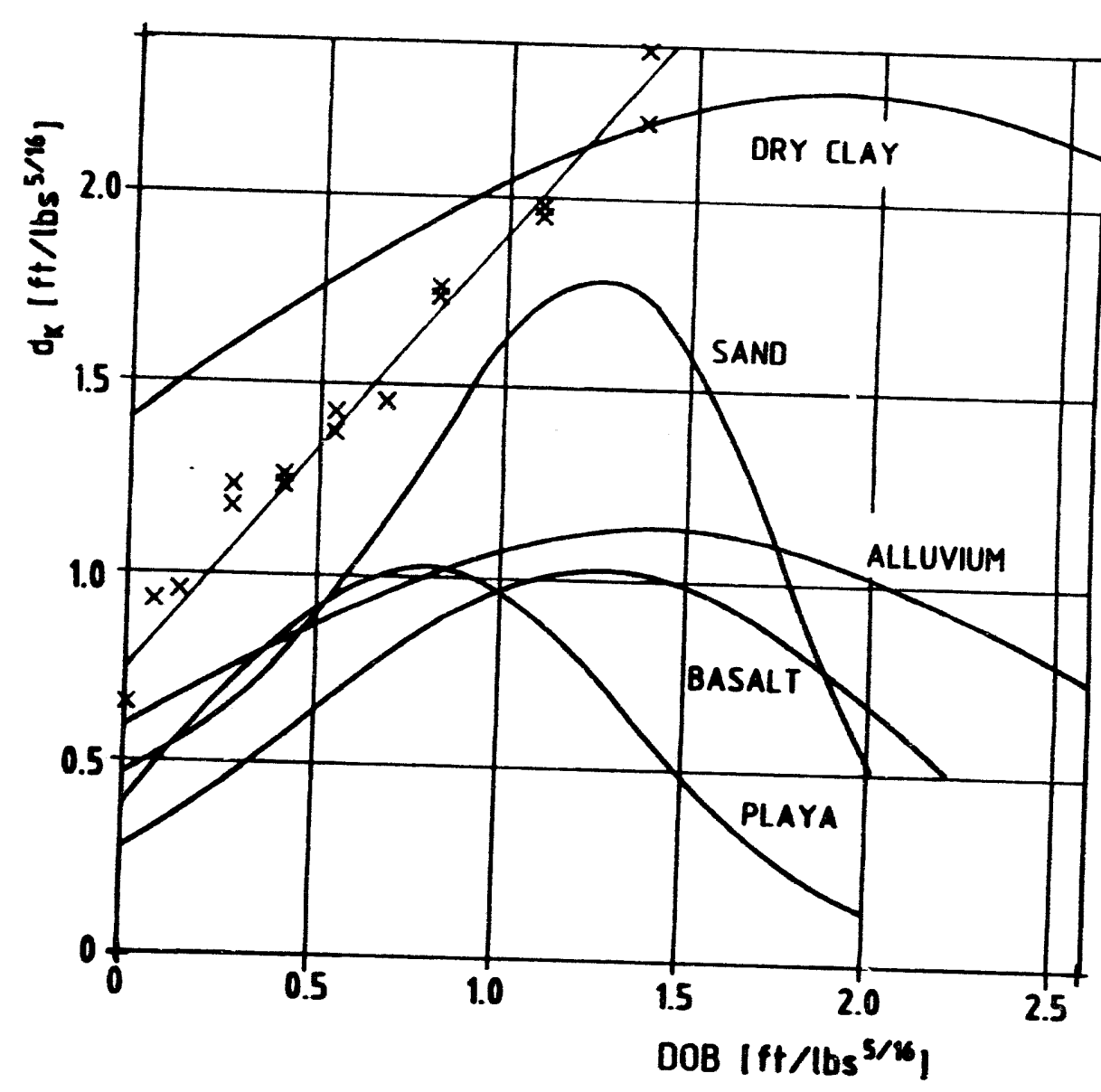

Figure 25

True crater depth vs DOB for water-saturated grout (wet YTONG) compared with apparent crater depth of real soil materials [3]. 


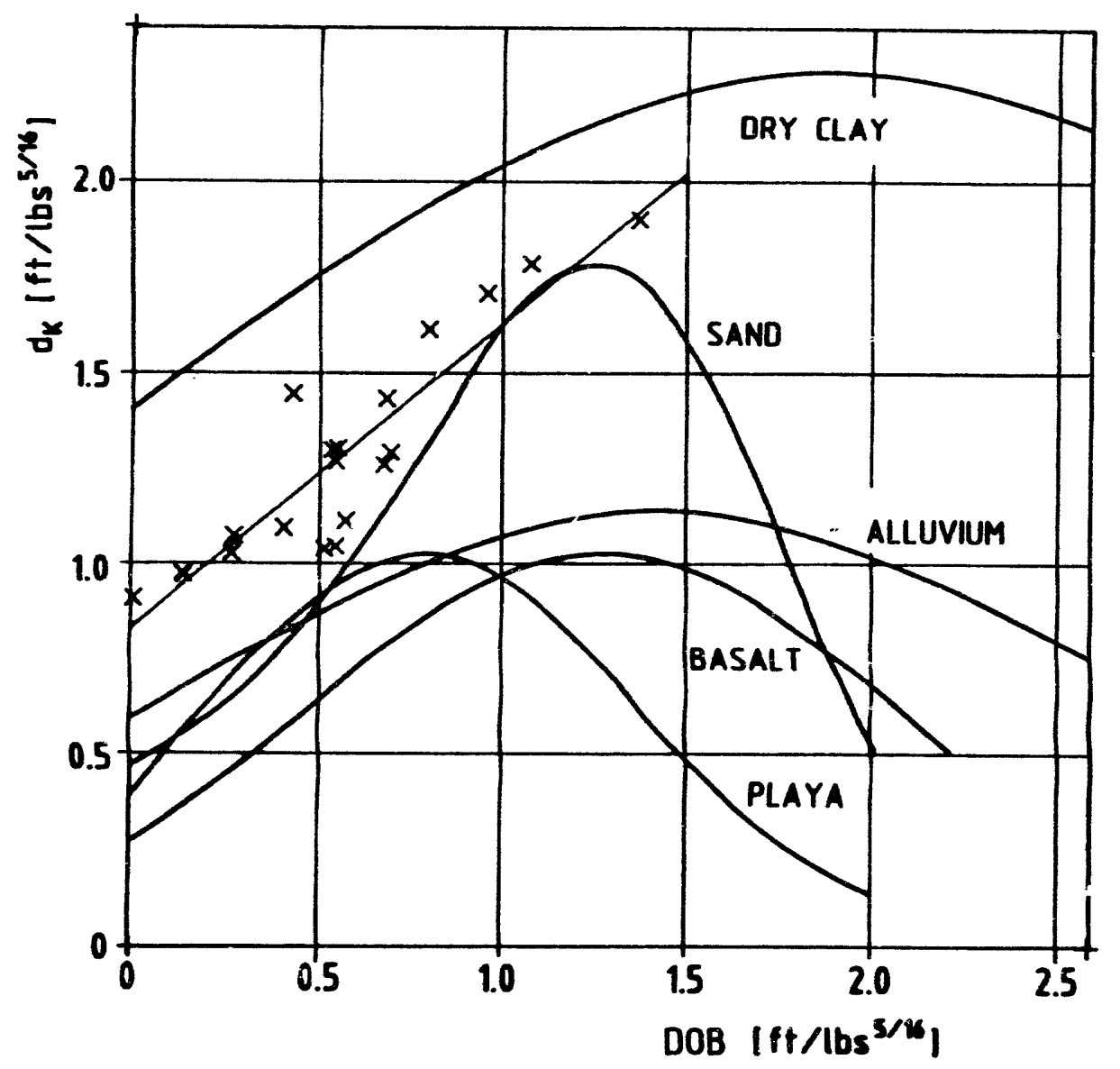

Figure 26 True crater depth vs DOB at wet clay/loam compared with apparent crater depth of real soil materials [3].

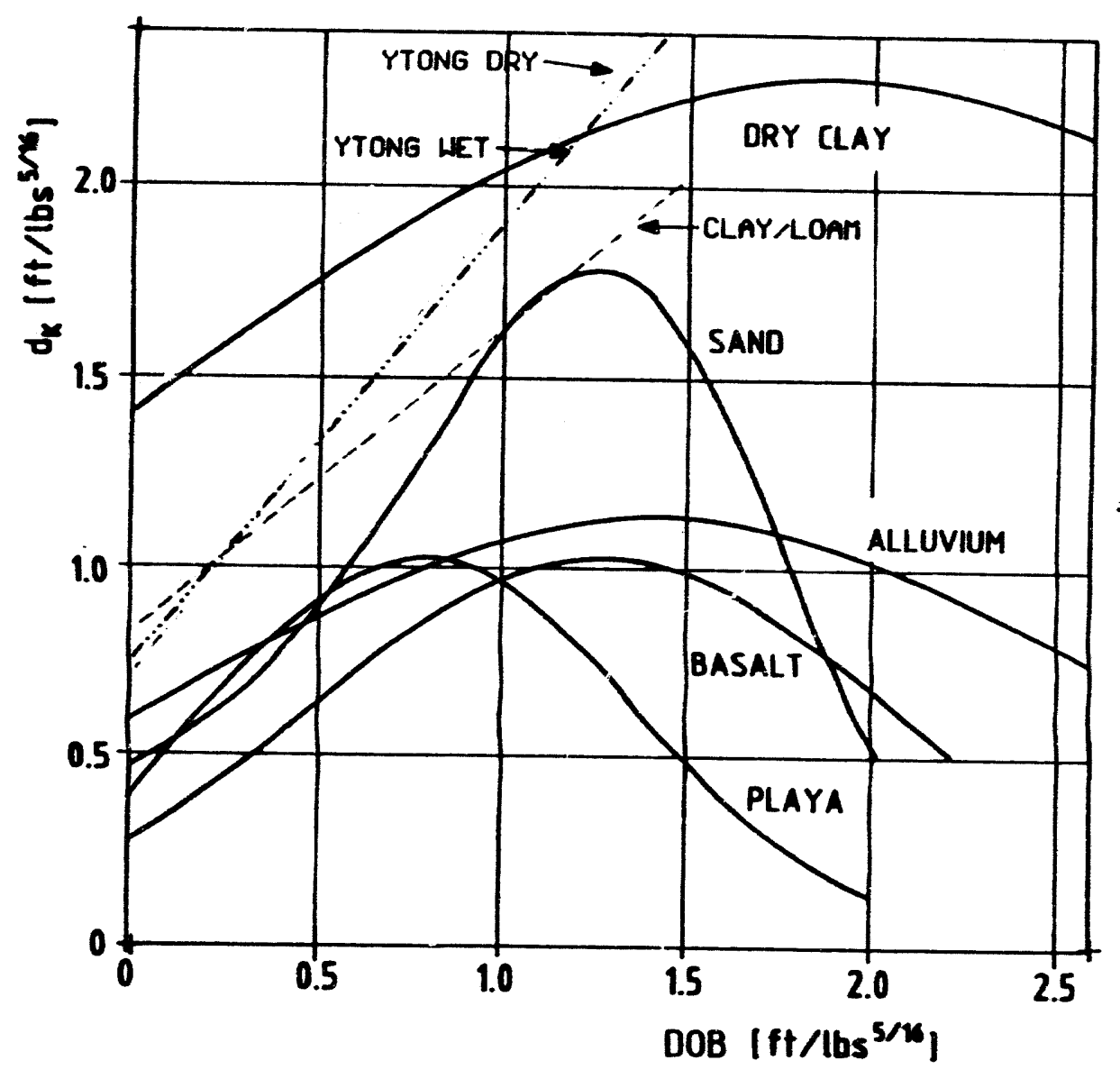

Figure 27 Comparison of linear approximation curves for true crater depth with apparent crater depth of real soil material [3]. 


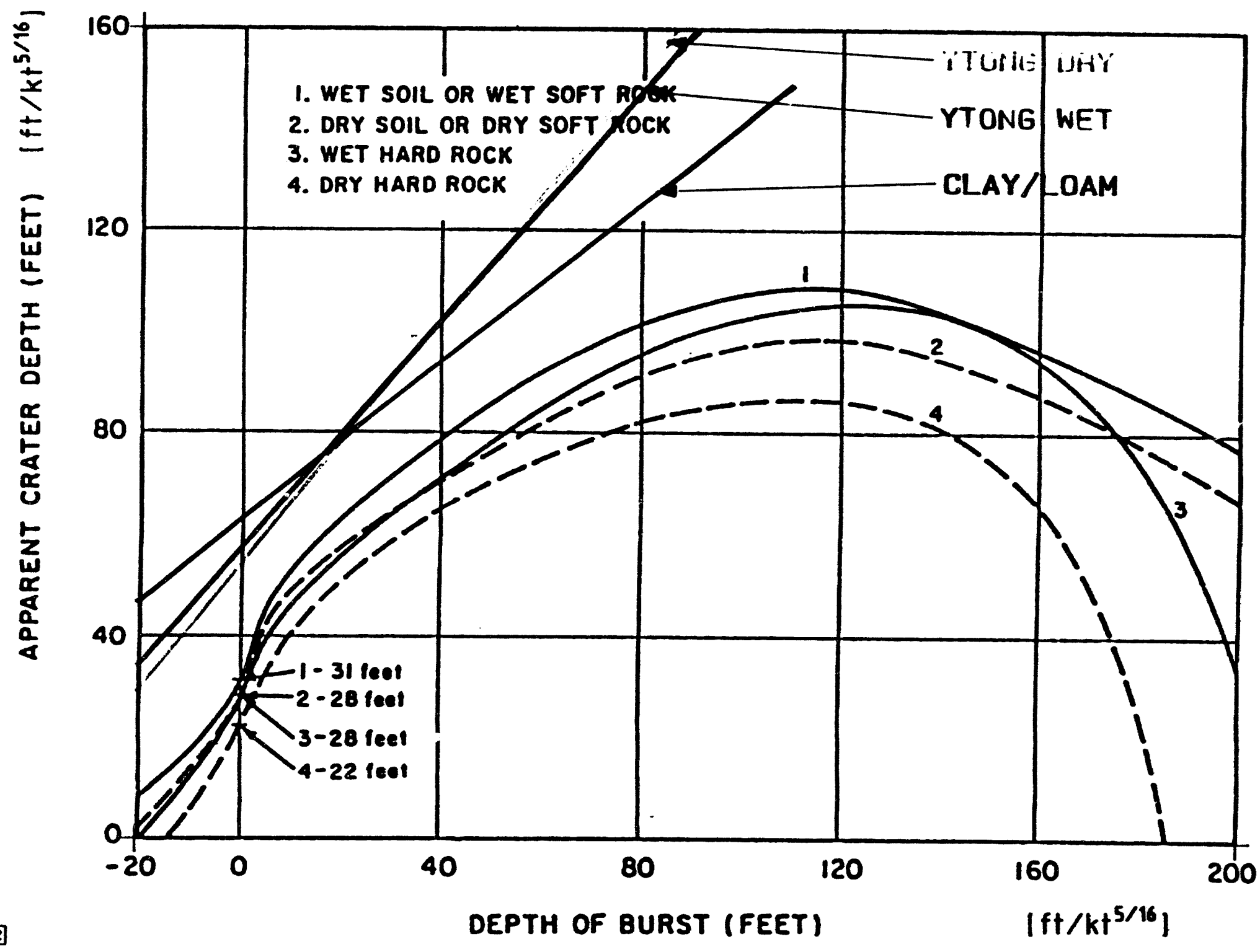

\$

Figure 28 Comparison of measured true crater depth with apparent crater depth of different soil material [Ref. 11]. 

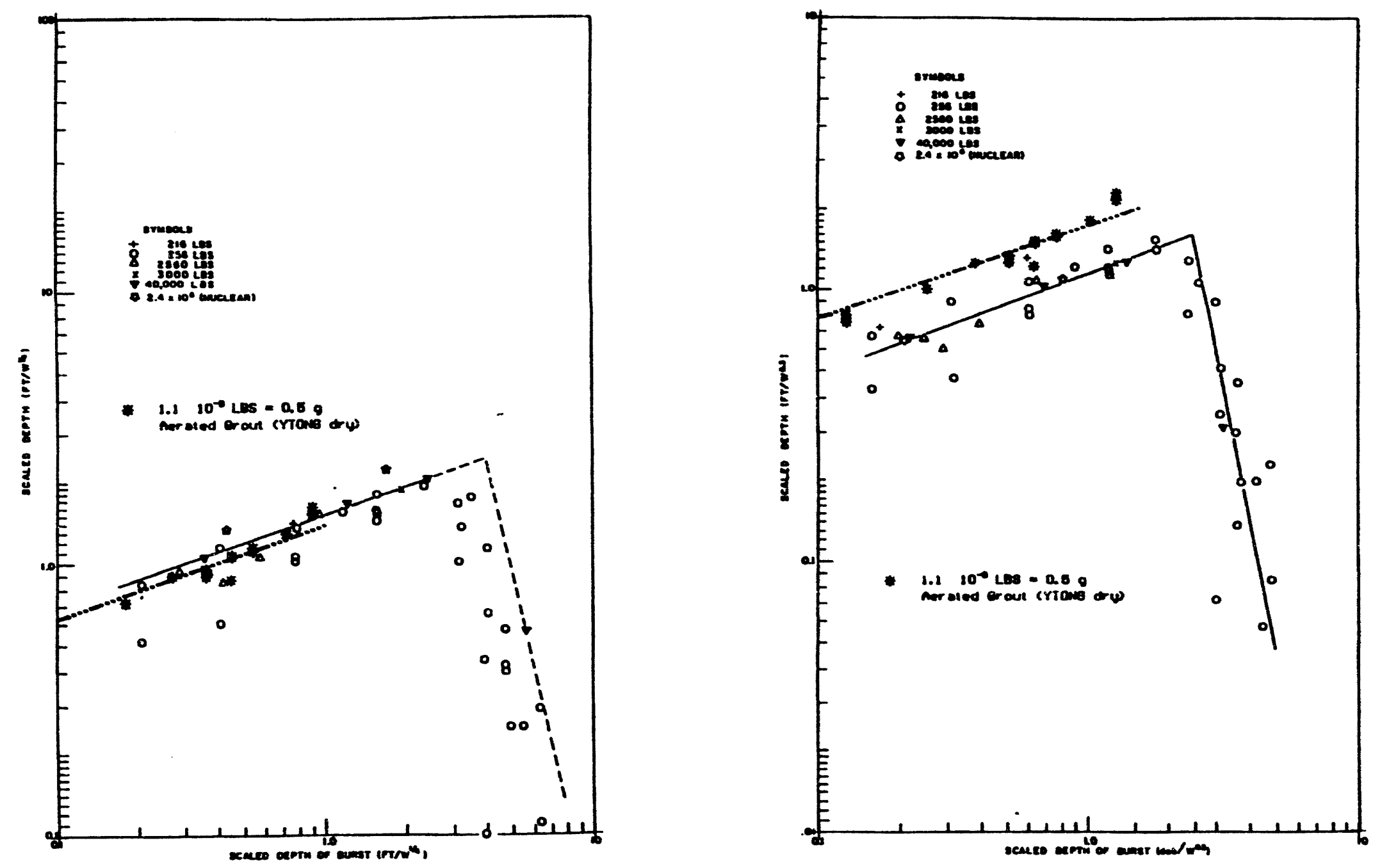

Figure 29 True crater depth vs DOB for dry YTONG compared with apparent crater depth of desert alluvium [12].

$\begin{array}{ll}\text { left diagram: } & W^{1 / 4} \text { scaling } \\ \text { right diagram: } & \text { W }^{0.3} \text { scaling }\end{array}$ 

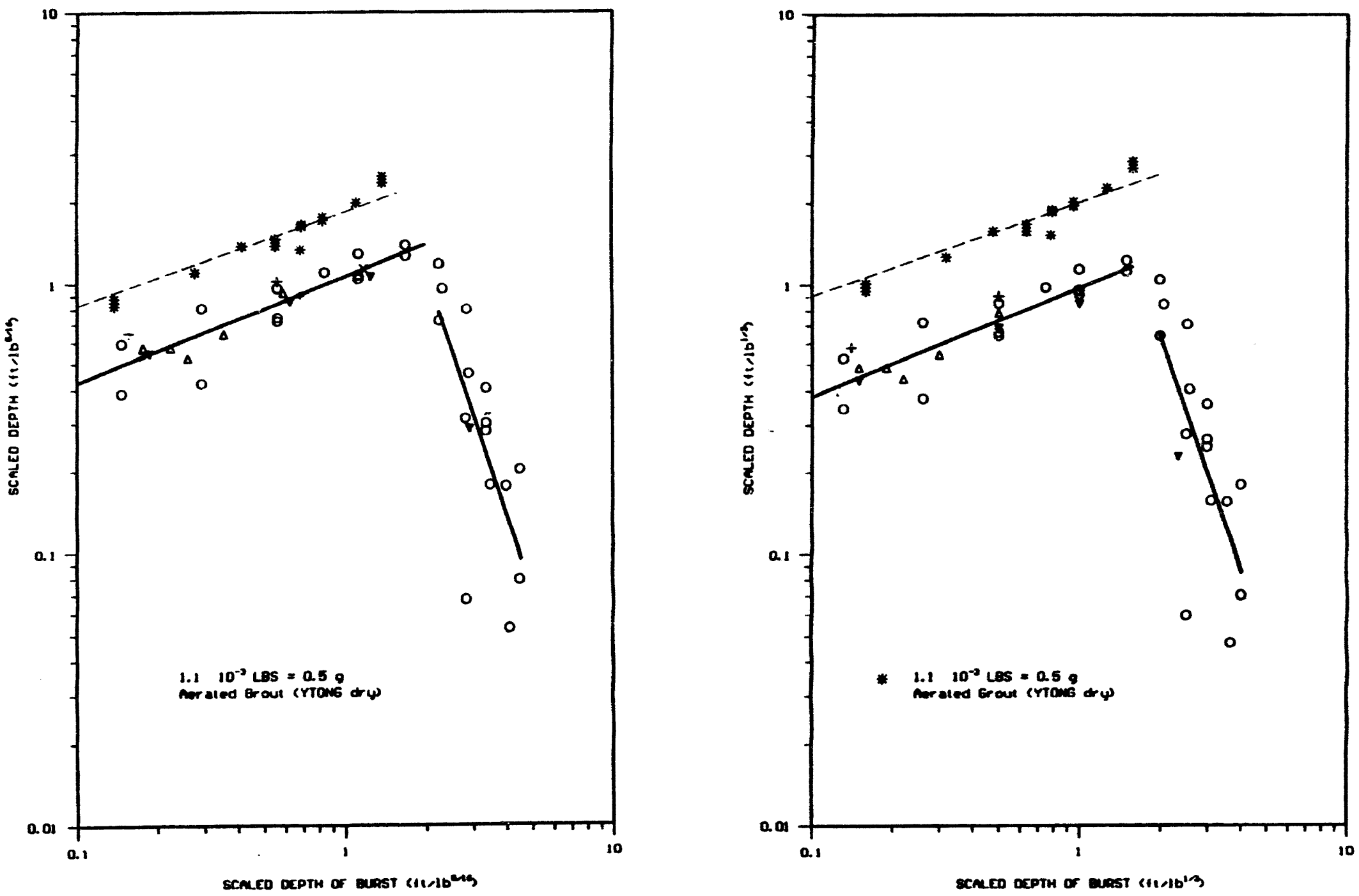

용

Figure 29

Continued.

left diagram: $\quad W^{5 / 16}$ scaling

right diagram: $\quad W^{1 / 3}$ scaling 

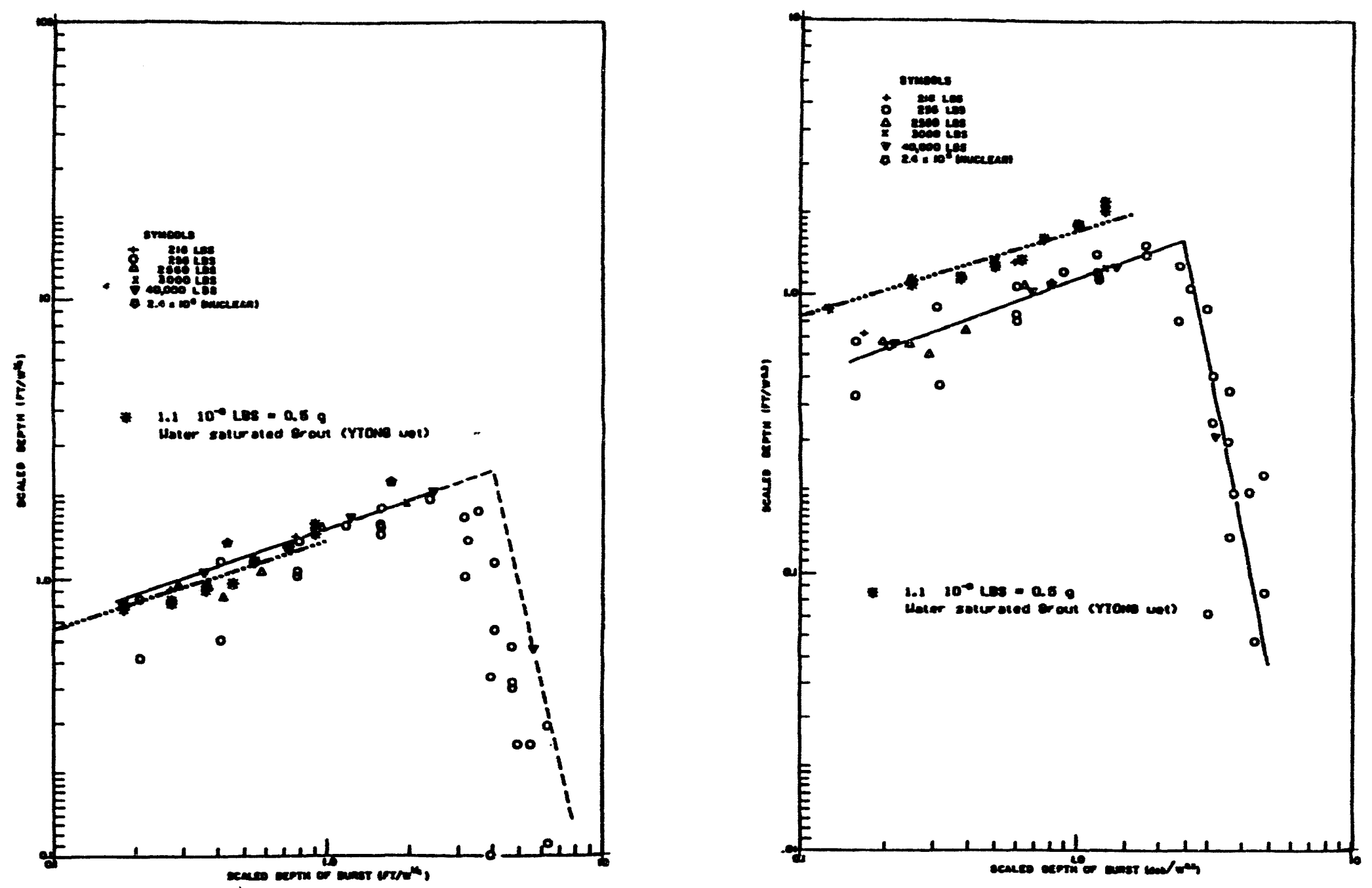

Figure 30 True crater depth vs DOB at wet YTONG compared with apparent crater depth at desert alluvium [12].

left diagram: $\quad W^{1 / 4}$ scaling

right diagram: $\quad$ W0.3 scaling 

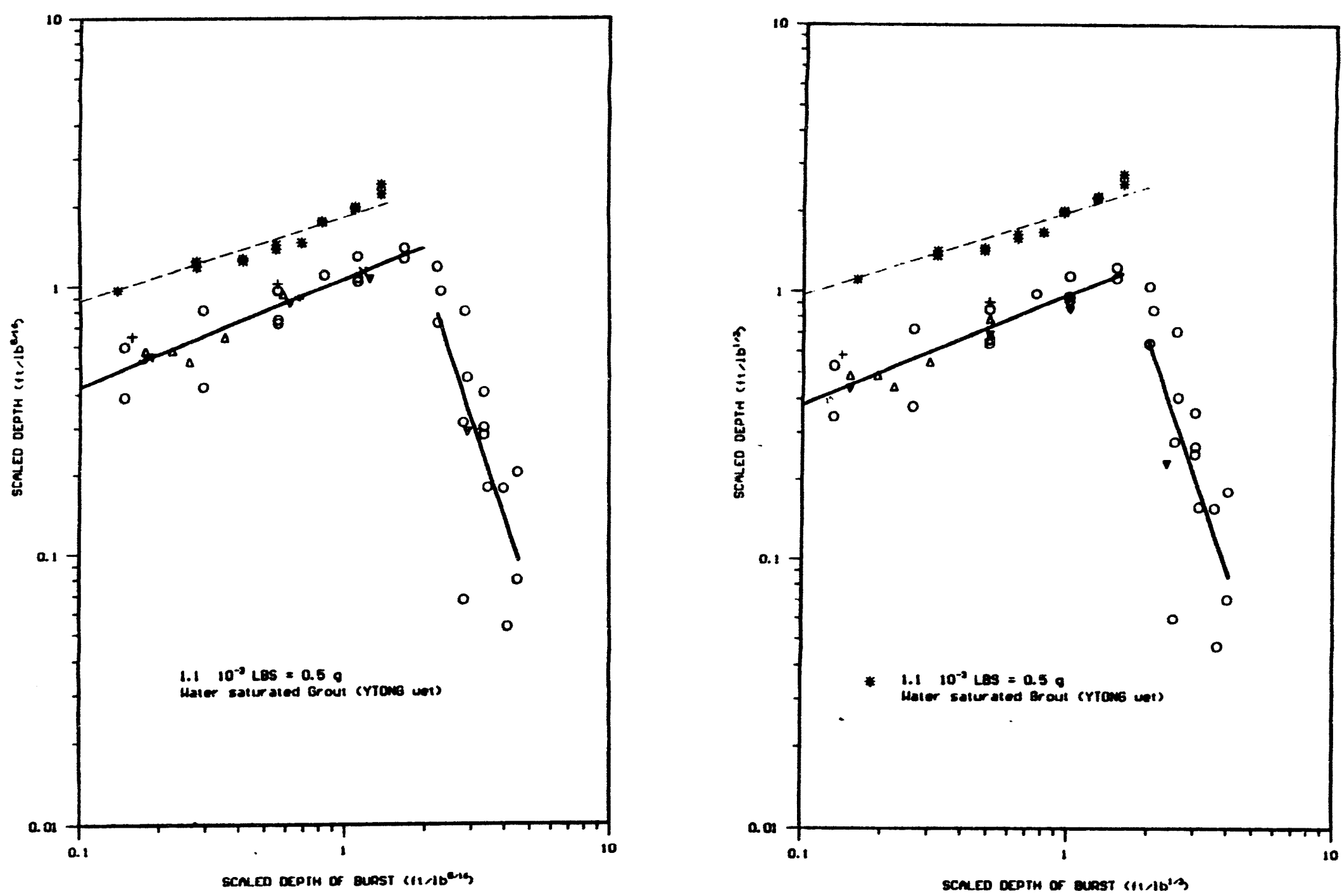

Figure 30 Continued

left diagram: $\quad W^{5 / 16}$ scaling

nght diagram: $\quad W^{1 / 3}$ scaling 


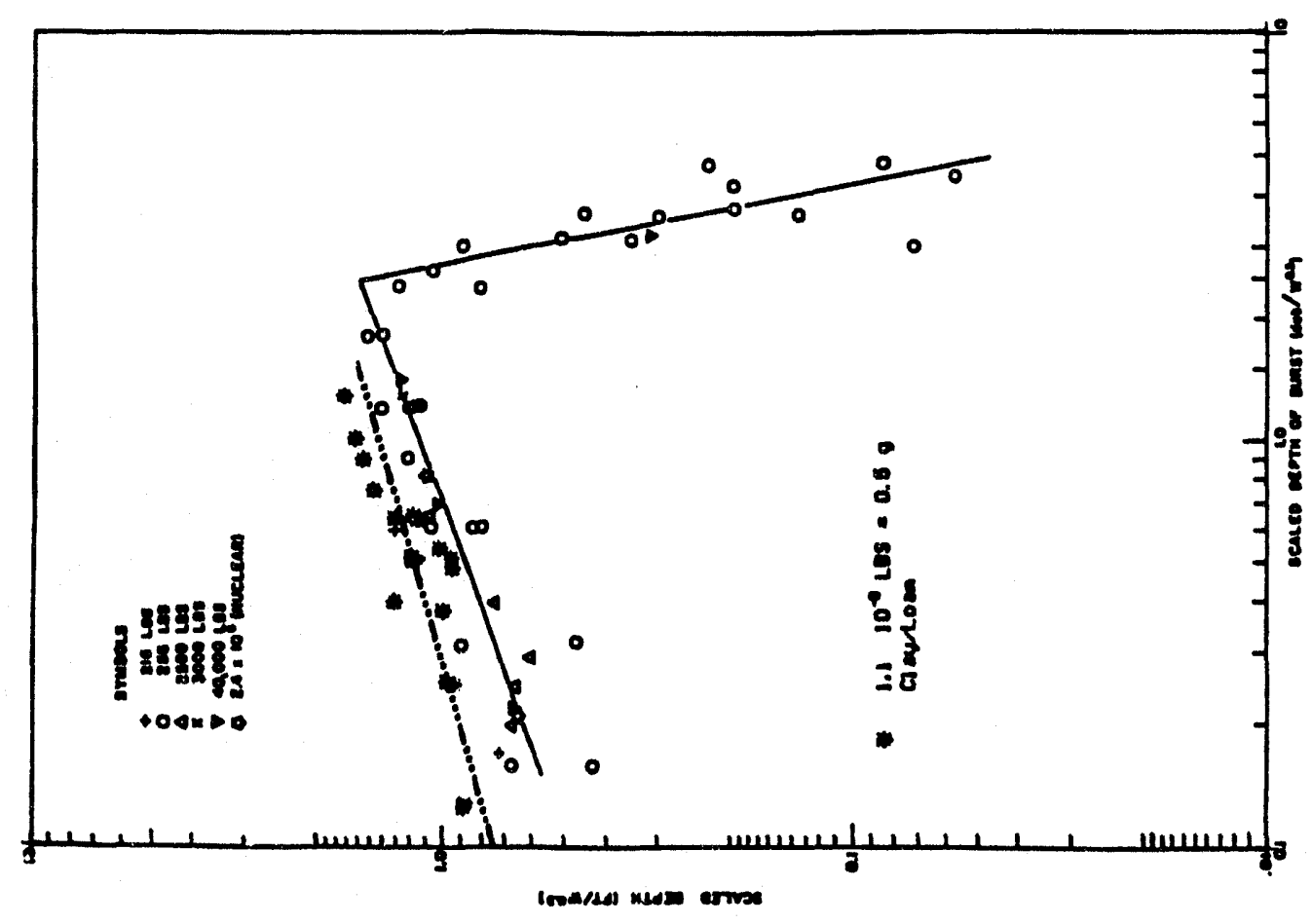

$\underset{8}{0}$

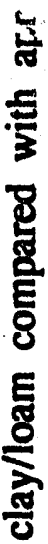

농. 쟁

तें

员政家

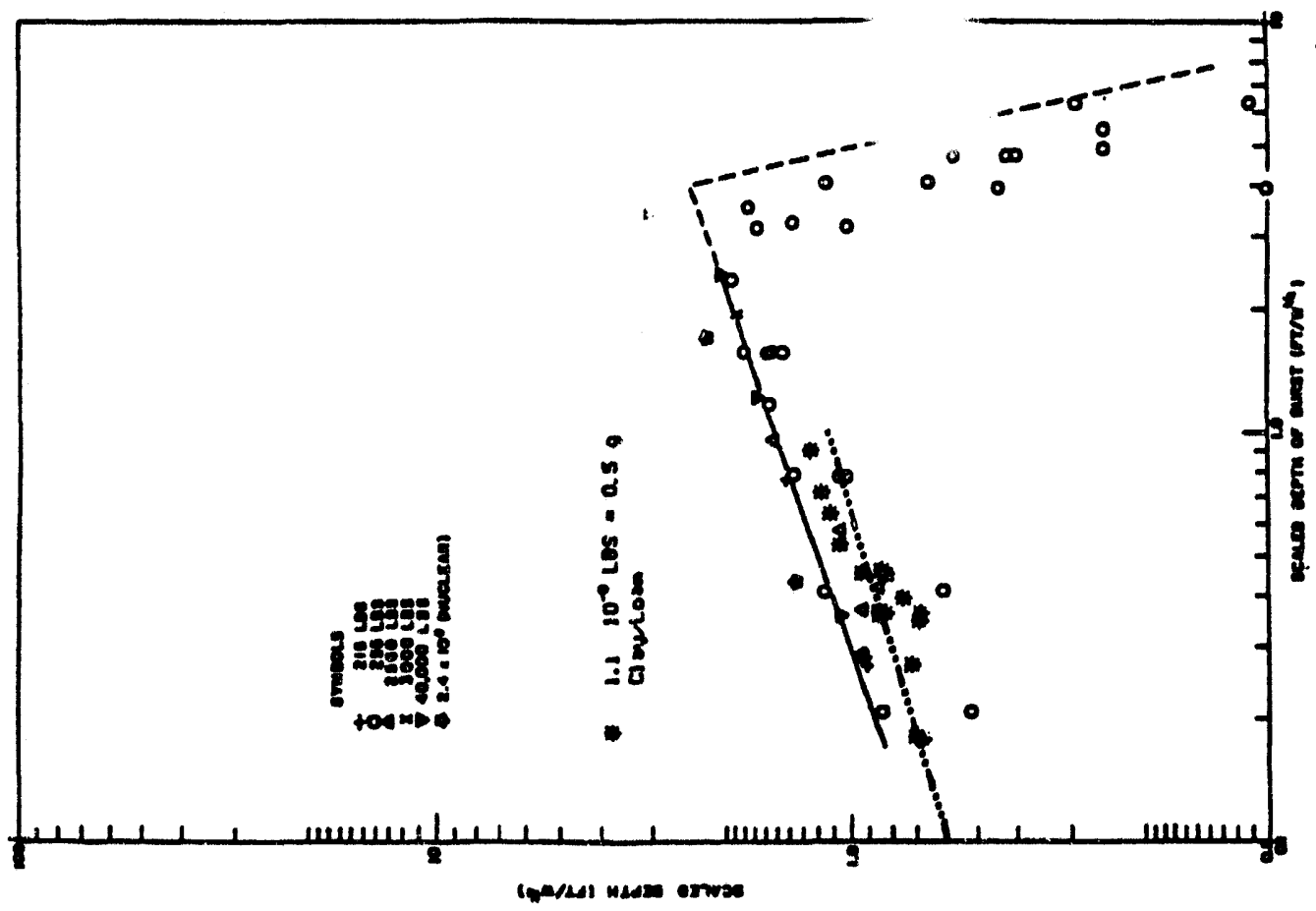

s.

흘

웡 过苋范

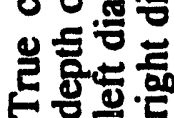



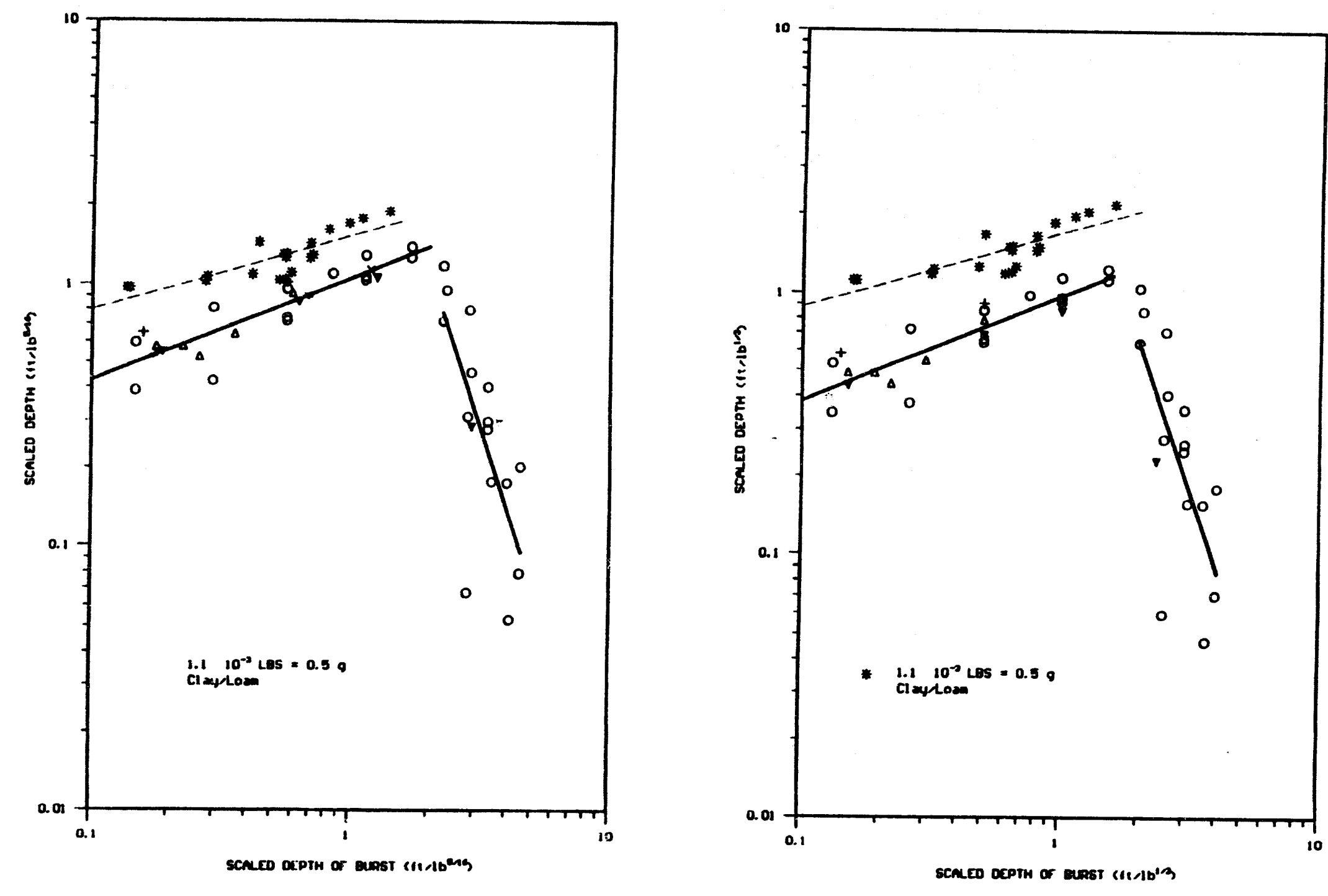

Figure 31 Continued.

left diagram:

right diagram: 

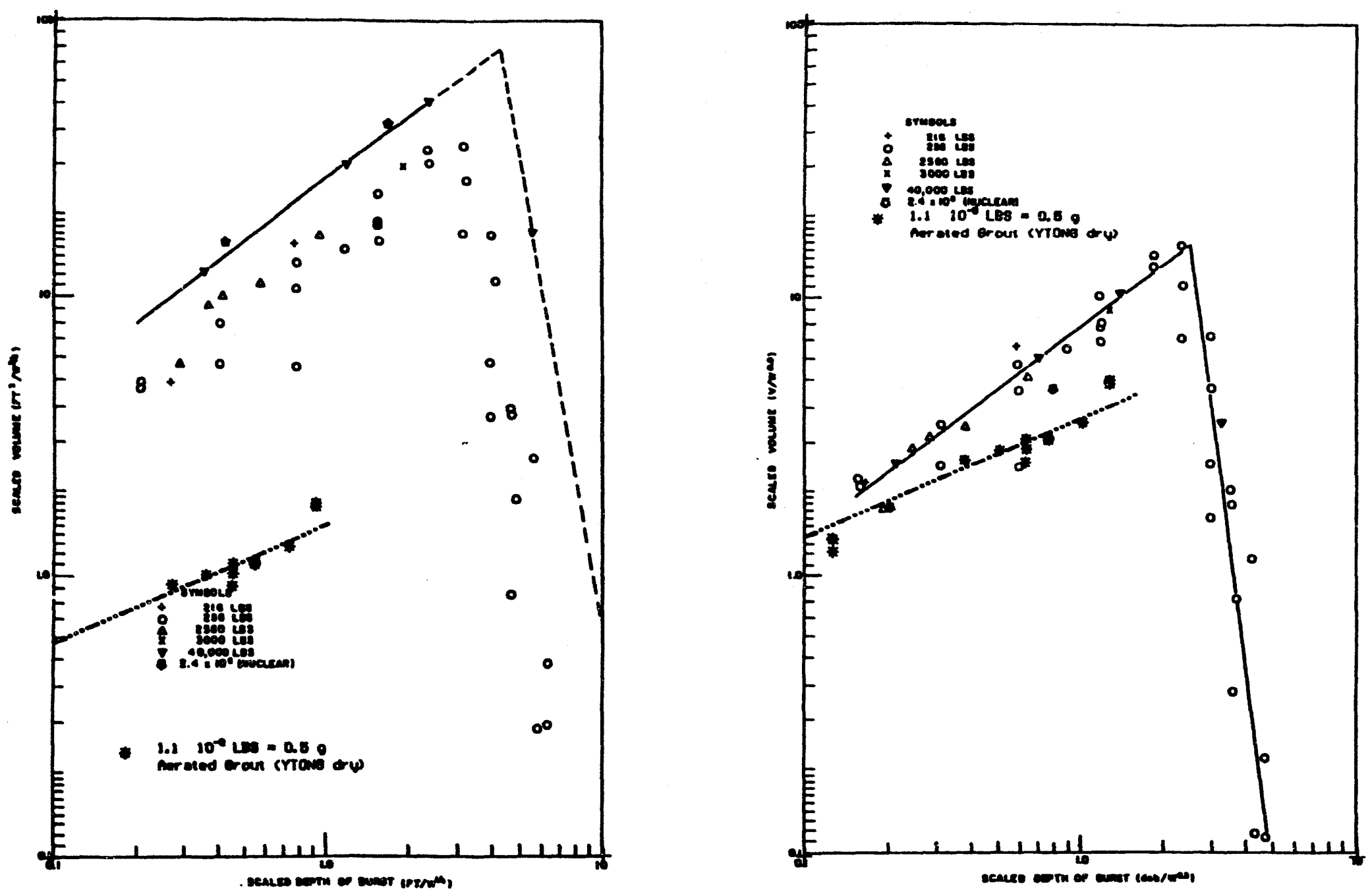

Figure 32 True crater volume vs DOB for dry YTONG compared with apparent crater volume of desert alluvium [12]

left diagram: $\quad W^{1 / 4}$-scaling

right diagram: $\quad$ W $^{0.3}$-scaling 

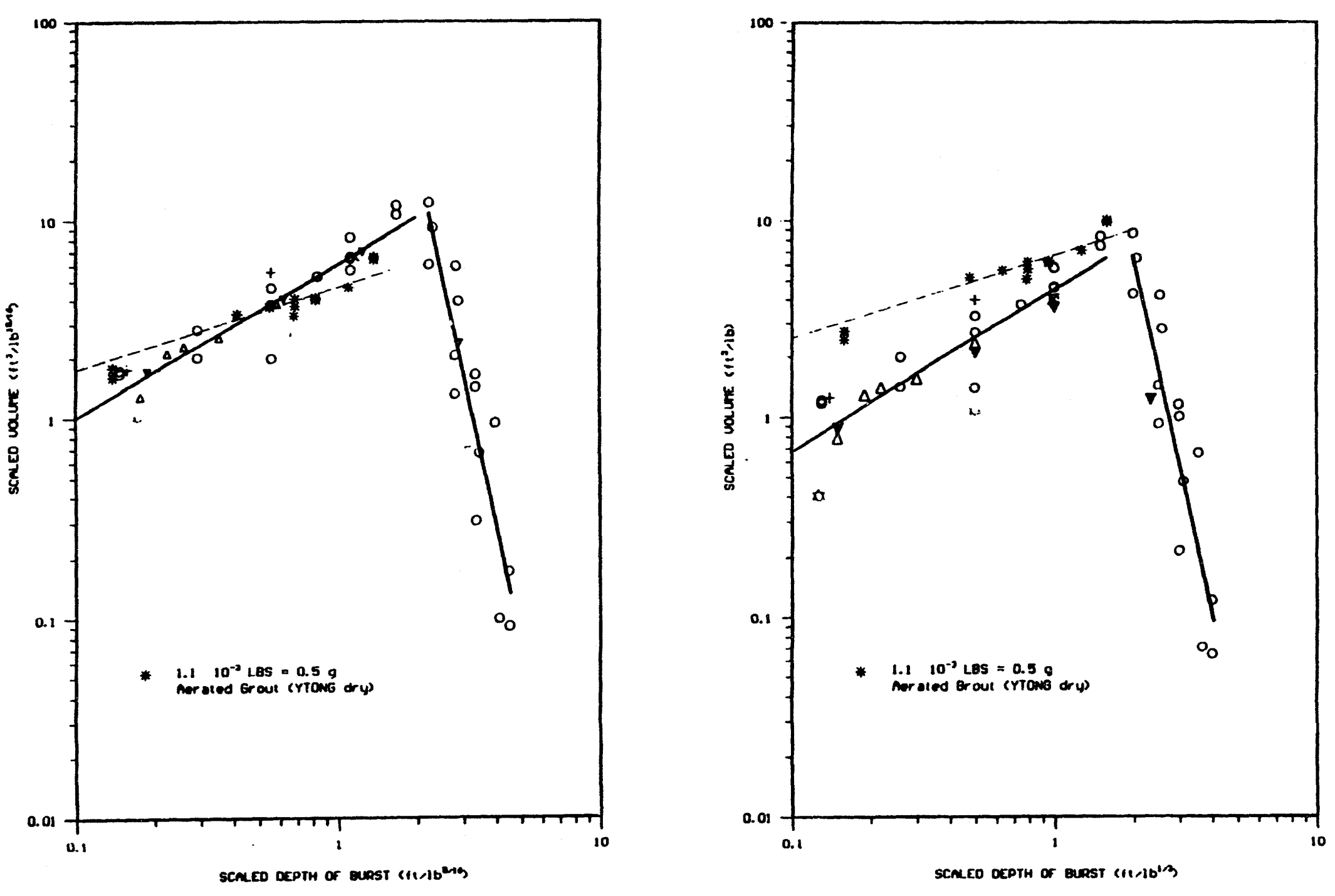

Figure 32 Continued.

left diagram: $\quad W^{5 / 16}$ scaling

right diagram: $\quad W^{1 / 3}$ scaling 

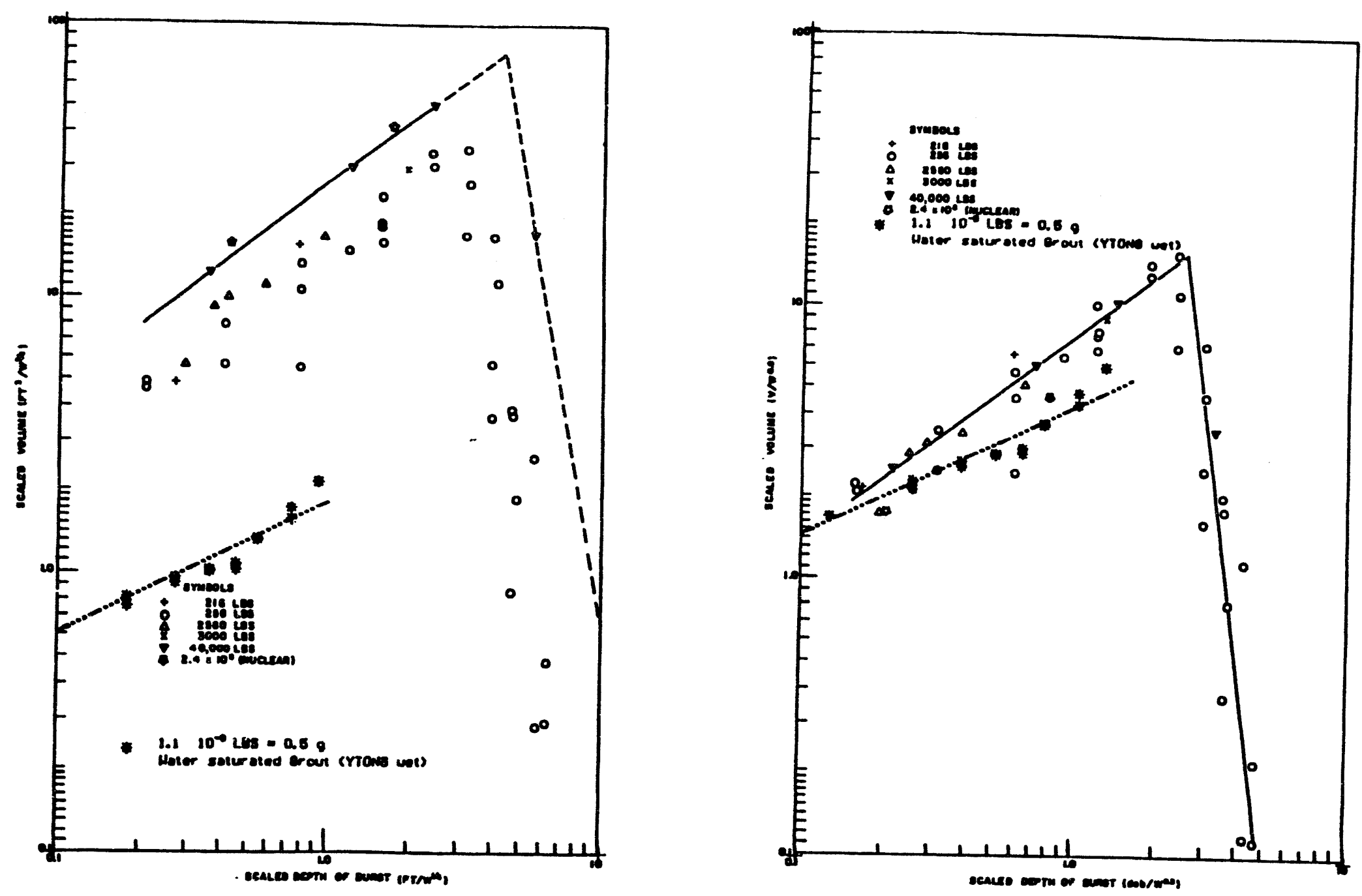

N

Figure 33

True crater volume vs DOB for wet YTONG compared with apparent crater volume of desert alluvium [12]

left diagram:

right diagram:

W1/4-scaling
W0.3-scaling 

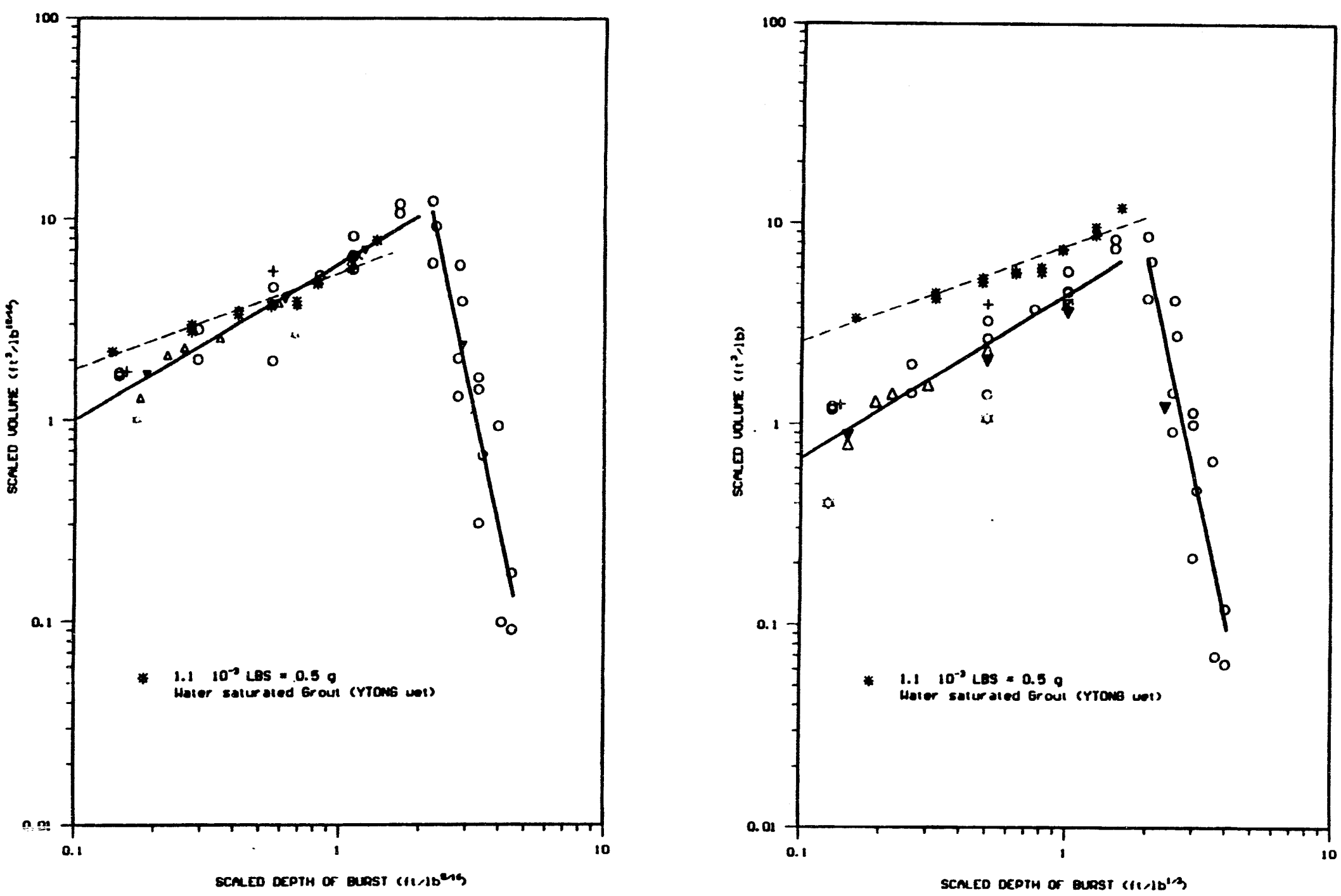

Figure 33 Continued.

left diagram:

right diagram: 

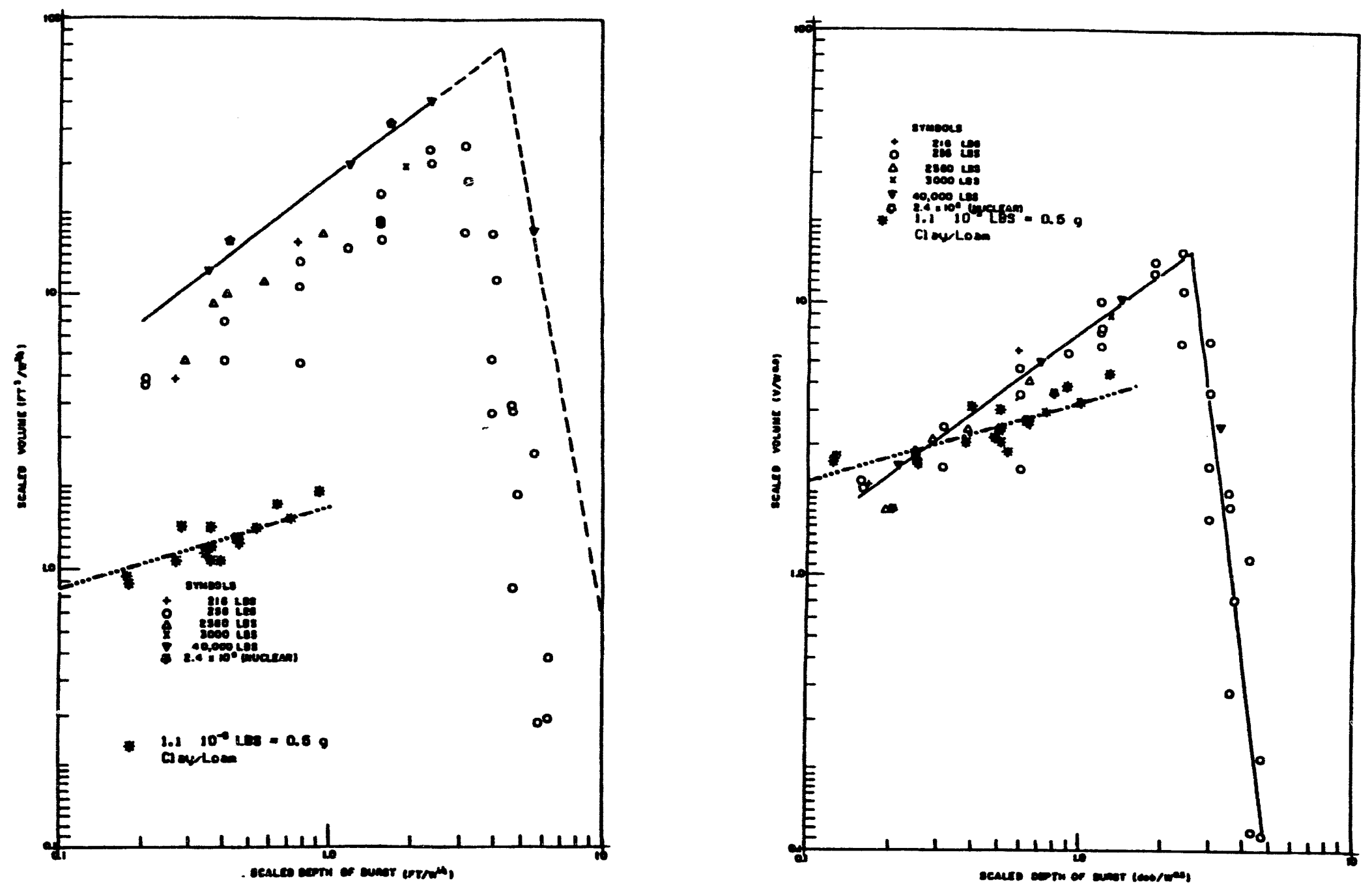

Figure 34 True crater volume for DOB at clay/loam compared with apparent crater volume of desert alluvium [12]

left diagram:

right diagram:

Wiriscaling

W0.3-scaling 


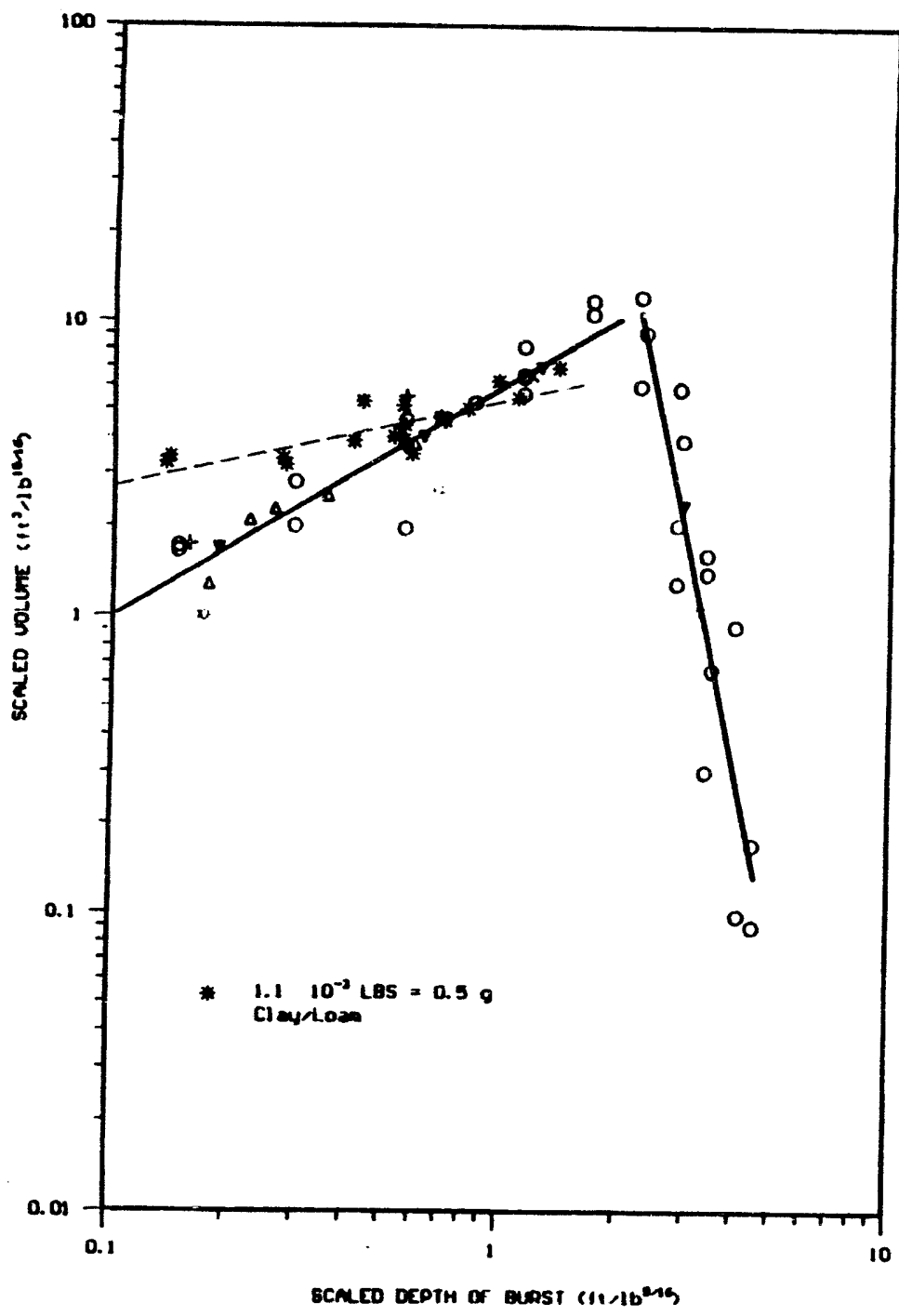

Figure 34 Continued.

left diagram:

right diagram:

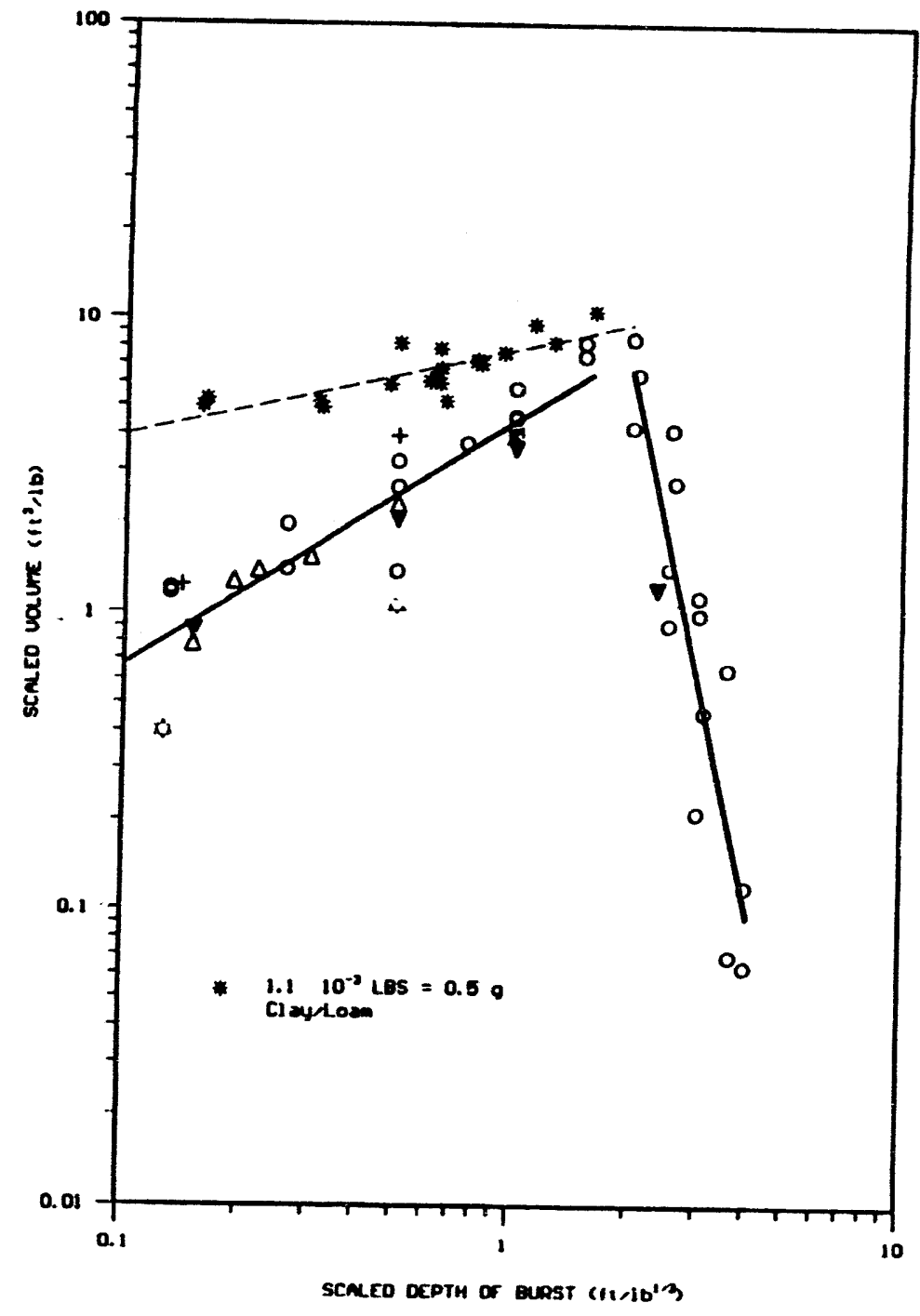

जับ 


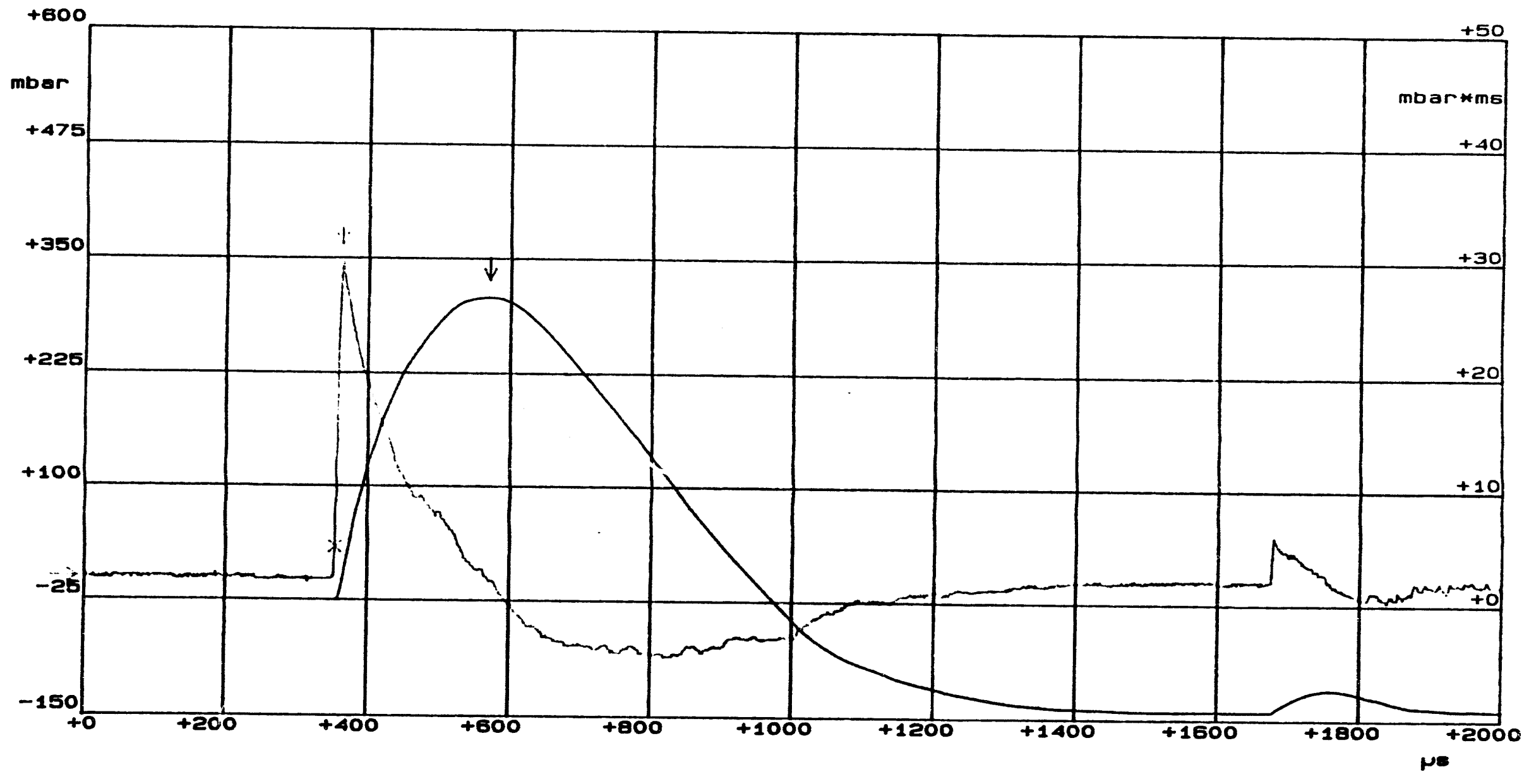

$071704 . \mathrm{KMM} / \mathrm{Gg} / \mathrm{NV}$

Mk 4 1bar/V an LVer

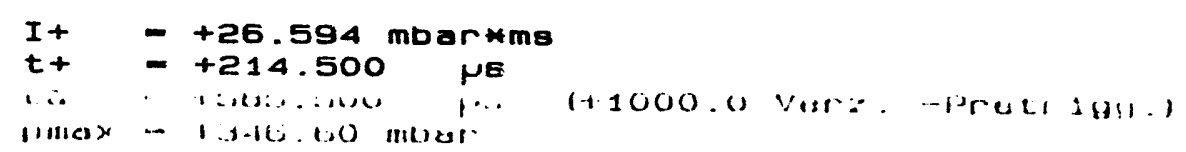

Figure 35 Examiple of a pressure-time record.

$\mathrm{DOB}=1.0 \mathrm{~cm} \quad$ Distance from GZ: $27 \mathrm{~cm}$

Soil Inaterial: dry aerated grout (dry YTONG)

Test No.: 717/4

Peak overpressure, time of arrival, positive phase duration and positive impulse resp. are recorded. 

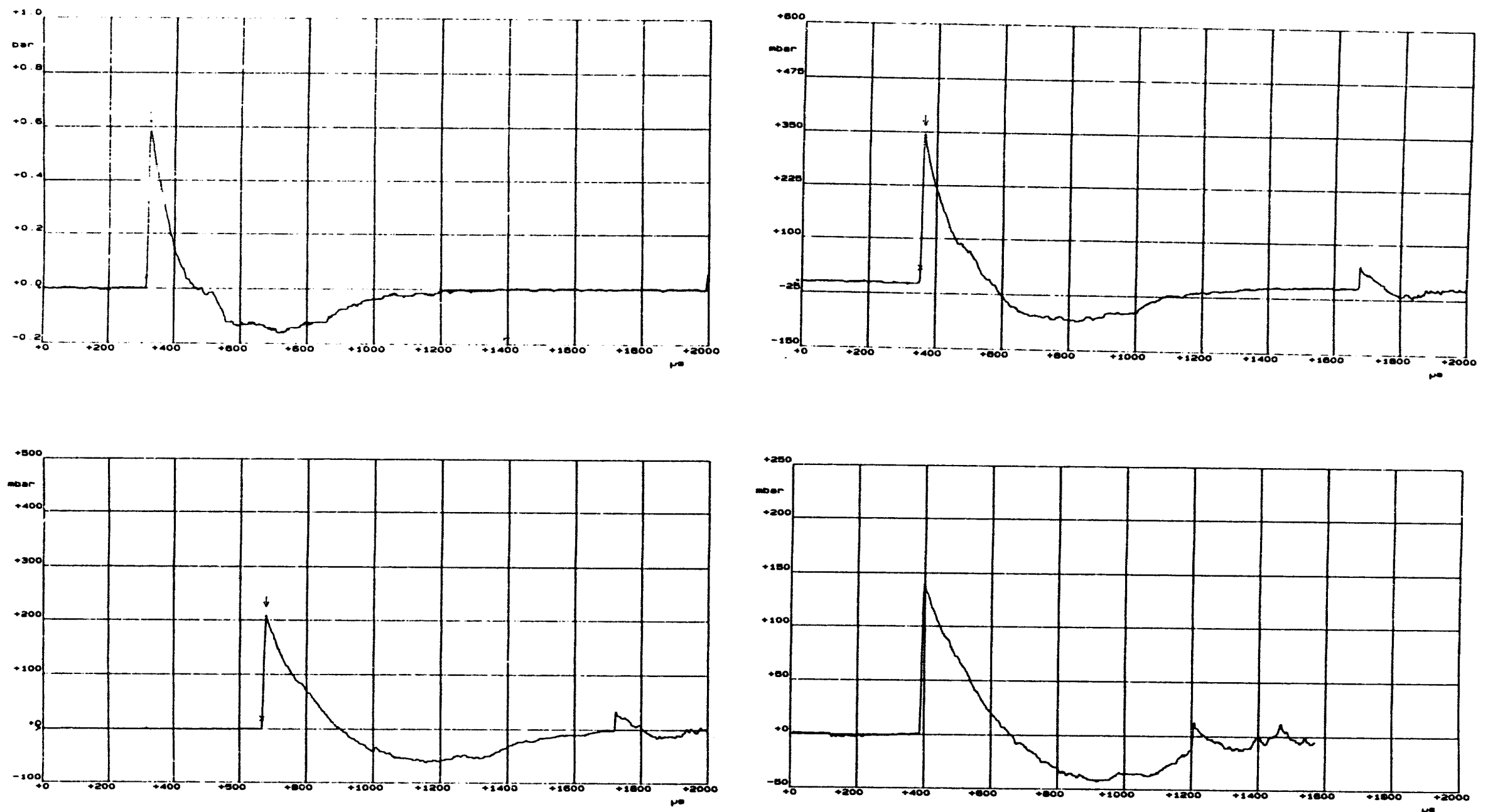

Figure 36 Comparison of pressure-time records at various distances

Charge weight: $0.5 \mathrm{~g}$

Distance from GZ

$15 \mathrm{~cm}\left(1.89 \mathrm{~m} / \mathrm{kg}^{1 / 3}\right) ; 27 \mathrm{~cm}\left(3.40 \mathrm{~m} / \mathrm{kg}^{1 / 3}\right)$

$39 \mathrm{~cm}\left(4.91 \mathrm{~m} / \mathrm{kg}^{1 / 3}\right) ; 57 \mathrm{~cm}\left(7.18 \mathrm{~m} / \mathrm{kg}^{1 / 3}\right)$

Soil material: dry aerated grout (dry YTONG)

DOB: $1 \mathrm{~cm}\left(0.126 \mathrm{~m} / \mathrm{kg}^{1 / 3}\right)$

Test No.: 717/2; 717/4; 717/6; 717/9 

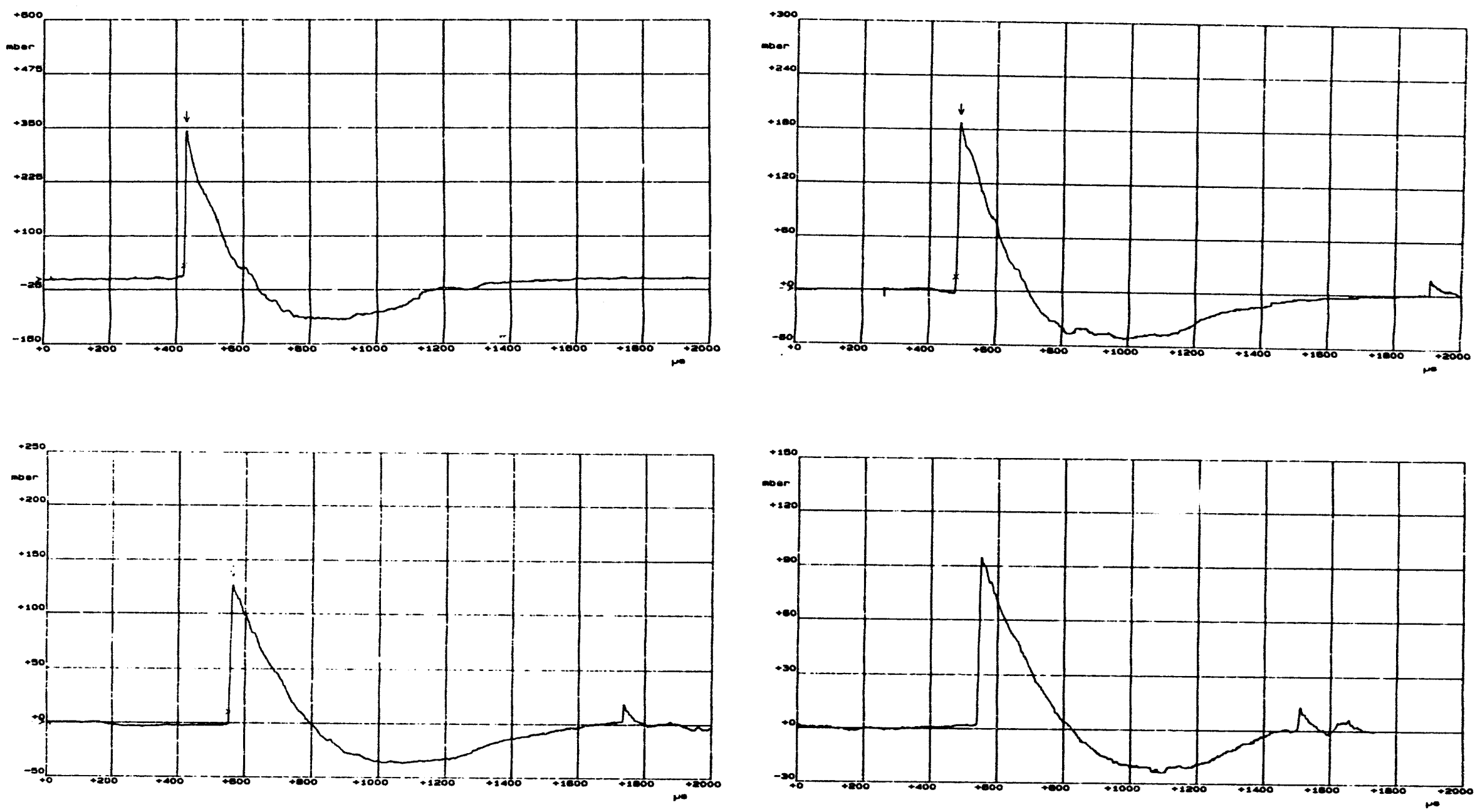

\section{Figure 36 Continued:}

DOB: $2 \mathrm{~cm}\left(0.252 \mathrm{~m} / \mathrm{kg}^{1 / 3}\right)$

Test No.: 719/2; 719/4; 719/6; 719/9 

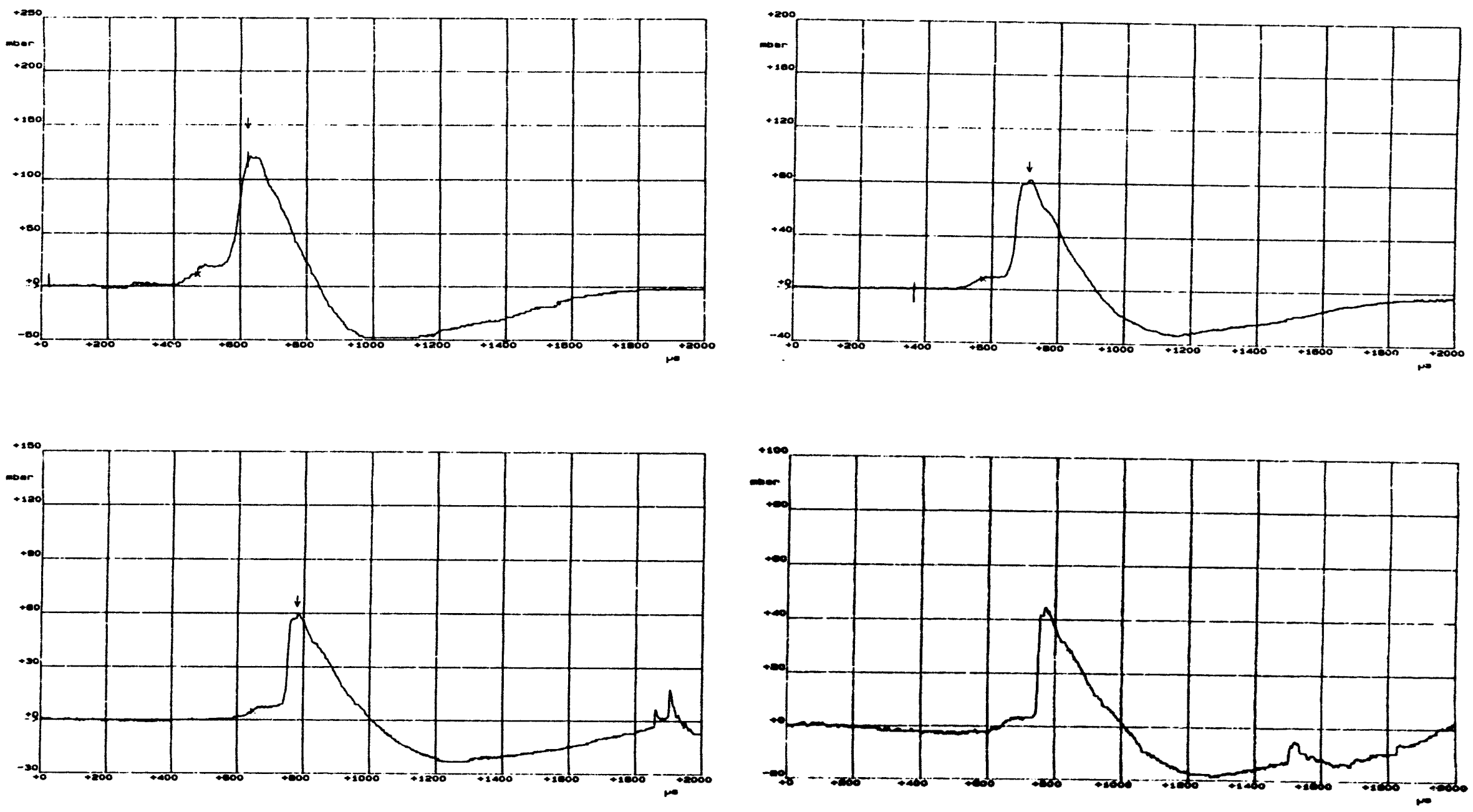

Figure 36

Concluded:

DOB: $3 \mathrm{~cm}\left(0.378 \mathrm{~m} / \mathrm{kg}^{\mathrm{I} / 3}\right)$

Test No.: 720/2; 720/4; 720/6; 720/9 
$D O B=1 \mathrm{~cm}$

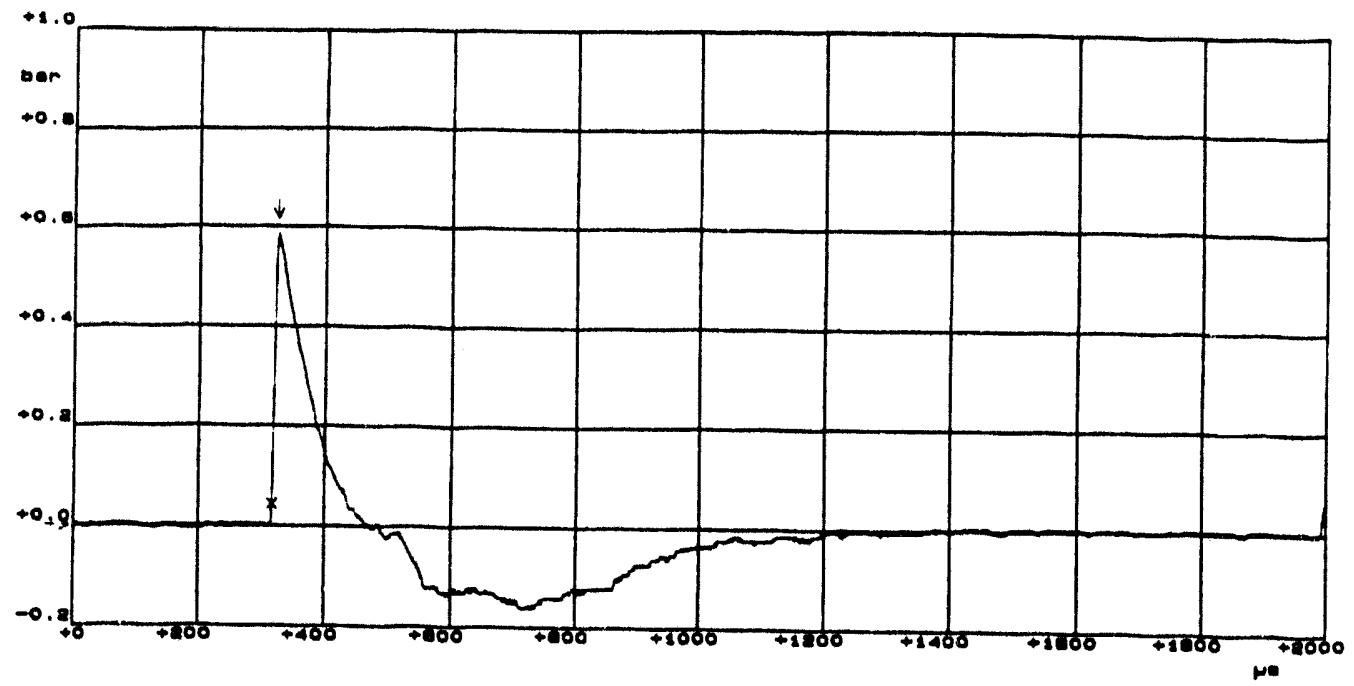

$2 \mathrm{~cm}$
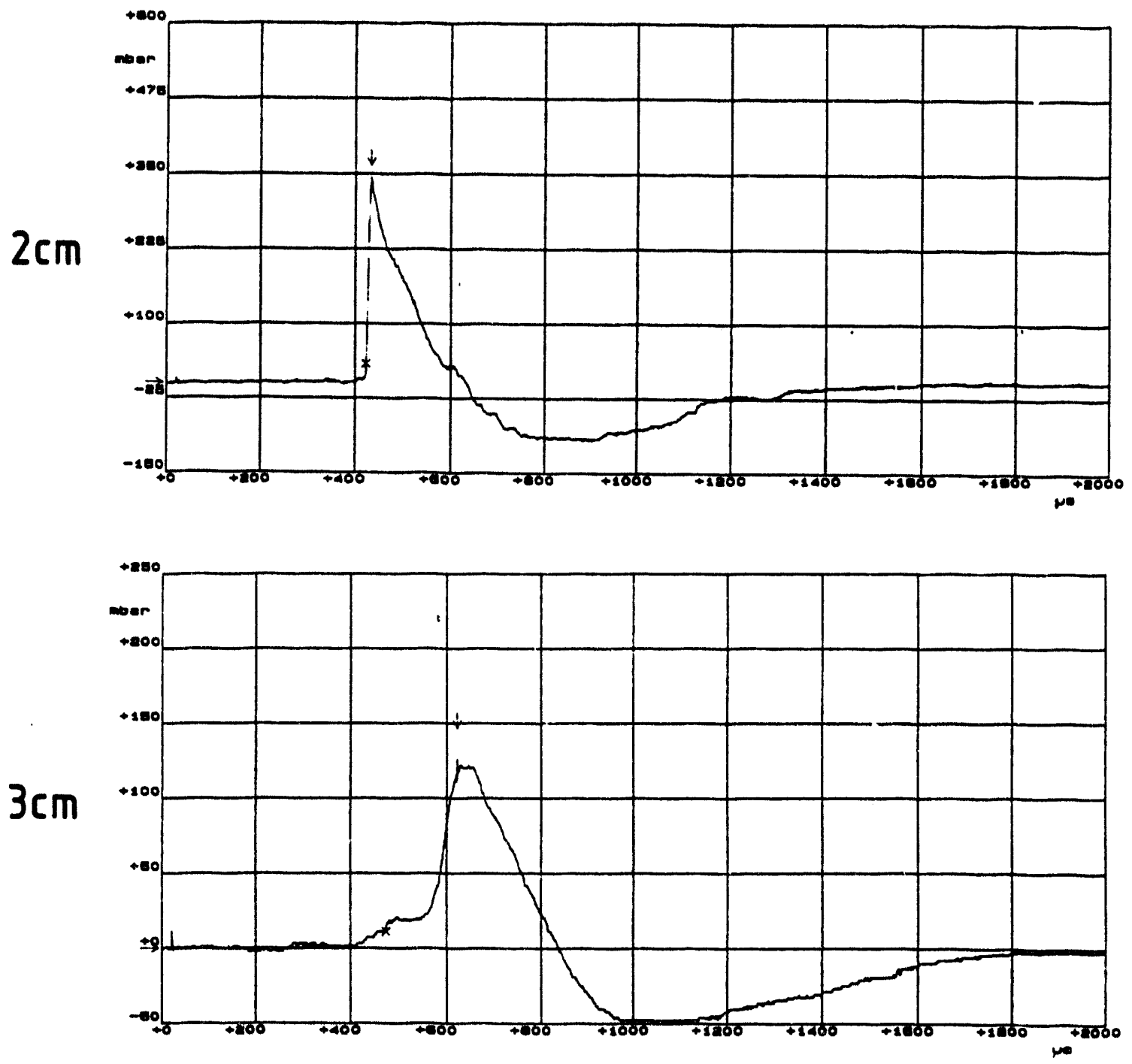

Figure 37 Comparison of pressure-time records at different DOB Soil material: dry aerated grout (dry YTONG)

Distance from GZ $\quad 15 \mathrm{~cm}\left(1.89 \mathrm{~m} / \mathrm{kg}^{1 / 3}\right)$

Test No.: 717/2; 719/2; 720/2 

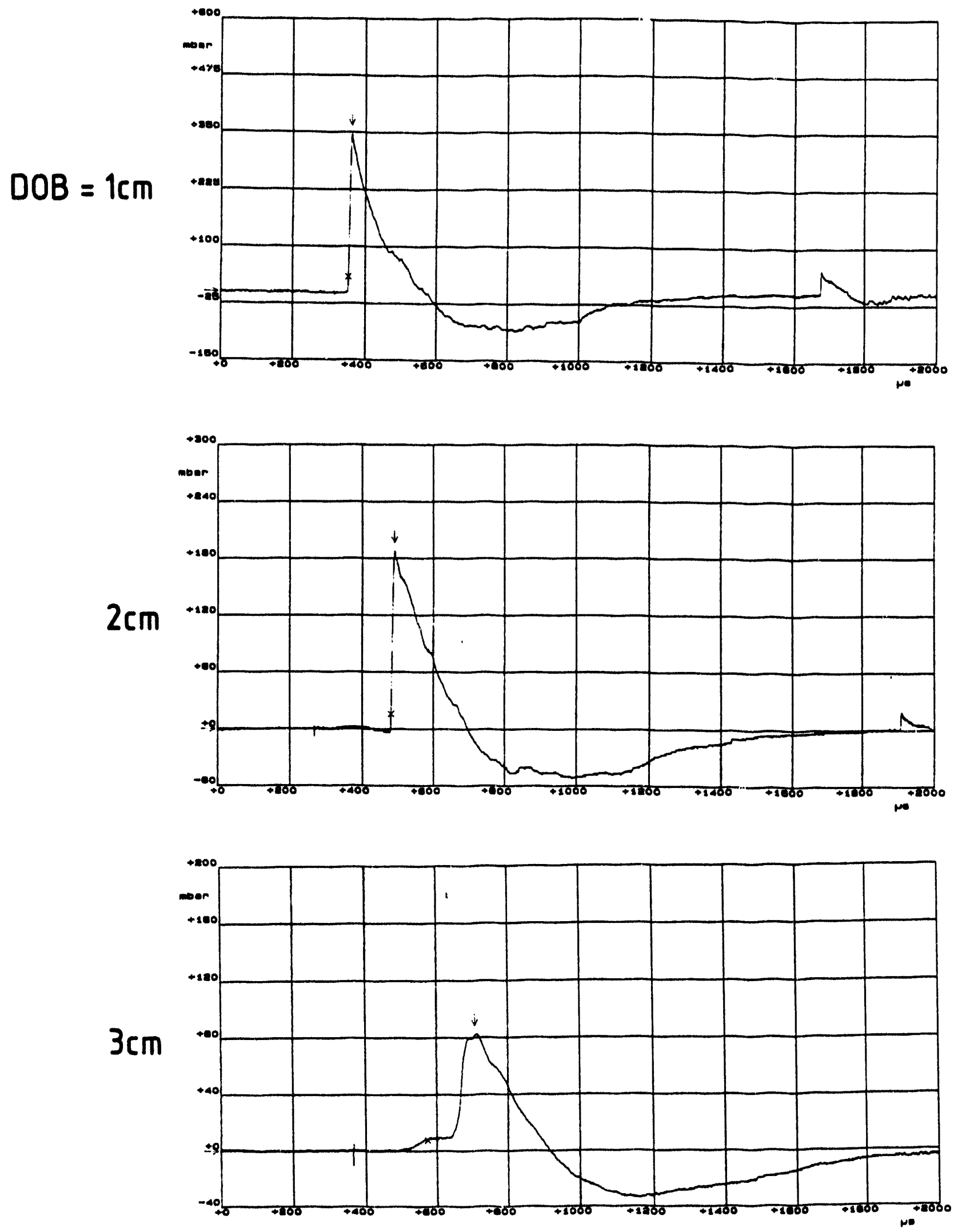

Figure 37 Continued:

Distance from GZ $27 \mathrm{~cm}\left(3.40 \mathrm{~m} / \mathrm{kg}^{1 / 3}\right)$

Test No.: $717 / 4 ; 719 / 4 ; 720 / 4$ 
i
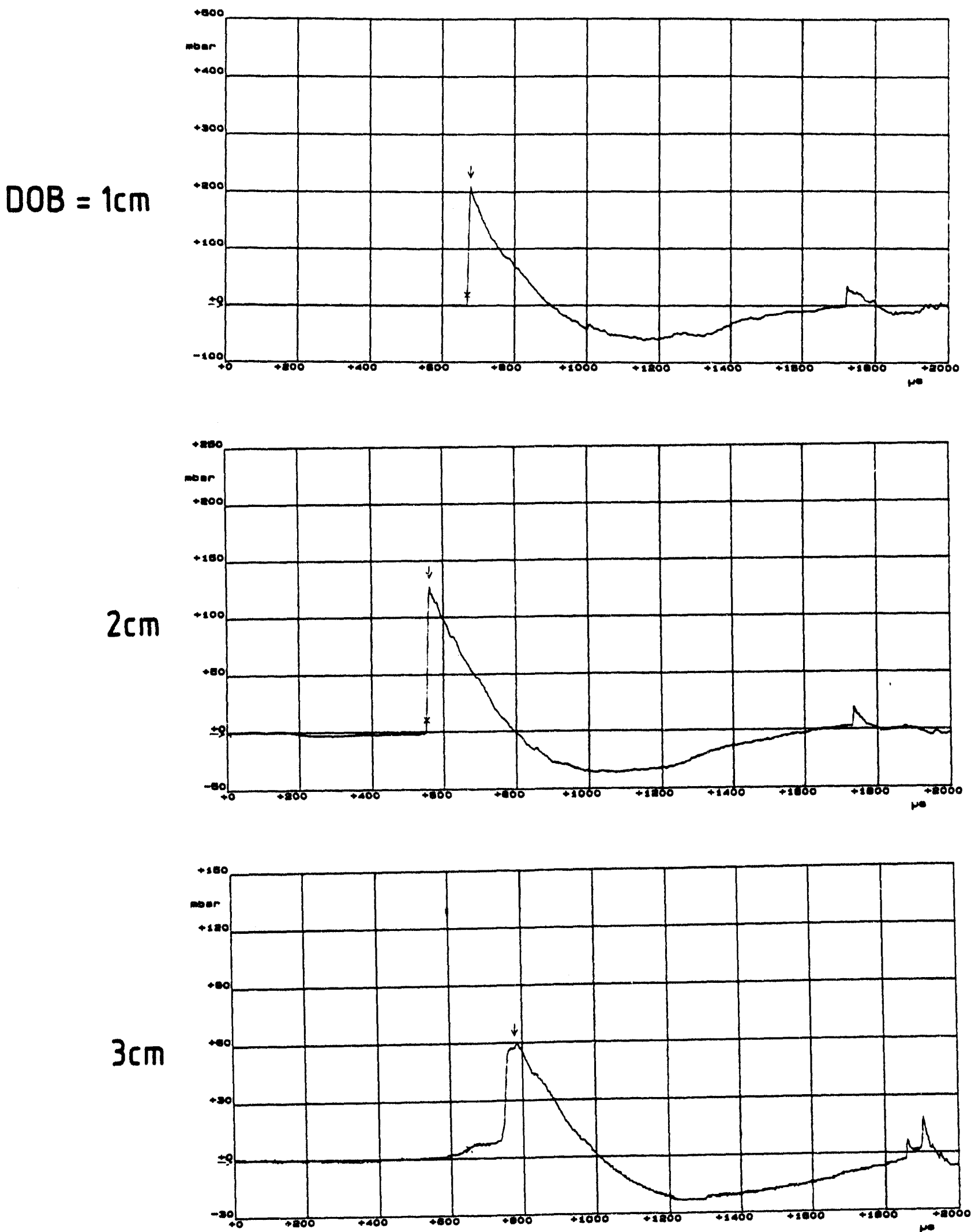

Figure 37 Continued:

Distance from G2 $39 \mathrm{~cm}\left(4.91 \mathrm{~m} / \mathrm{kg}^{1 / 3}\right)$

Test No.: $717 / 6 ; 719 / 6 ; 720 / 6$ 
$D O B=1 \mathrm{~cm}$

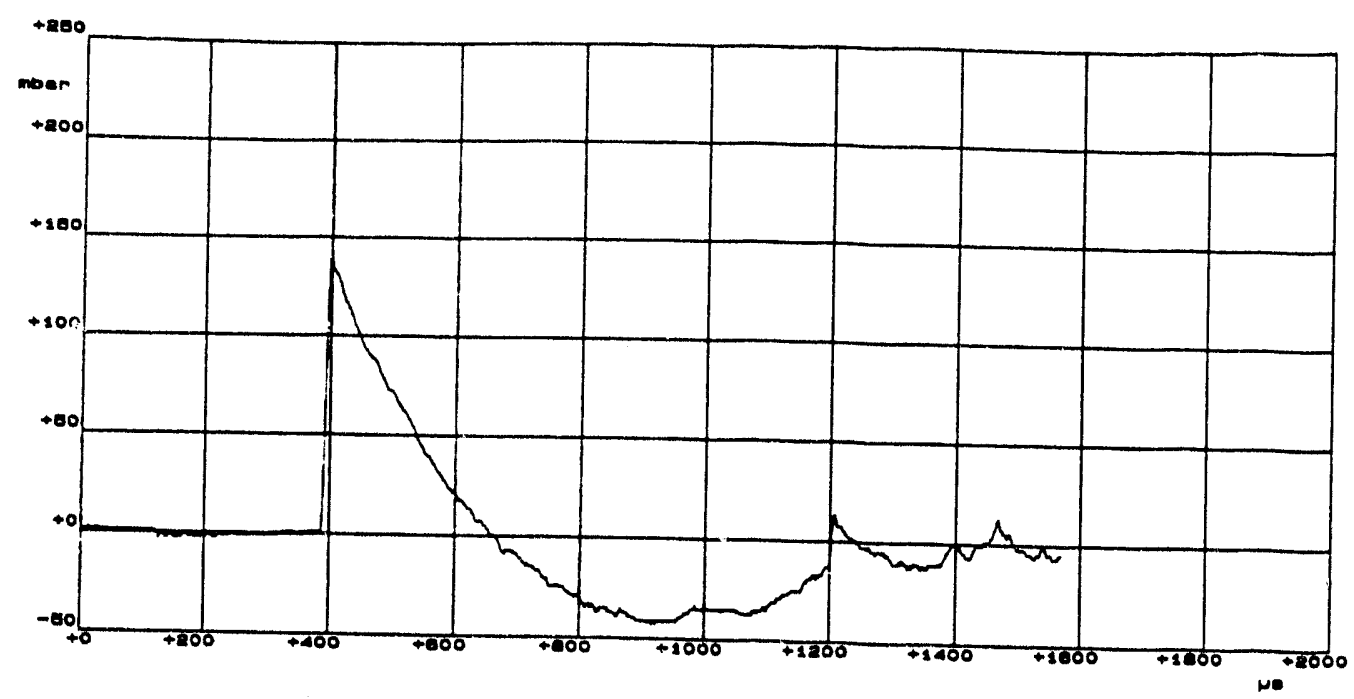

$2 \mathrm{~cm}$
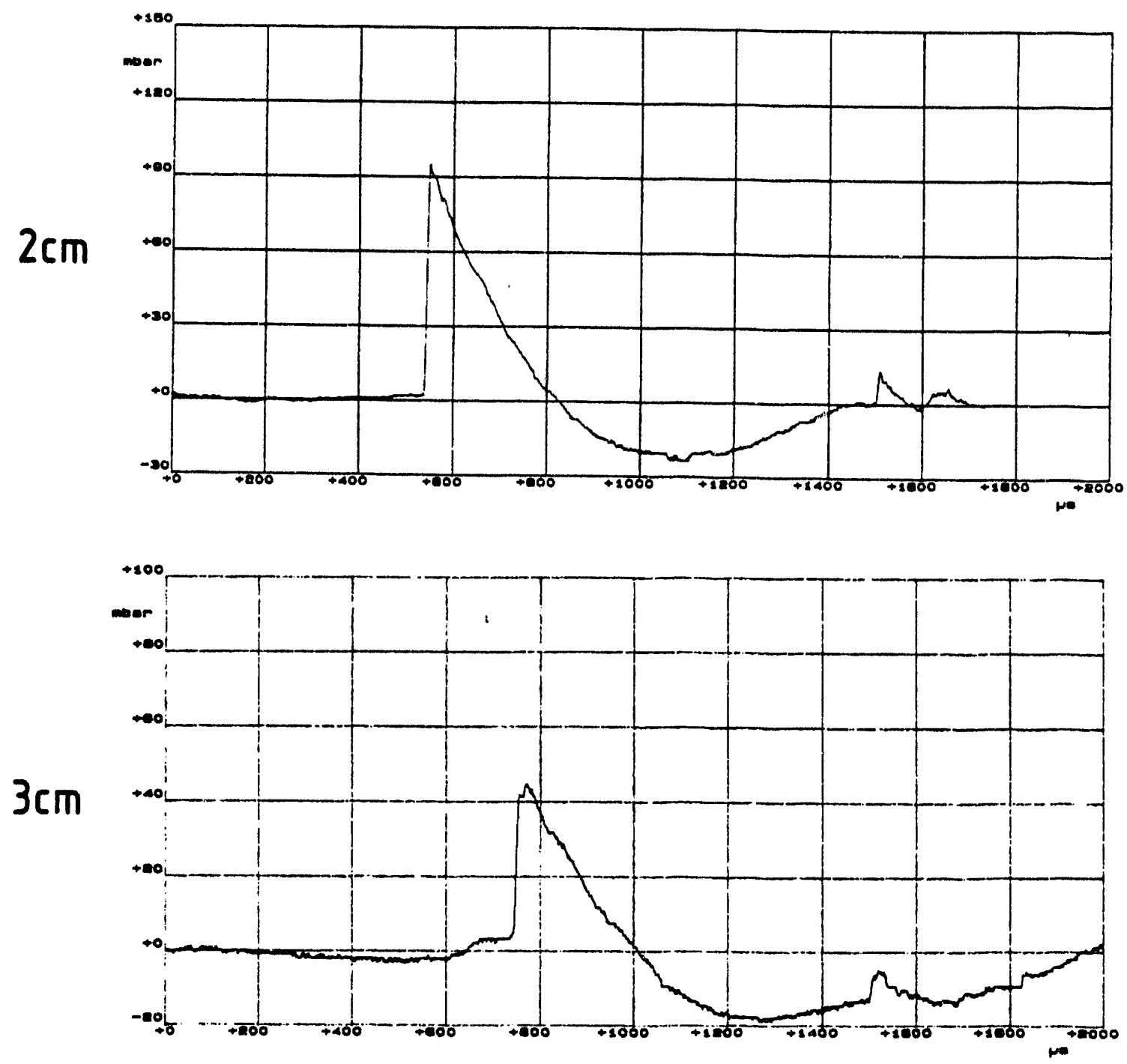

Figure 37 Concluded:

Distance from GZ $\quad 57 \mathrm{~cm}\left(7.18 \mathrm{~m} / \mathrm{kg}^{1 / 3}\right)$

Test No.: 717/9; 719/9; 720/9 

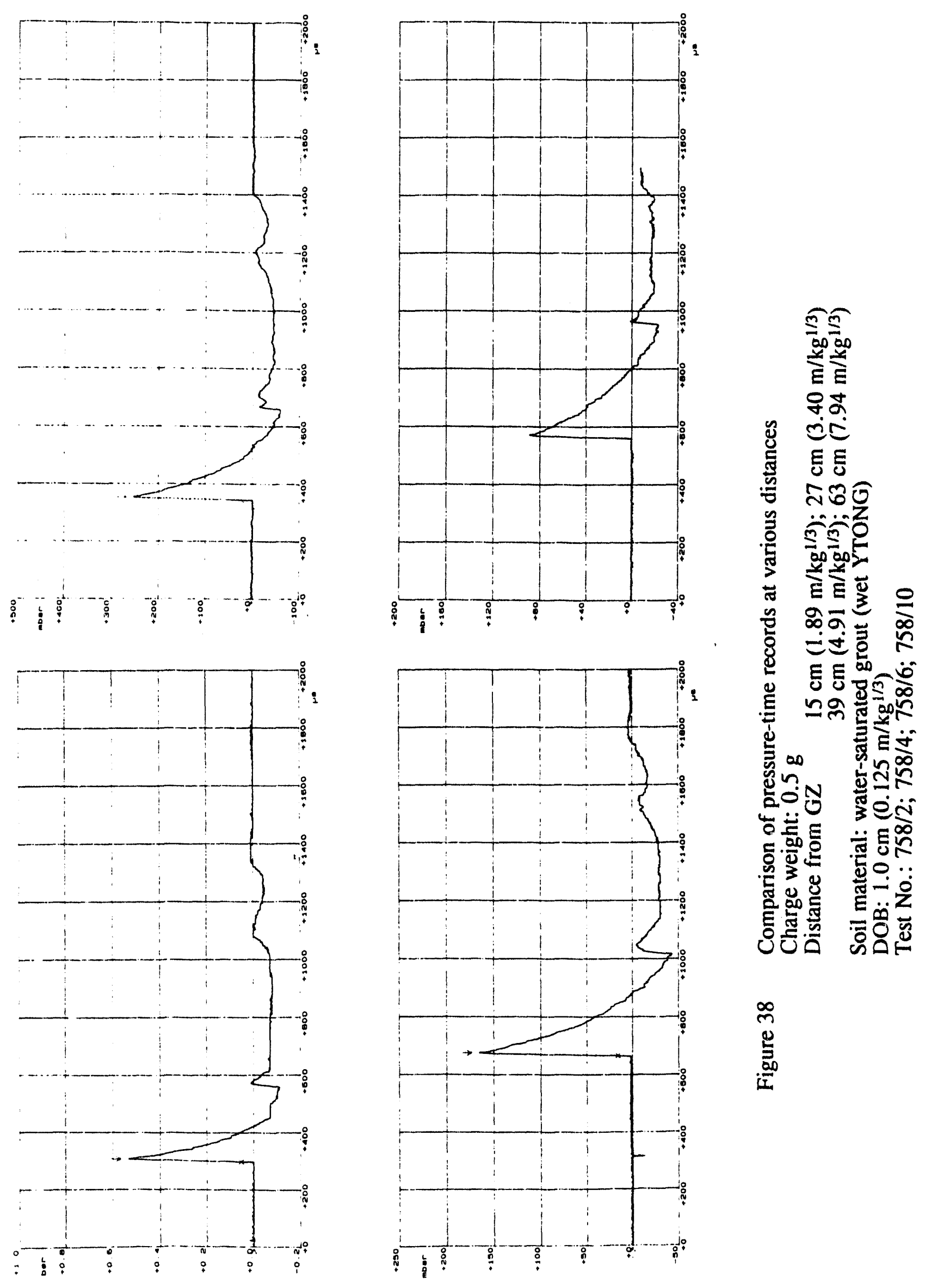

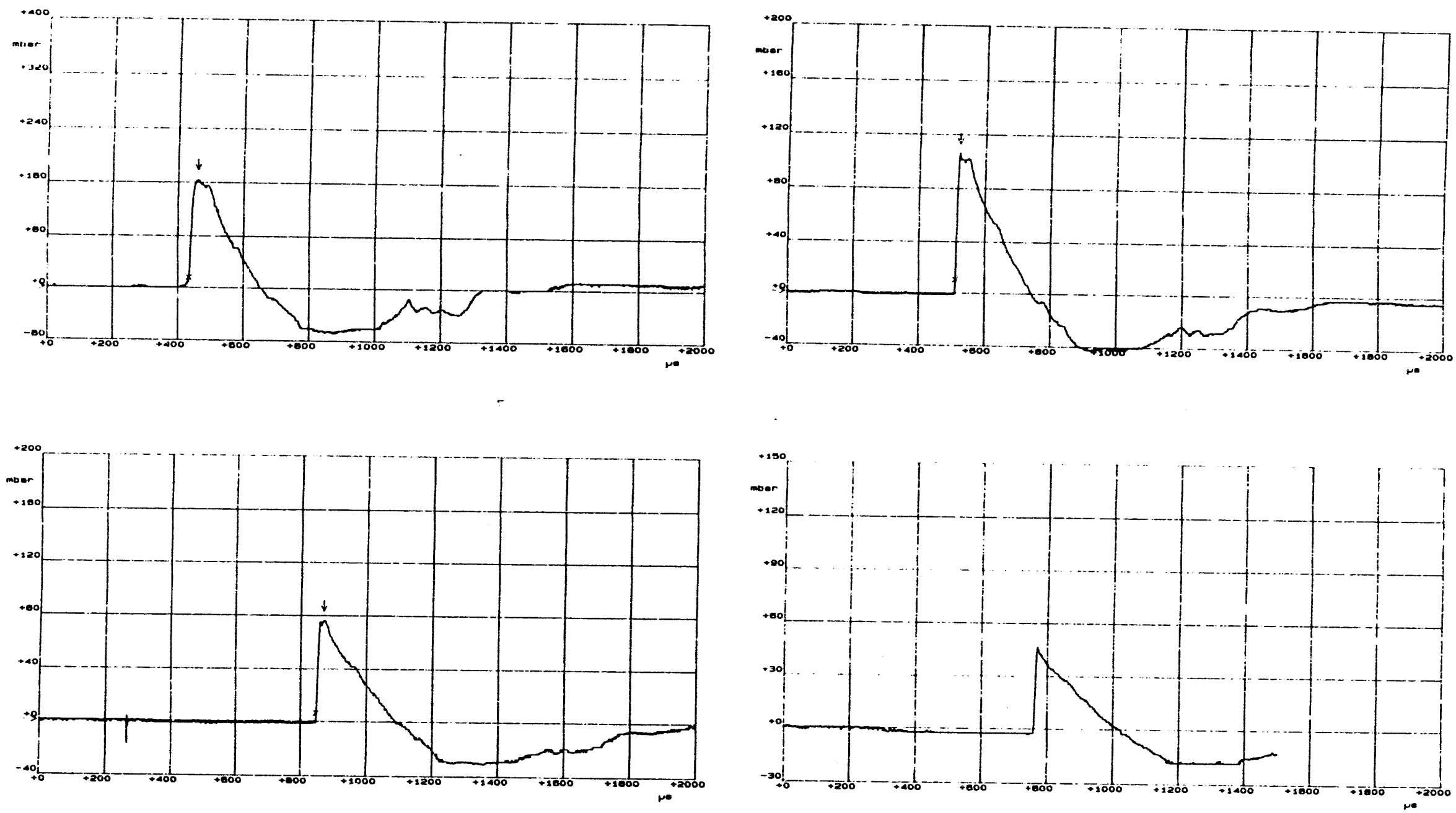

Figure 38

Continued:

DOB: $2.0 \mathrm{~cm}\left(0.252 \mathrm{~m} / \mathrm{kg}^{1 / 3}\right)$

Test No.: 789/2; 789/4; 789/6; 789/10 

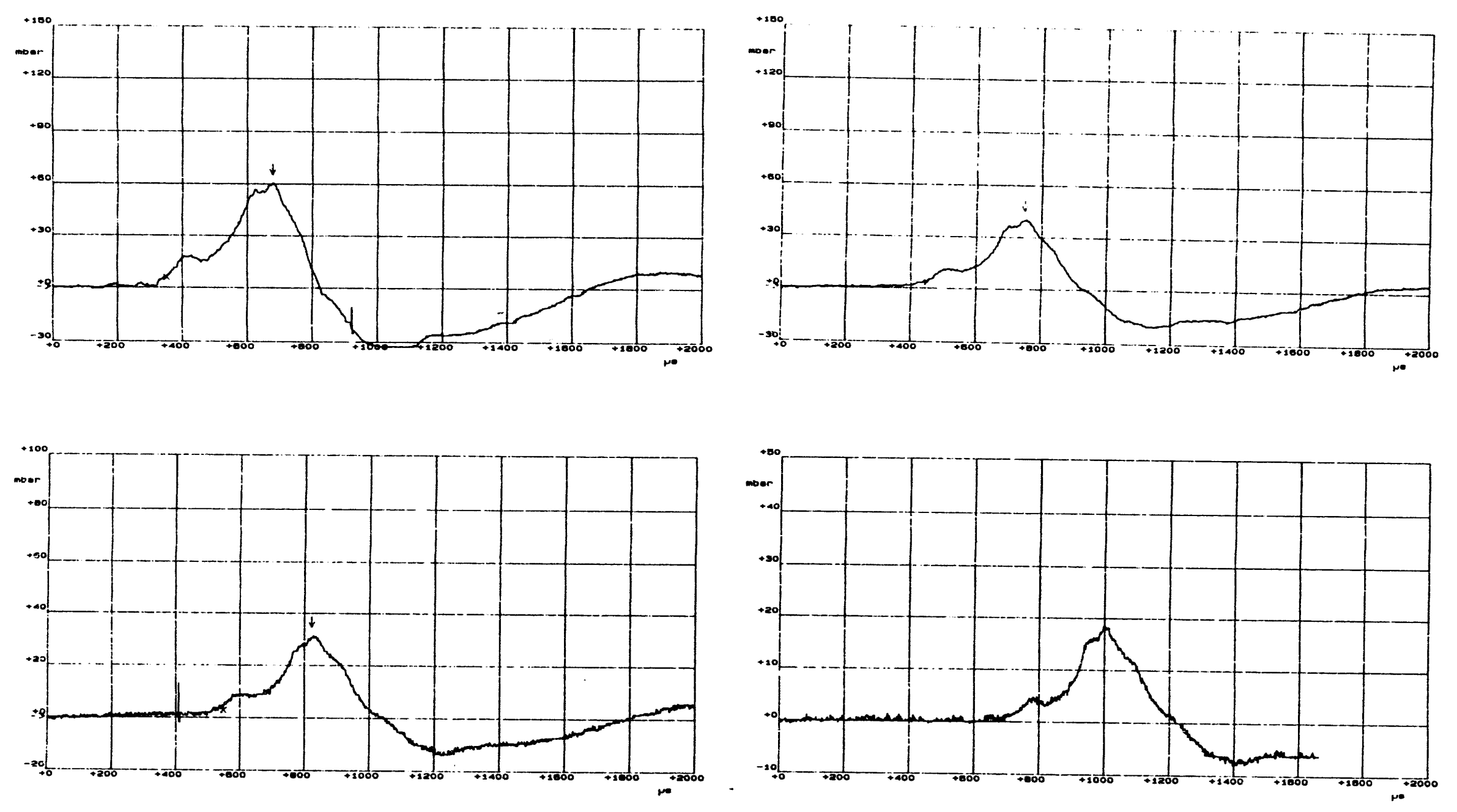

Figure 38 Concluded:

DOB: $3.0 \mathrm{~cm}\left(0.378 \mathrm{~m} / \mathrm{kg}^{1 / 3}\right)$

Test No.: 792/2; 792/4; 792/6; 792/10 

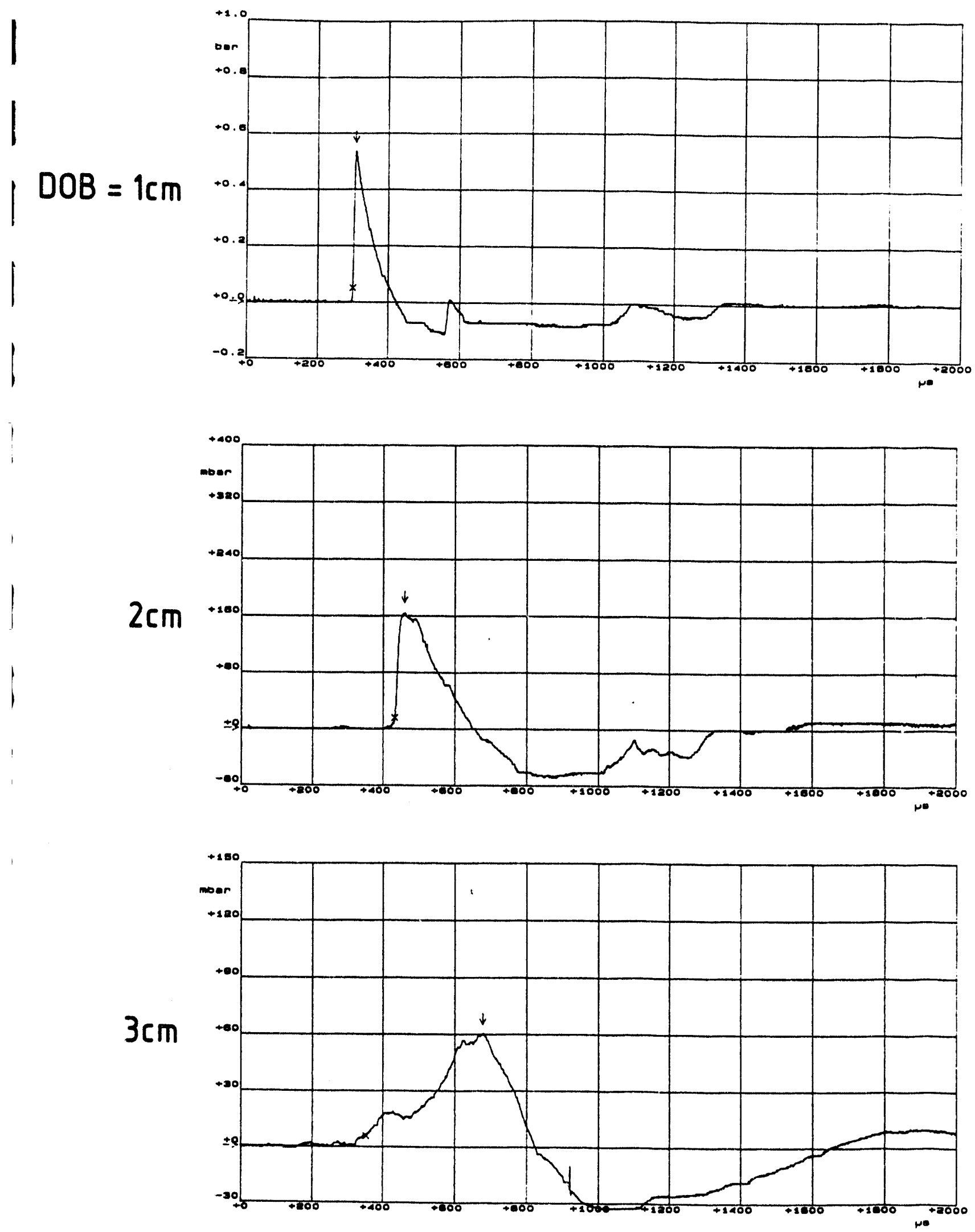

Figure 39 Comparison of pressure-time records at different DOB

Soil material: water saturated grout (wet YTONG)

Distance from GZ: $15 \mathrm{~cm}\left(1.89 \mathrm{~m} / \mathrm{kg}^{1 / 3}\right)$

Test No. 758/2; 789/2;792/2 

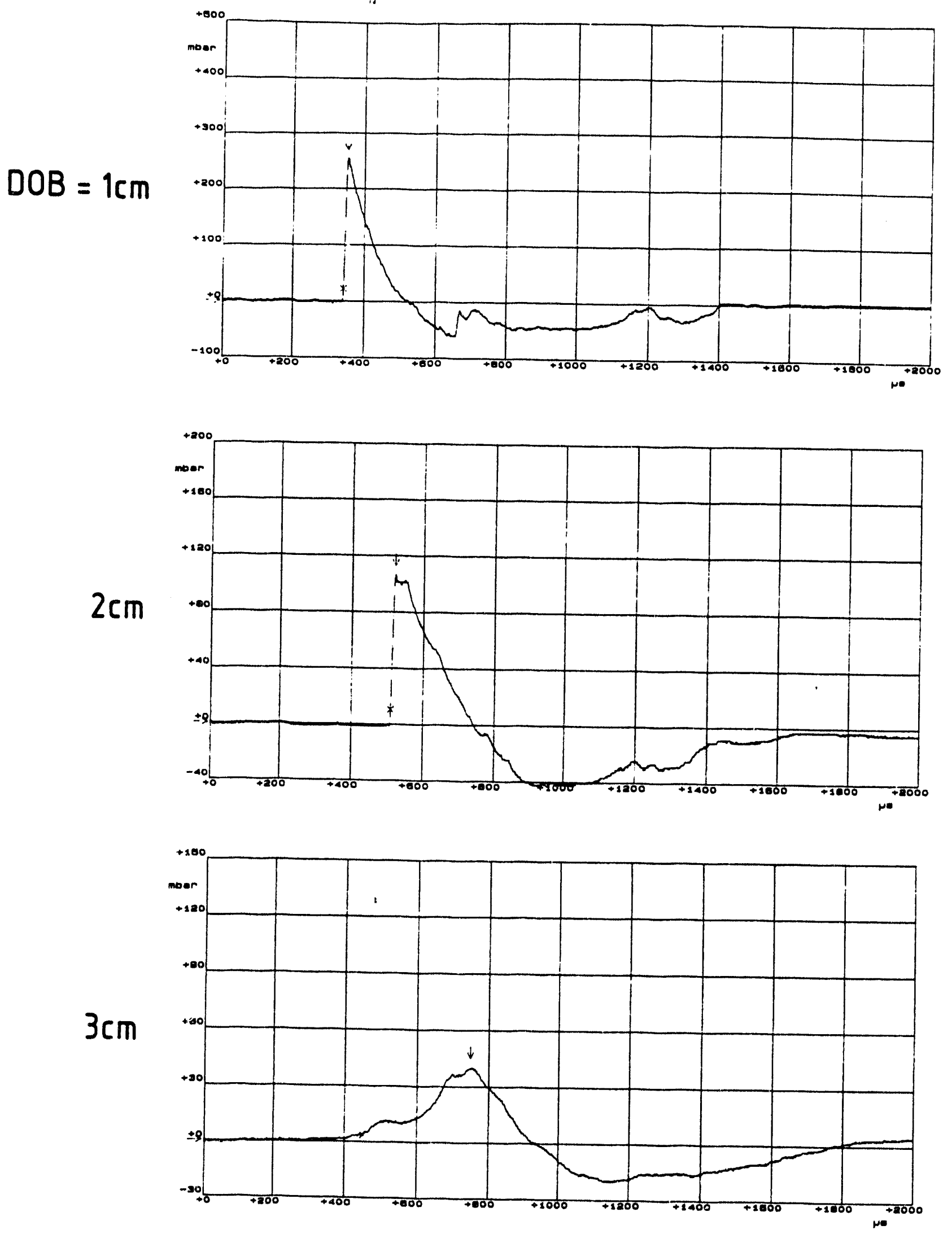

Figure 39 Continued:

Distance from GZ: $27 \mathrm{~cm}\left(3.40 \mathrm{~m} / \mathrm{kg}^{1 / 3}\right)$

Test No. 758/4; 789/4; 792/4 
$D O B=1 \mathrm{~cm}$
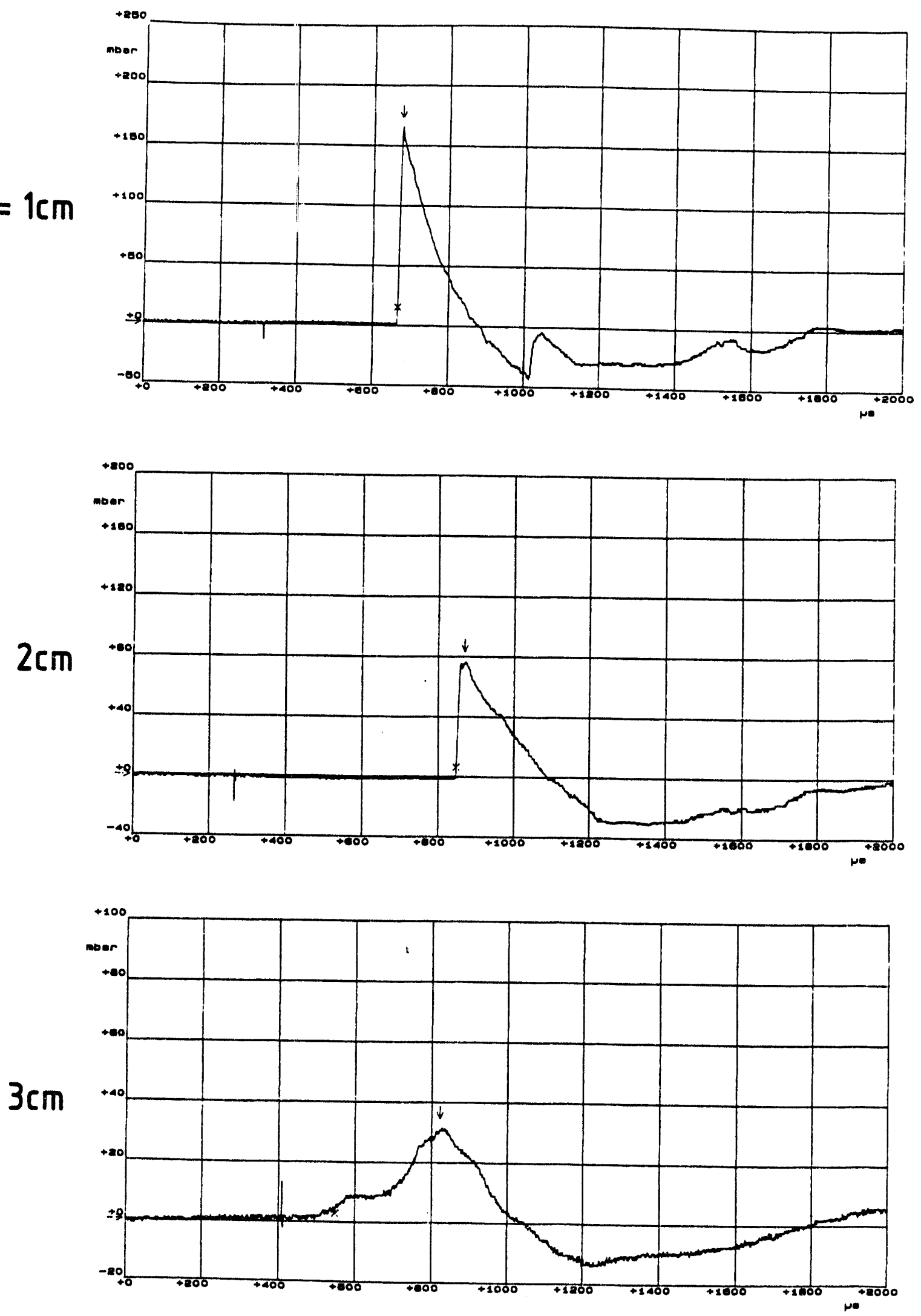

Figure 39 Continued:

Distance from GZ: $39 \mathrm{~cm}\left(4.91 \mathrm{~m} / \mathrm{kg}^{1 / 3}\right)$

Test No. 758/6; 789/6; 792/6 
$D O B=1 \mathrm{~cm}$

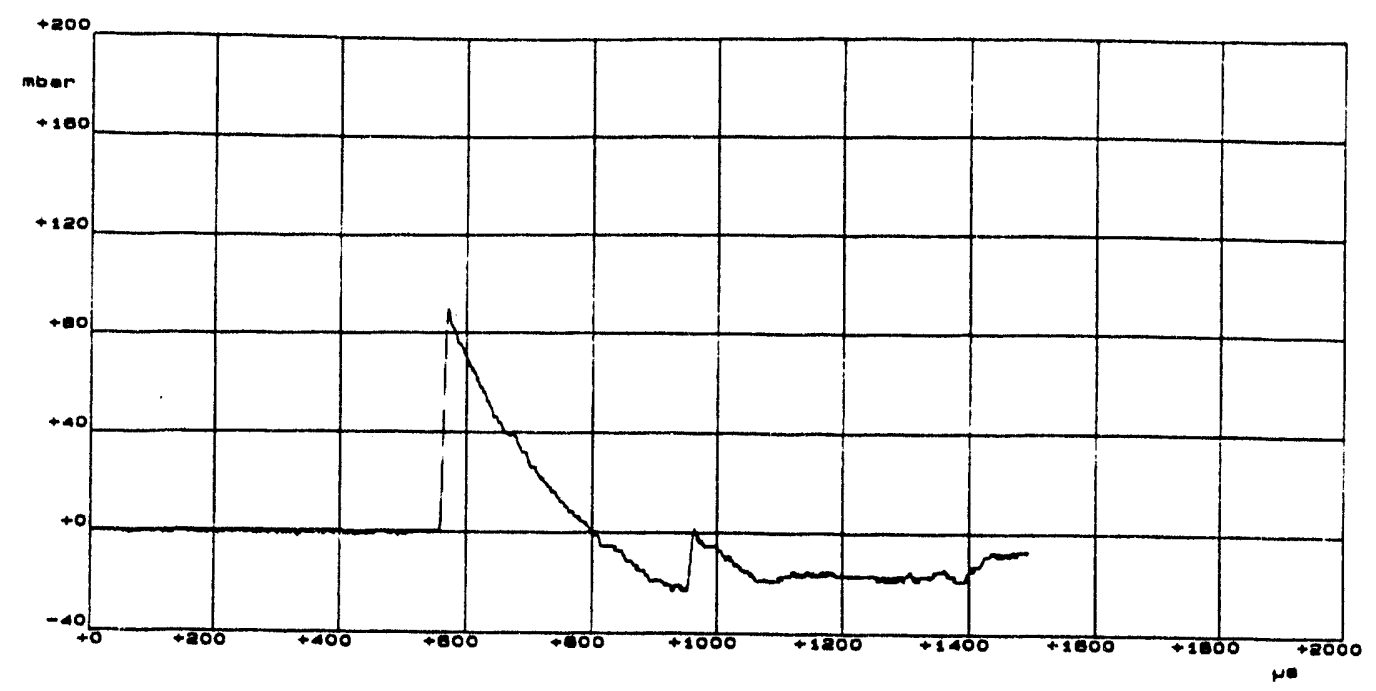

$2 \mathrm{~cm}$
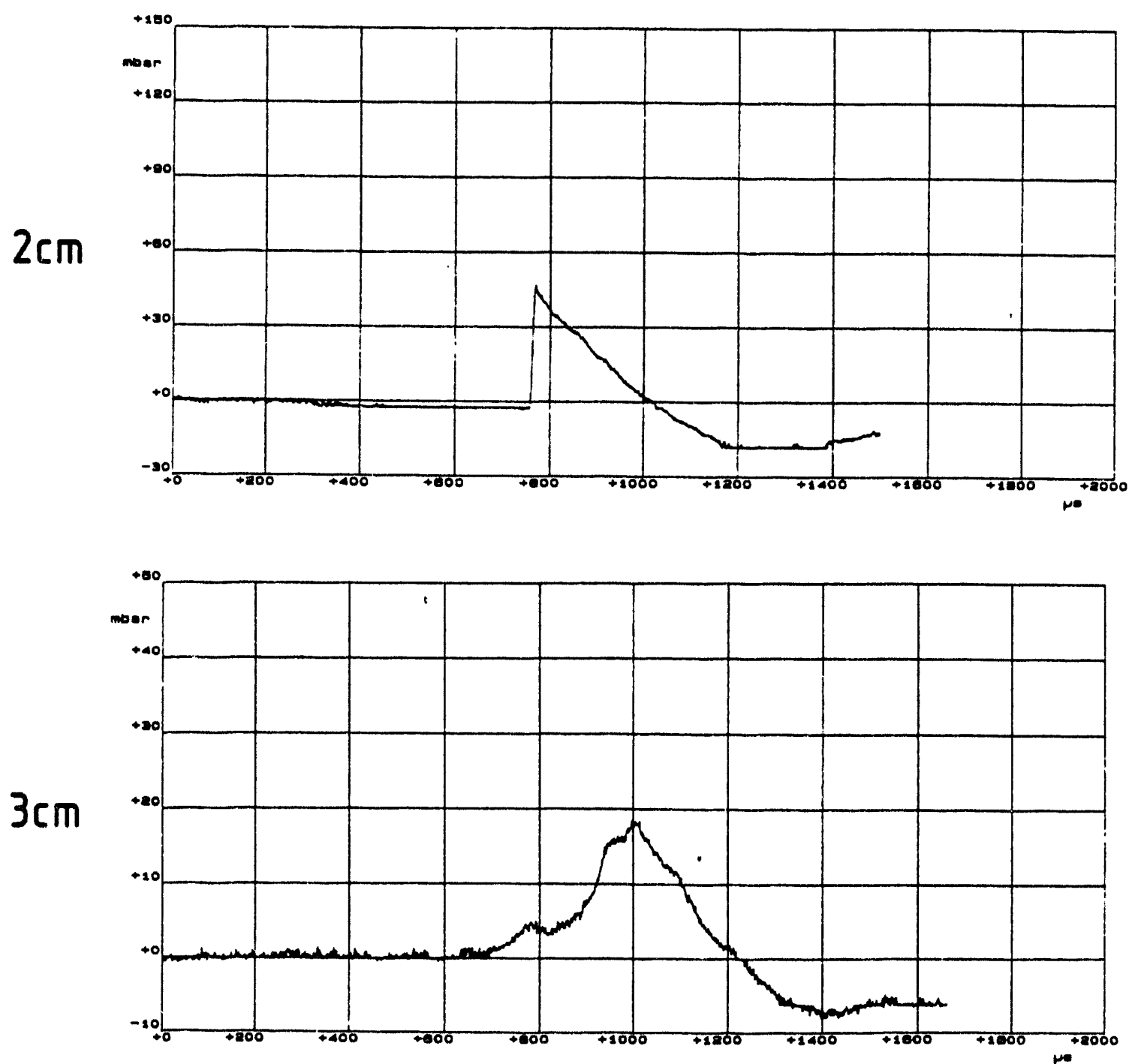

Figure 39 Concluded:

Distance from GZ: $63 \mathrm{~cm}\left(7.94 \mathrm{~m} / \mathrm{kg}^{1 / 3}\right)$

Test No. 758/10; 789/10; 792/10 

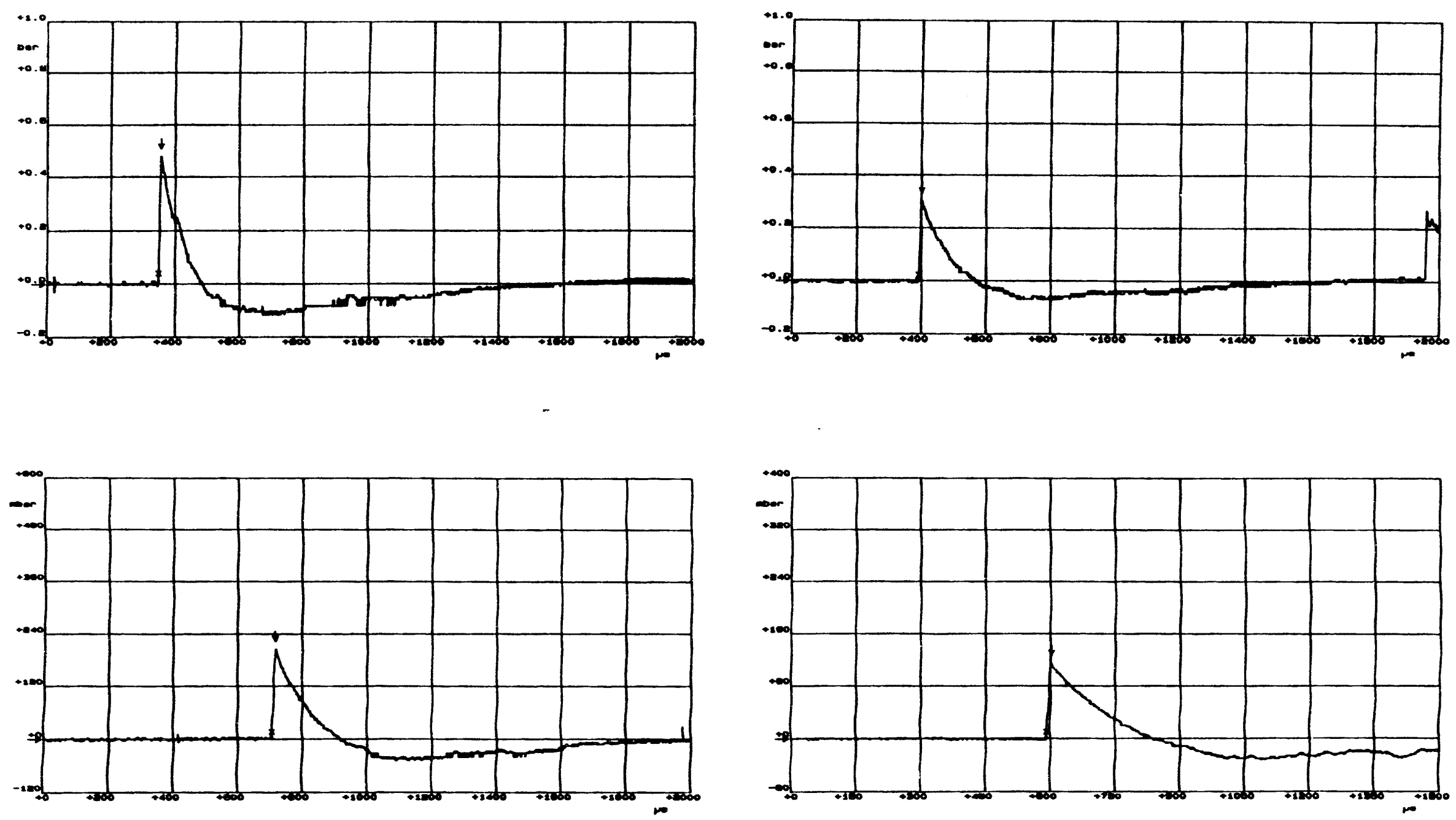

Figure 40 Comparison of pressure-time records at various distances

Charge weight: $0.53 \mathrm{~g}$

Distance from GZ:

$15 \mathrm{~cm}\left(1.85 \mathrm{~m} / \mathrm{kg}^{1 / 3}\right) ; 27 \mathrm{~cm}\left(3.33 \mathrm{~m} / \mathrm{kg}^{1 / 3}\right)$

$39 \mathrm{~cm}\left(4.81 \mathrm{~m} / \mathrm{kg}^{1 / 3}\right) ; 63 \mathrm{~cm}\left(7.77 \mathrm{~m} / \mathrm{kg}^{1 / 3}\right)$

Soil material: wet clay/loam

DOB: $1.0 \mathrm{~cm}$

Test No.: $811 / 2 ; 811 / 4 ; 811 / 6 ; 811 / 10$ 
0I/018 9/018 t/018

แอ $0^{\circ} \mathrm{Z}: \mathrm{gOC}$

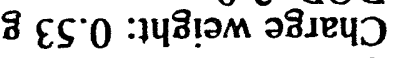

0t วมกริ!บ

สี
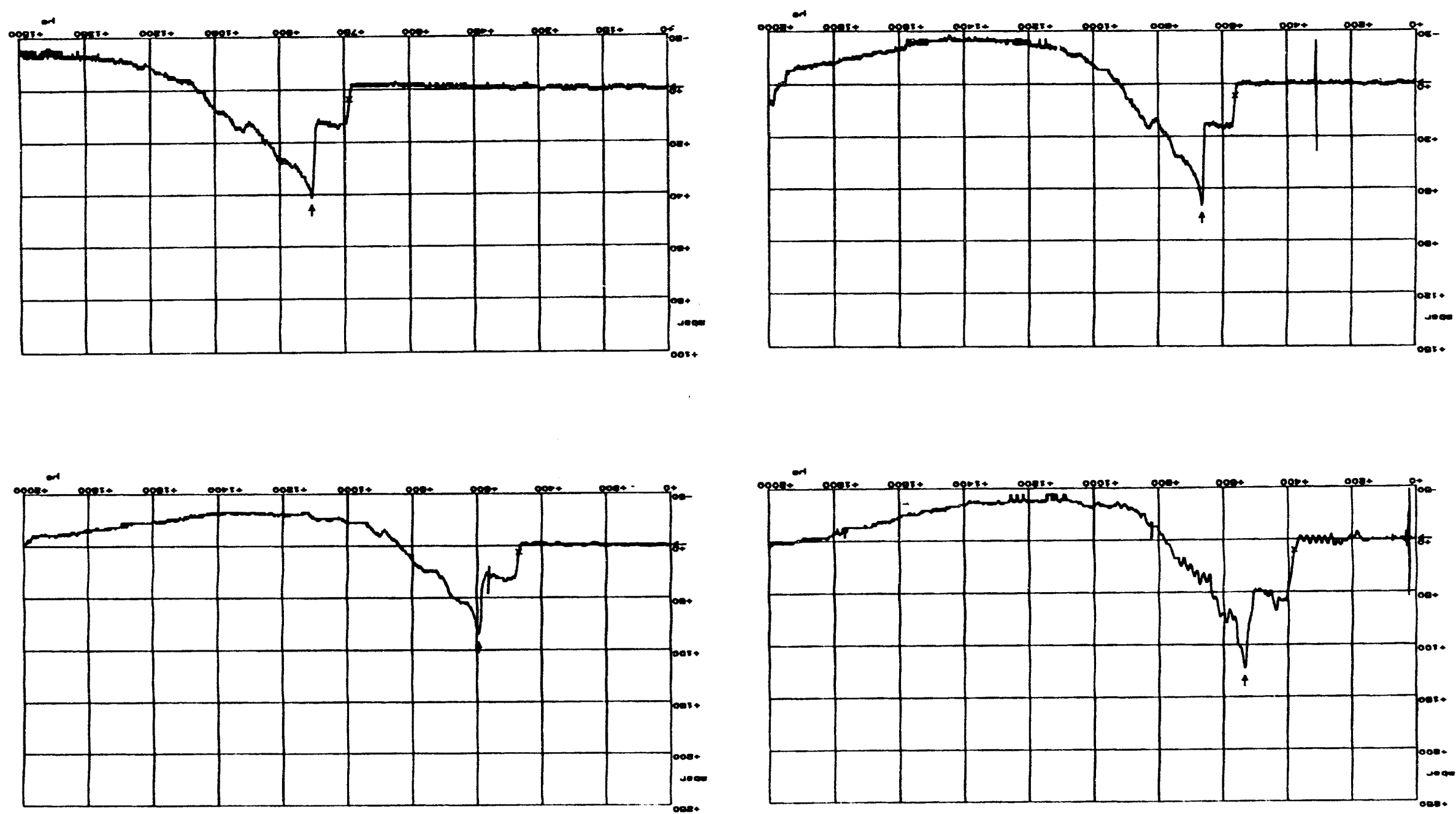

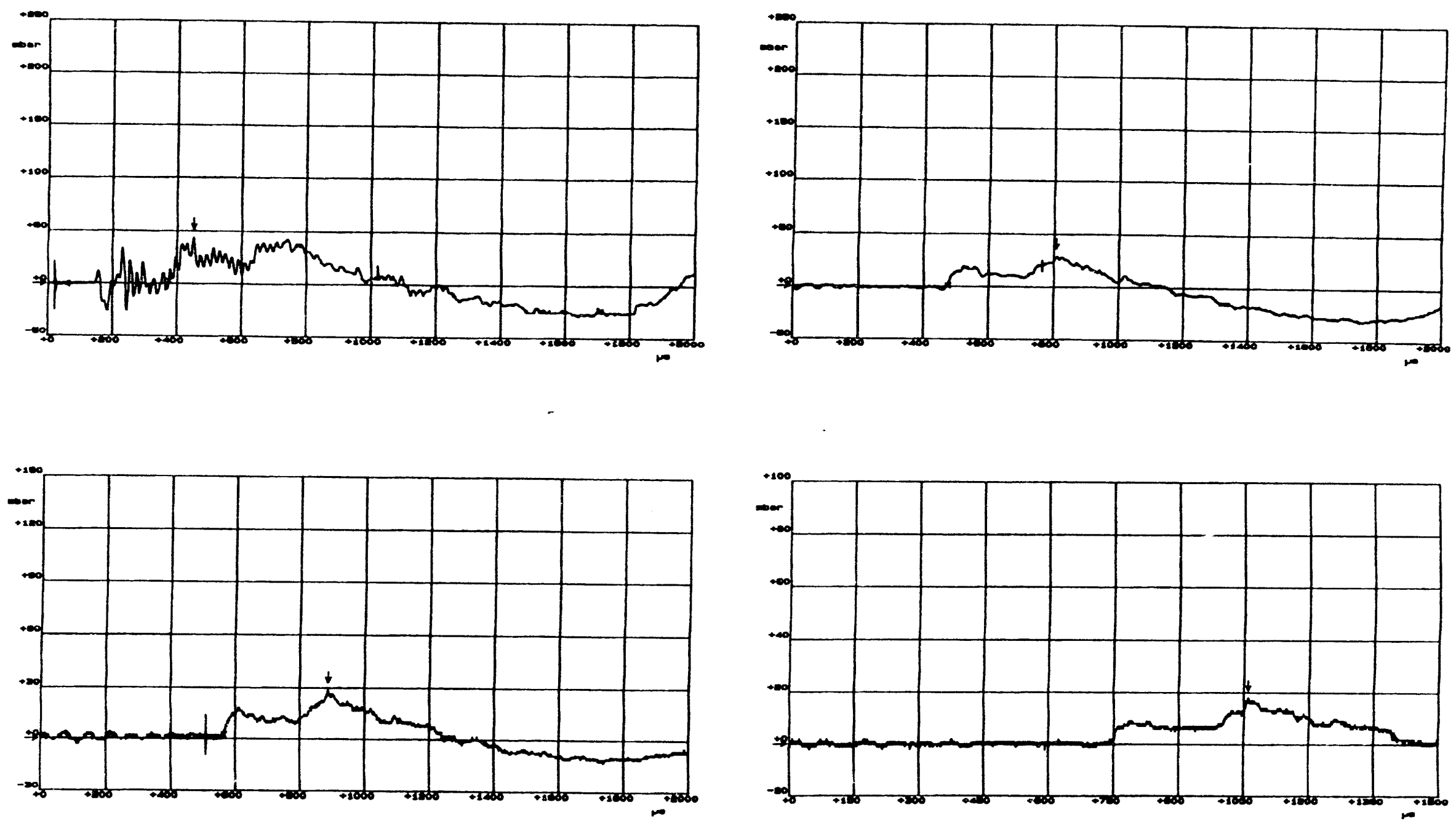

Figure 40

Concluded:

Charge weight: $0.54 \mathrm{~g}$

DOB: $3.0 \mathrm{~cm}$

Test No.: 763/2; 763/4; 763/6; 763/10 
$D O B=1 \mathrm{~cm}$

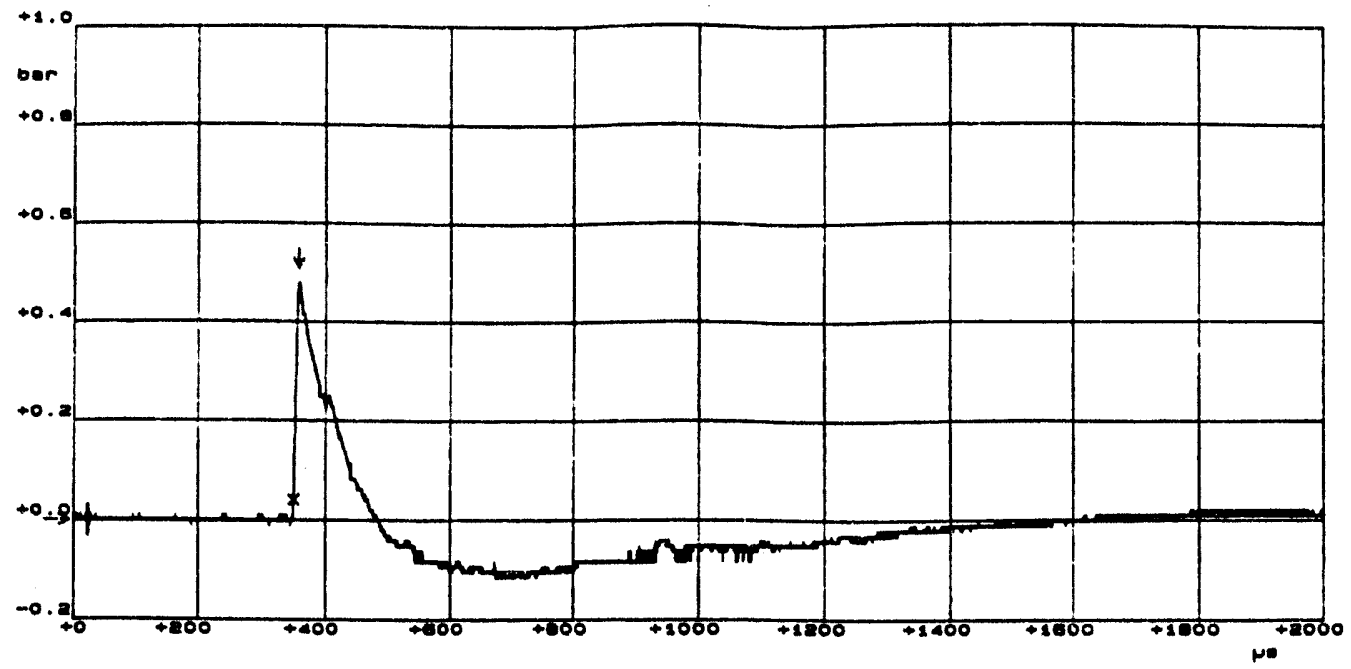

$D O B=2 \mathrm{~cm}$

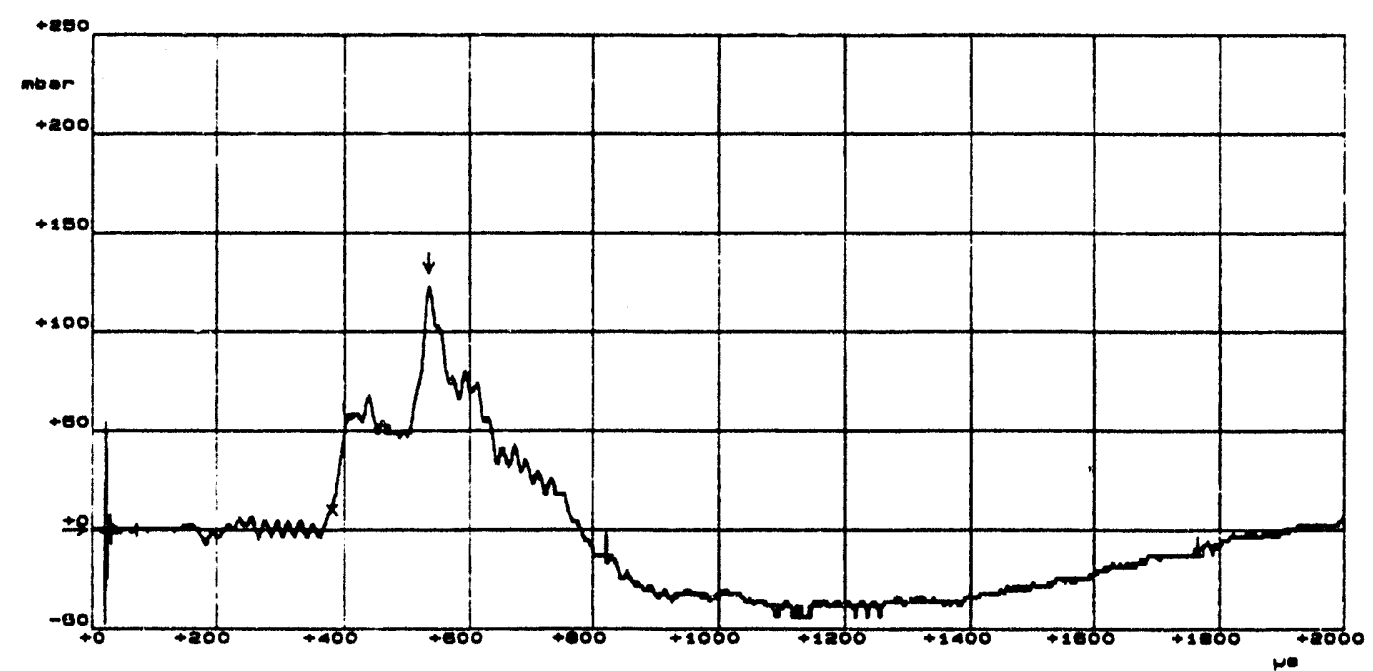

$D O B=3 \mathrm{~cm}$

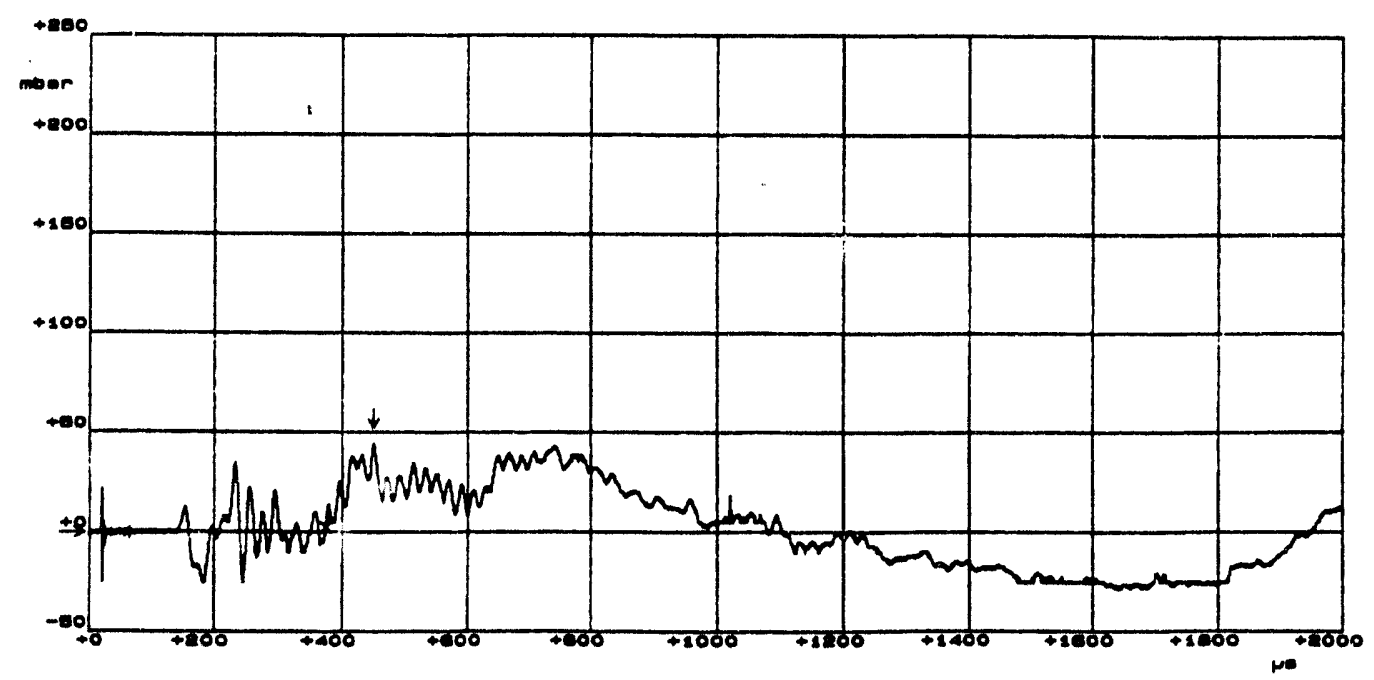

Figure 41 Comparison of pressure-time records at different DOB

Soil material: wet clay/loam

Distance from GZ: $15 \mathrm{~cm}\left(1.85 \mathrm{~m} / \mathrm{kg}^{1 / 3}\right)$

Test No. 811/2;810/2;763/2 
$D O B=1 \mathrm{~cm}$

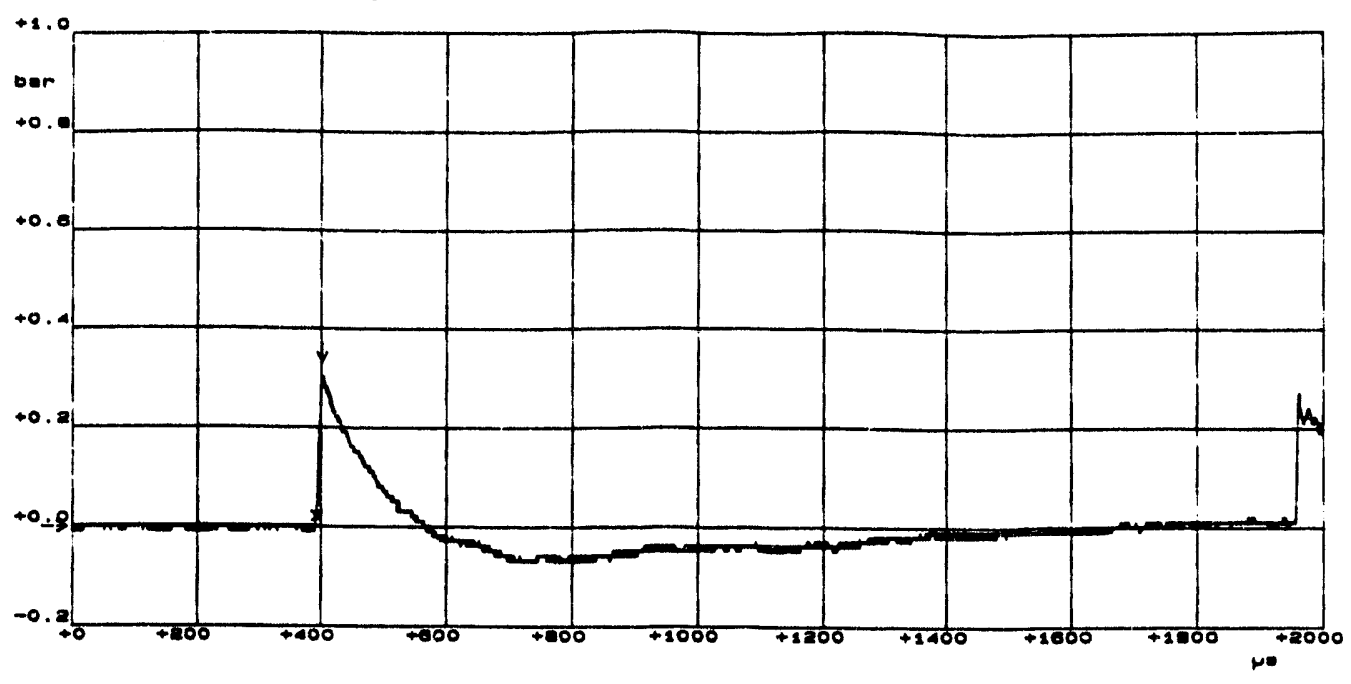

$D O B=2 \mathrm{~cm}$

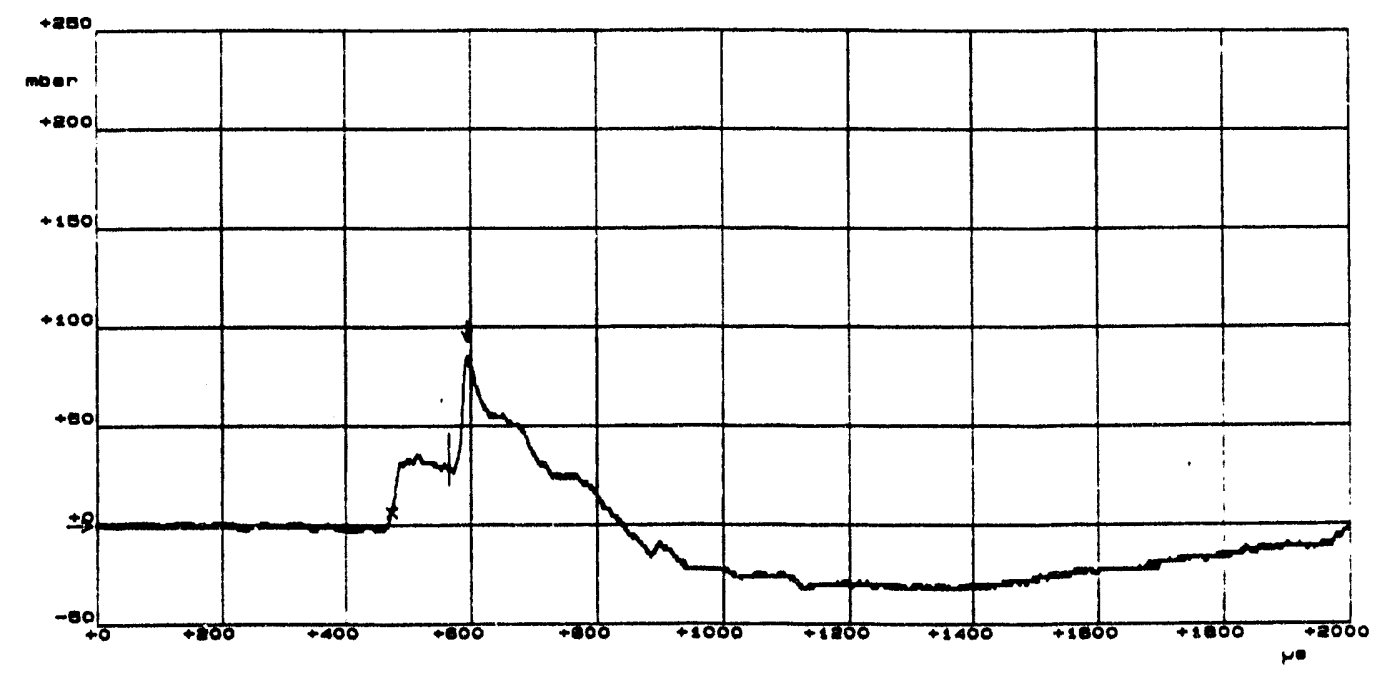

$D O B=3 \mathrm{~cm}$

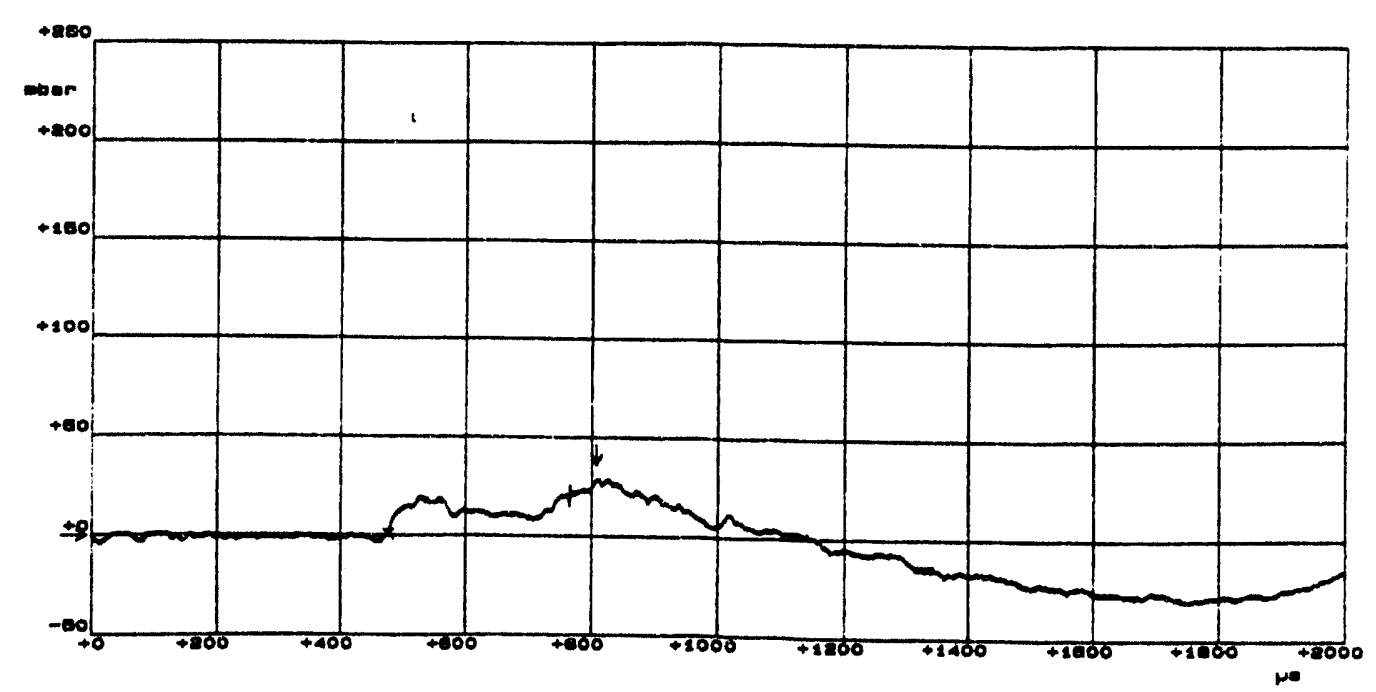

Figure 41 Continued:

Distance from GZ: $27 \mathrm{~cm}\left(3.33 \mathrm{~m} / \mathrm{kg}^{1 / 3}\right)$

Test No. 811/4; 810/4; 763/4 


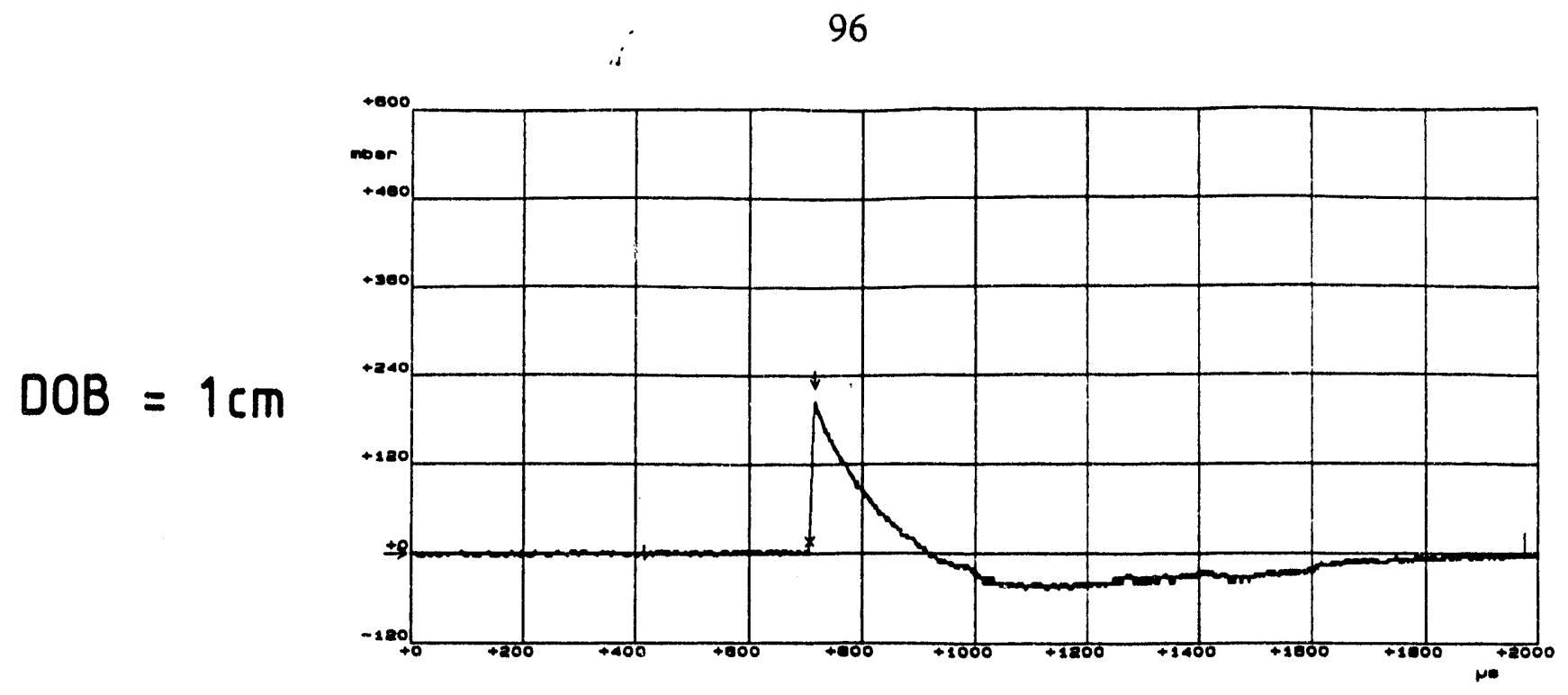

$D O B=2 \mathrm{~cm}$

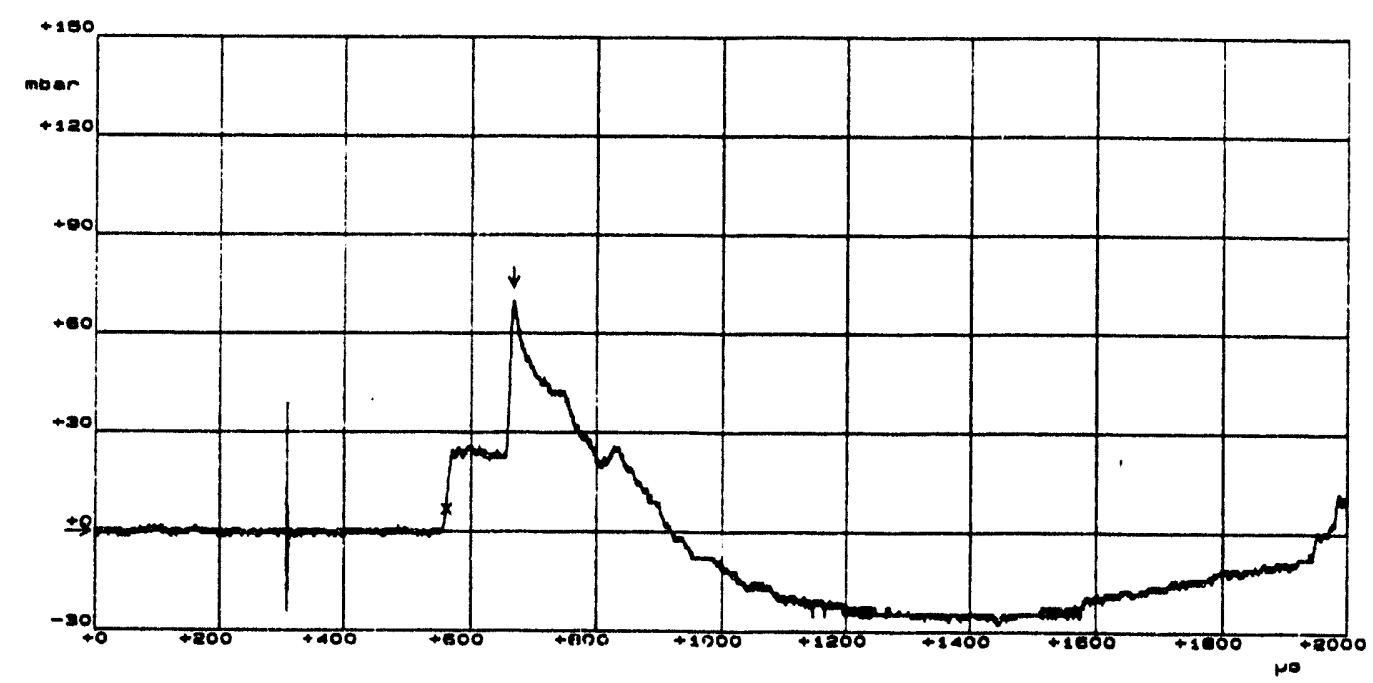

$D O B=3 \mathrm{~cm}$

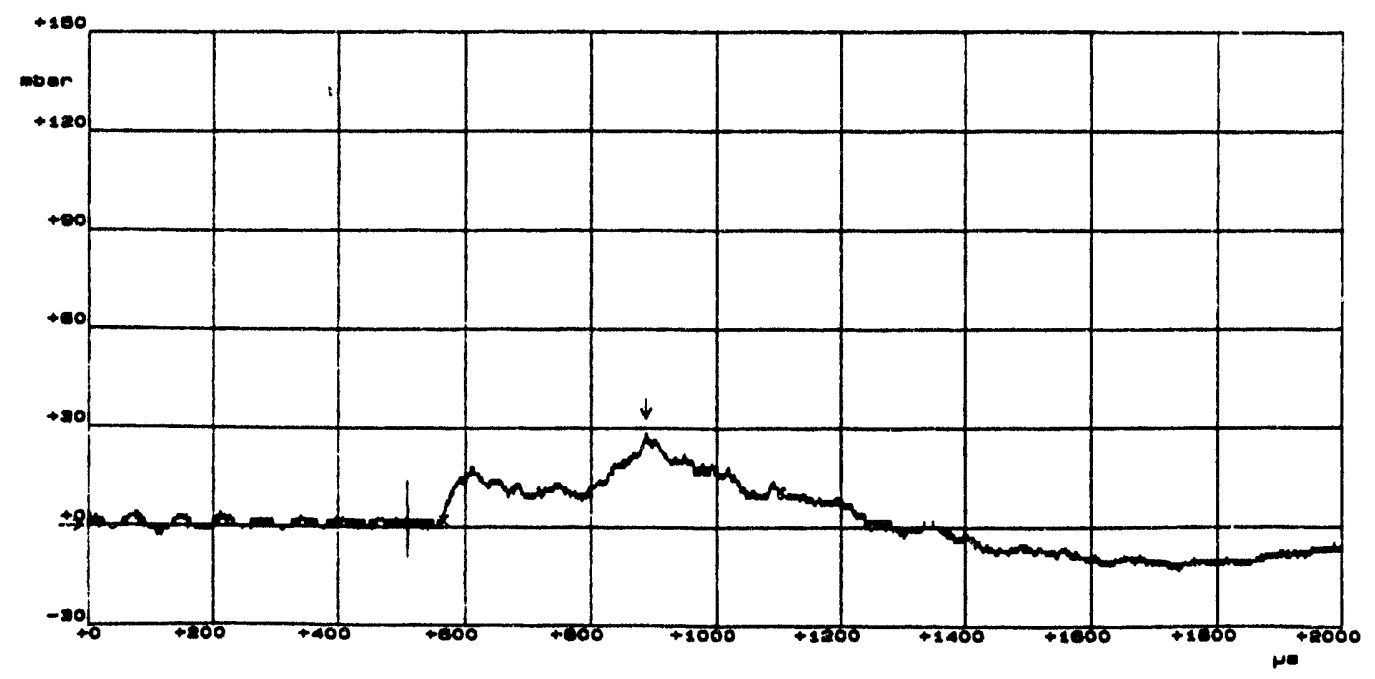

Figure 41 Continued:

Distance from GZ: $39 \mathrm{~cm}\left(4.81 \mathrm{~m} / \mathrm{kg}^{1 / 3}\right)$

Test No. 811/6; 810/6; 763/6 
$D O B=1 \mathrm{~cm}$

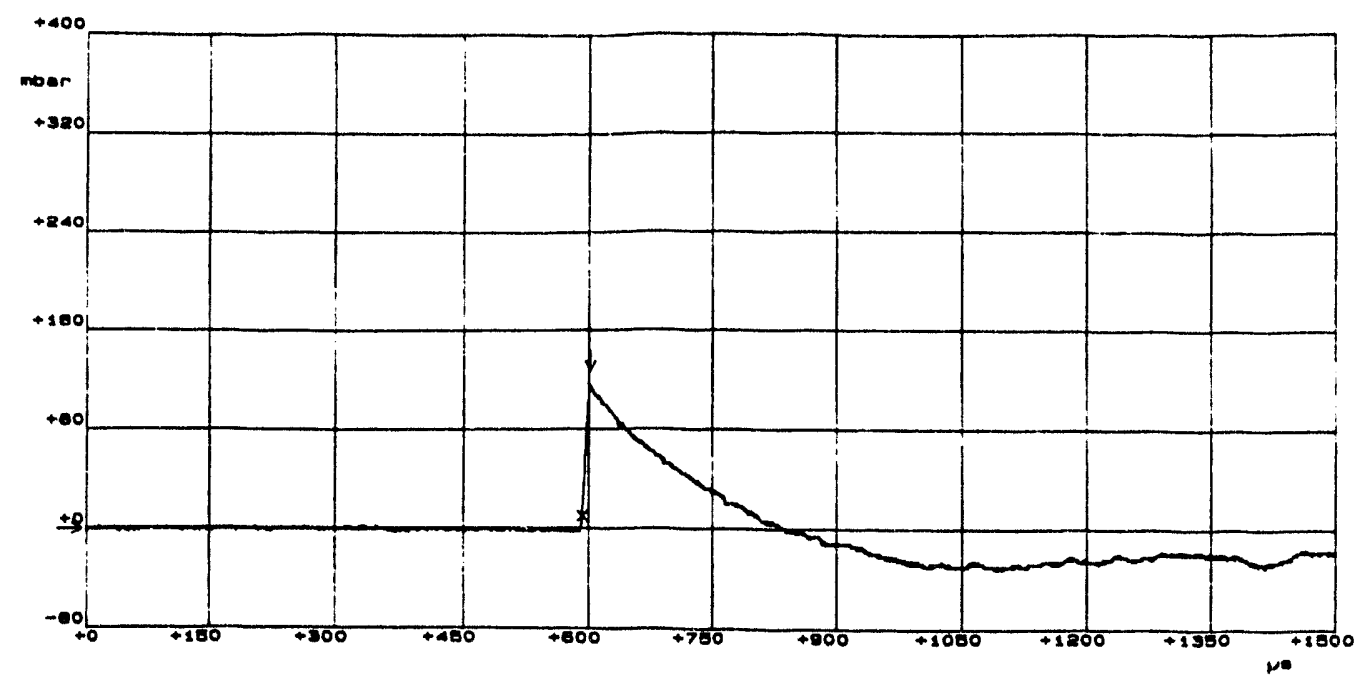

$D O B=2 \mathrm{~cm}$

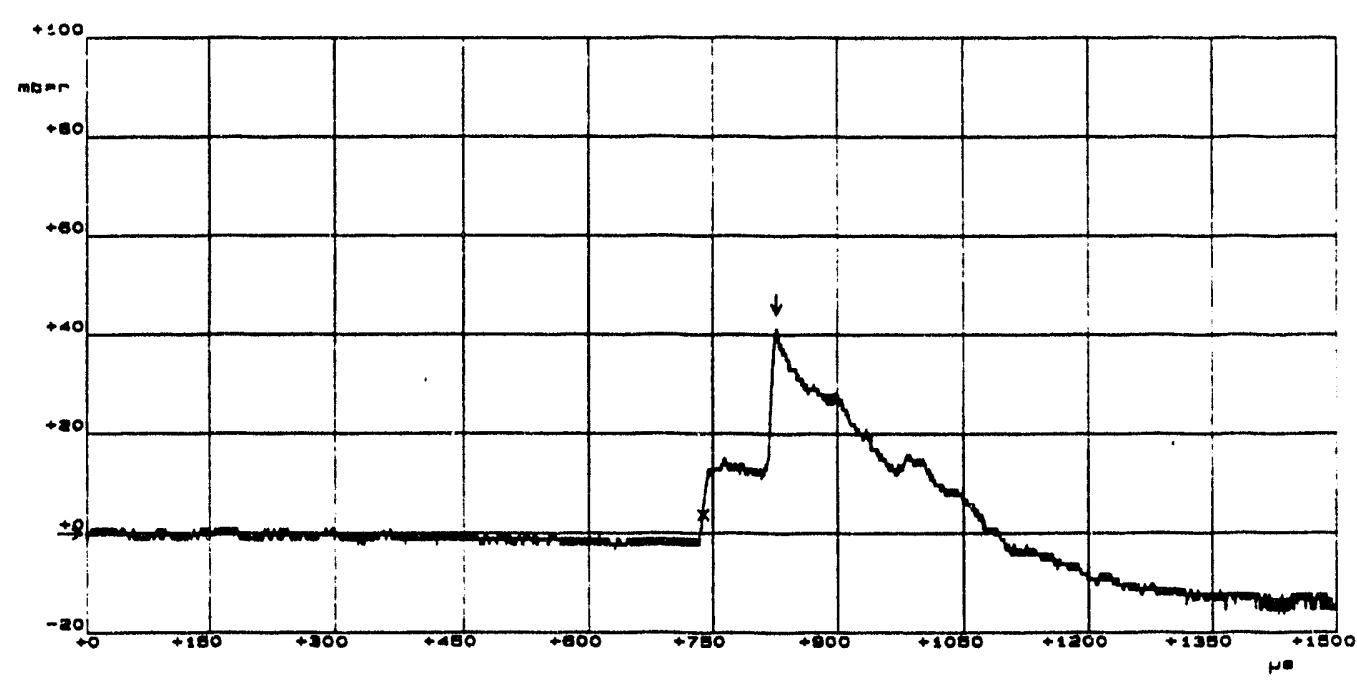

$D O B=3 \mathrm{~cm}$

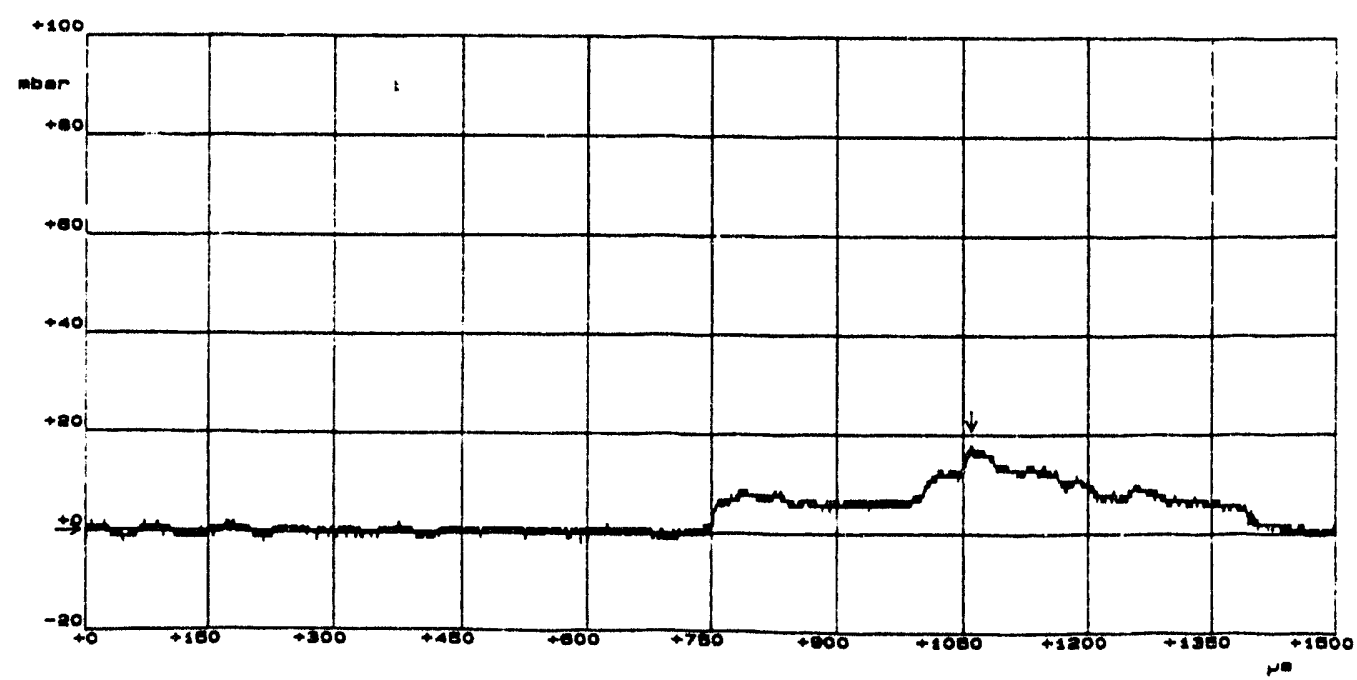

Figure 41 Concluded:

Distance from GZ: $63 \mathrm{~cm}\left(7.77 \mathrm{~m} / \mathrm{kg}^{1 / 3}\right)$

Test No. 811/10; 810/10; 763/10 

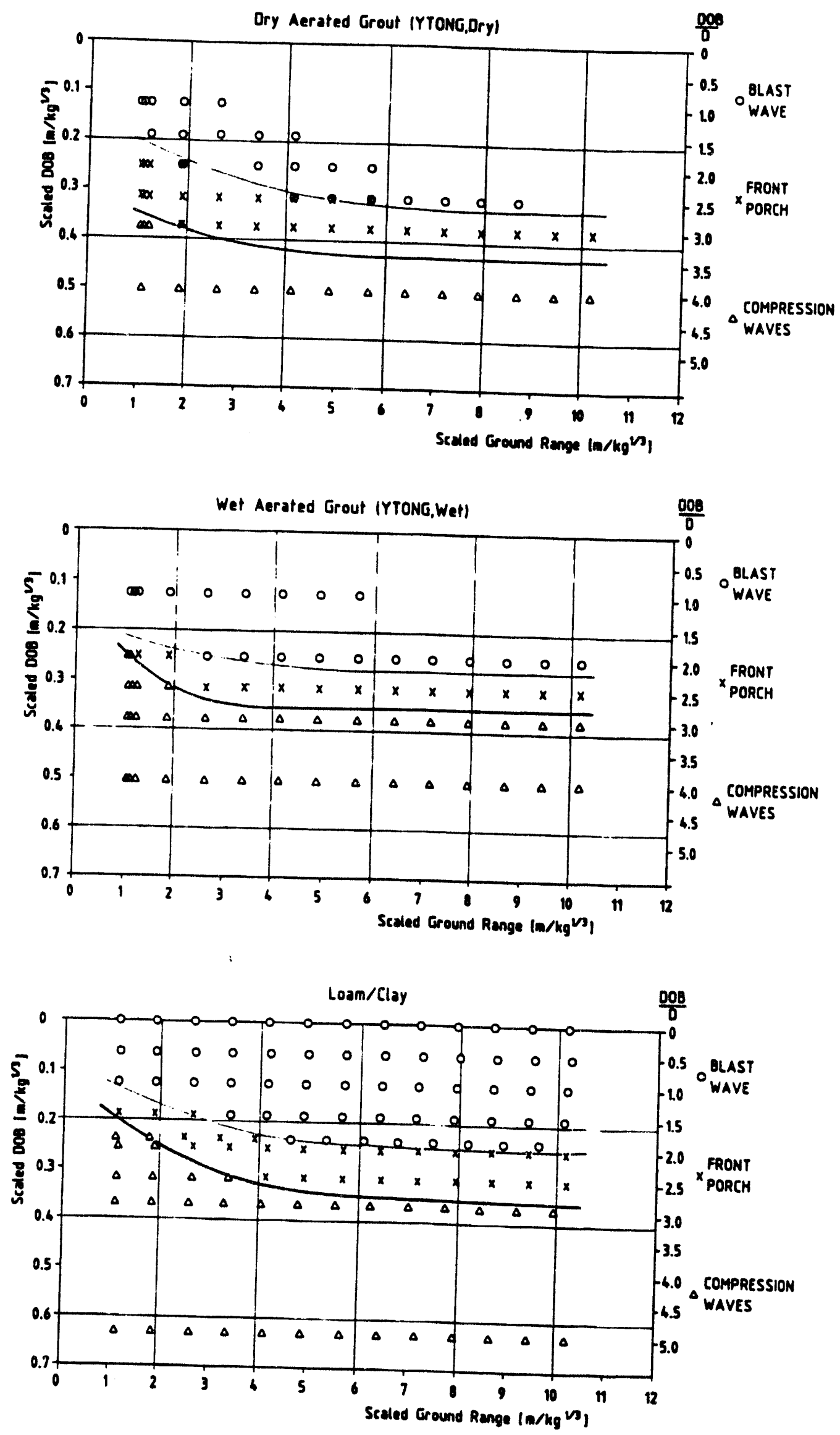
$\begin{array}{ll}\text { Figure } 42 & \text { Domains of different wave forms for DOB in dry aerated grout (dry } \\ \text { YTONG), water saturated grout (wet YTONG) and wet clay/loam. }\end{array}$ 

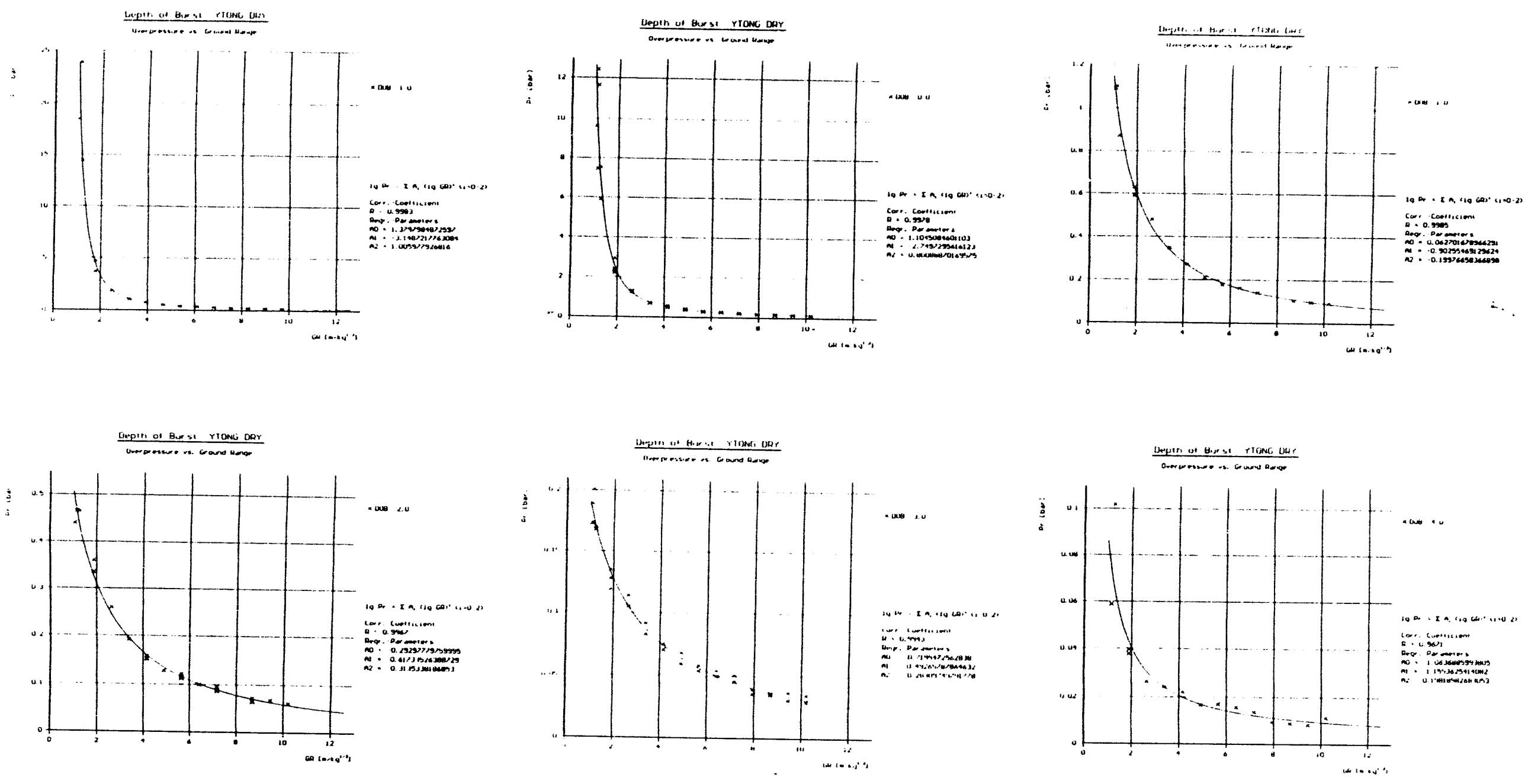

Figure 43

Peak overpressure vs ground range at different DOB Soil material: dry aerated grout (dry YTONG)

DOB $=-1.0 \mathrm{~cm} \quad$ DOB $=0.0 \mathrm{~cm} \quad$ DOB $=1.0 \mathrm{~cm}$

$\mathrm{DOB}=2.0 \mathrm{~cm} \quad \mathrm{DOB}=3.0 \mathrm{~cm} \quad \mathrm{DOB}=4.0 \mathrm{~cm}$ 

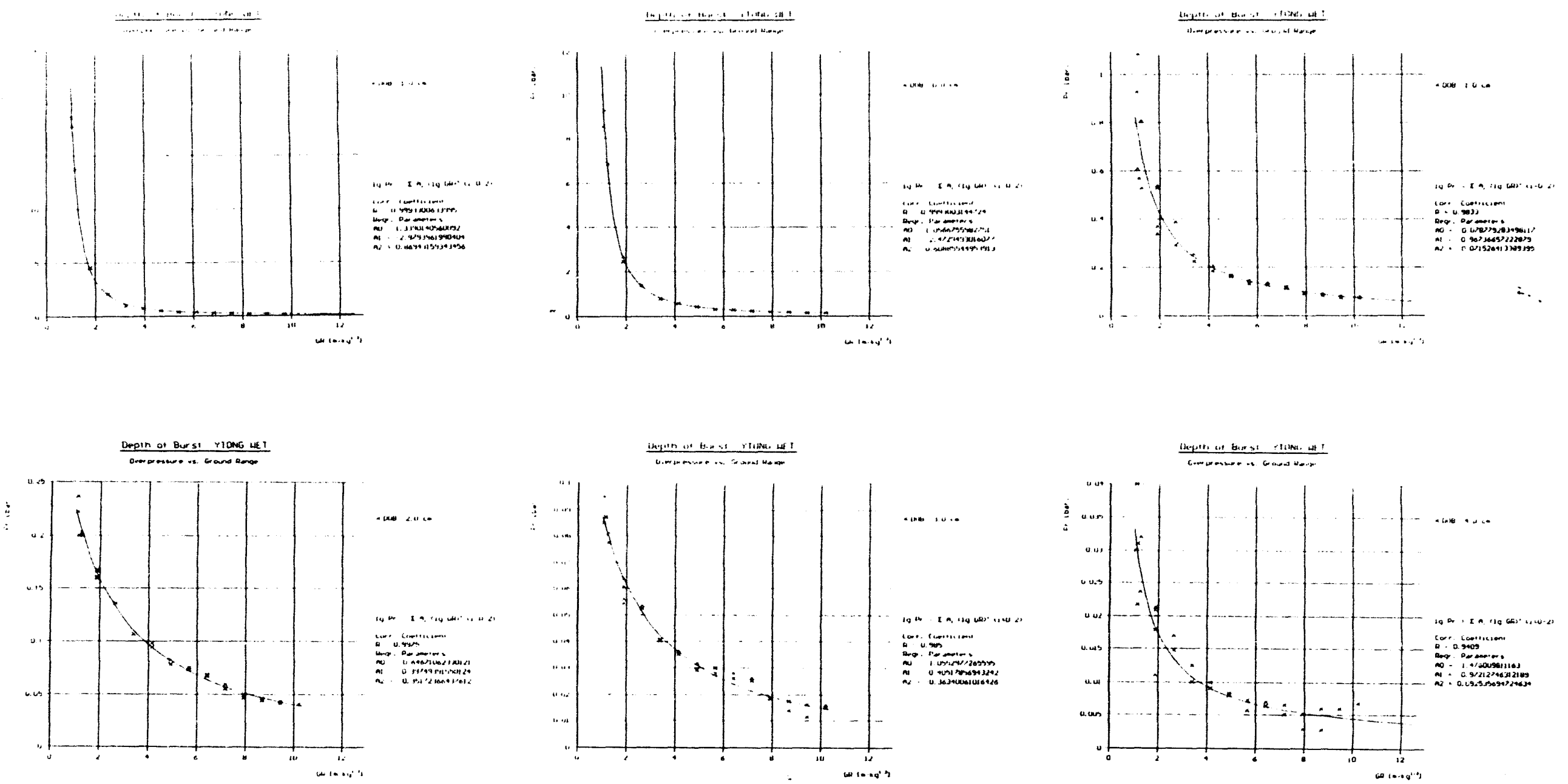

$\overline{8}$

Figure 44 Peak overpressure vs ground range at different DOB

Soil material: water saturated grout (wet YTONG)

DOB $=-1.0 \mathrm{~cm} \quad$ DOB $=0.0 \mathrm{~cm} \quad$ DOB $=1.0 \mathrm{~cm}$

$\mathrm{DOB}=2.0 \mathrm{~cm} \quad \mathrm{DOB}=3.0 \mathrm{~cm} \quad \mathrm{DOB}=4.0 \mathrm{~cm}$ 

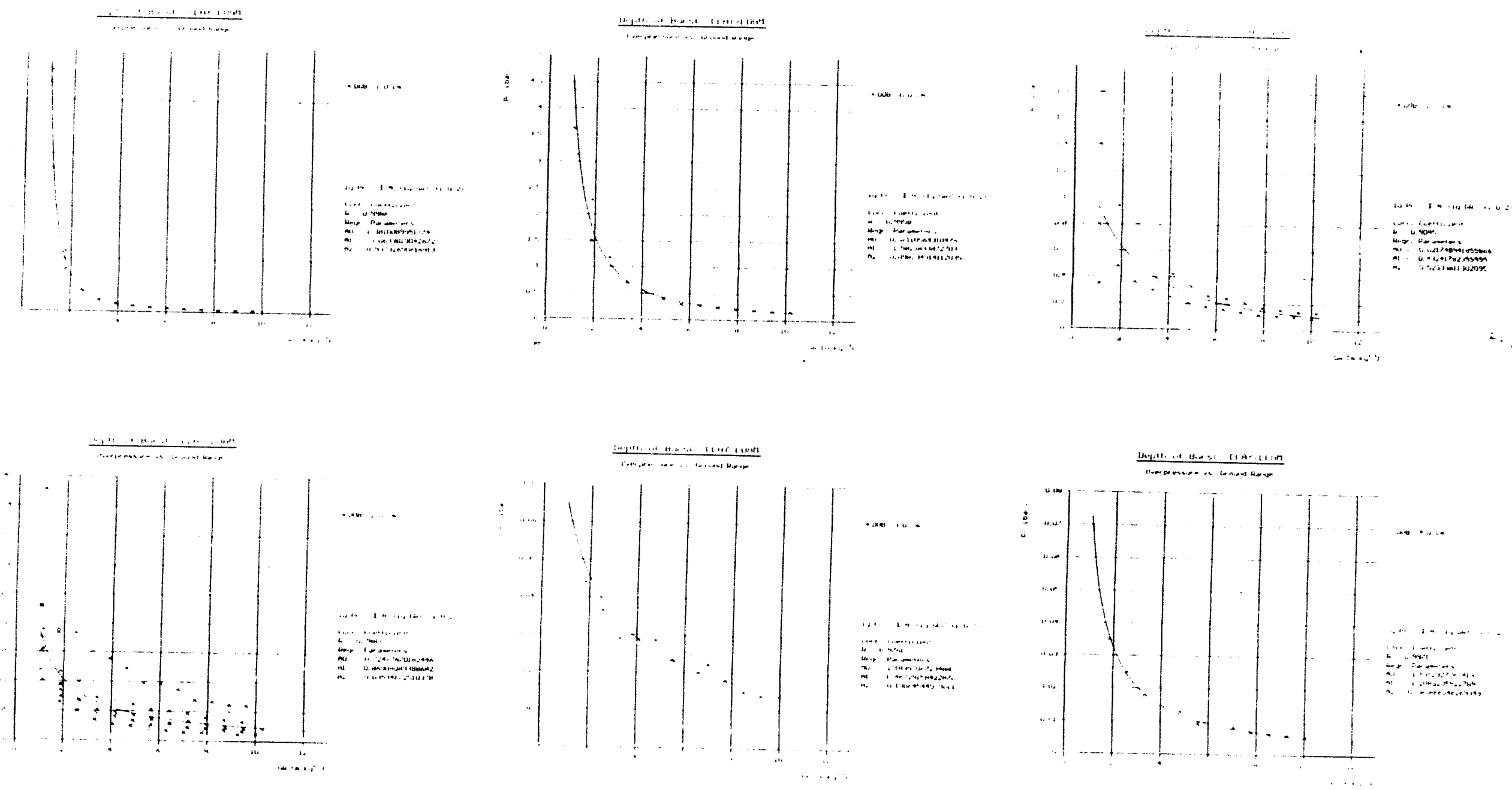

ㅎ

Figure 45 Peak overpressure vs ground range at different DOB Soil material: clay/loam

$\begin{array}{lll}\mathrm{DOB}=-1.0 \mathrm{~cm} & \text { DOB }=0.0 \mathrm{~cm} & \text { DOB }=1.0 \mathrm{~cm} \\ \mathrm{DOB}=2.0 \mathrm{~cm} & \text { DOB }=3.0 \mathrm{~cm} & \text { DOB }=4.0 \mathrm{~cm}\end{array}$ 


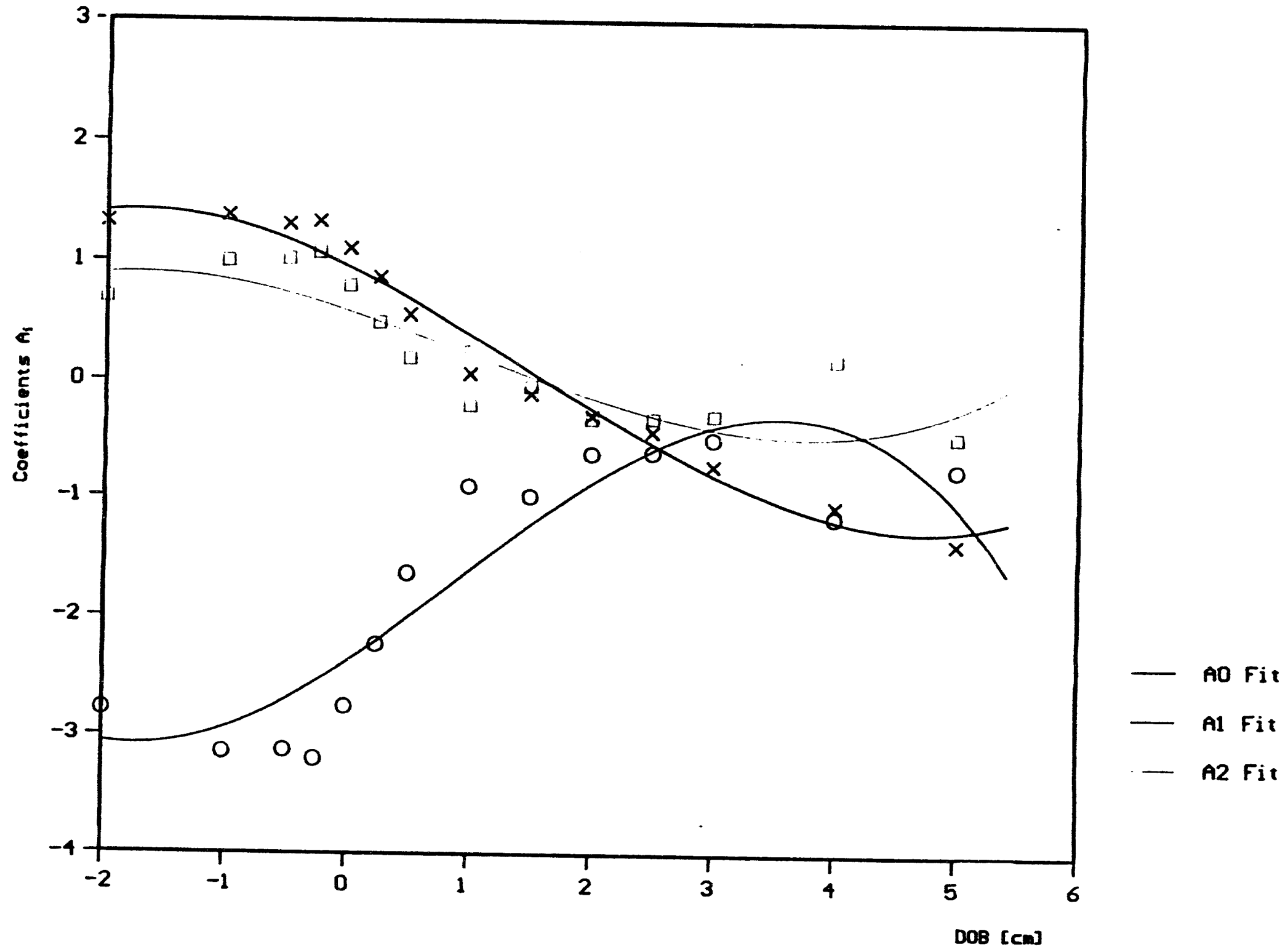

Figure 46 Coefficients $a_{i}$ vs DOB of the approximation function $\log p=\sum_{0}^{2} a_{i}(\log G R)^{i}$ for dry YTONG. 


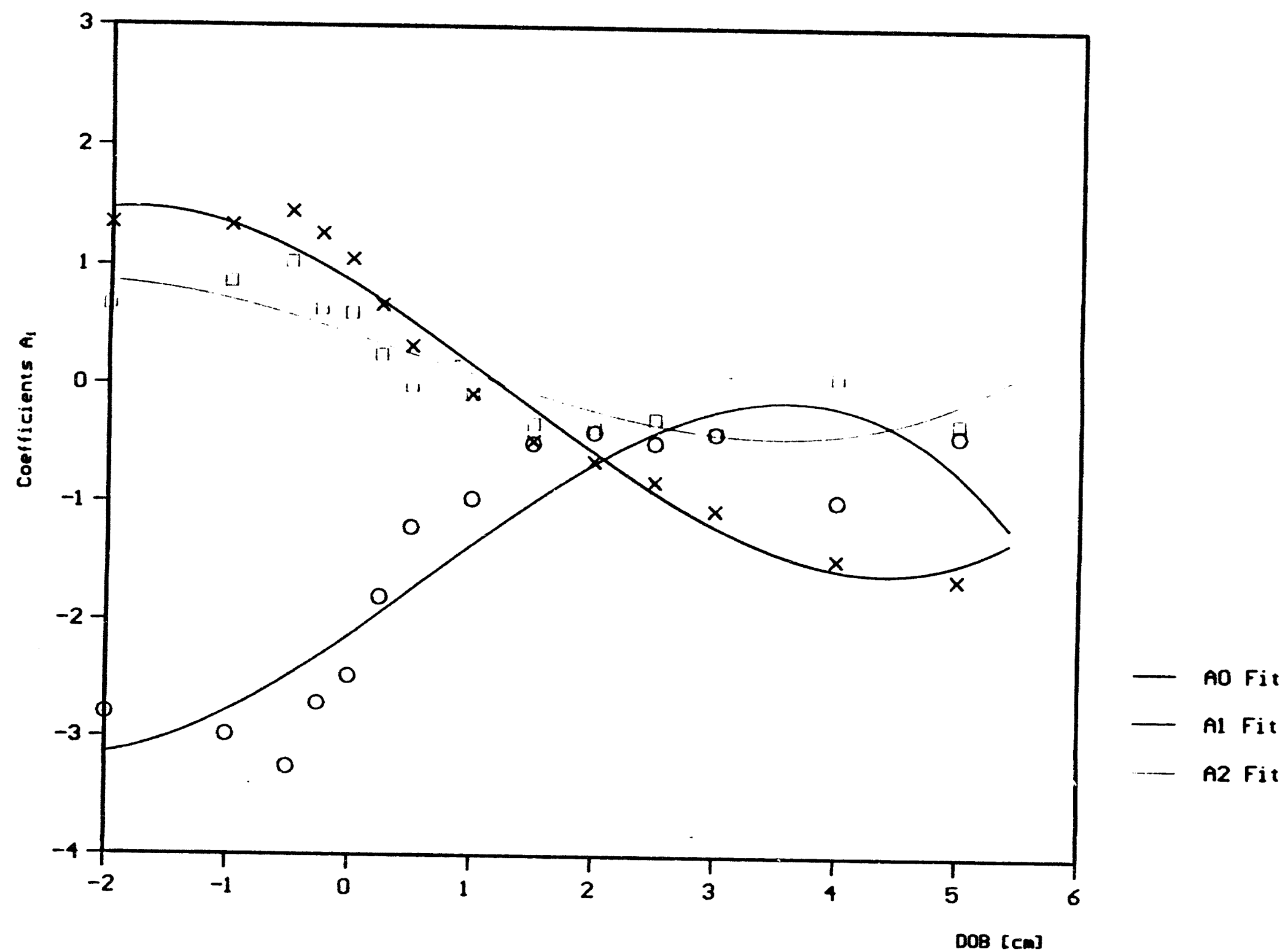

Figure 47 Coefficients $a_{i}$ vs DOB of the approximation function $\log p=\sum_{0}^{2} a_{i}(\log G R)^{i}$ for wet YTONG. 


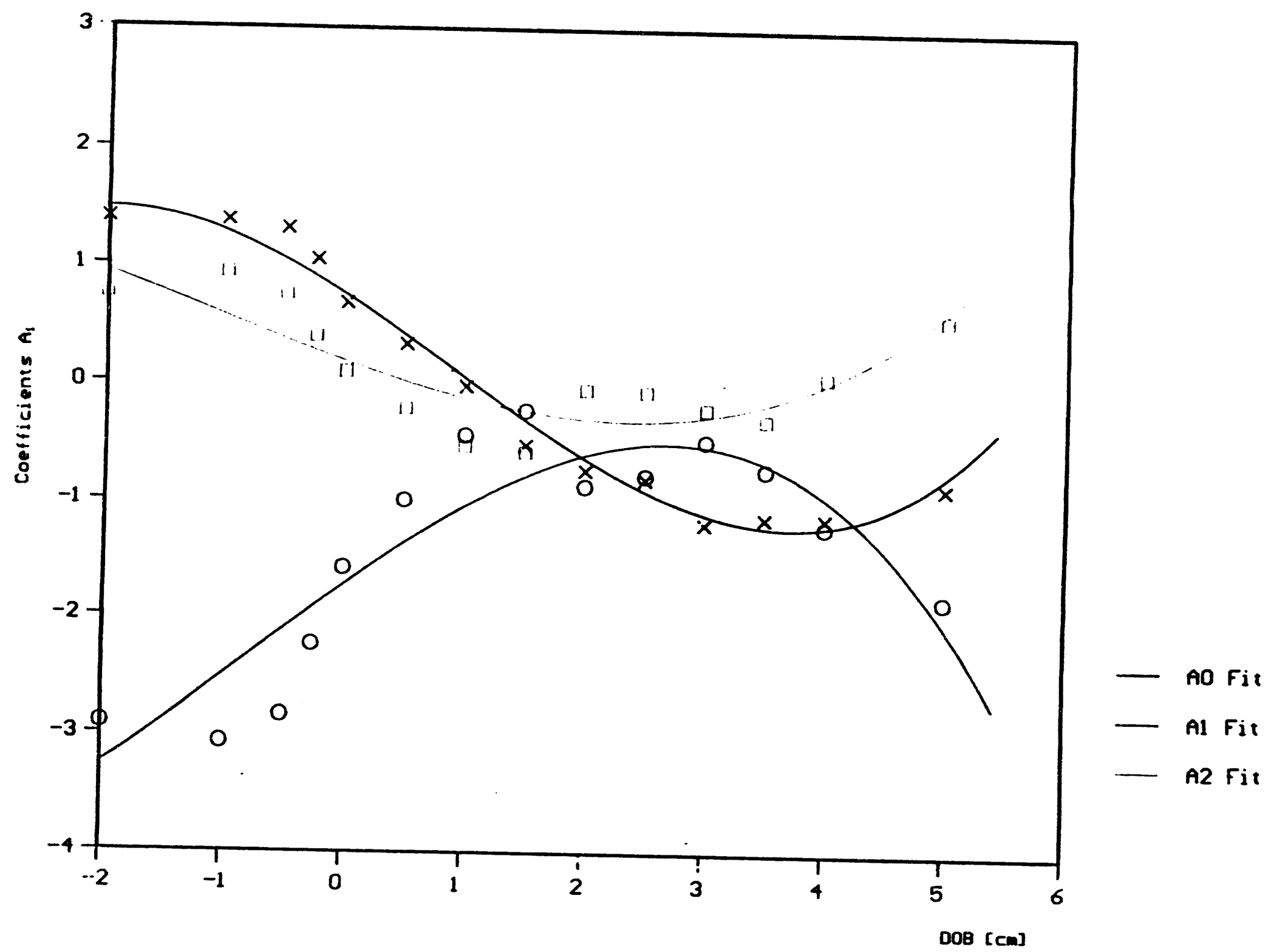

Figure 48 Coefficients $a_{i}$ vs DOB of the approximation function $\log p=\sum_{0}^{2} a_{i}(\log G R)^{i}$ for clay/loam. 


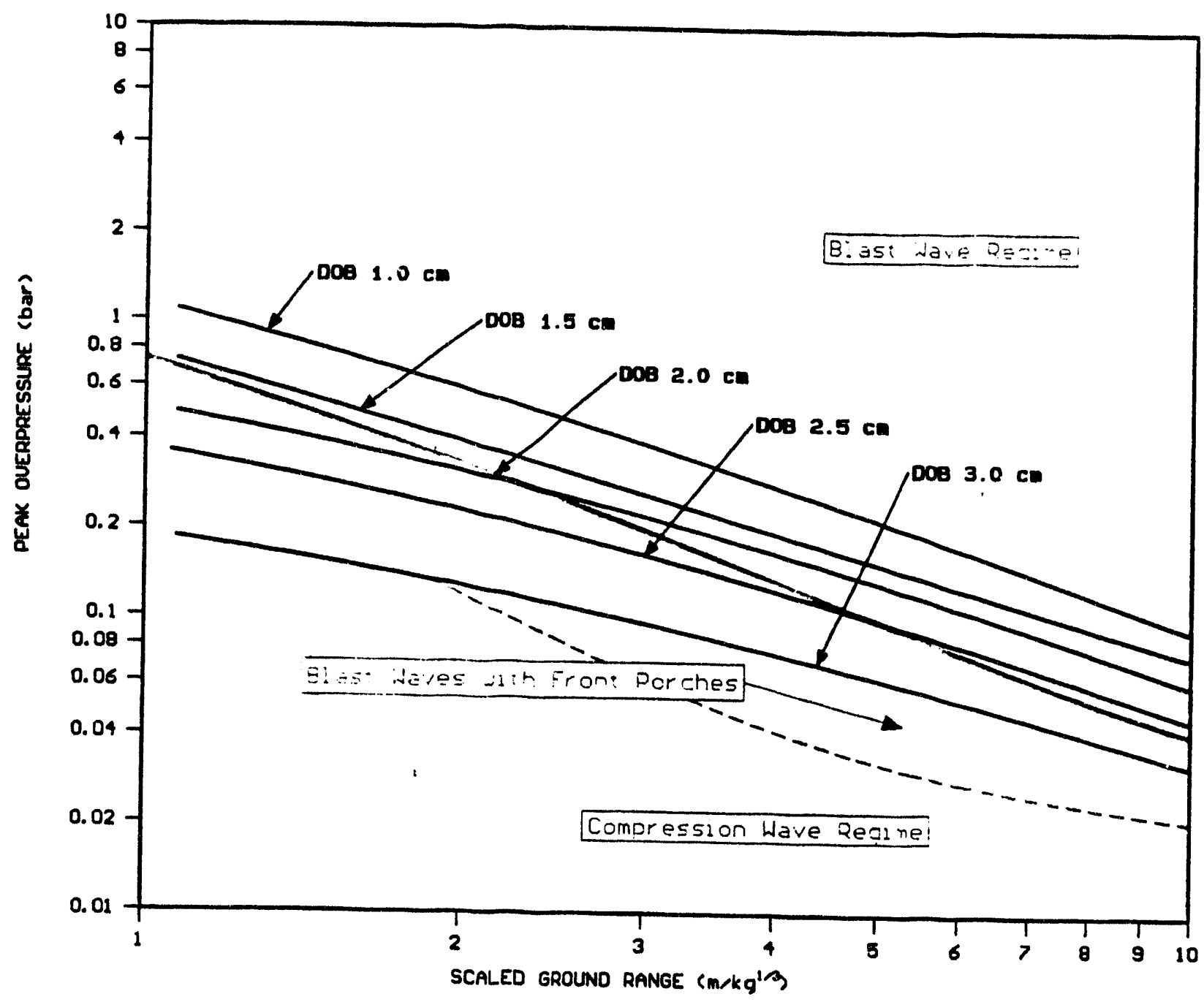

Figure 49 Peak Overpressure vs Ground Range (Logarithmic plot with domains of different wave forms).

Soil material: dry aerated grout (dry YTONG) 


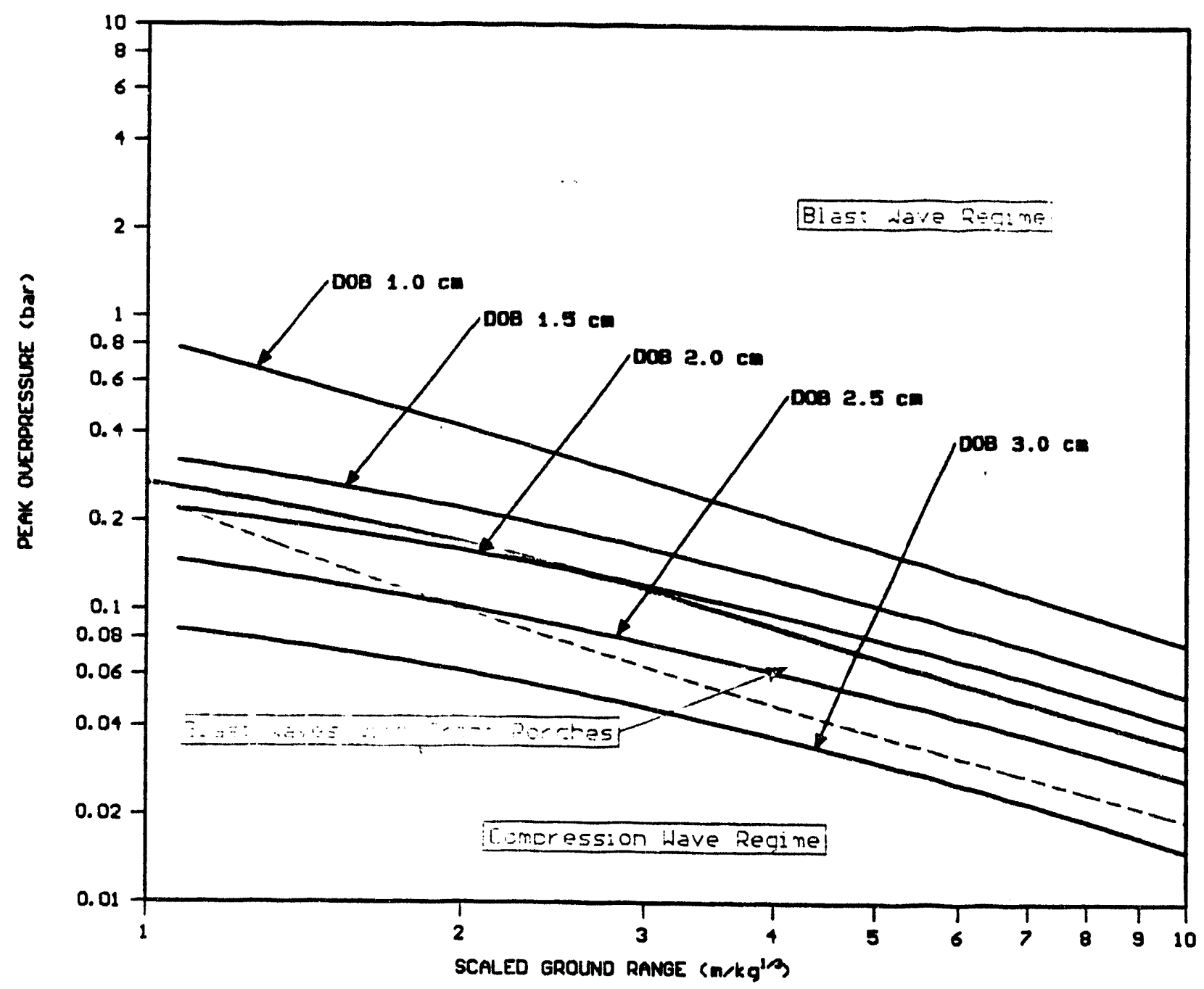

Figure 50 Peak Overpressure vs Ground Range (Logarithmic plot with domains of different wave forms).

Soil material: water saturated grout (wet YTONG) 


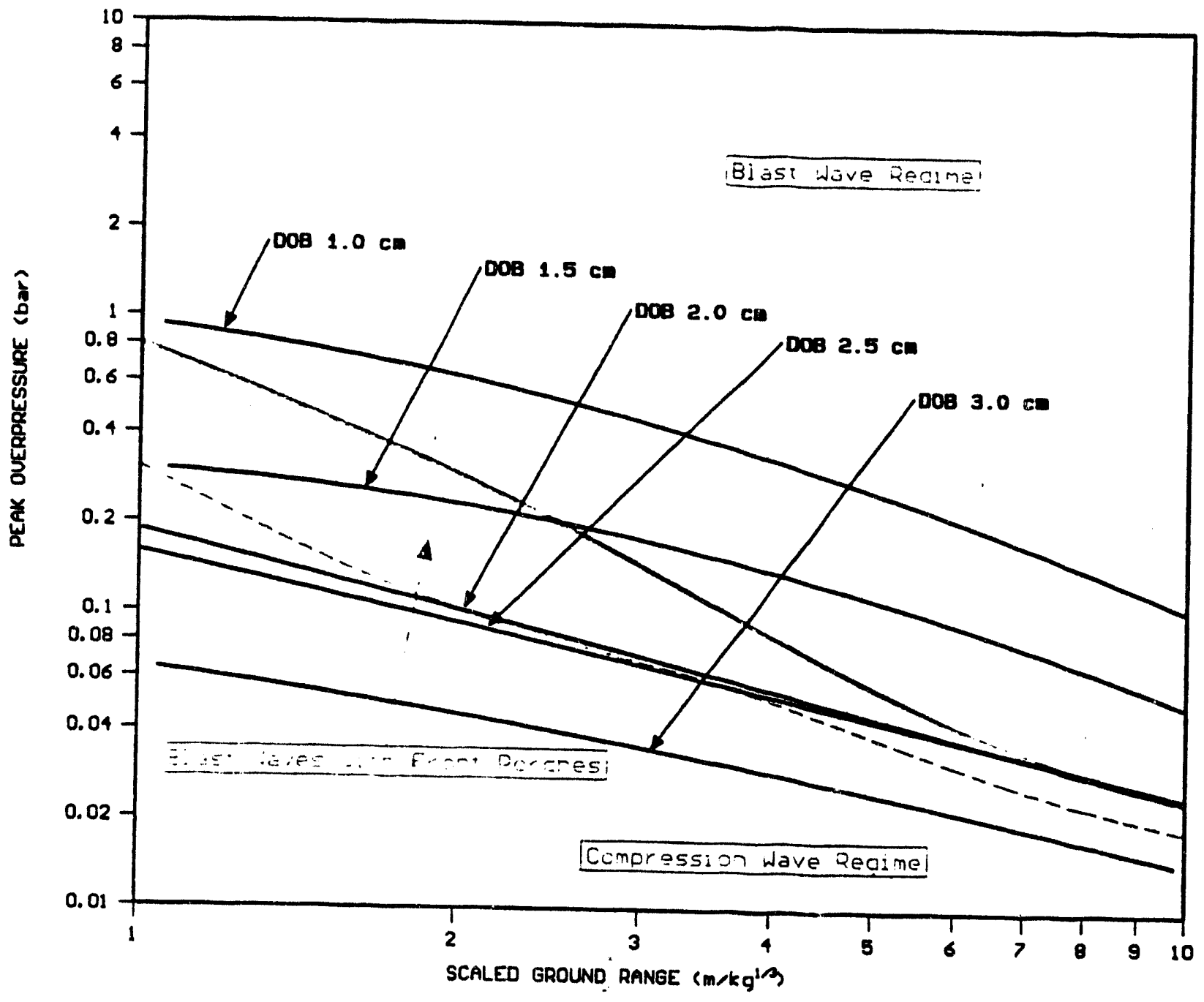

Figure 51 Peak Overpressure vs Ground Range (Logarithmic plot with domains of different wave forms).

Soil material: wet clay/loam 


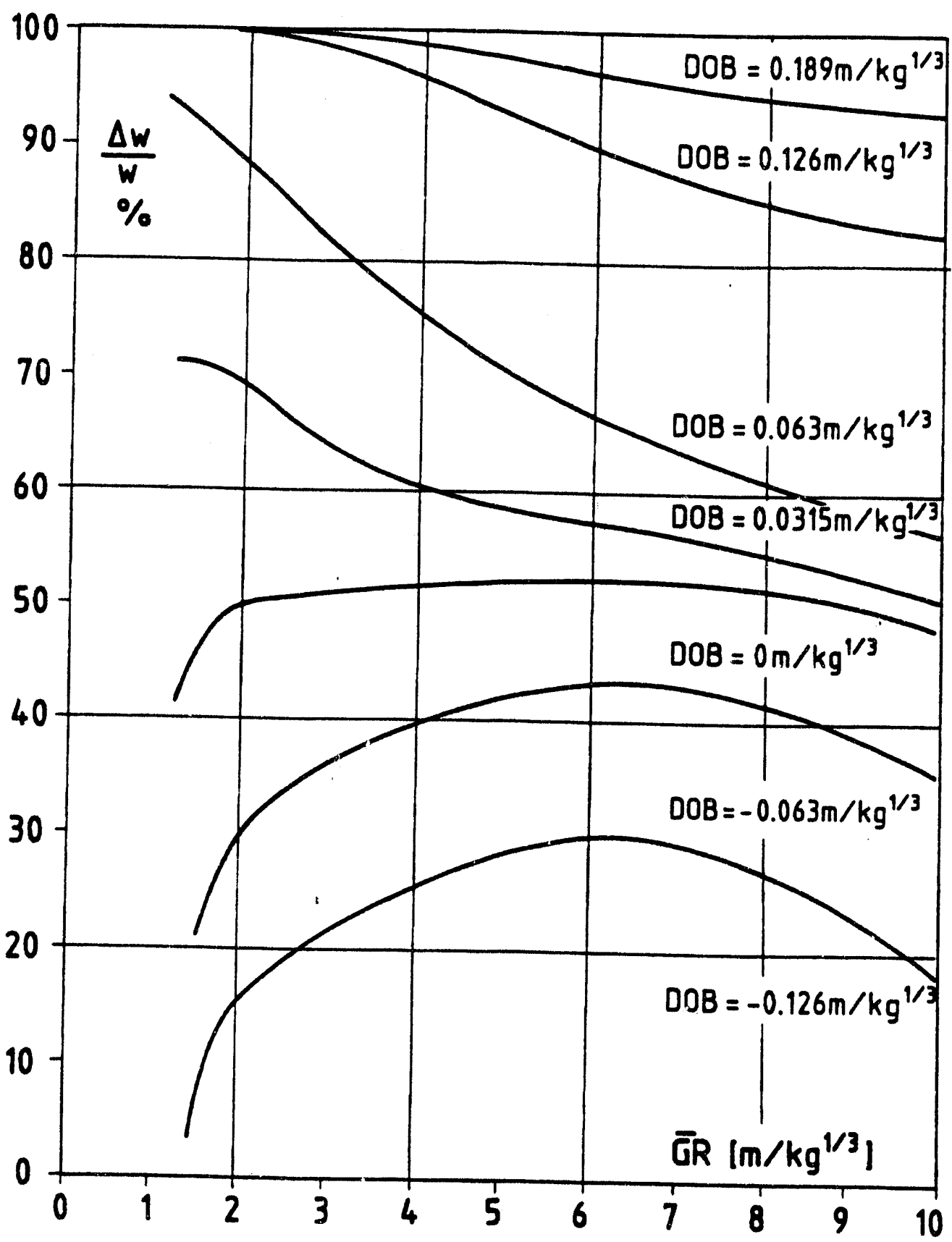

Figure 52 Percentage of Energy Losses vs Ground Range Soil material: dry aerated grout (dry YTONG) 


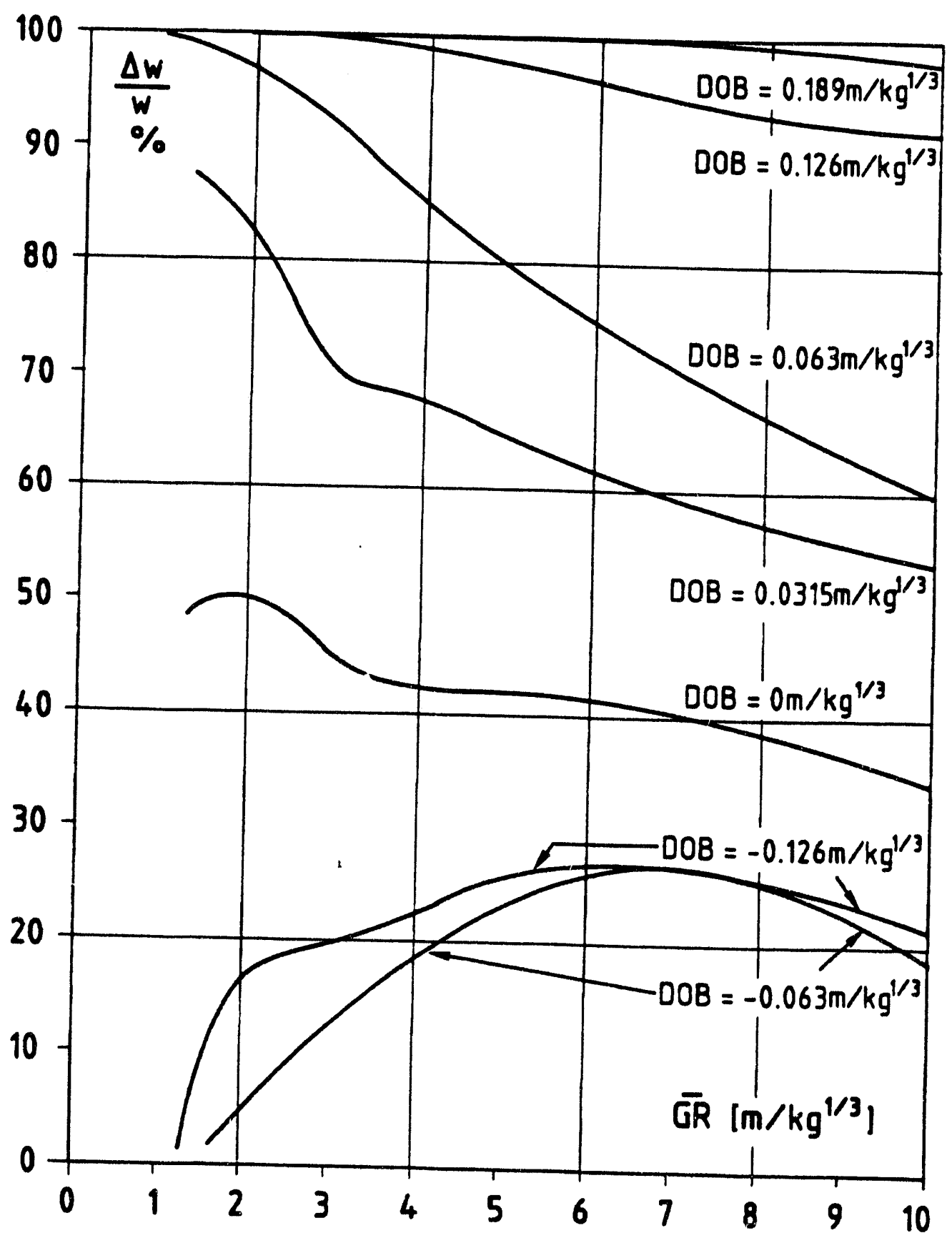

Figure 53 Percentage of Energy Losses vs Ground Range Soil material: water saturated grout (wet YTONG) 
$\therefore \quad 110$

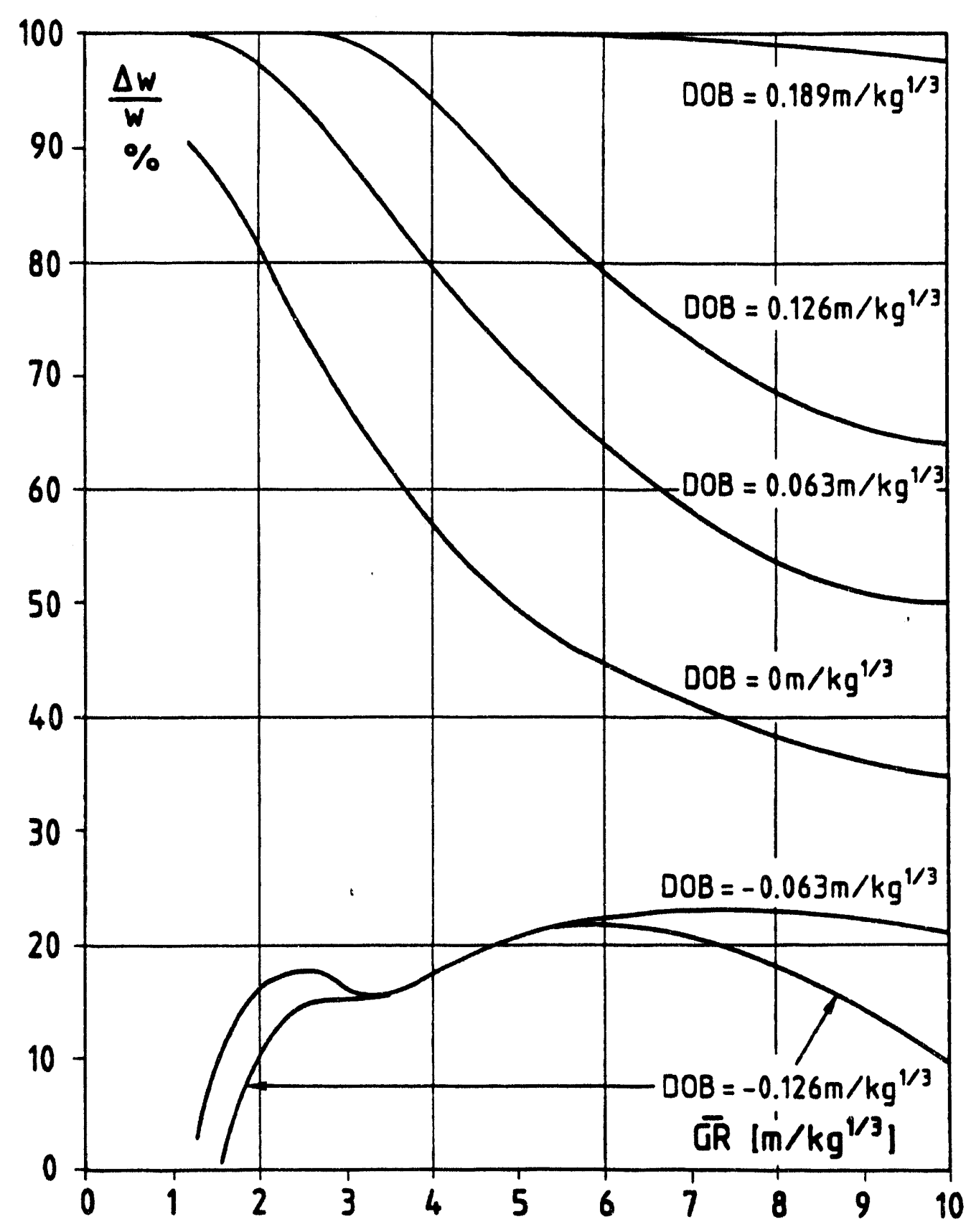

Figure 54 Percentage of Energy Losses vs Ground Range Soil material: clay/loam 


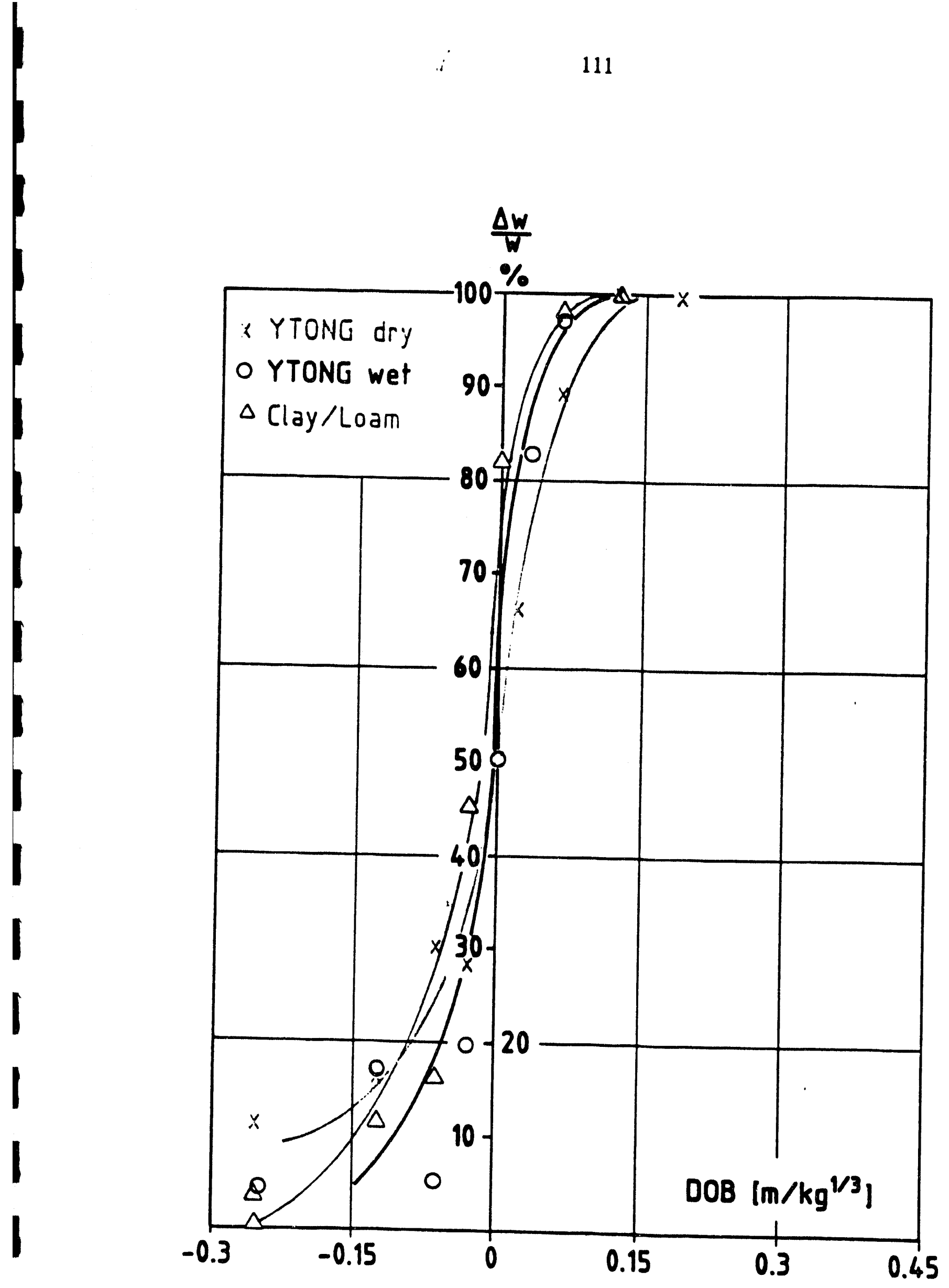

Figure 55 Percentage of Energy Losses vs DOB at GR $=2\left[\mathrm{~m} / \mathrm{kg}^{1 / 3}\right]$ 


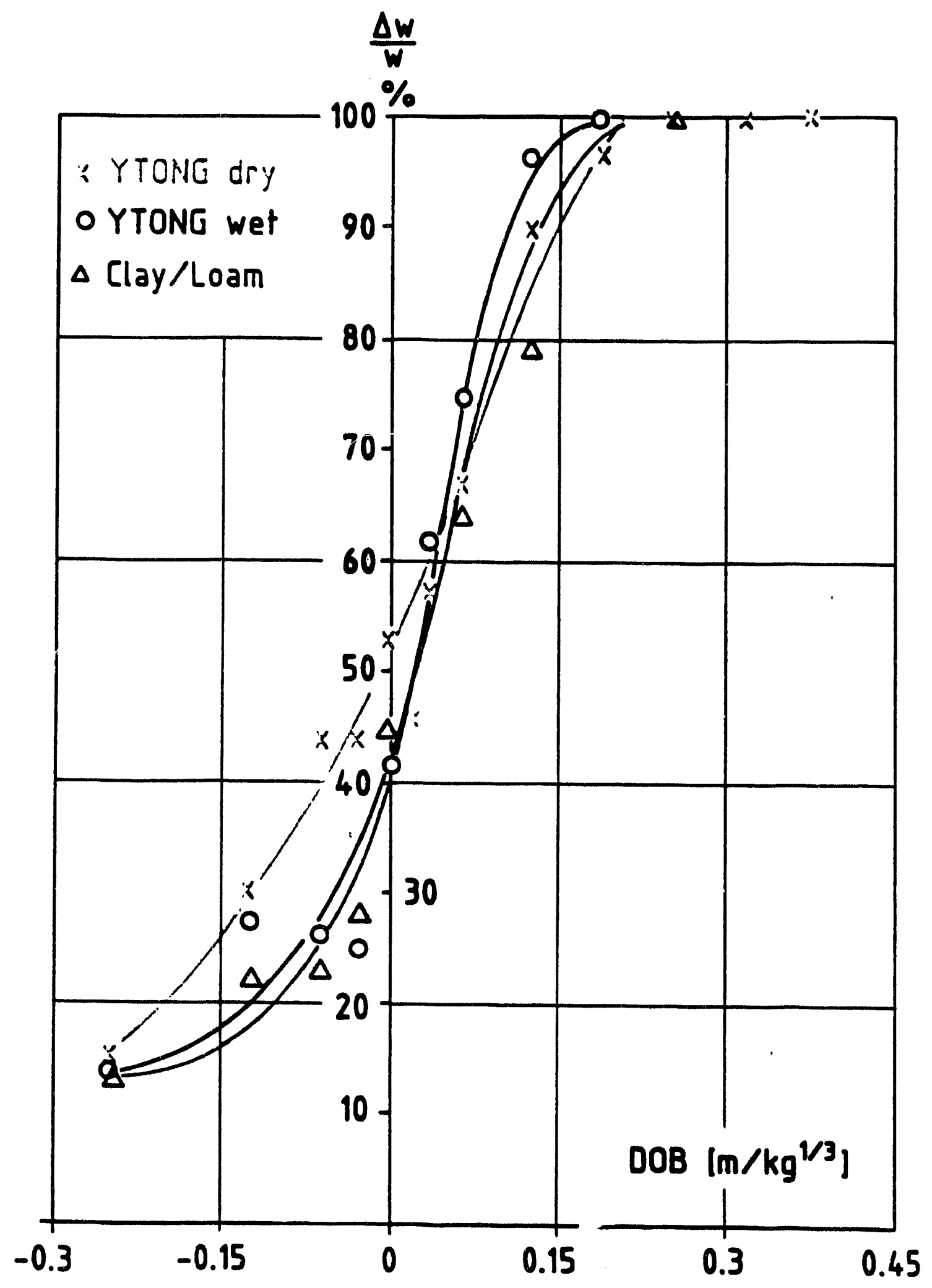

Figure 56 Percentage of Energy Losses vs DOB at GR $=6\left[\mathrm{~m} / \mathrm{kg}^{1 / 3}\right]$ 


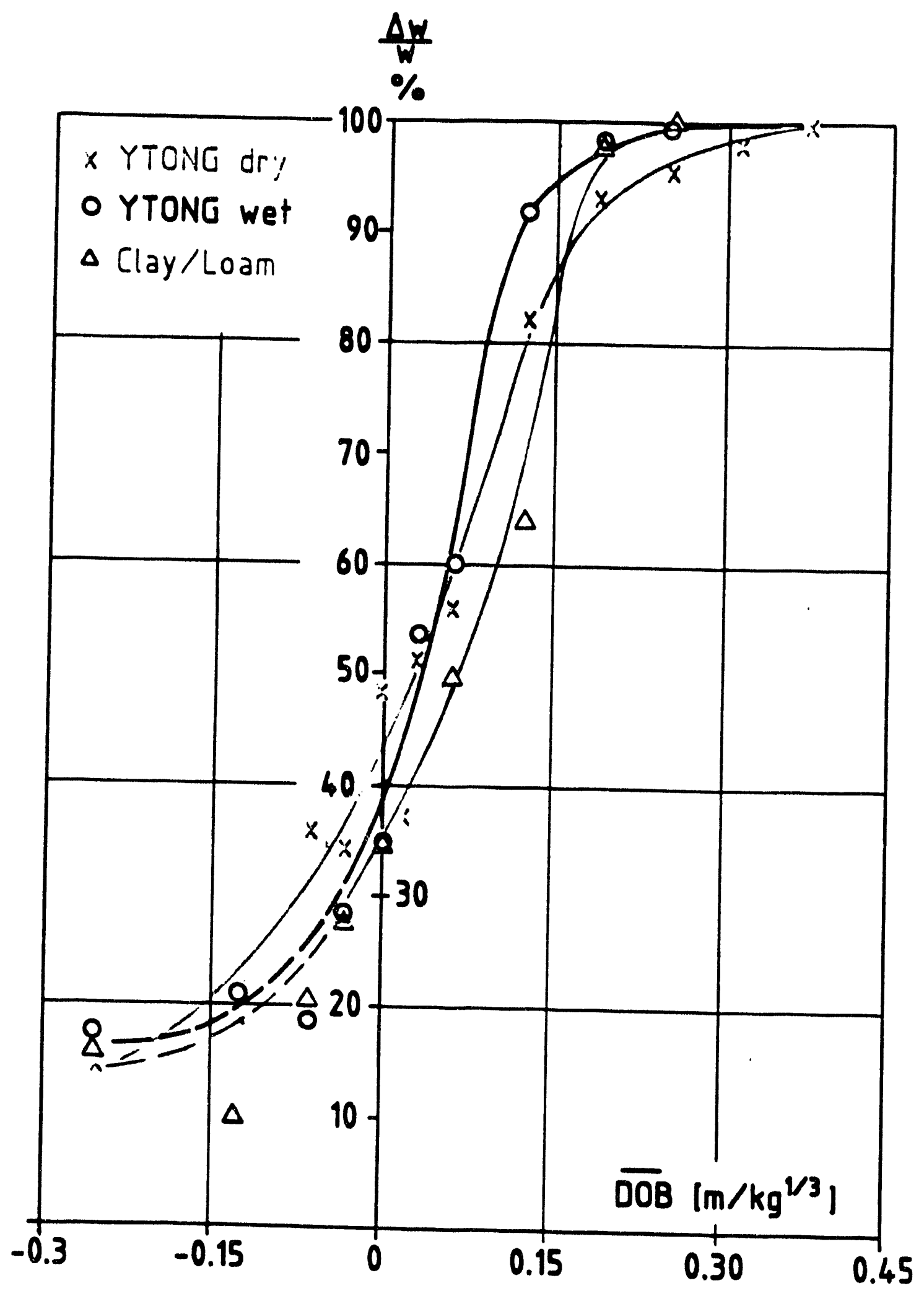

Figure 57 Percentage of Energy Losses vs DOB at GR $=10\left[\mathrm{~m} / \mathrm{kg}^{1 / 3}\right]$ 


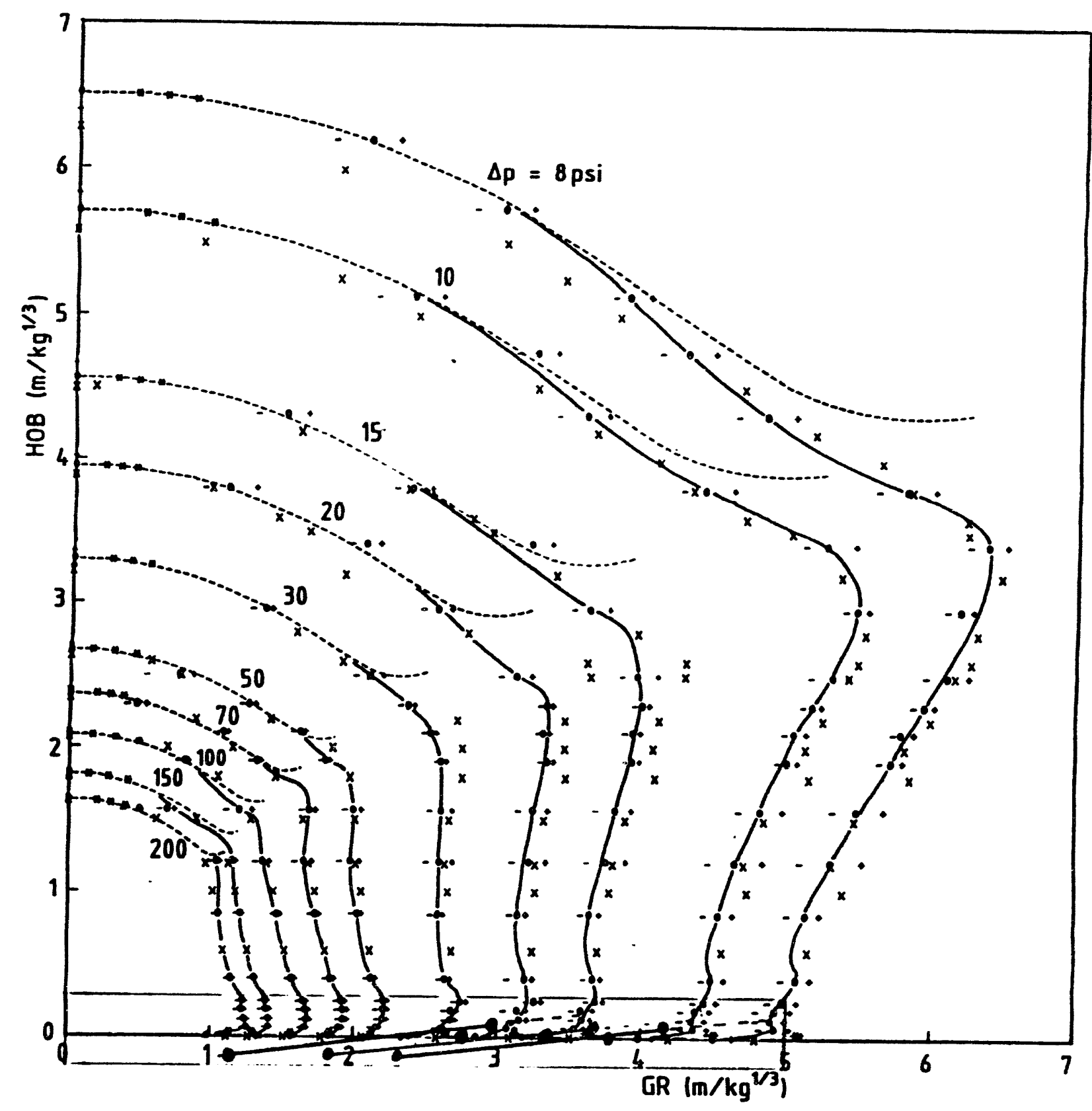



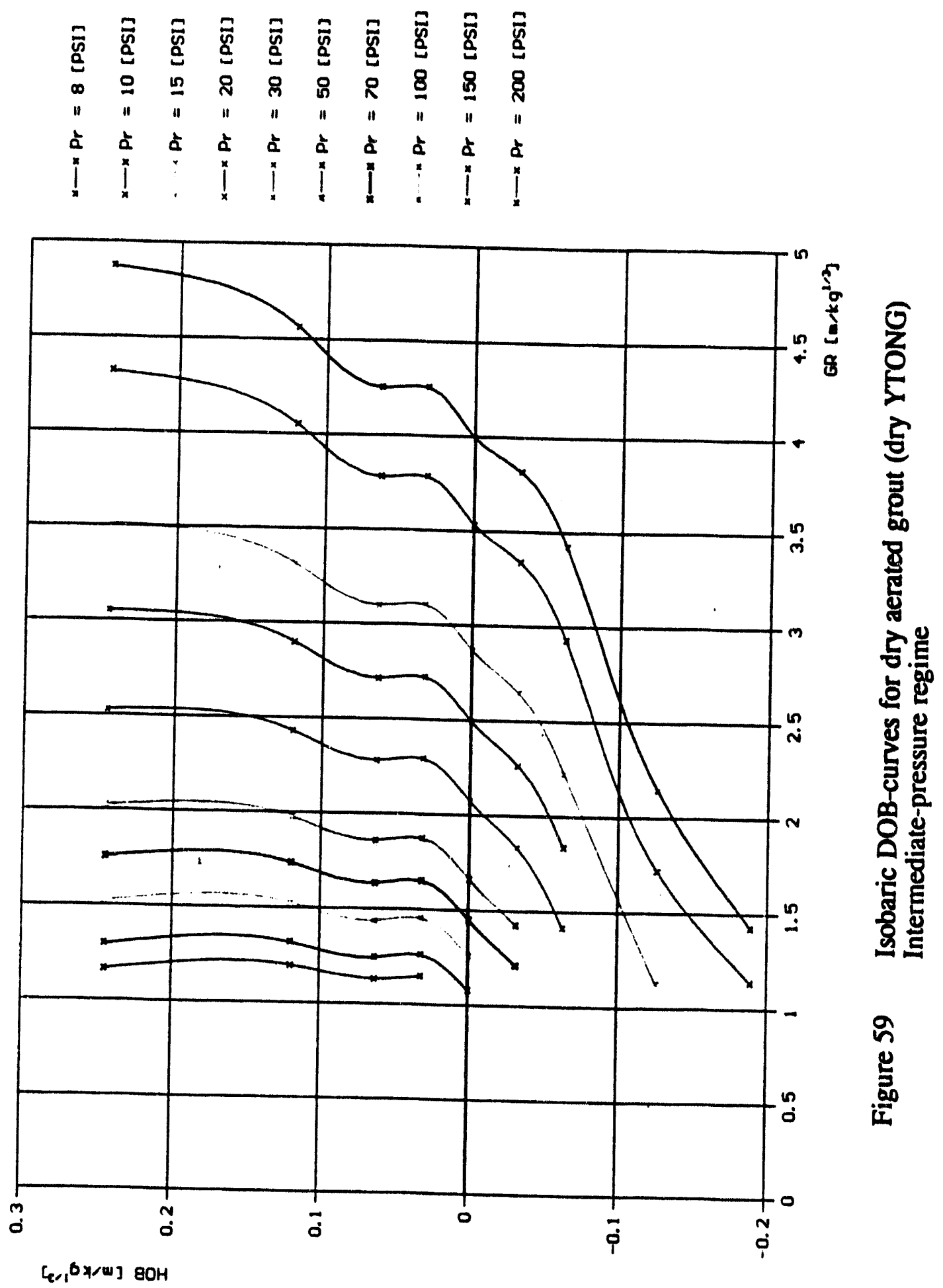


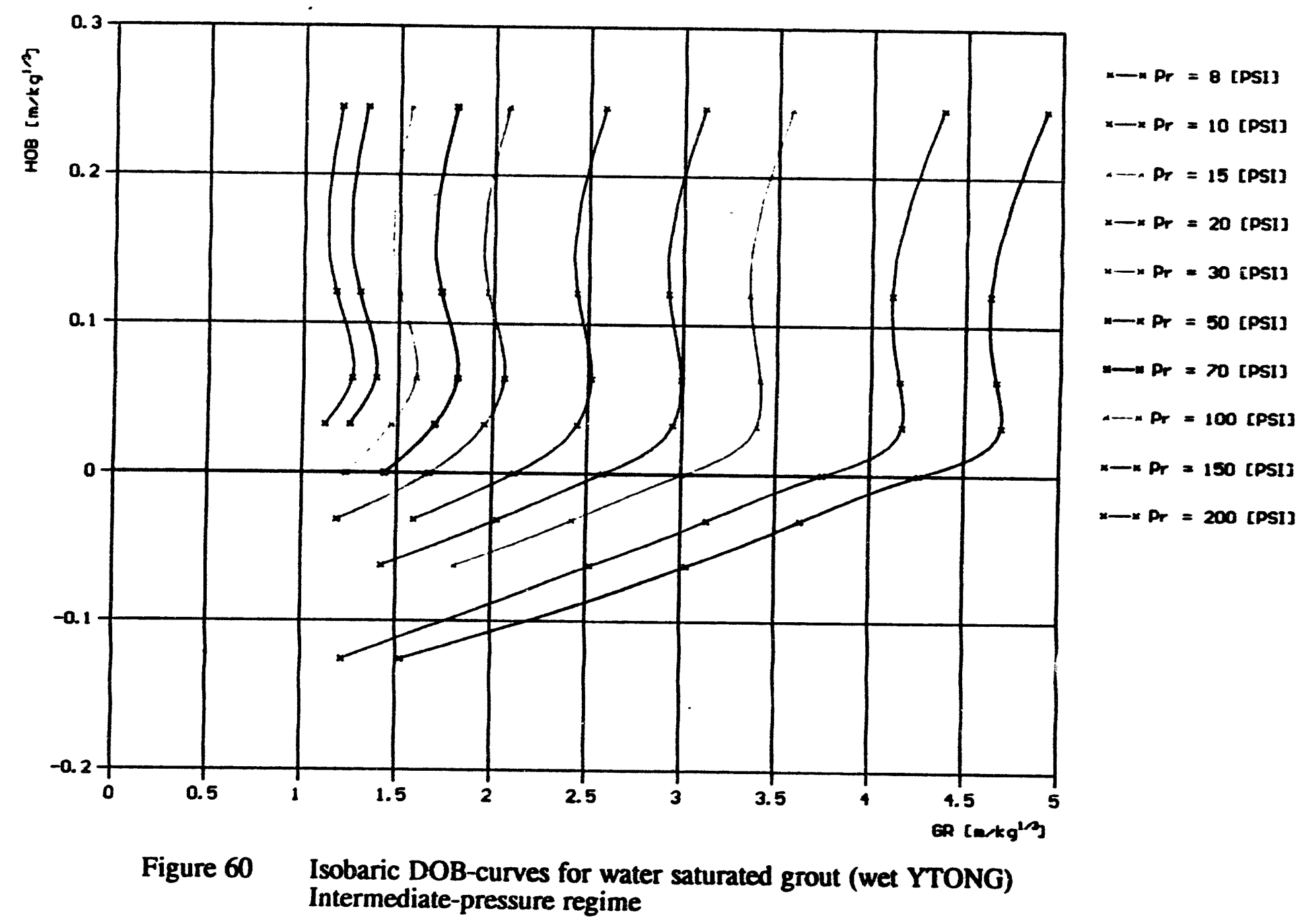




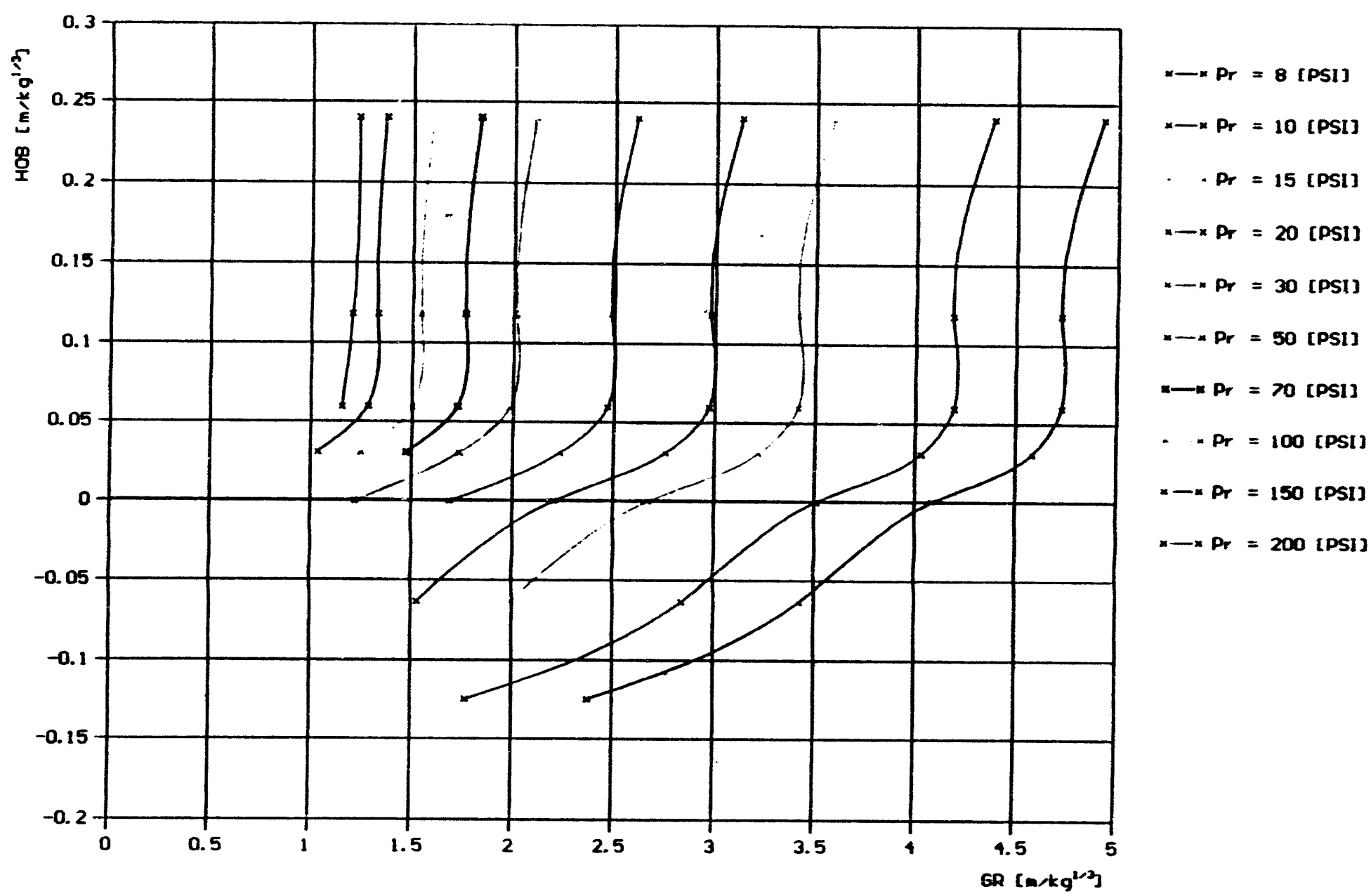

Figure 61 Isobaric DOB-curves for clay/loam Intermediate-pressure regime 

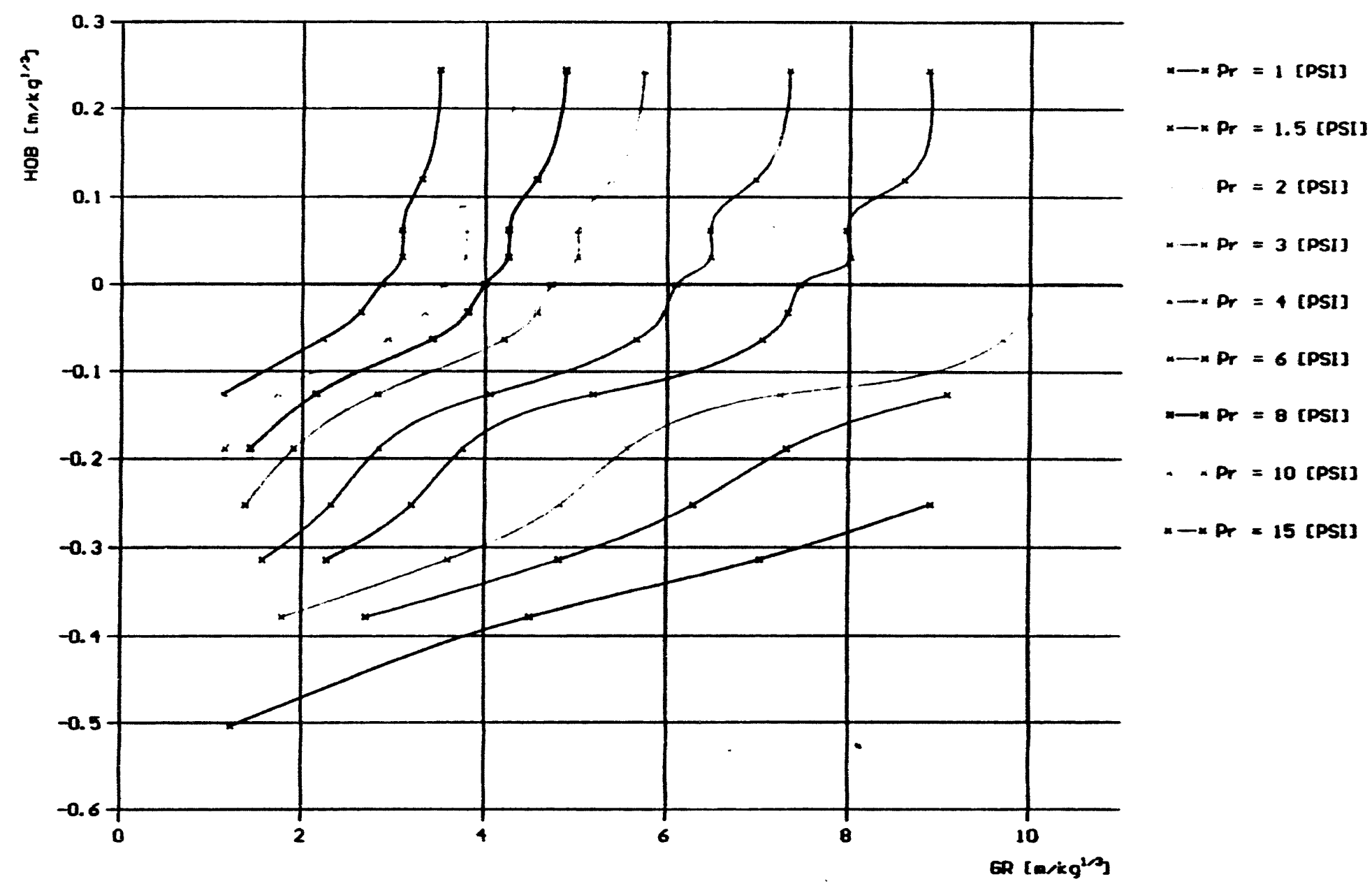

Figure 62 Isobaric DOB-curves for dry aerated grout (dry YTONG) Low-pressure regime 


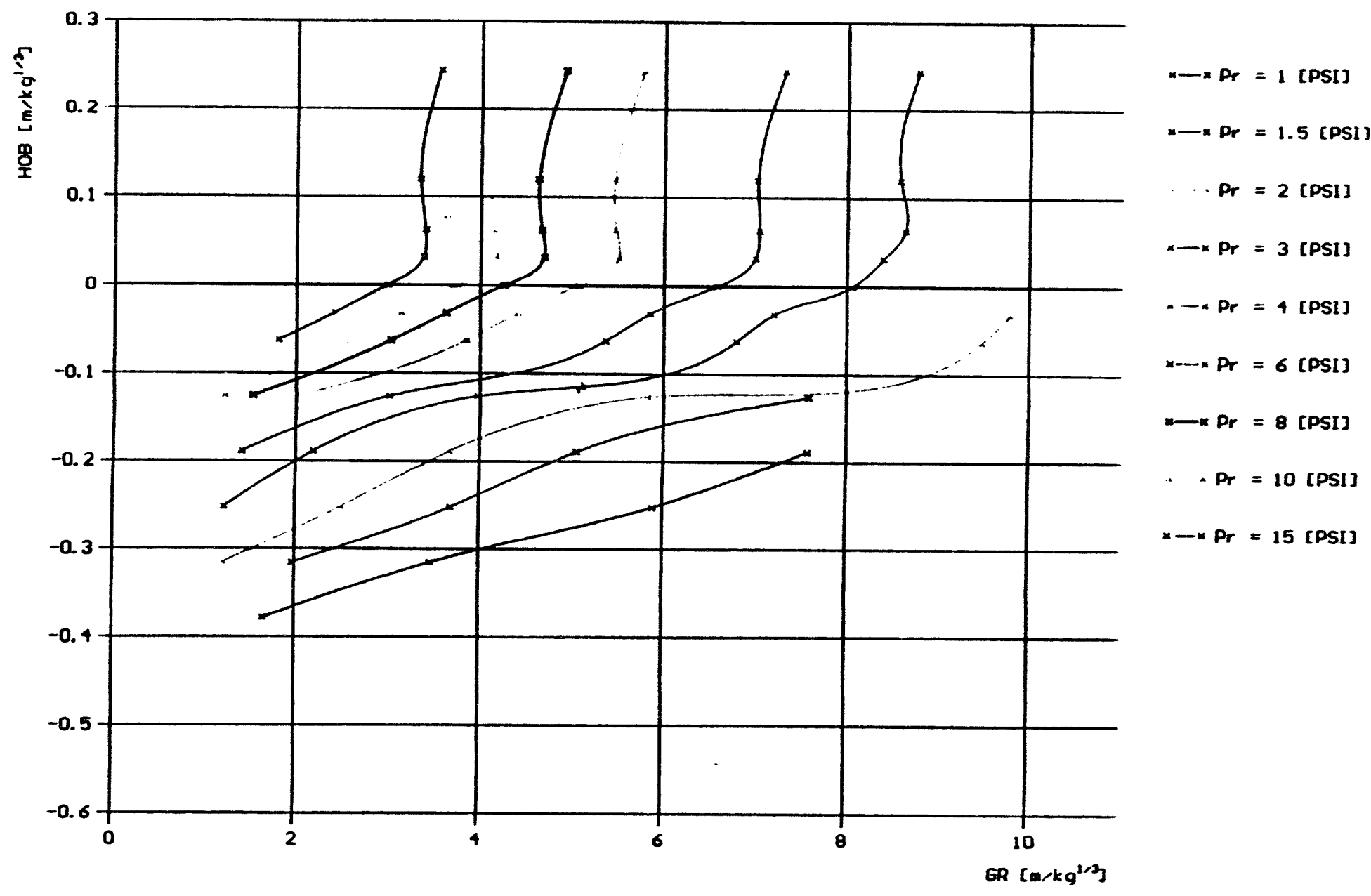

Figure 63 Isobaric DOB-curves for water saturated grout (wet YTONG) Low-pressure regime 


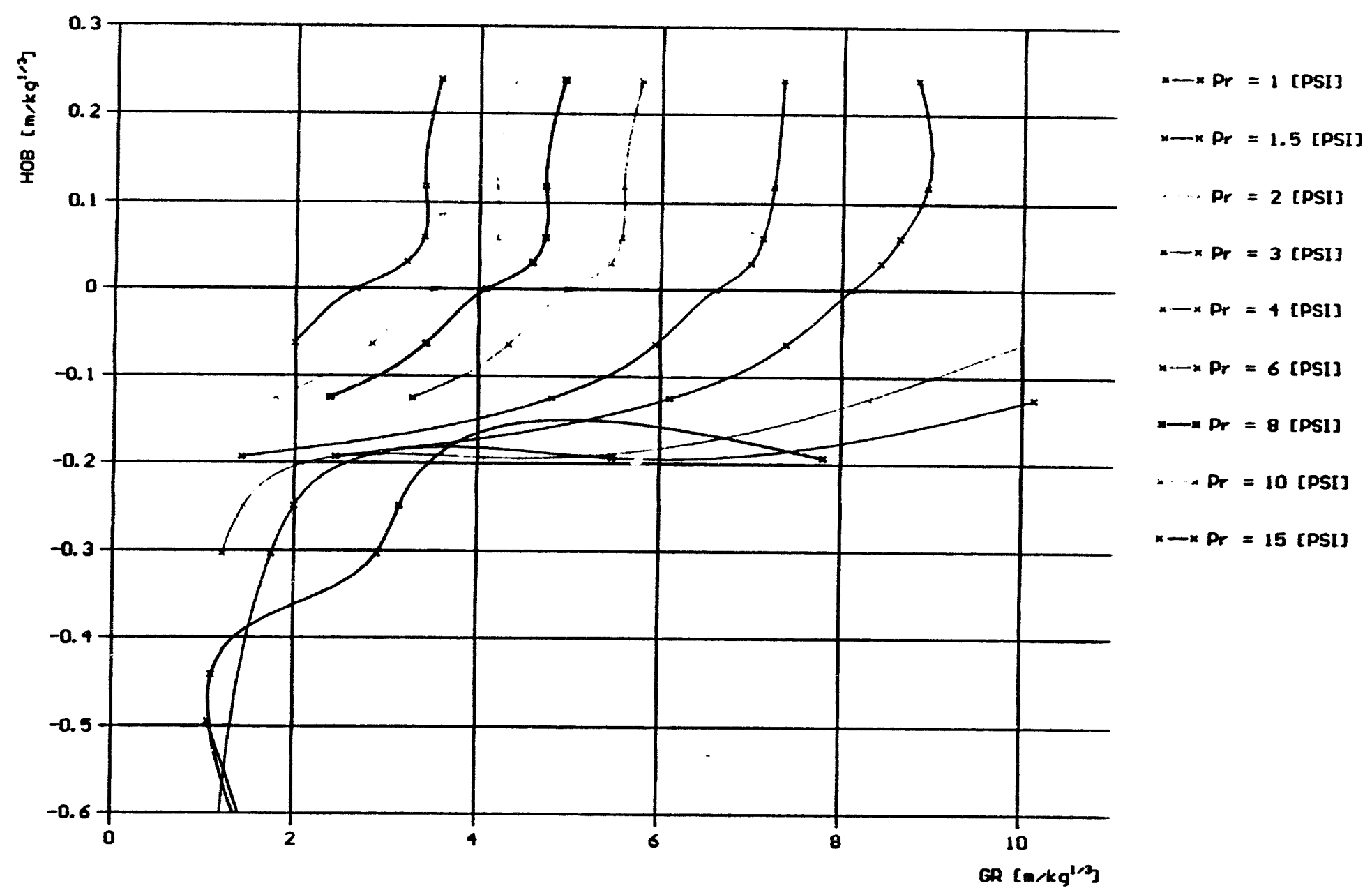

Figure 64 Isobaric DOB-curves for clay/loam Low-pressure regime 


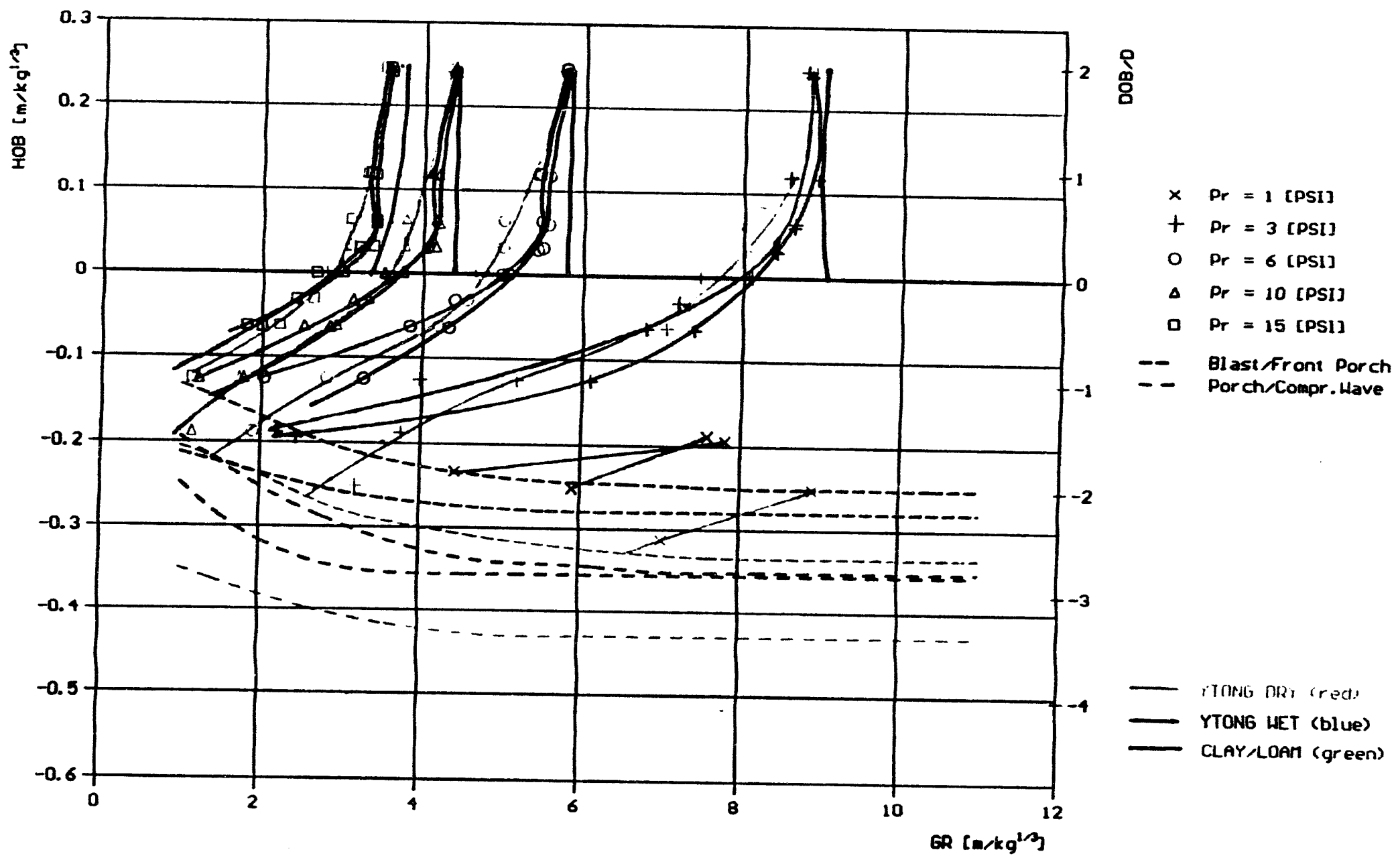

Figure 65 Comparison of isobaric DOB-curves for the three soil materials in the low-pressure regime. Black curves are valid for "hydrodynamically smooth surface".

Pressure parameter: 1 psi; 3 psi; 6 psi; 10 psi; 15 psi 


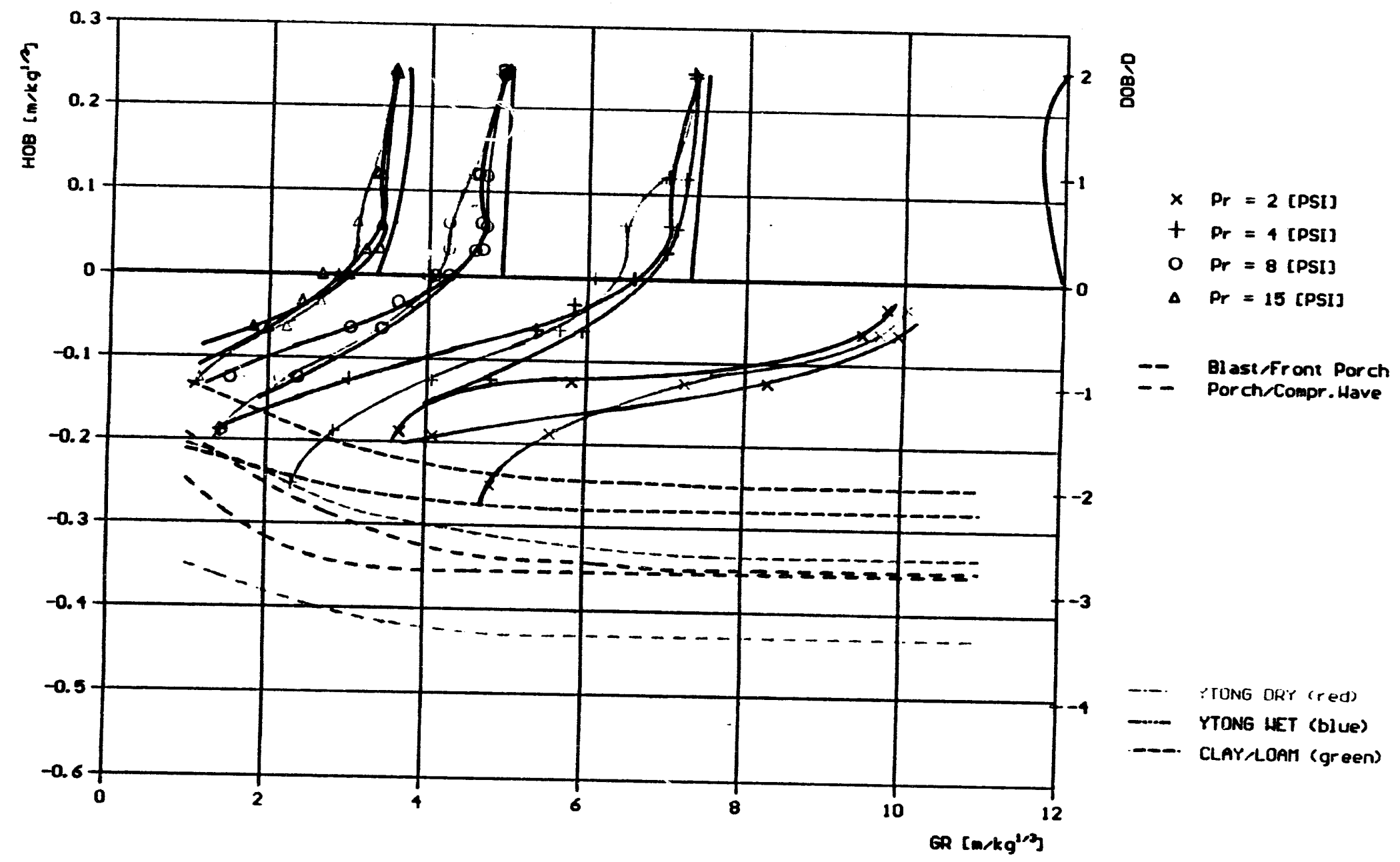

Figure 66 Comparison of isobaric DOB-curves for the three soil materials in the low-pressure regime. Black curves are valid for "hydrodynamically smooth surface".

Pressure parameter: 2 psi; 4 psi; 8 psi; 15 psi 
DOB Peak-Overpressure Curves

YTONG DRY, YTONG WET, CLAY,LLAM

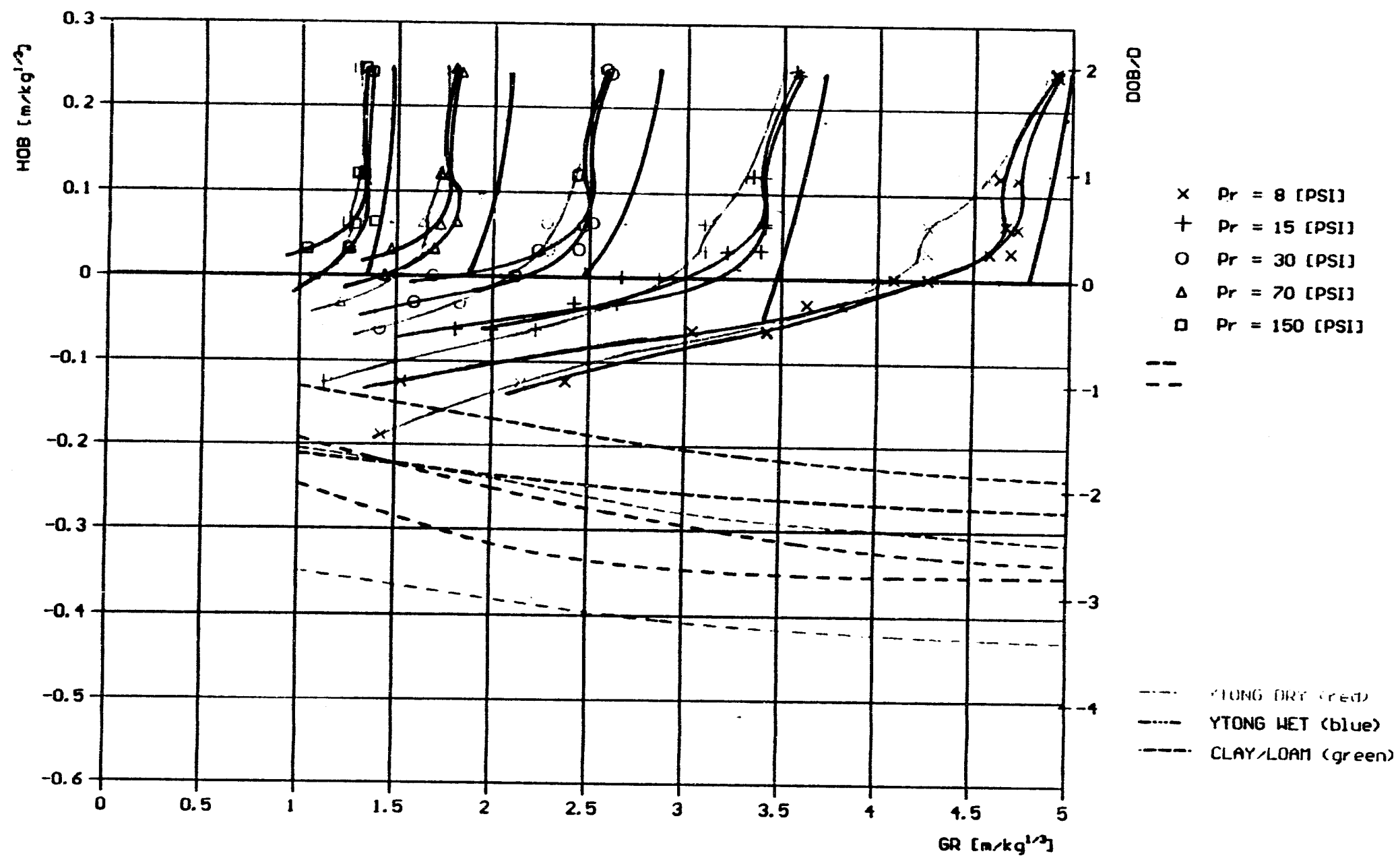

Figure 67 Comparison of isobaric DOB-curves for the three soil materials in the intermediate-pressure regime.

Black curves are valid for "hydrodynamically smooth surface".

Pressure parameter: 8 psi; 15 psi; 30 psi; 70 psi; 150 psi 


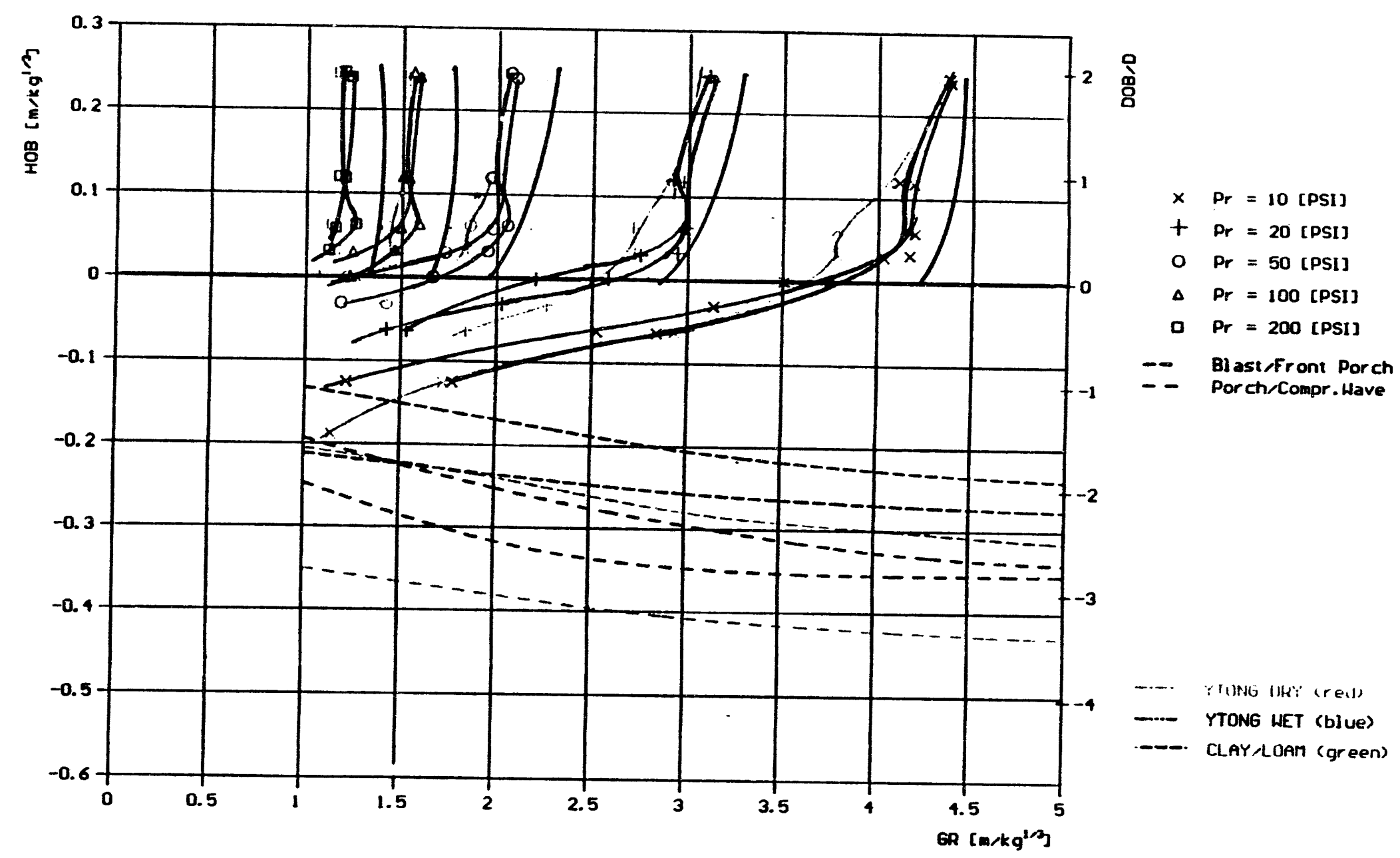

Figure 68 Comparison of isobaric DOB-curves for the three soil materials in the intermediate-pressure regime. Black curves are valid for "hydrodynamically smooth surface".

Pressure parameter: $10 \mathrm{psi} ; 20 \mathrm{psi} ; 50 \mathrm{psi} ; 100 \mathrm{psi} ; 200 \mathrm{psi}$ 

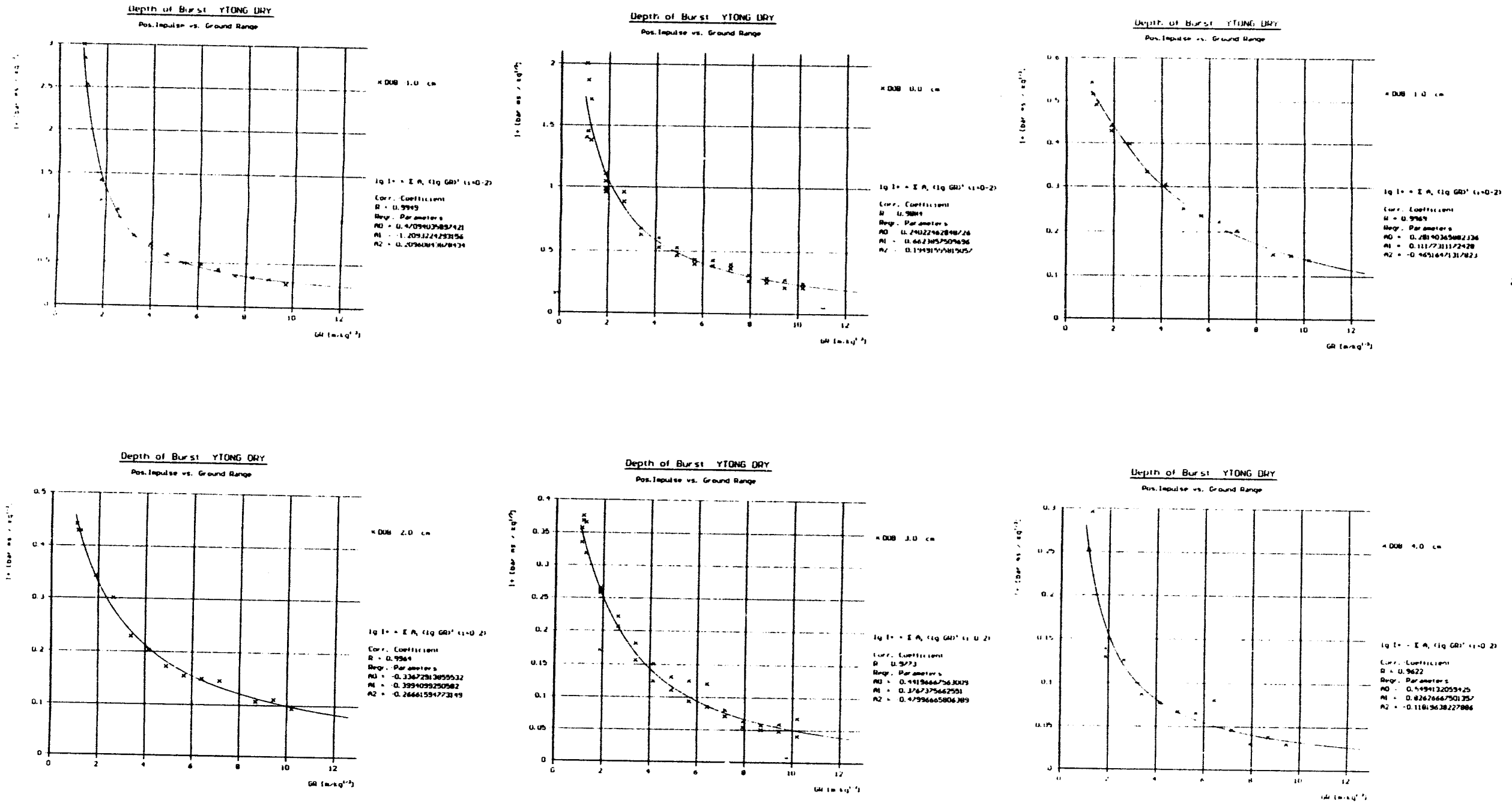

Figure 69

Positive phase impulse vs ground range at different DOB. Soil material: dry aerated grout
(dry YTONG) (dry YTONG)

DOB $=-1.0 \mathrm{~cm}$; $\mathrm{DOB}=2.0 \mathrm{~cm}$;

$$
\begin{array}{ll}
\mathrm{DOB}=0 \mathrm{~cm} ; & \mathrm{DOB}=1.0 \mathrm{~cm} \\
\mathrm{DOB}=3.0 \mathrm{~cm} ; & \mathrm{DOB}=4.0 \mathrm{~cm}
\end{array}
$$



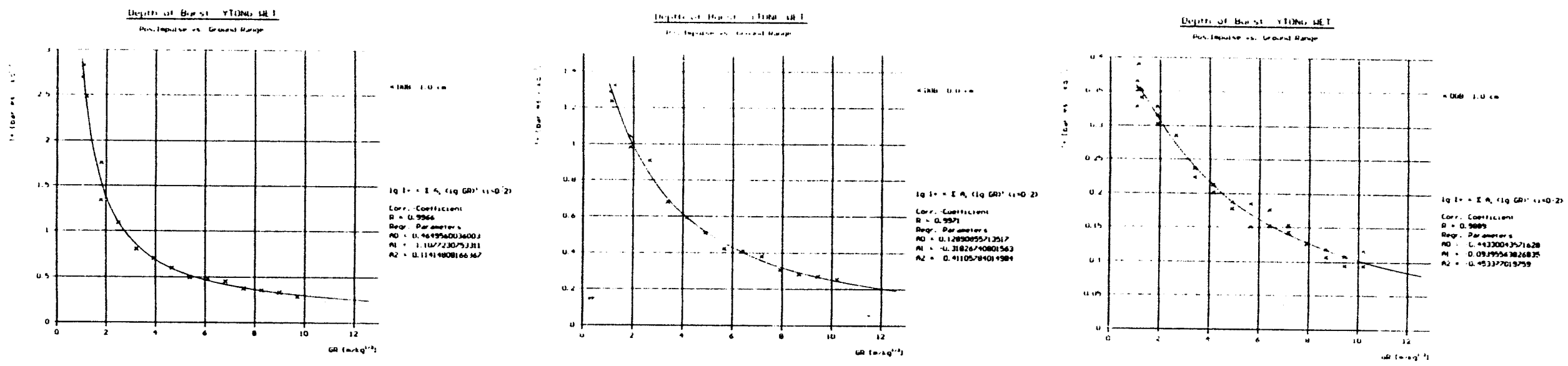

a
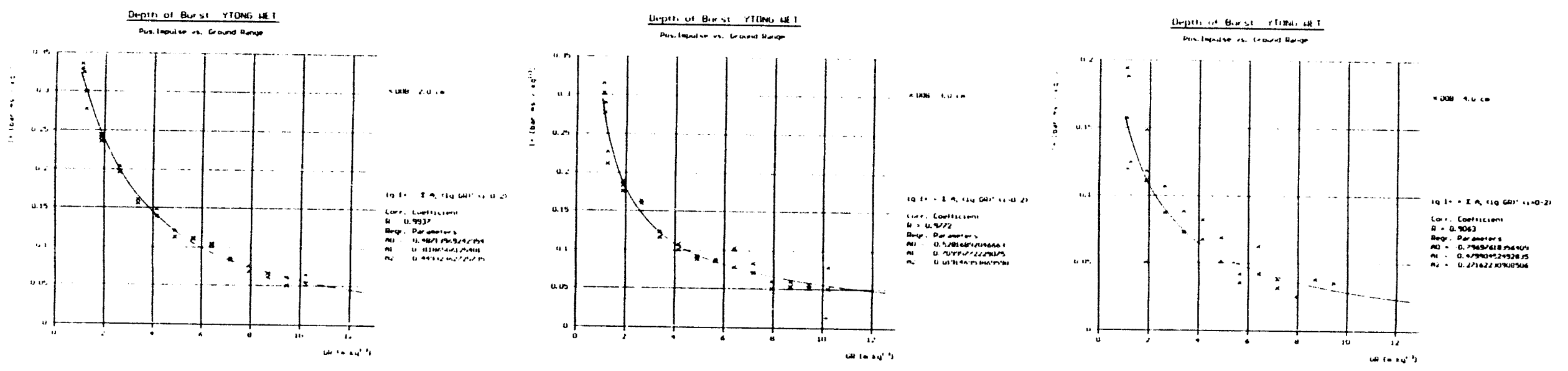

Figure 70

Positive phase impul

DOB $=-1.0 \mathrm{~cm}$;

$\mathrm{DOB}=2.0 \mathrm{~cm}$;

$\mathrm{DOB}=0 \mathrm{~cm}$;

$\mathrm{DOB}=3.0 \mathrm{~cm}$;

$\mathrm{DOB}=1.0 \mathrm{~cm}$

$\mathrm{DOB}=4.0 \mathrm{~cm}$ 

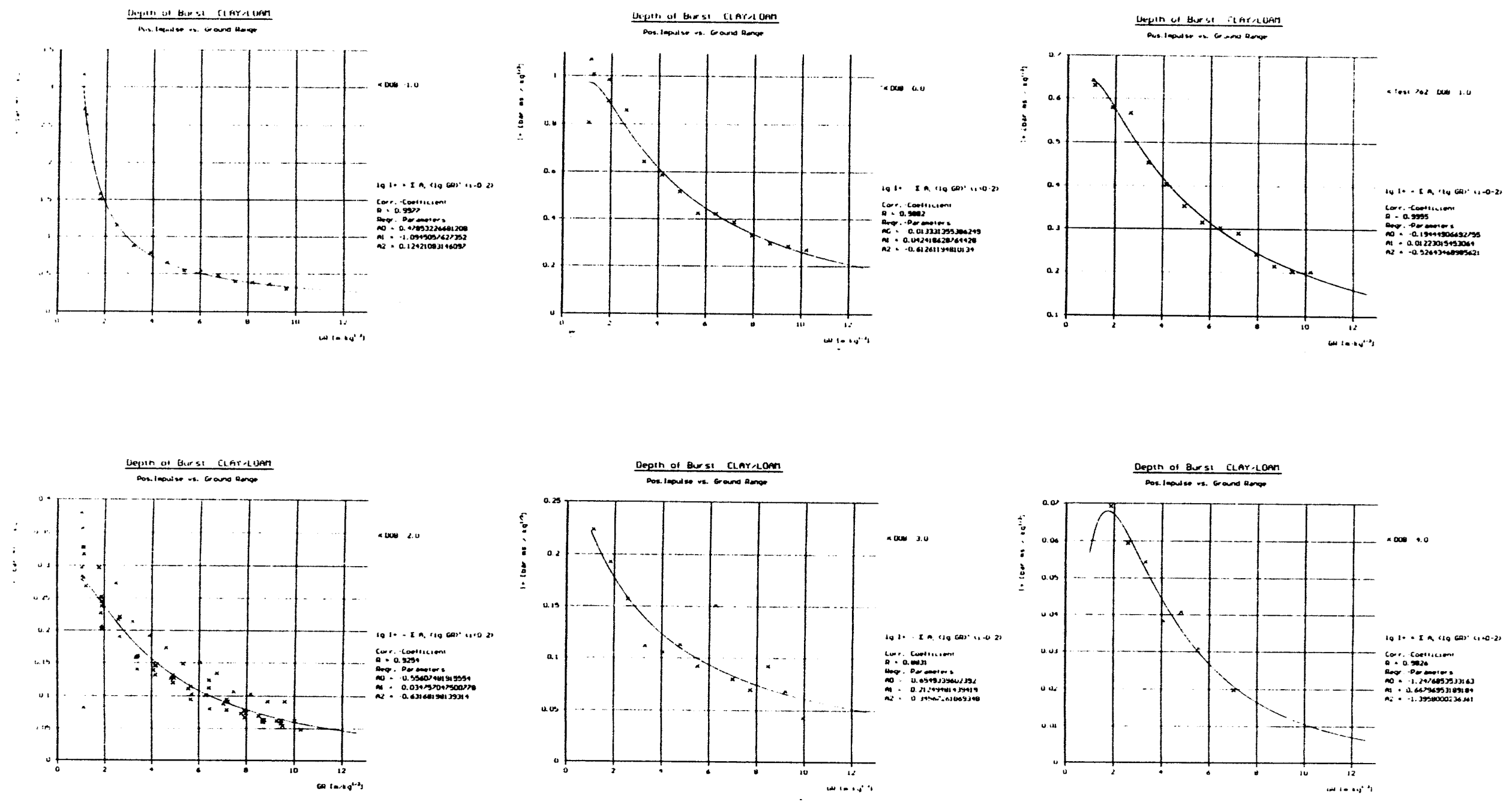

Figure 71 Positive phase impulse vs ground range at different DOB. Soil material: clay/loam $\mathrm{DOB}=-1.0 \mathrm{~cm} ; \quad \mathrm{DOB}=0 \mathrm{~cm} ; \quad \mathrm{DOB}=1.0 \mathrm{~cm}$ $\mathrm{DOB}=2.0 \mathrm{~cm} ; \quad \mathrm{DOB}=3.0 \mathrm{~cm} ; \quad \mathrm{DOB}=4.0 \mathrm{~cm}$ 


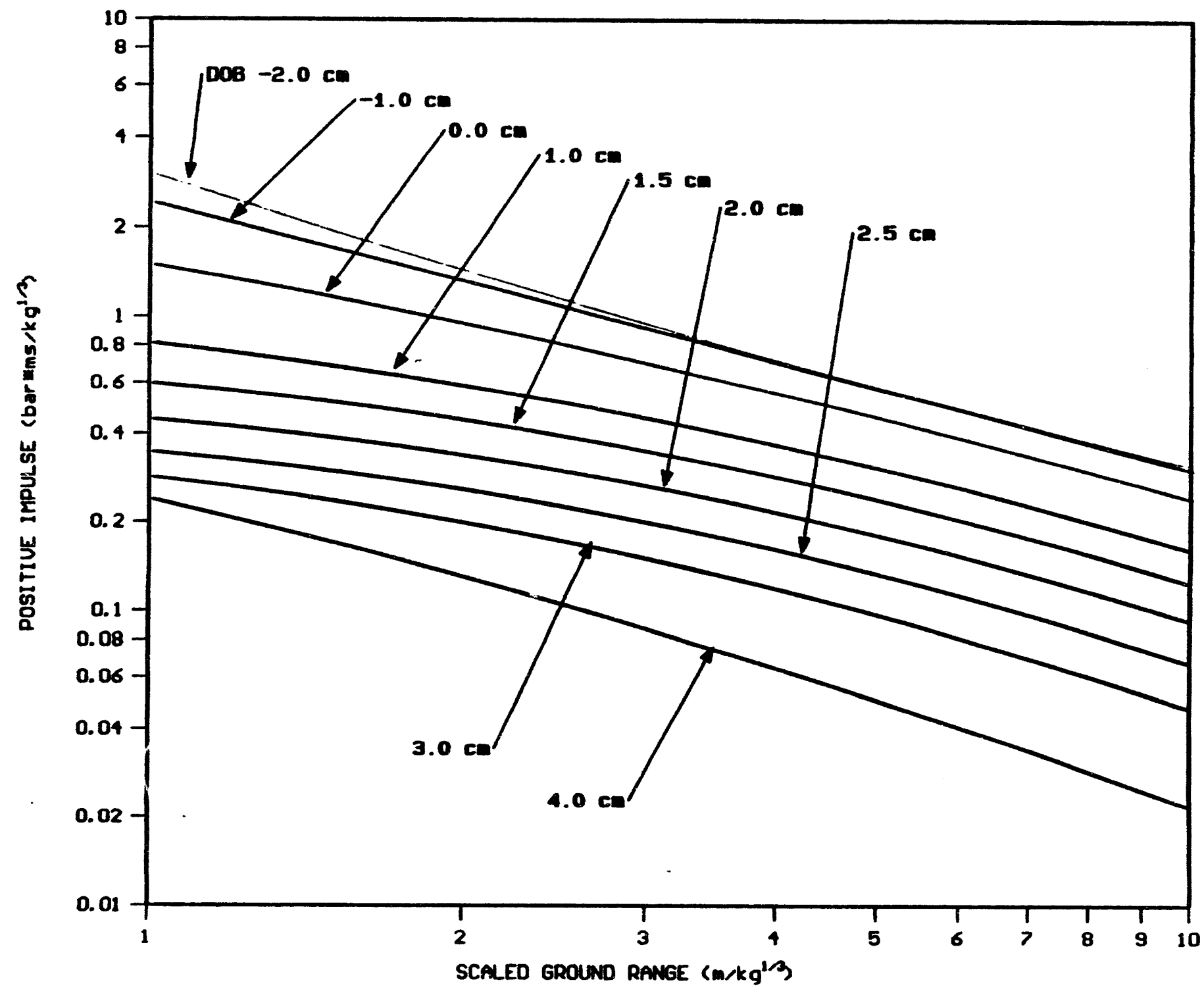

Figure 72 Logarithmic plot for impulse-range curves.

Soil material: aerated grout (dry YTONG) 


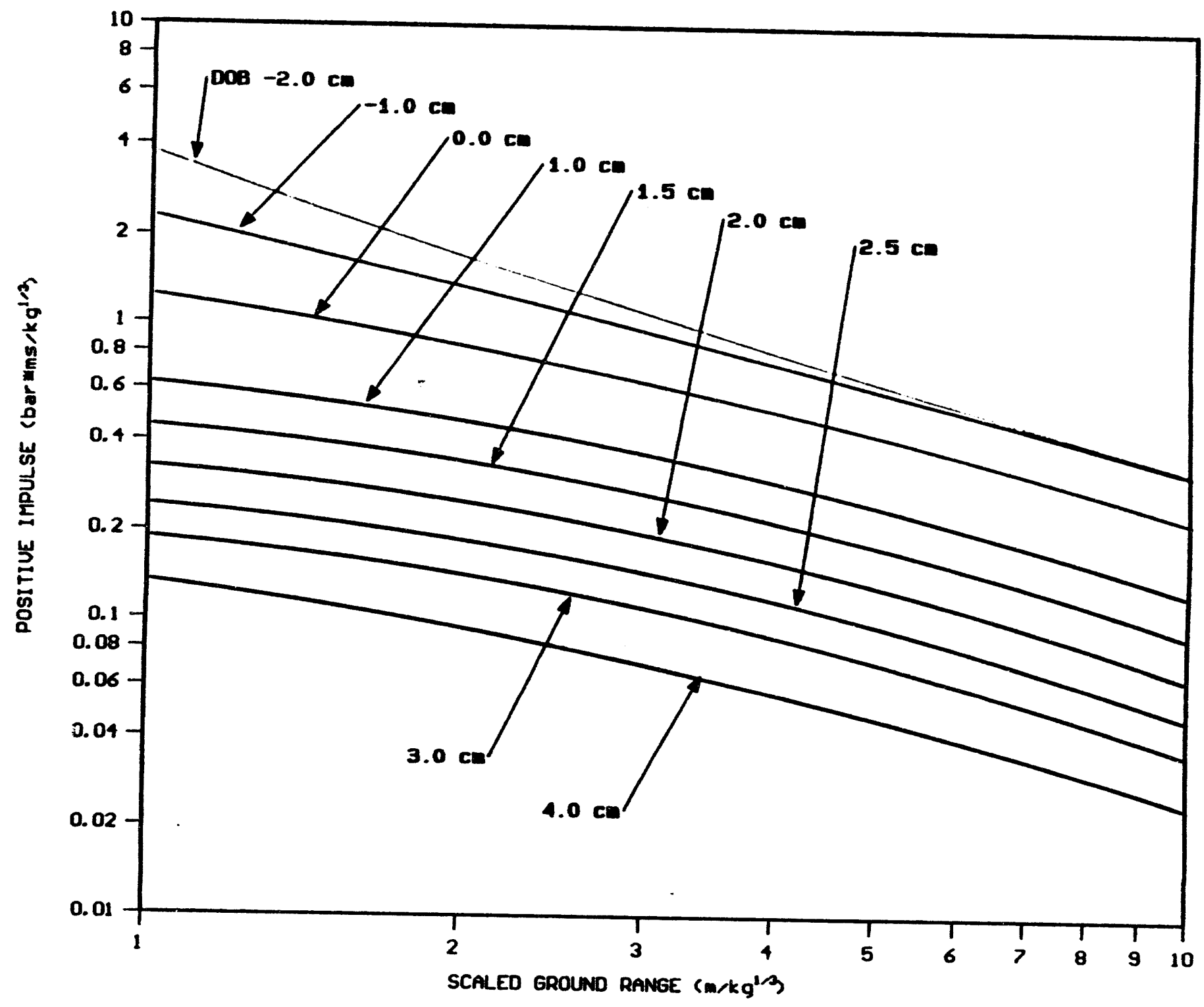

Figure 73 Logarithmic plots for impulse-range curves Soil material: water saturated grout (wet YTONG) 


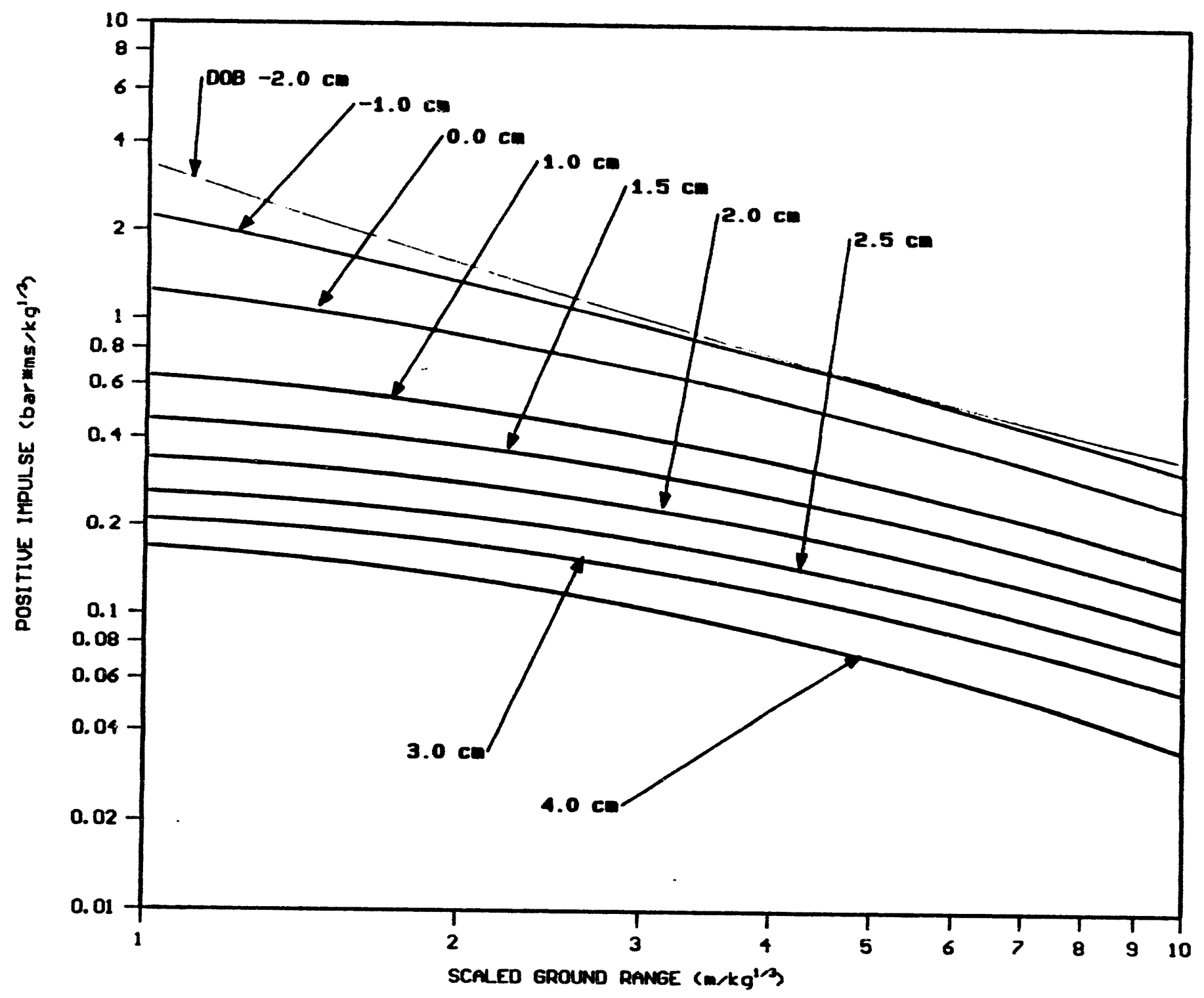

Figure 74 Logarithmic plots for impulse-range curves Soil material: clay/loam 


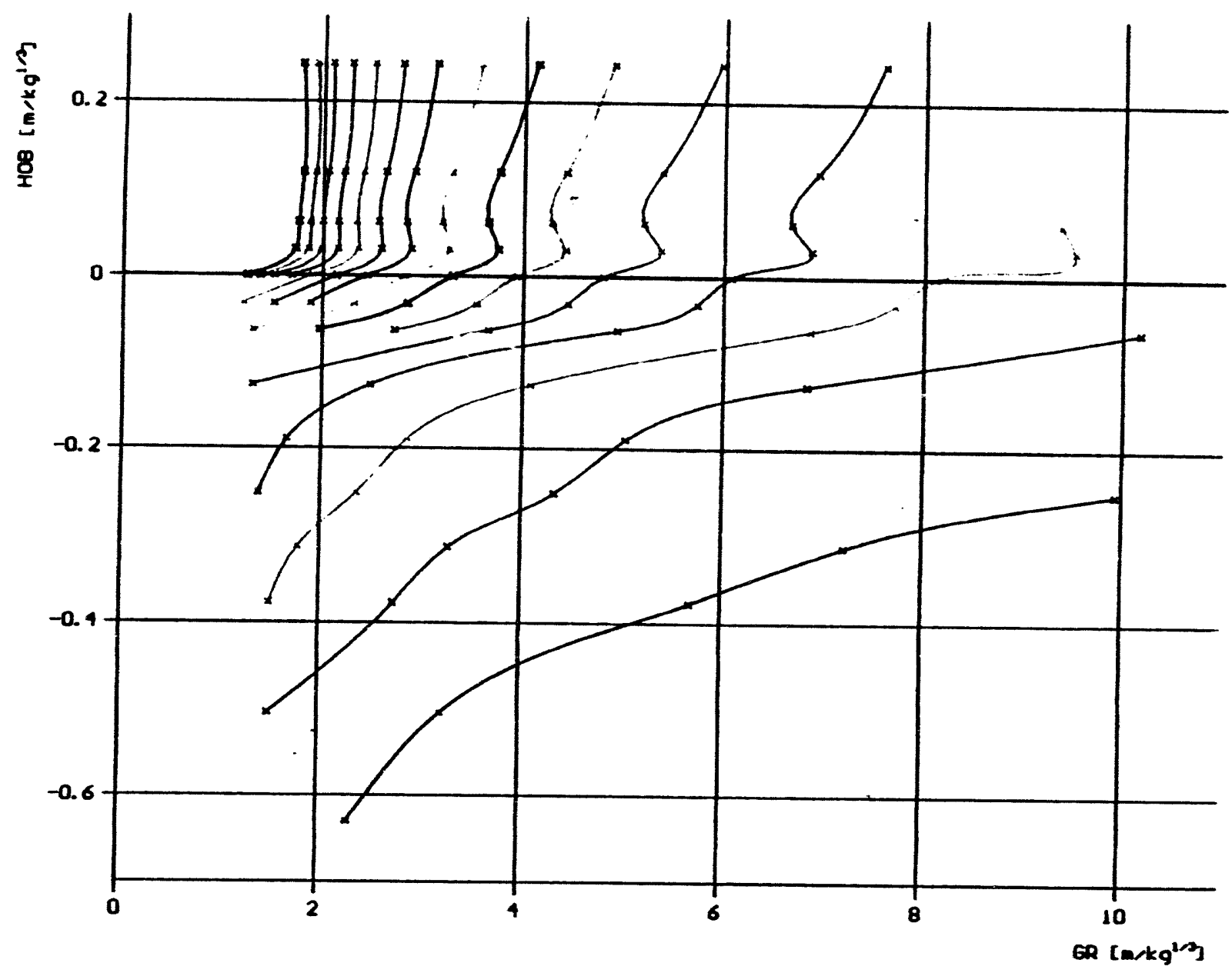

*-* I+ $=0.1$ [barmms $/ k^{1 / 3}$ ] $\times 1+=0.2$ [barms $/ \mathrm{kg}^{1 / 3}$ ] …. It $=0.3$ cbarmas $/ k^{2 / 3}$ \#-1+ $=0.4$ [barmas/kg1/3] n $* 1+=0.5$ [barmas/kg/3) $\ldots 1+=0.6$ [barmms $/ k^{1 / 3}$ - It = 0.7 [barmas/kg/3] ... It $=0.8$ cbarmms/kg/3] $\because \ldots 1+=0.9$ cbarmins $/ k^{1 / 3}$ $x$-x I+ $=1$ [barmas/kgi/3] $--* 1+=1.1$ [barmas $/ \mathrm{kg}^{2 / 3}$ ] $-\infty 1+=1.2$ [barmins $/ \mathrm{kg}^{1 / 3}$

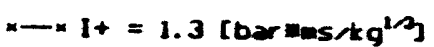
$\leadsto \ldots I+=1.4$ cbarmos $/ k g^{13}$ WI+ = 1.5 cbarmaskgi3

Figure 75 Iso-impulse DOB curves for aerated grout (dry YTONG) 


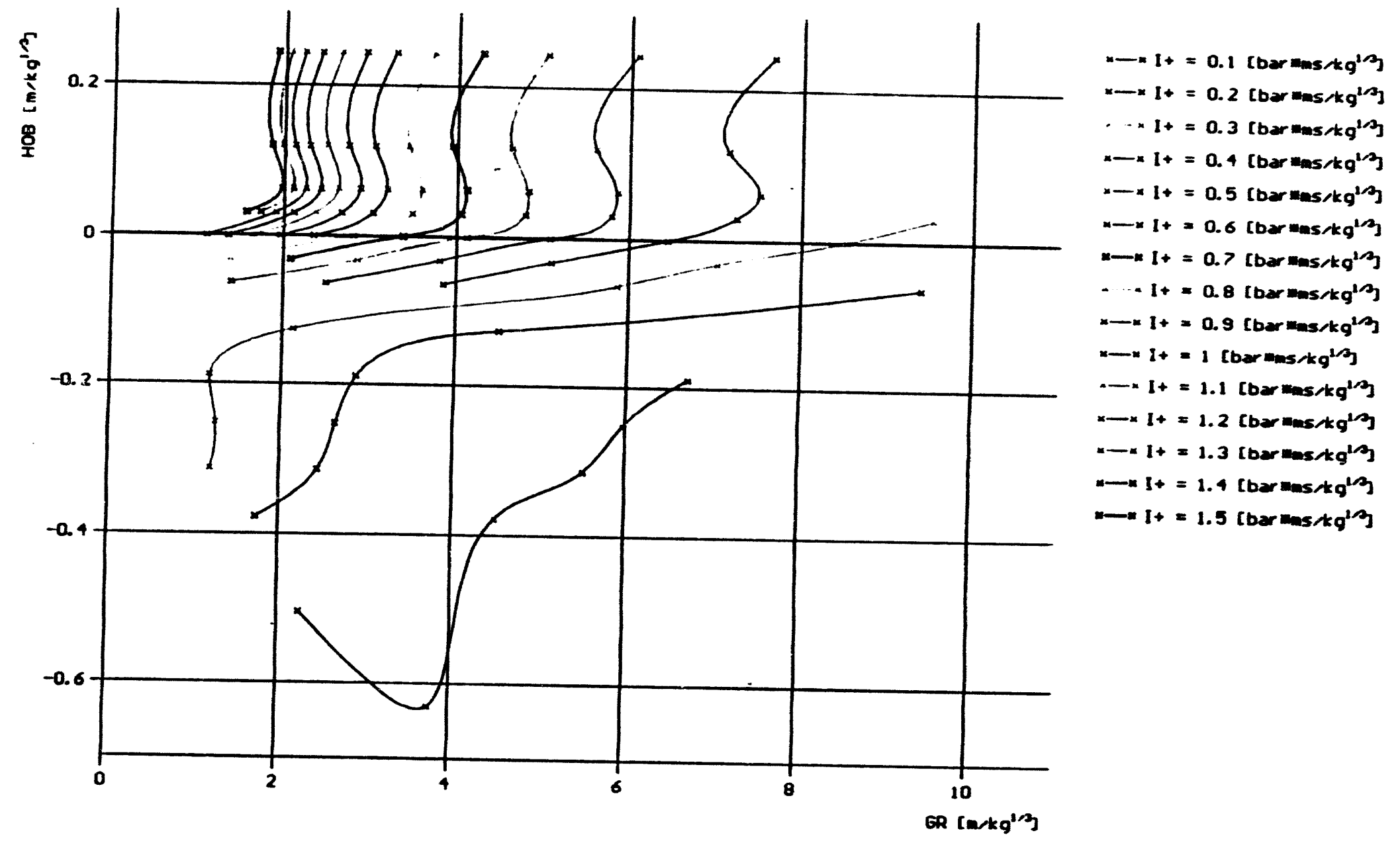

Figure 76 Iso-impulse DOB curves for water saturated grout (wet YTONG) 


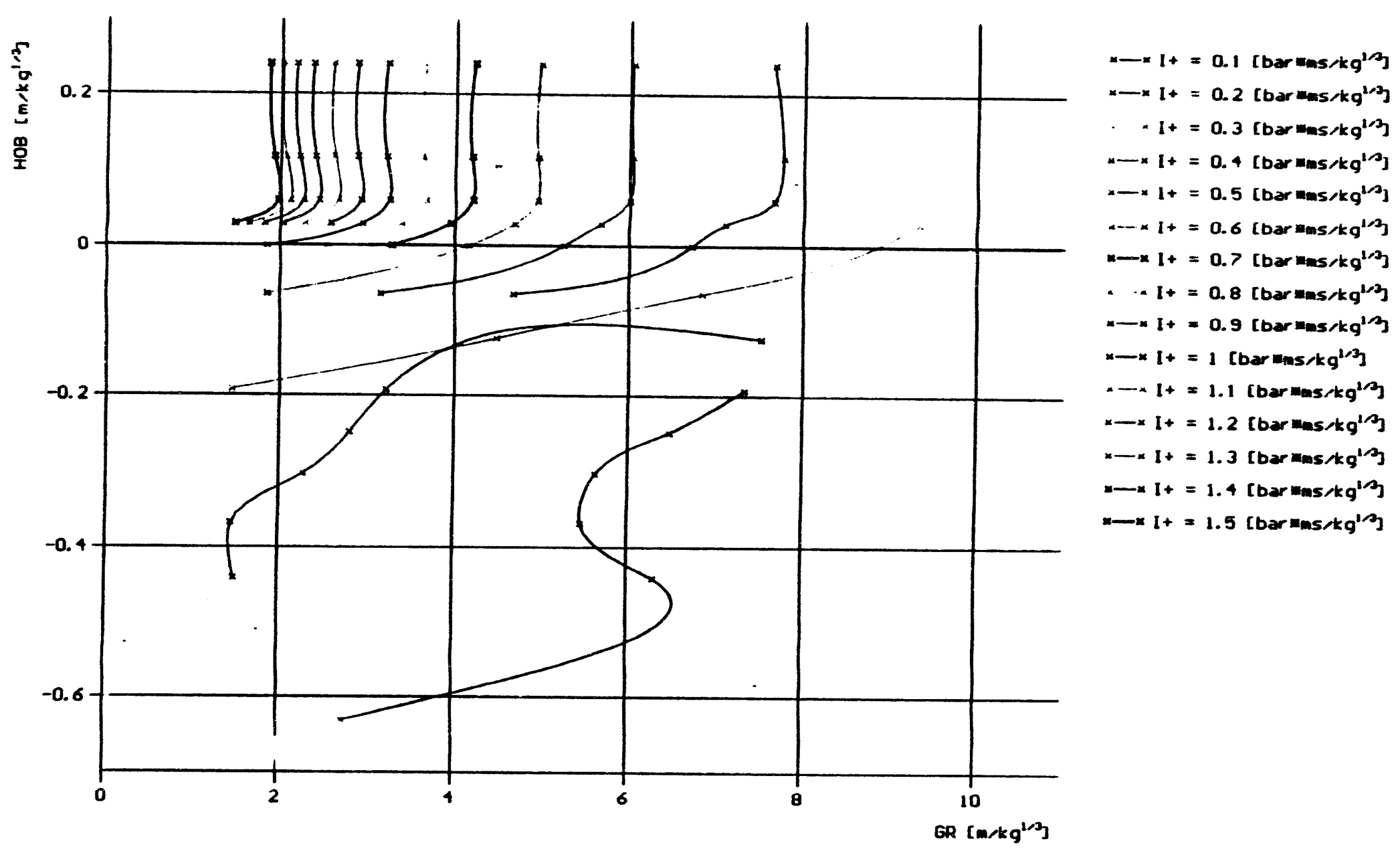

$\vec{w}$

Figure 77 Iso-impulse DOB-curves for clay/loam. 

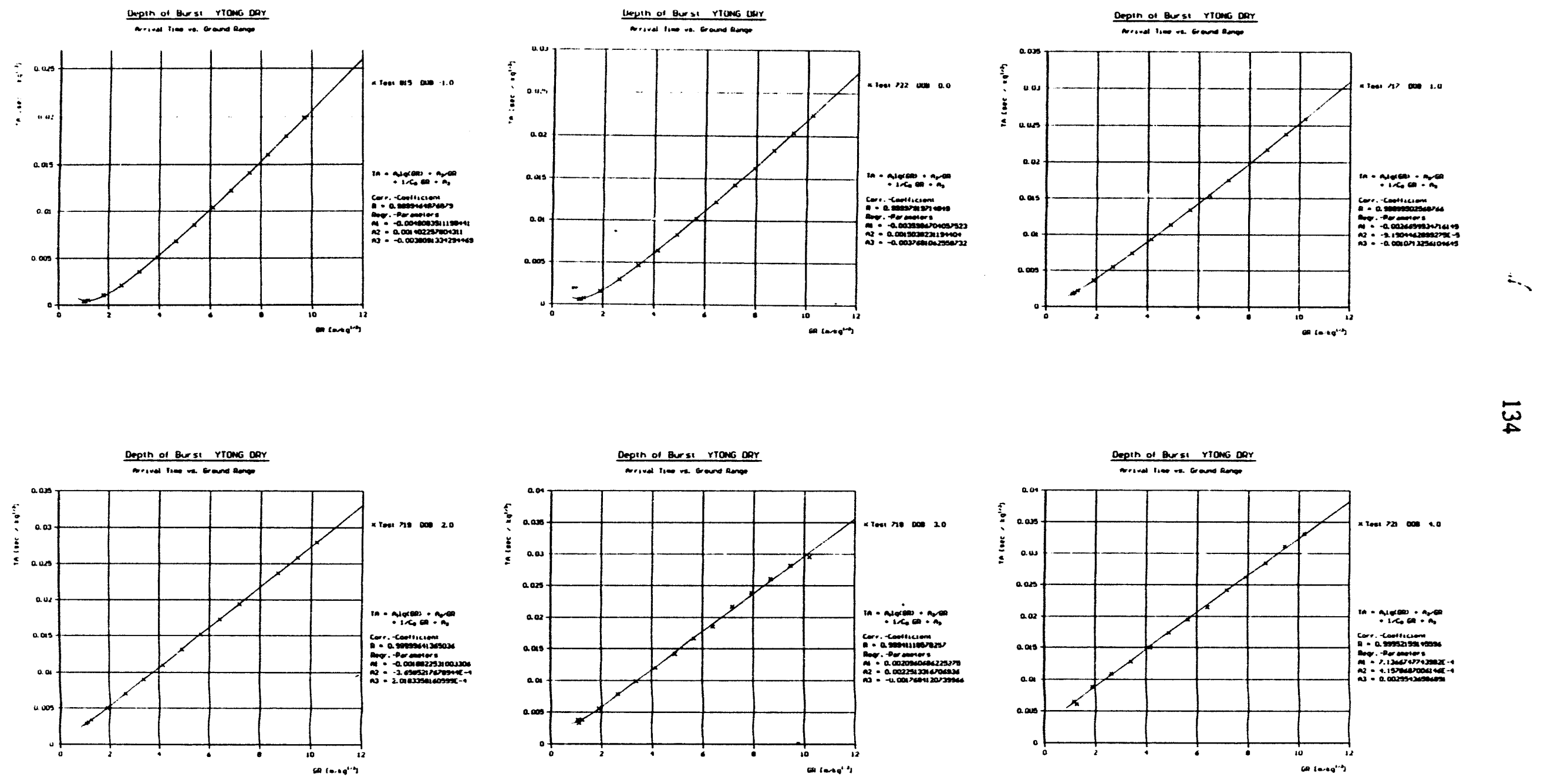

Figure 78

Time of arrival vs ground range at different DOB. Soil material: dry aerated grout (dry YTONG) $\mathrm{DOB}=-1.0 \mathrm{~cm}$; $\mathrm{DOB}=0 \mathrm{~cm}$; $\mathrm{DOB}=1.0 \mathrm{~cm}$ $\mathrm{DOB}=2.0 \mathrm{~cm}$; 


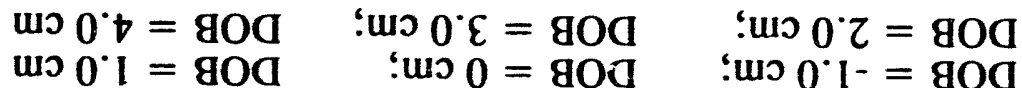

'wo $0^{\circ} 1-=$ gOC

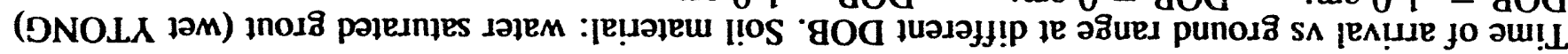

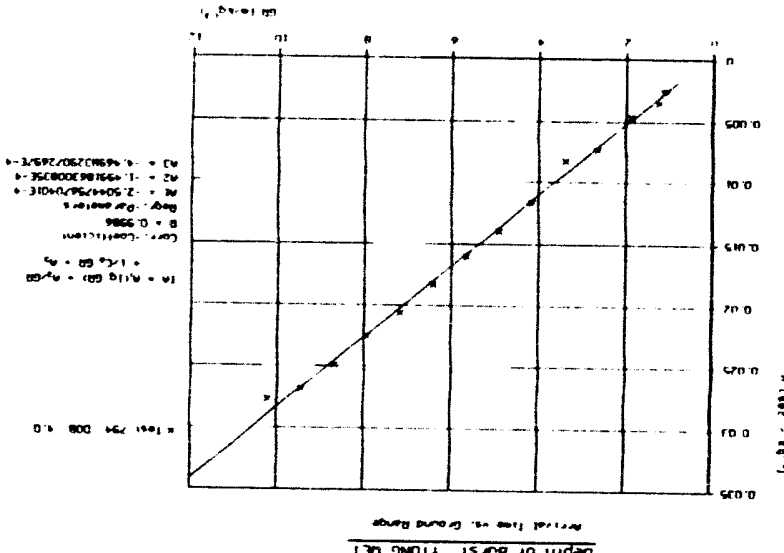

$\check{2}$
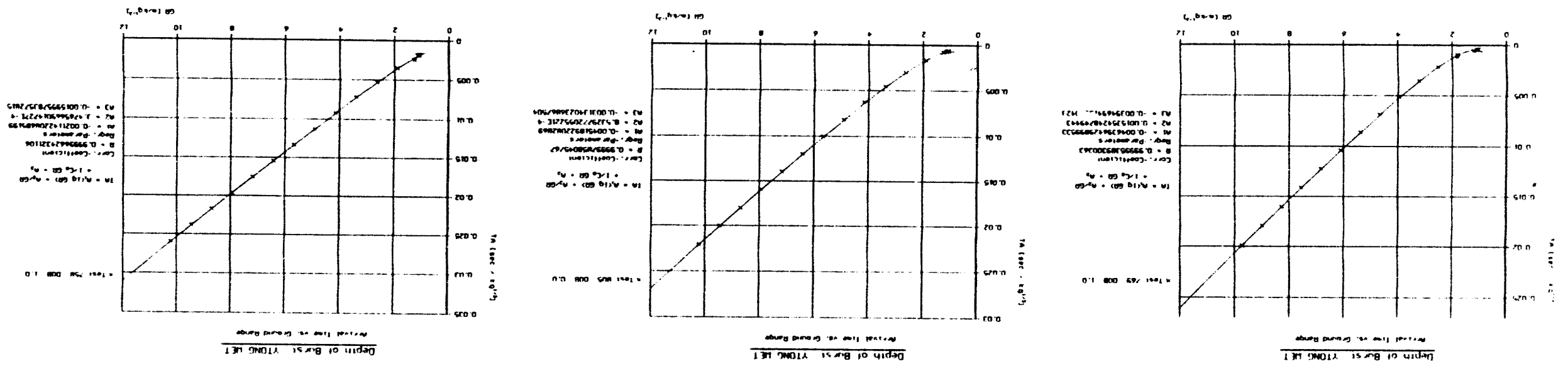
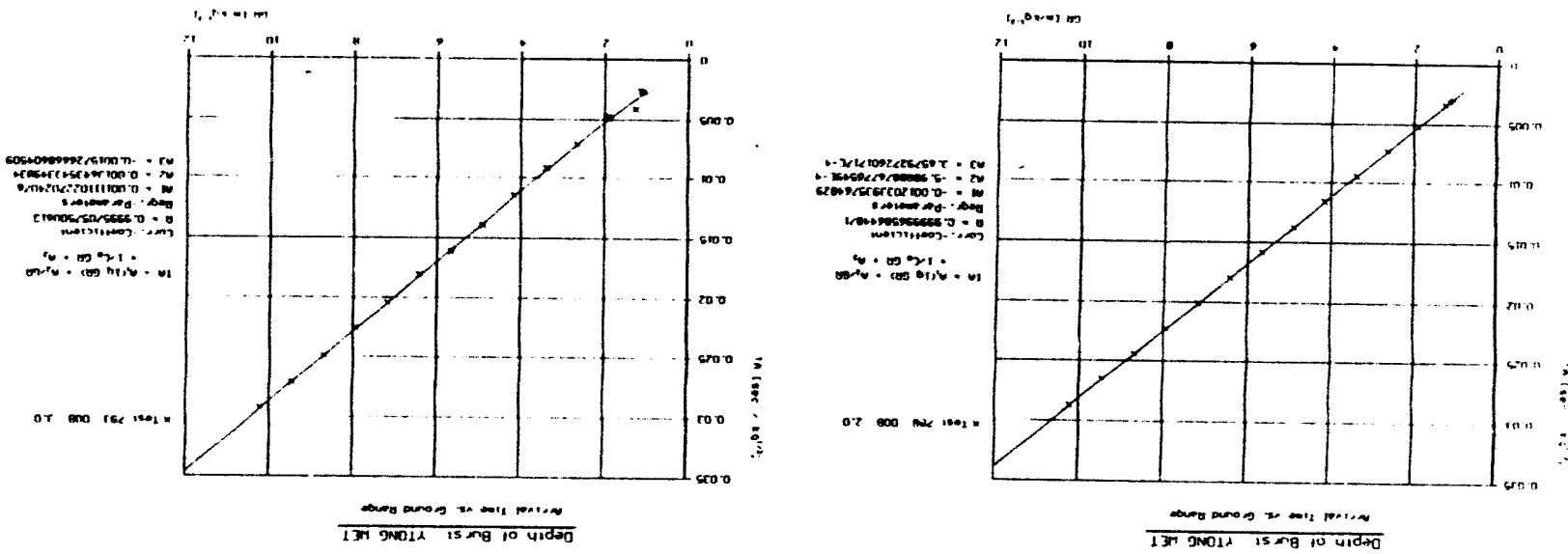

का 5012 is 

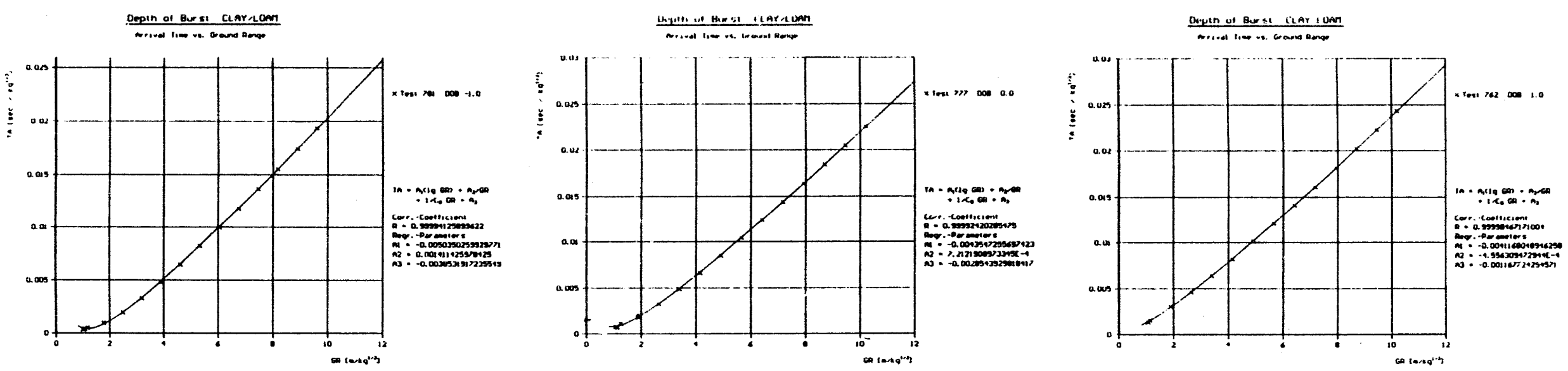

$\ddot{w}$
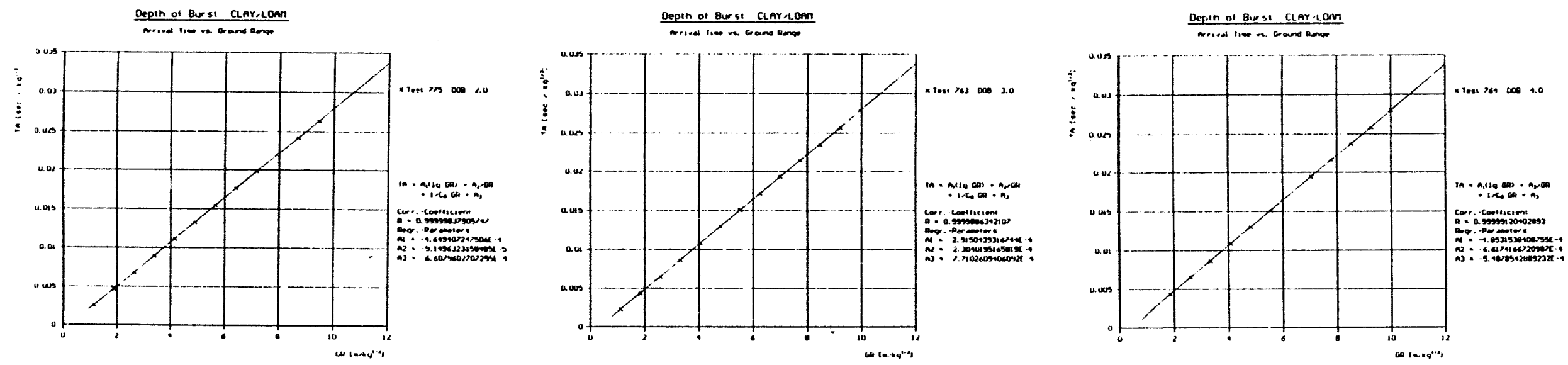

Figure 80 Time of arrival vs ground range at different DOB. Soil material: clay/loam DOB $=-1.0 \mathrm{~cm}$
DOB $=2.0 \mathrm{~cm}$

$\mathrm{DOB}=0 \mathrm{~cm}$;

DOB $=1.0 \mathrm{~cm}$

$\mathrm{DOB}=4.0 \mathrm{~cm}$ 


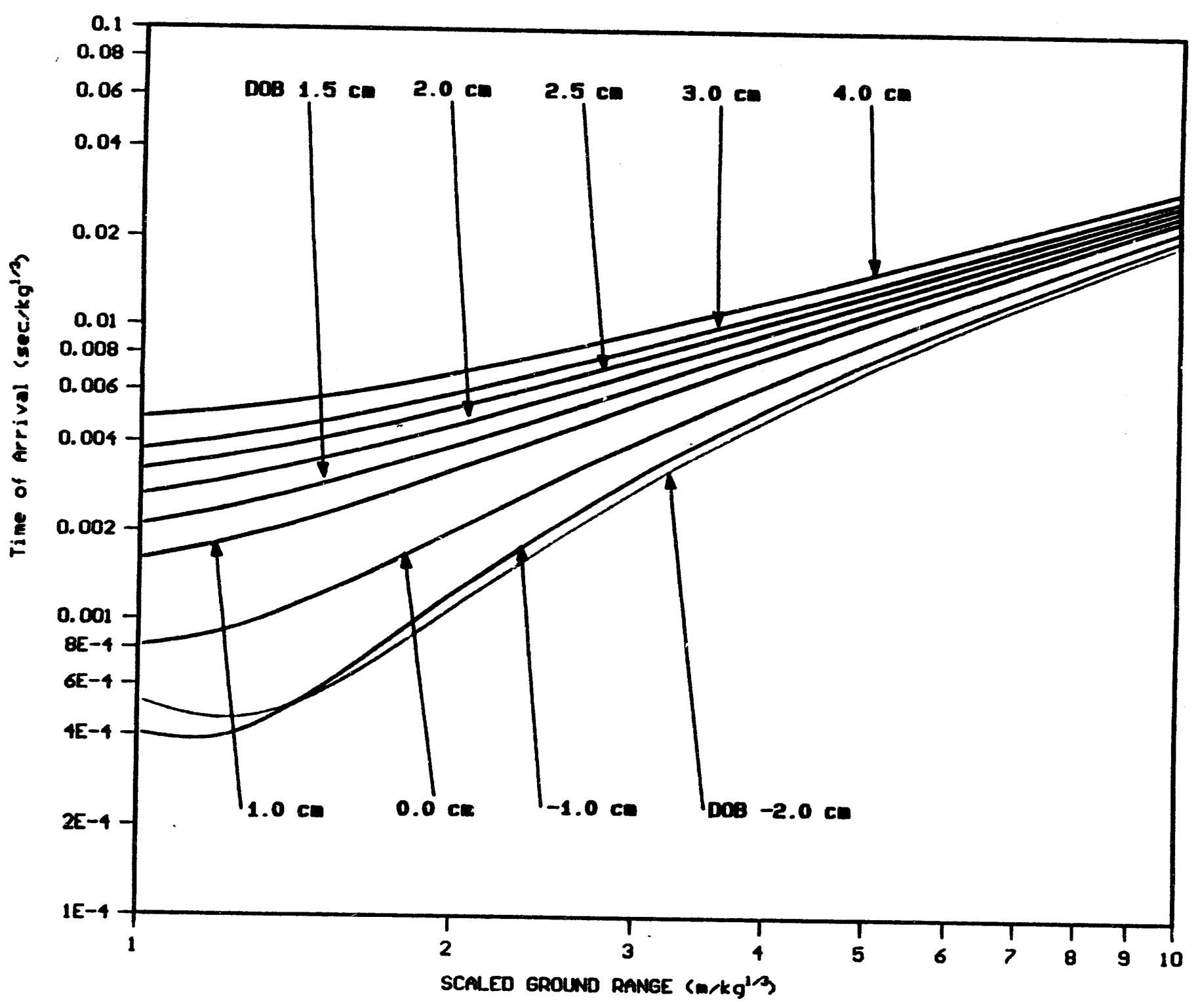

Figure $81 \quad$ Logarithmic plots of arrival-time range curves.

Soil material: aerated grout (dry YTONG) 


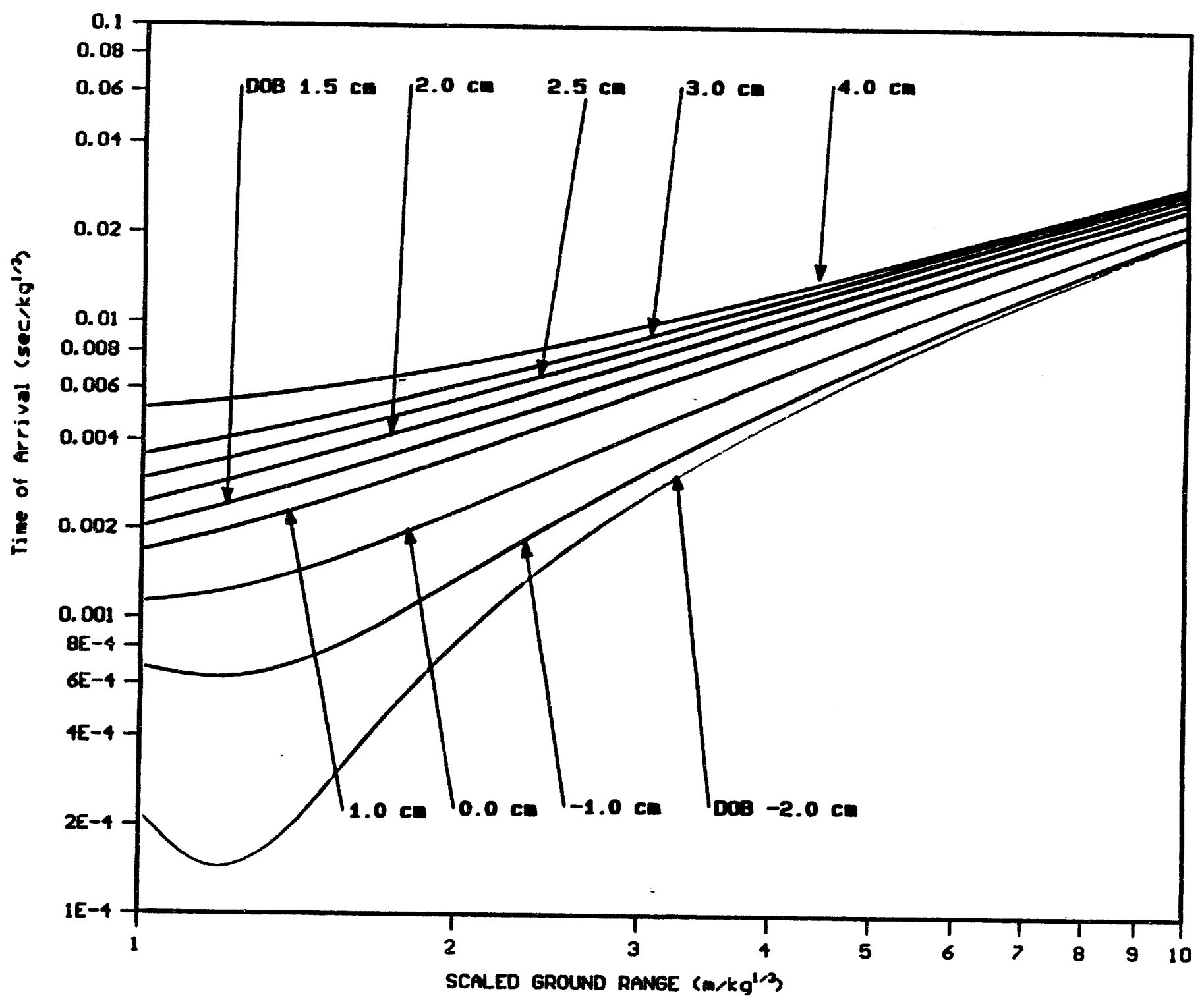

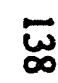

Figure 82 Logarithmic plots of arrival-time range curves.

Soil material: water saturated grout (wet YTONG) 


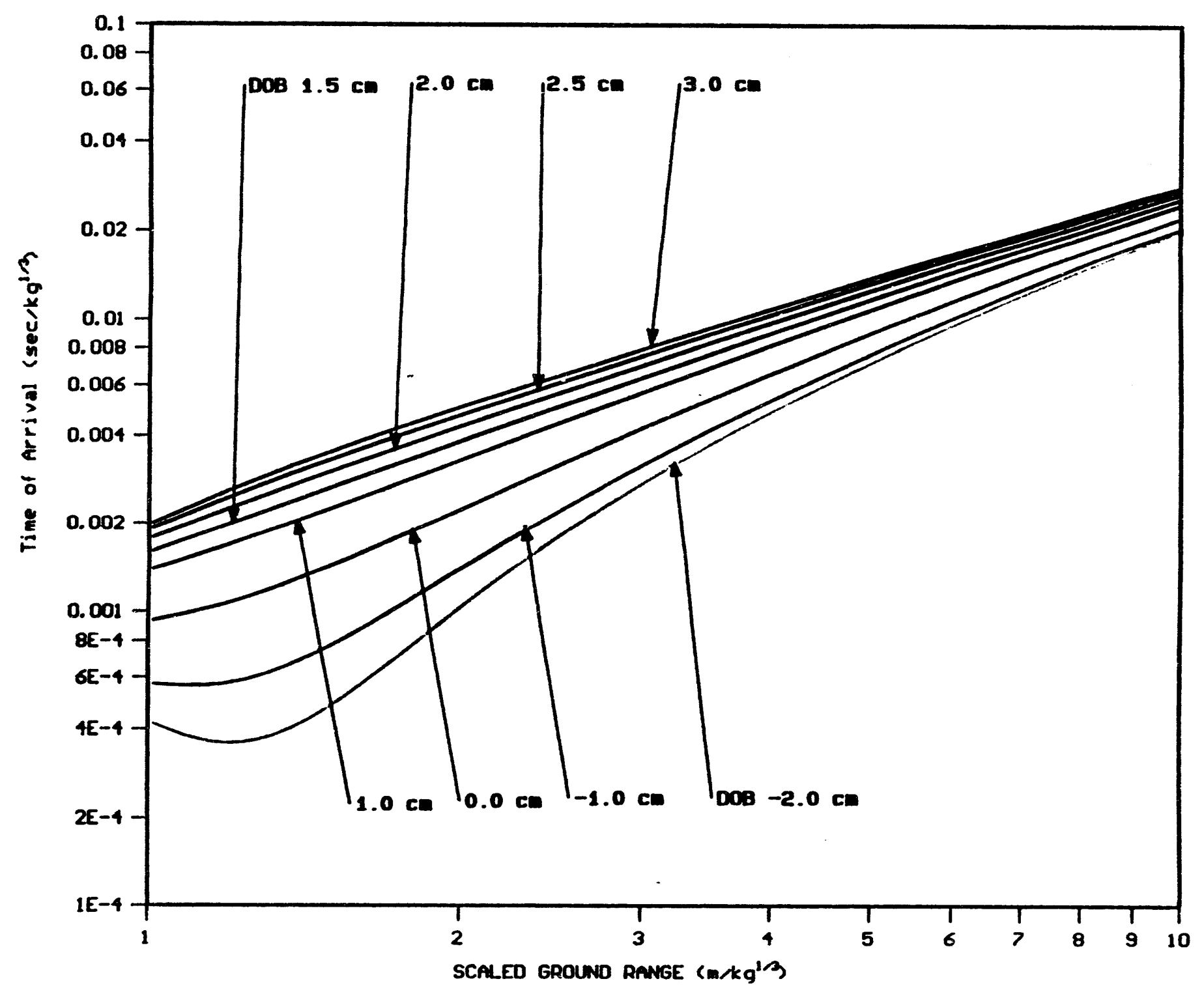

$\bar{\emptyset}$

Figure 83 Logarithmic plots of arrival-time range curves.

Soil material: clay/loam 


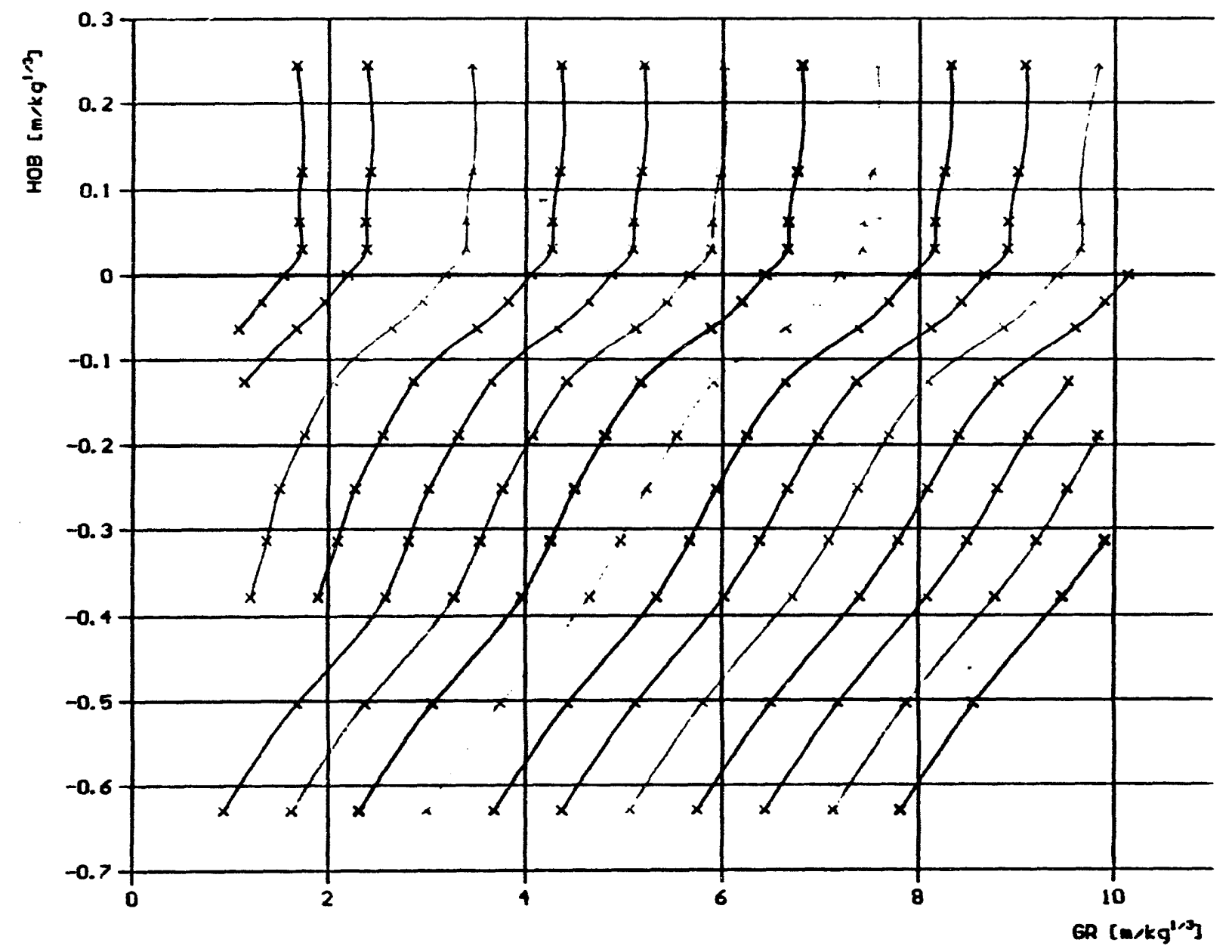

$x$ X TA $=0.001\left[\sec / \mathrm{kg}^{1 / 3}\right]$ $X-x$ TA $=0.002\left[\sec / \mathrm{kg}^{1 / 3}\right]$ - $\times$ TA $=0.004\left[\sec / \mathrm{kg}^{1 / 3}\right]$ $x-x$ TA $\left.=0.006\left[\sec / k^{1 / 3}\right)^{1 / 3}\right]$ $x-x$ TA $=0.008\left[\sec / k^{1 / 3}\right]$ $x-x$ TA $=0.01\left[\sec / k^{1 / 2}\right]$ $x-x$ TA $=0.012\left[\sec / k^{1 / 3}\right]$ $\ldots \ldots$ TA $=0.014[$ sec/kg/3] $x-x$ TA $=0.016\left[\sec / \mathrm{kg}^{1 / 3}\right]$ $x-x$ TA $=0.018\left[\sec / \mathrm{kg}^{1 / 3}\right]$ $x-x$ TA $=0.02[\sec / k g / 3]$ $x$ - $x$ TA $=0.022\left[\sec / k g^{2 / 3}\right]$ $x-x$ TA $=0.024\left[\sec k g^{1 / 3}\right]$ $x-x$ TA $=0.026\left[\sec / k^{1 / 3}\right]$ $x-x$ TA $=0.028\left[\sec / k^{1 / 3}\right]$

Figure 84 Constant arrival time DOB-curves for dry aerated grout (dry YTONG). 

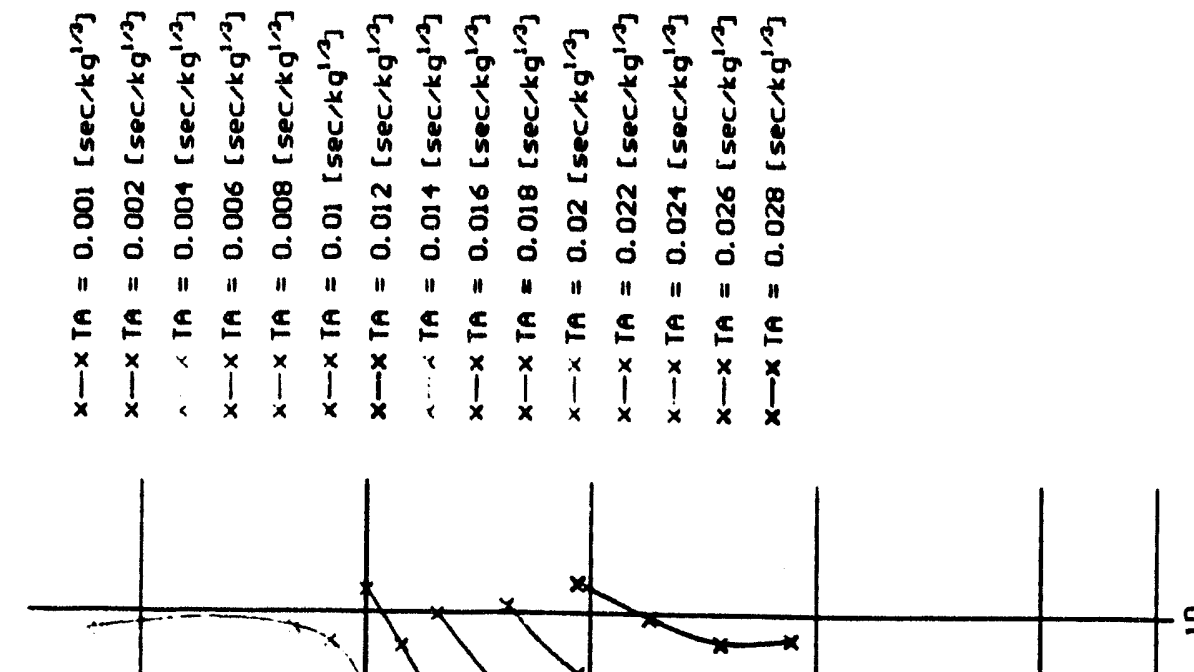

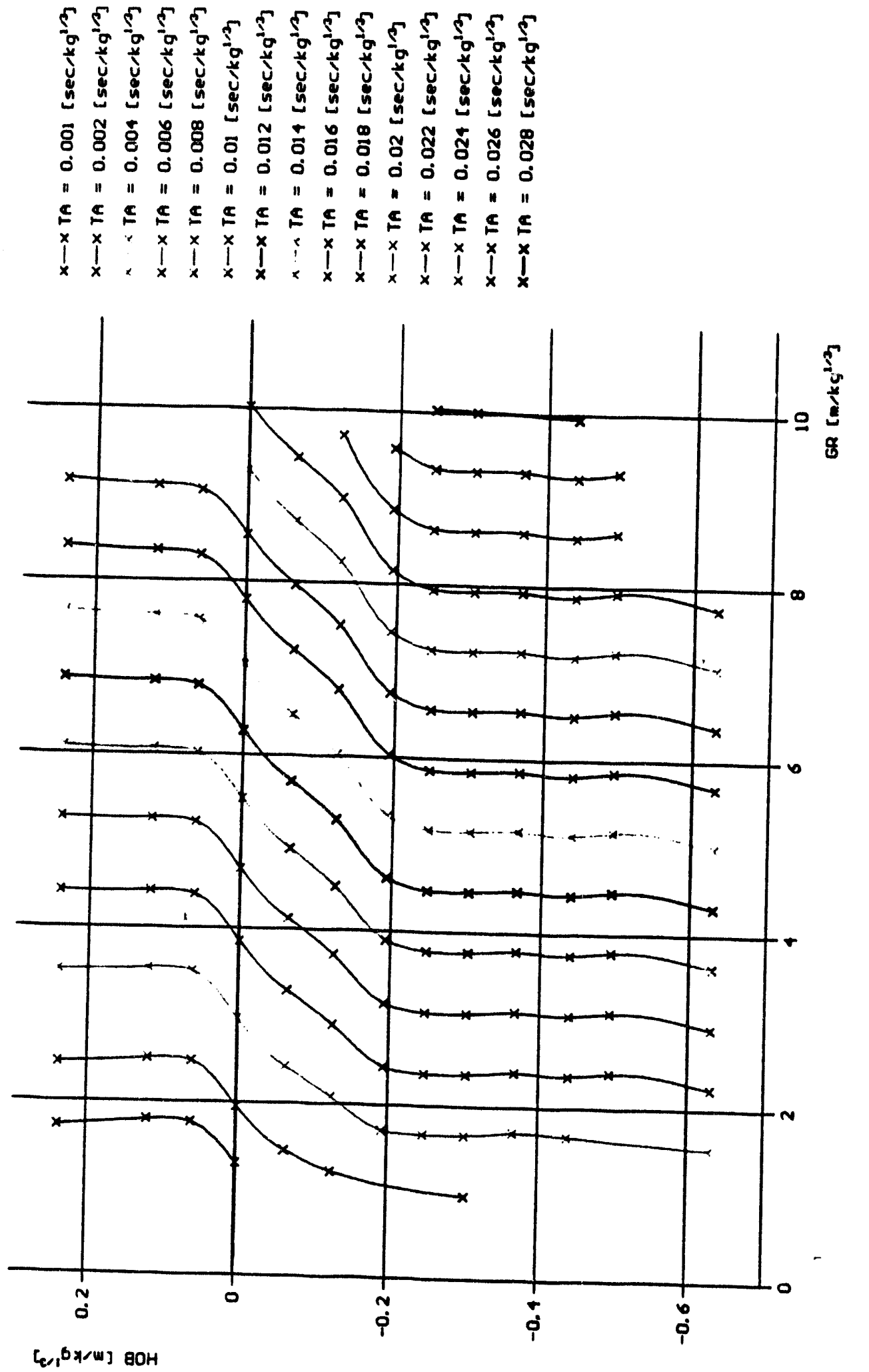

है 

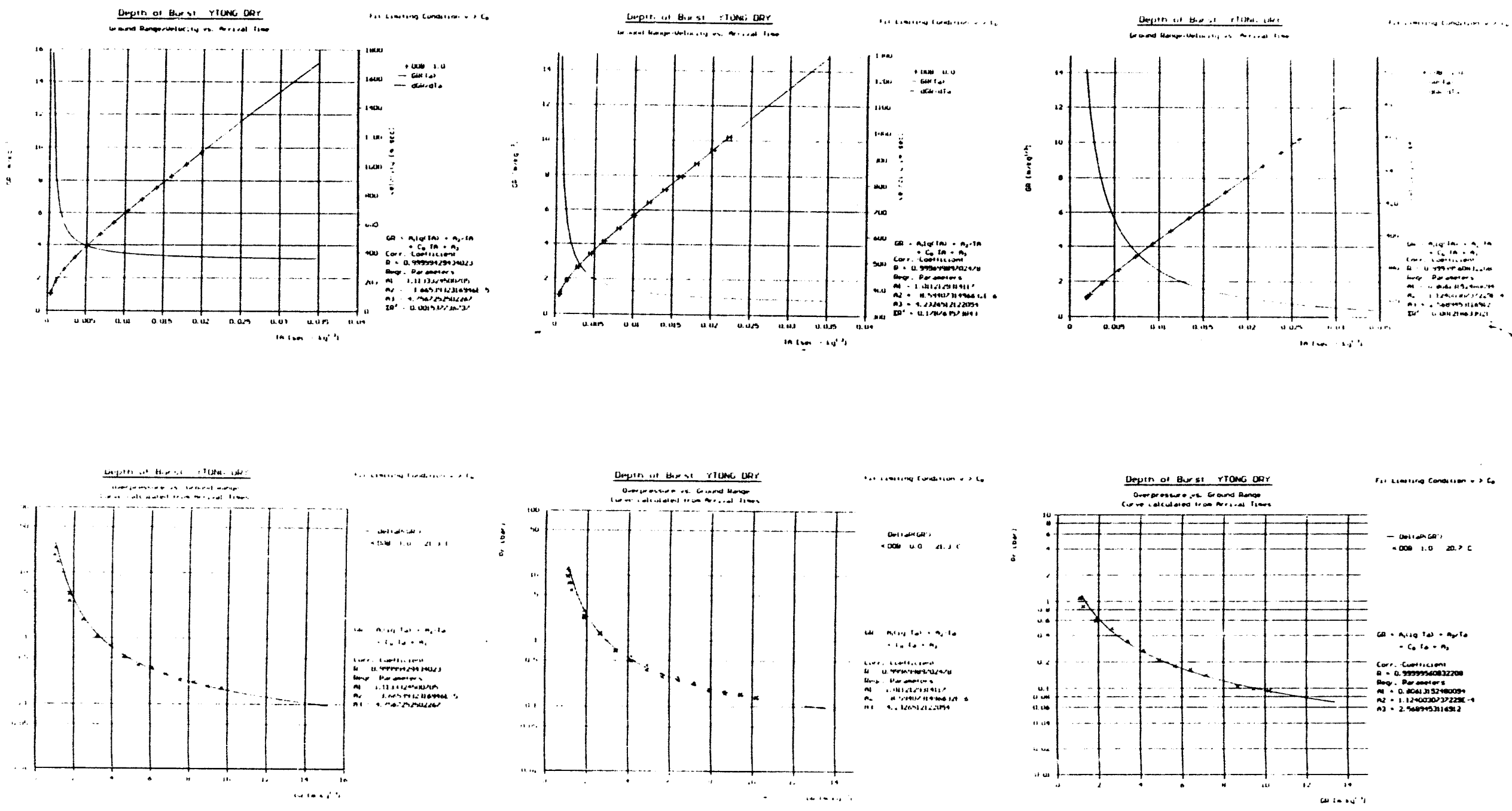

Figure 87 Determination of peak overpressure by using time-of-arrival data upper diagrams: lower diagrams: ground range vs arrival time with approximation curve and deduced shock front velocity soil material: calculated pressure-range curve compared with measured peak pressure values dry aerated grout (dry YTONG)

$\mathrm{DOB}=-1.0 \mathrm{~cm} ; \mathrm{DOB}=0 \mathrm{~cm} ; \mathrm{DOB}=1.0 \mathrm{~cm}$ 


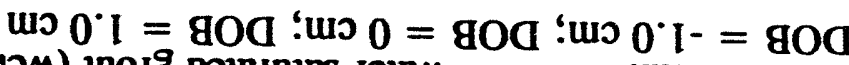

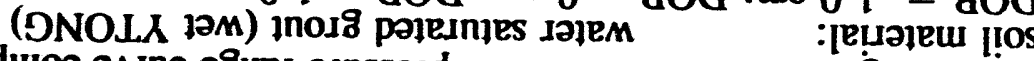

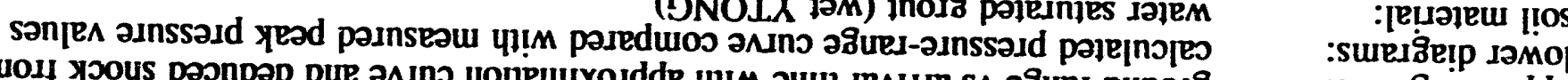

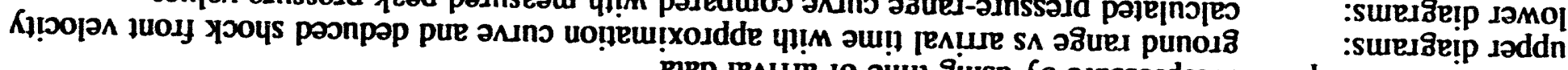

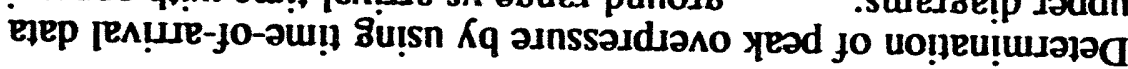
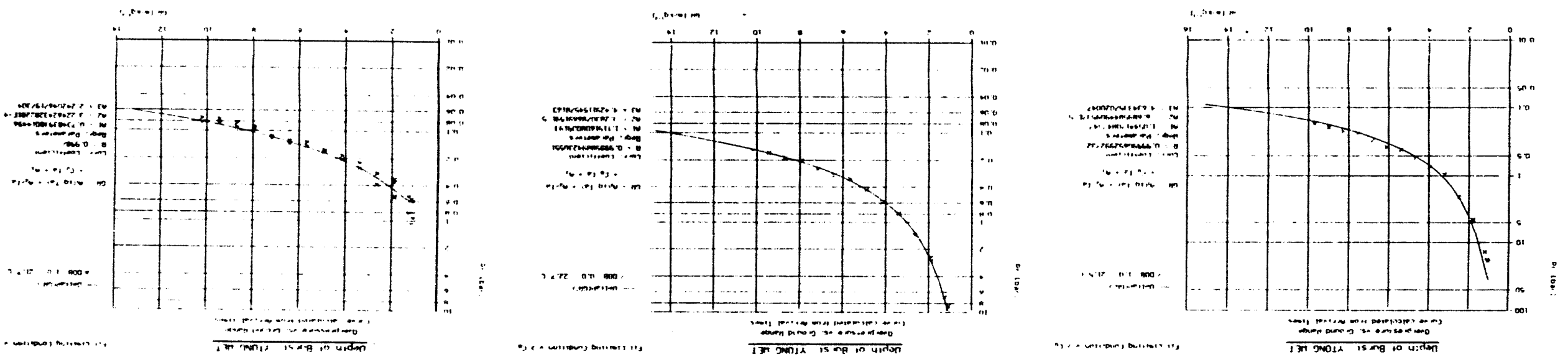

\section{专}
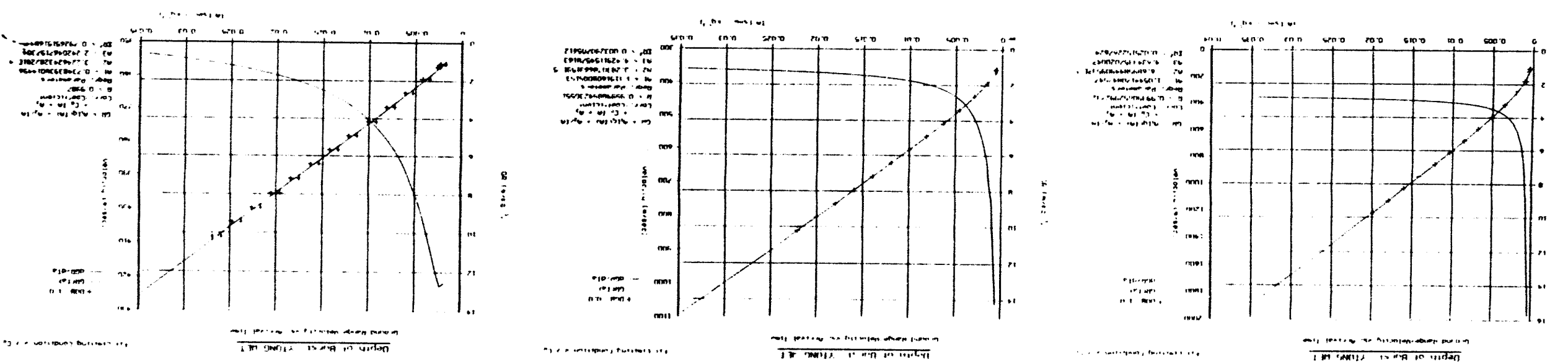

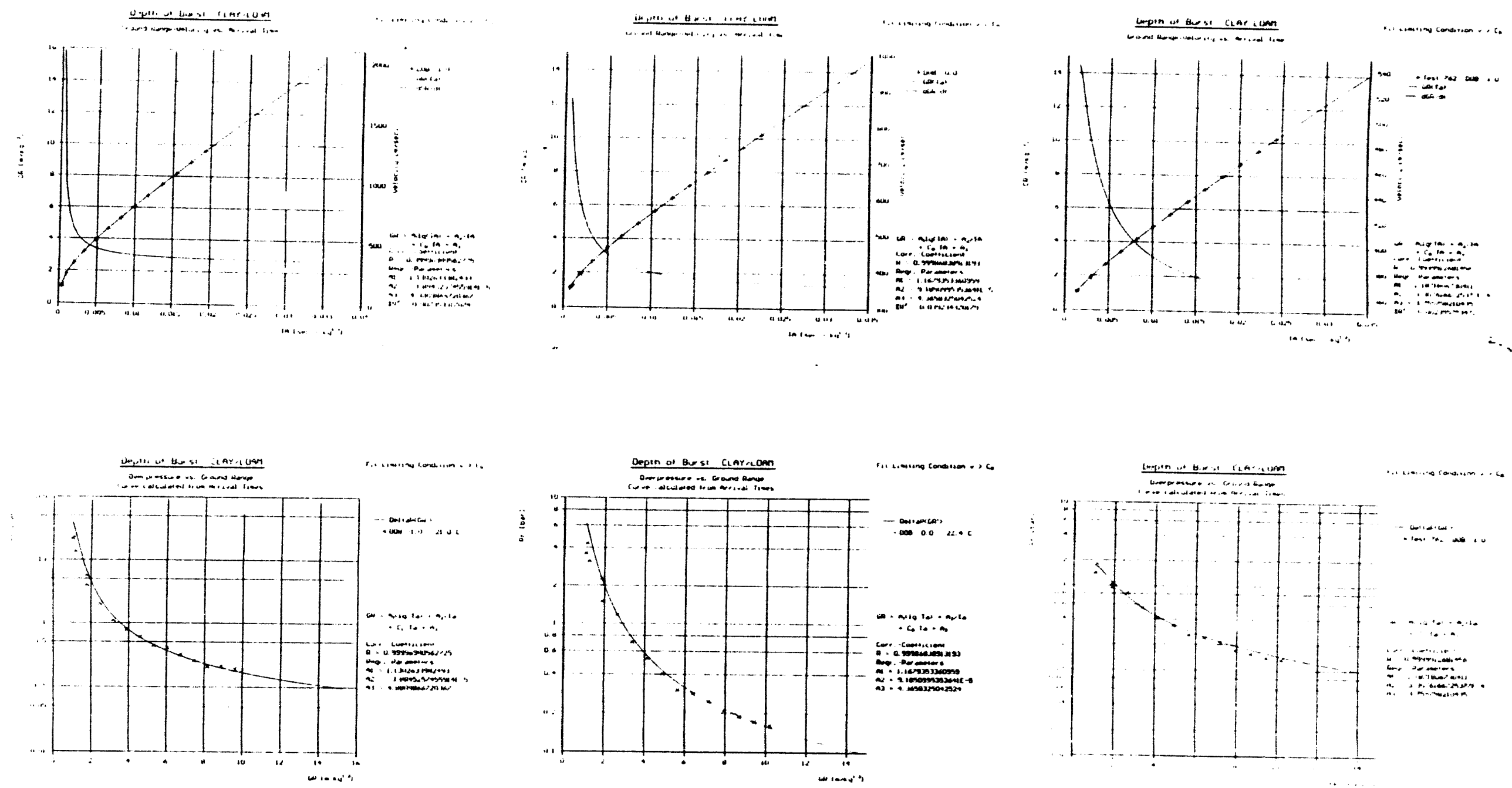

Figure 89 Determination of peak overpressure by using time-of-arrival data upper diagrams: lower diagrams: soil material: clay/loam ground range vs arrival time with approximation curve and deduced shock front velocity compared with measured peak pressure values $\mathrm{DOB}=-1.0 \mathrm{~cm} ; \mathrm{DOB}=0 \mathrm{~cm} ; \mathrm{DOB}=1.0 \mathrm{~cm}$ 

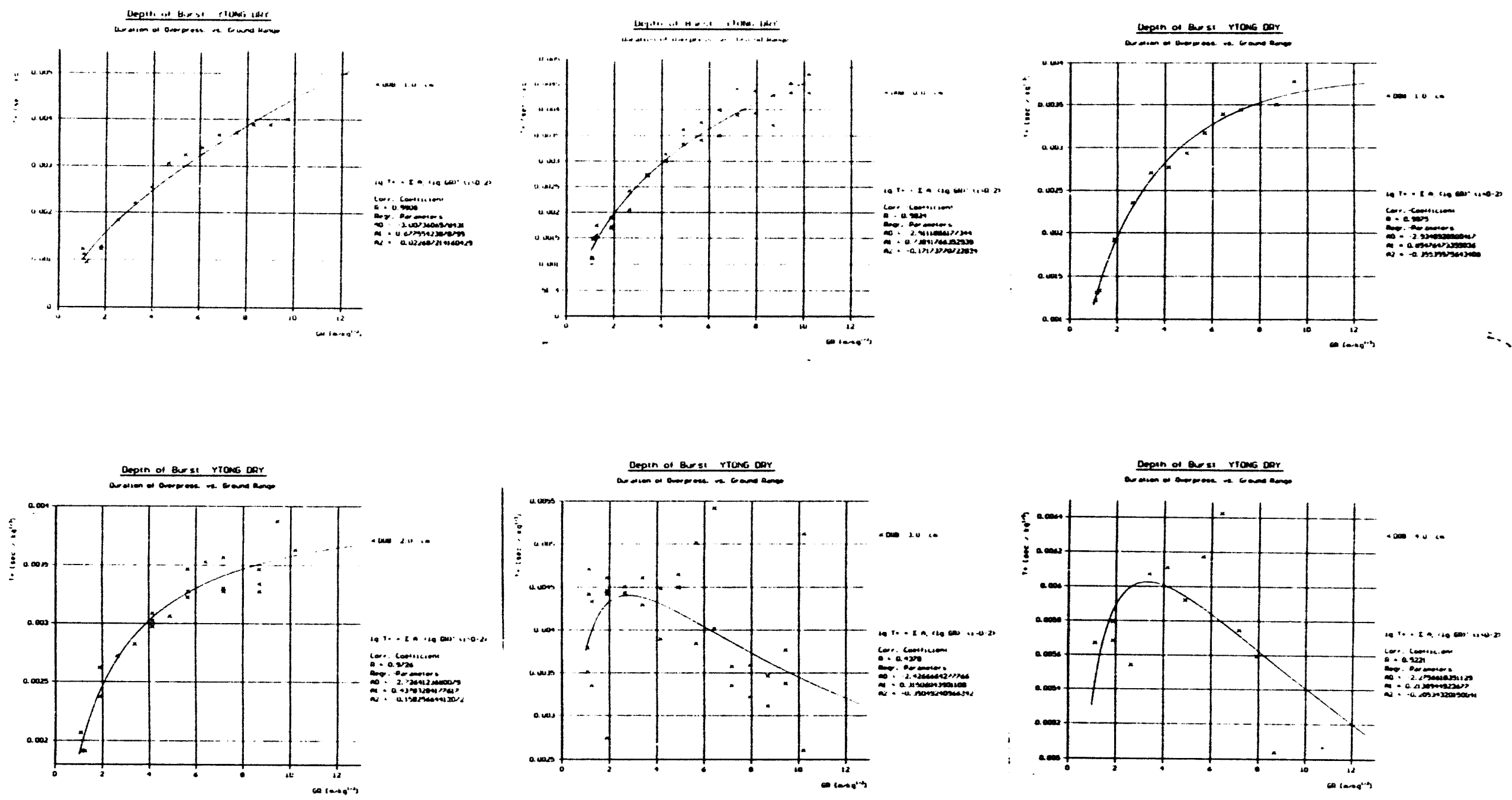

Figure 90

Time duration of positive overpressure phase vs ground range at different DOB soil material: dry aerated grout

$\mathrm{DOB}=-1.0 \mathrm{~cm} \quad \mathrm{DOB}=0 \mathrm{~cm} \quad \mathrm{DOB}=1.0 \mathrm{~cm}$

$\mathrm{DOB}=2.0 \mathrm{~cm} \quad \mathrm{DOB}=3.0 \mathrm{~cm} \quad \mathrm{DOB}=4.0 \mathrm{~cm}$ 

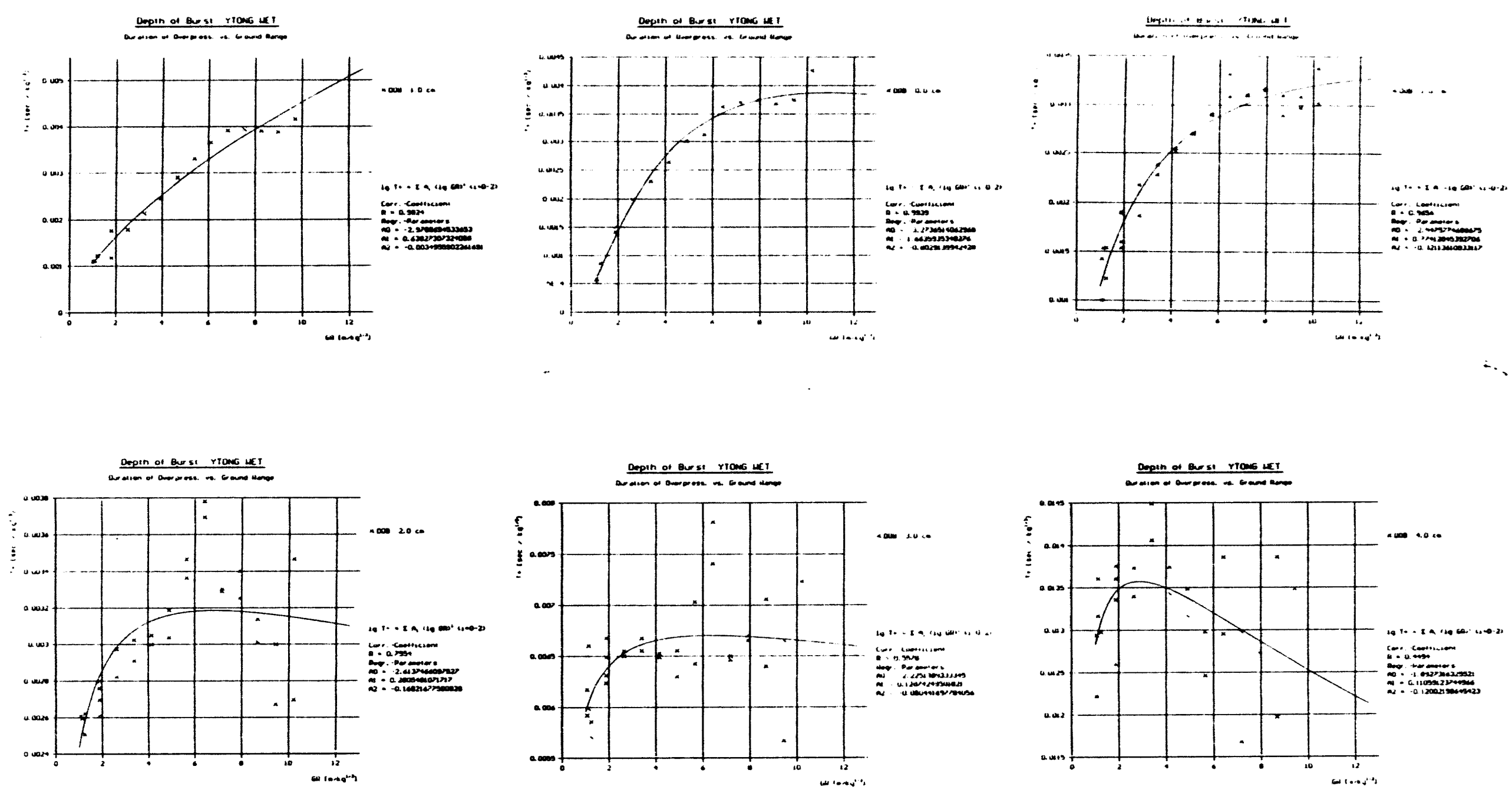

Figure 91 Time duration of positive overpressure phase vs ground range at different DOB soil material: water saturated grout (wet YTONG)

$\mathrm{DOB}=-1.0 \mathrm{~cm} \quad$ DOB $=0 \mathrm{~cm} \quad$ DOB $=1.0 \mathrm{~cm}$

$\mathrm{DOB}=2.0 \mathrm{~cm} \quad \mathrm{DOB}=3.0 \mathrm{~cm} \quad \mathrm{DOB}=4.0 \mathrm{~cm}$ 

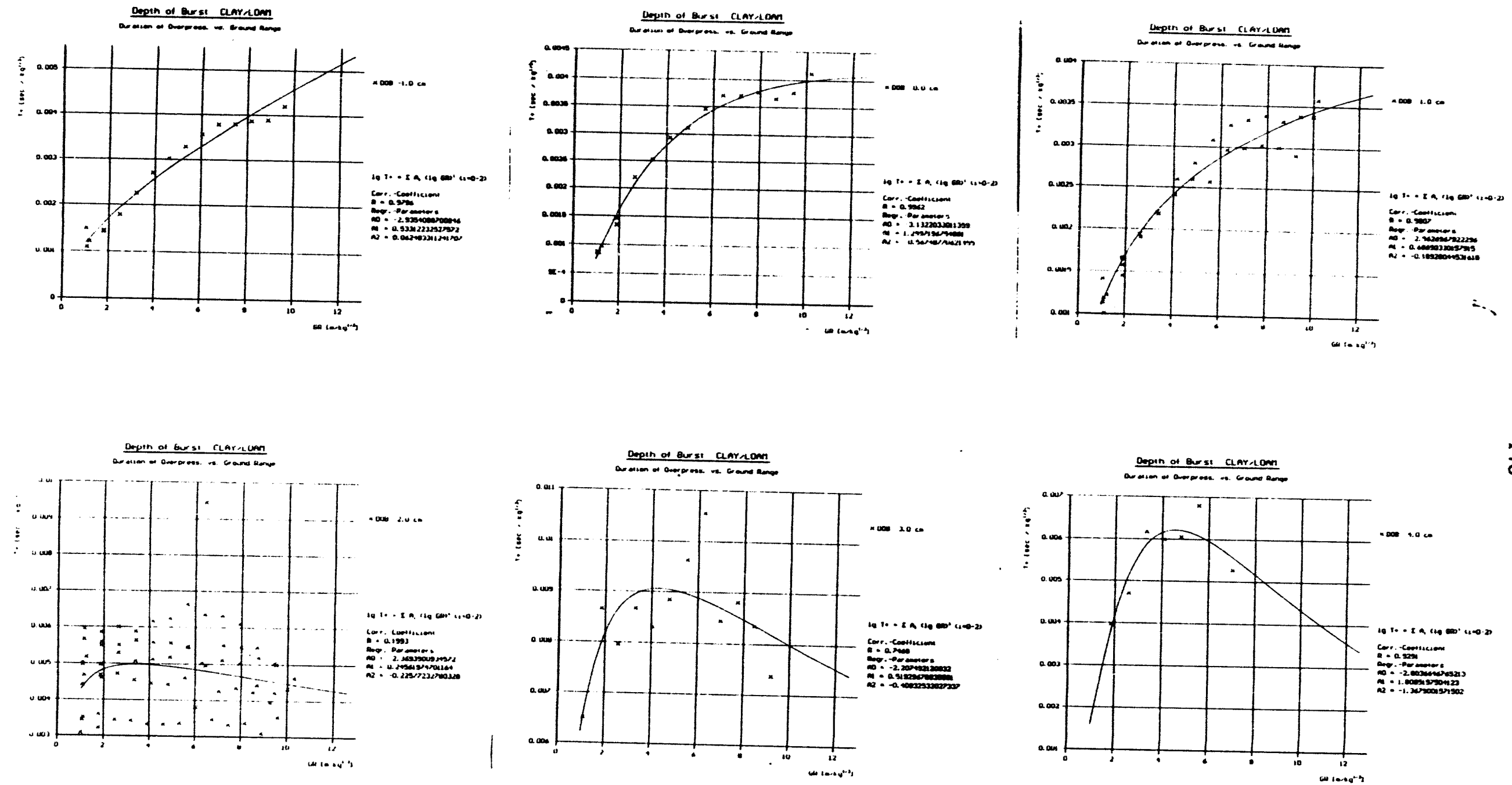

Figure 92

Time duration of positive overpressure phase vs ground range at different DOB soil material: clay/loam

$\mathrm{DOB}=-1.0 \mathrm{~cm}$

$\mathrm{DOB}=2.0 \mathrm{~cm}$

DOB $=0 \mathrm{~cm}$

$\mathrm{DOB}=1.0 \mathrm{~cm}$

$\mathrm{DOB}=4.0 \mathrm{~cm}$ 


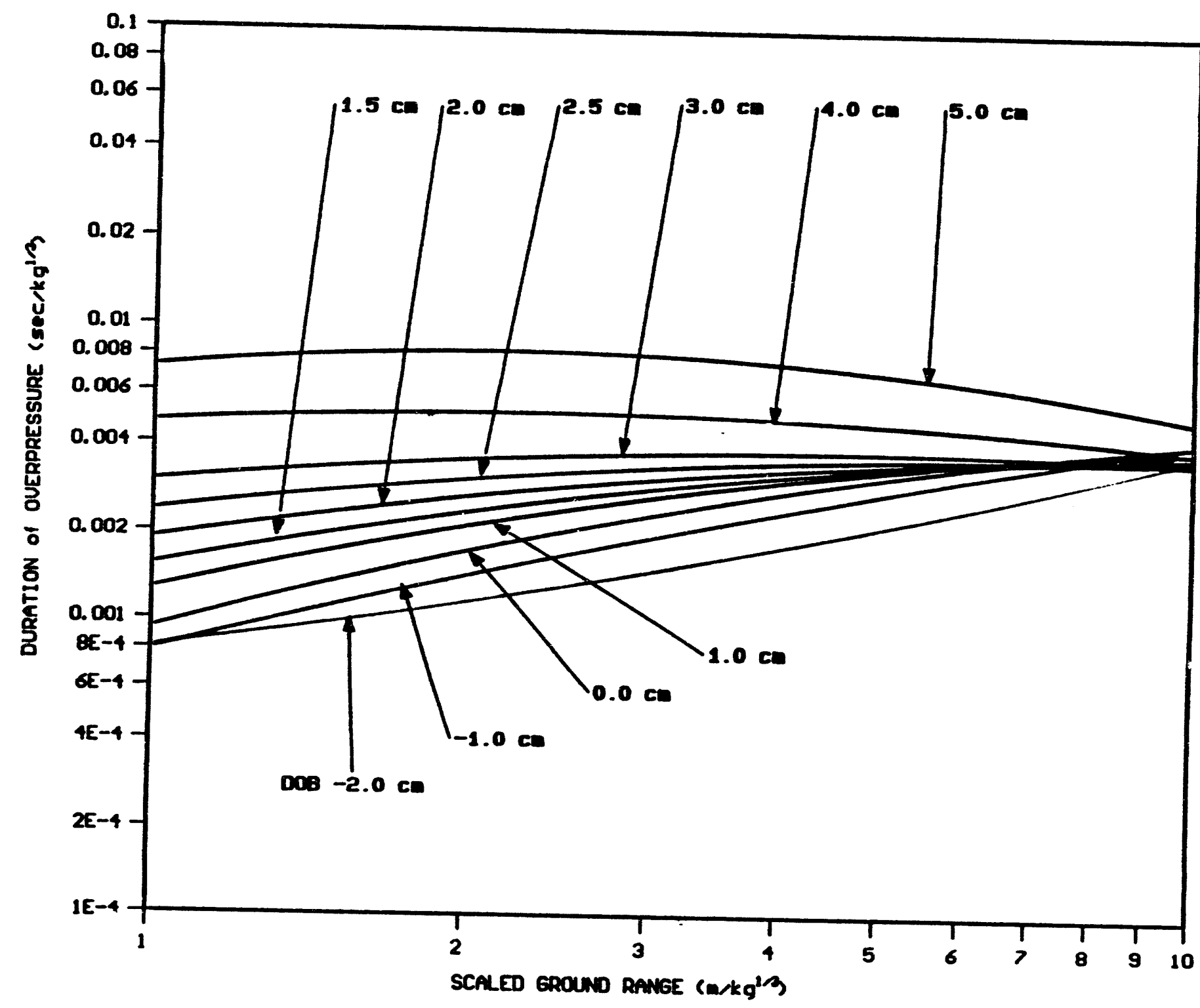

E

Figure 93 Logarithmic plots of positive phase duration range curves.

Soil material: aerated grout (dry YTONG) 


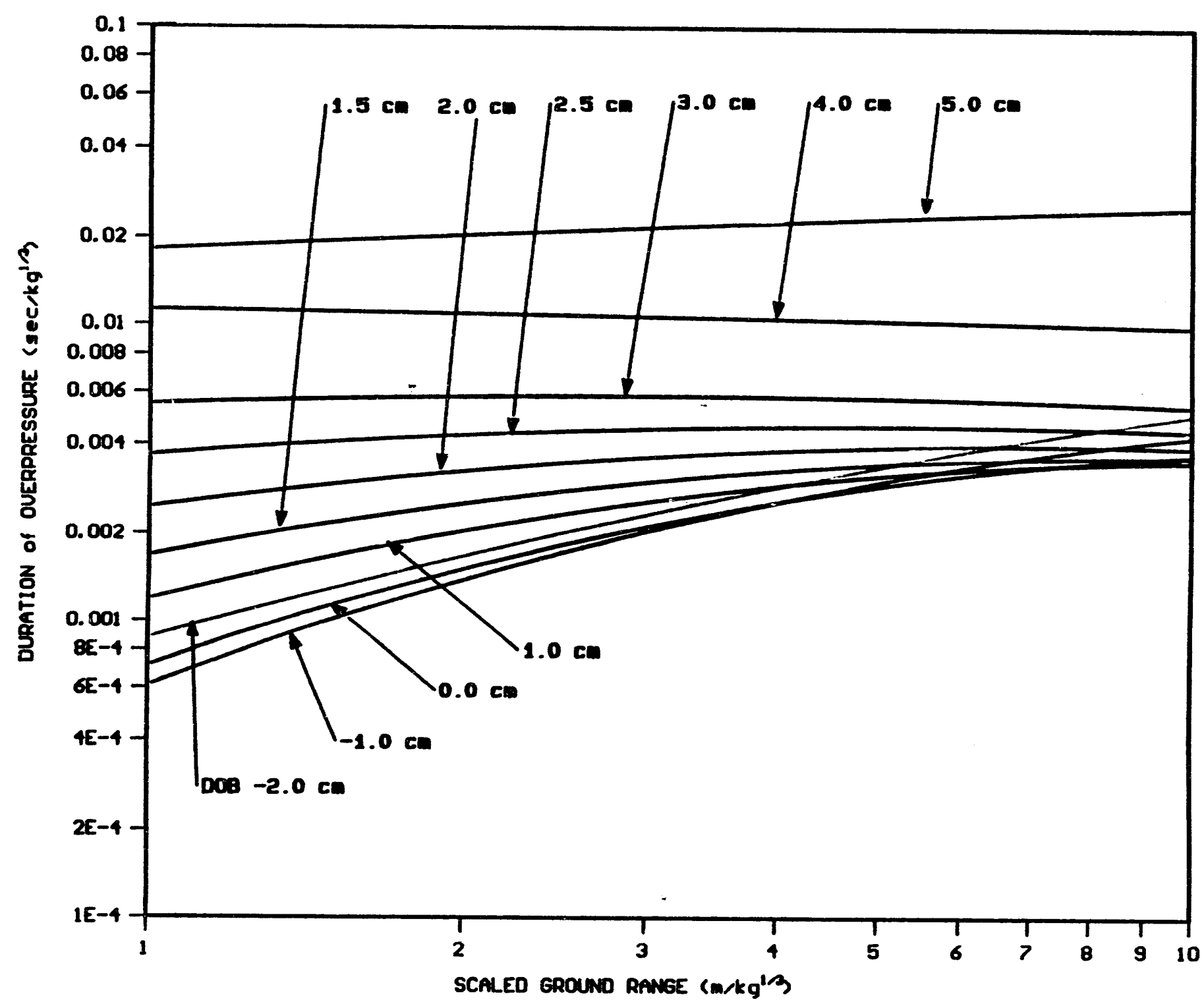

$\overline{\check{\sigma}}$

Figure 94 Logarithmic plots of positive phase duration range curves.

Soil material: water saturated grout (wet YTONG) 


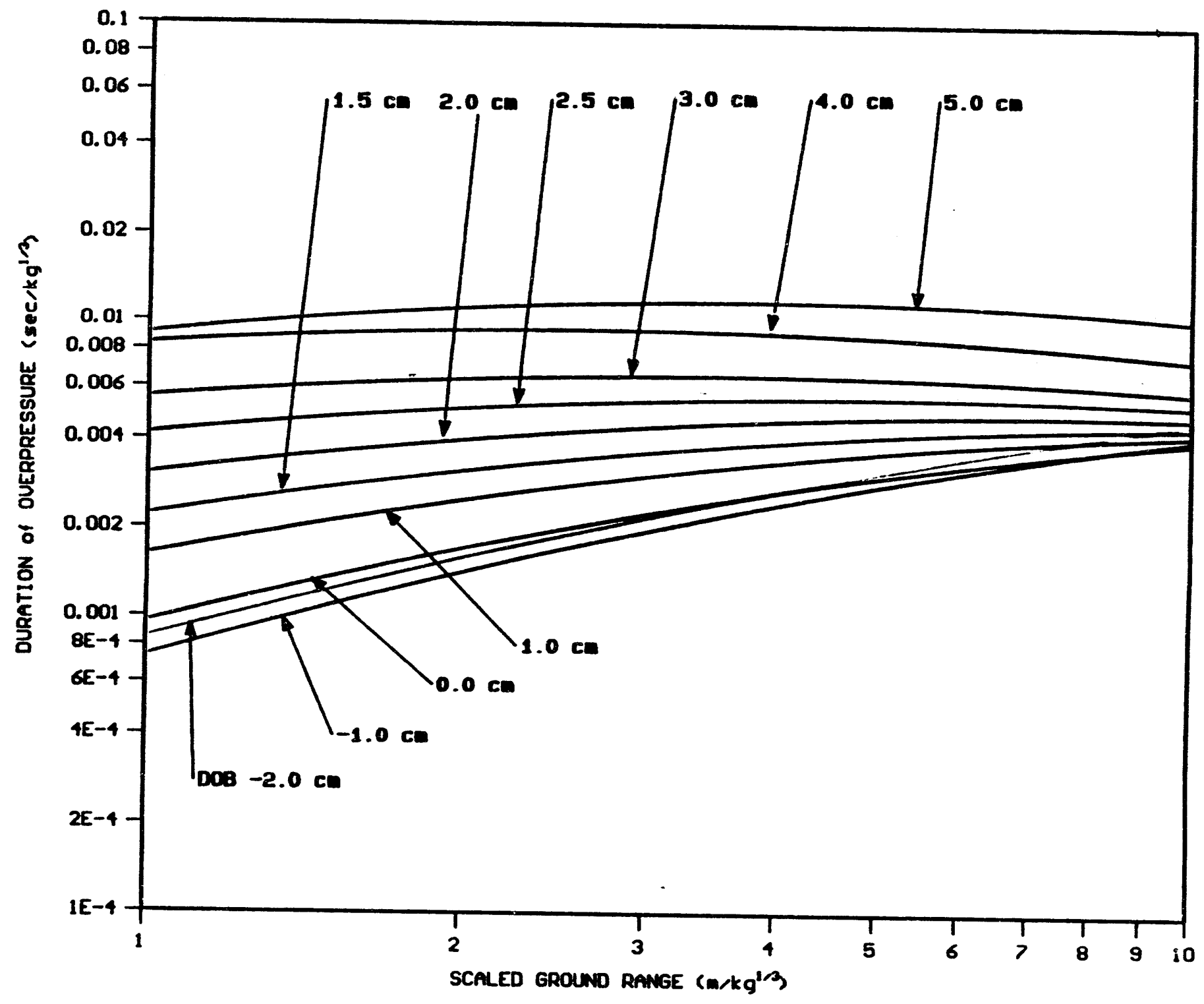

$\bar{\Xi}$

Figure 95 Logarithmic plots of positive phase duration range curves. Soil material: clay/loam 


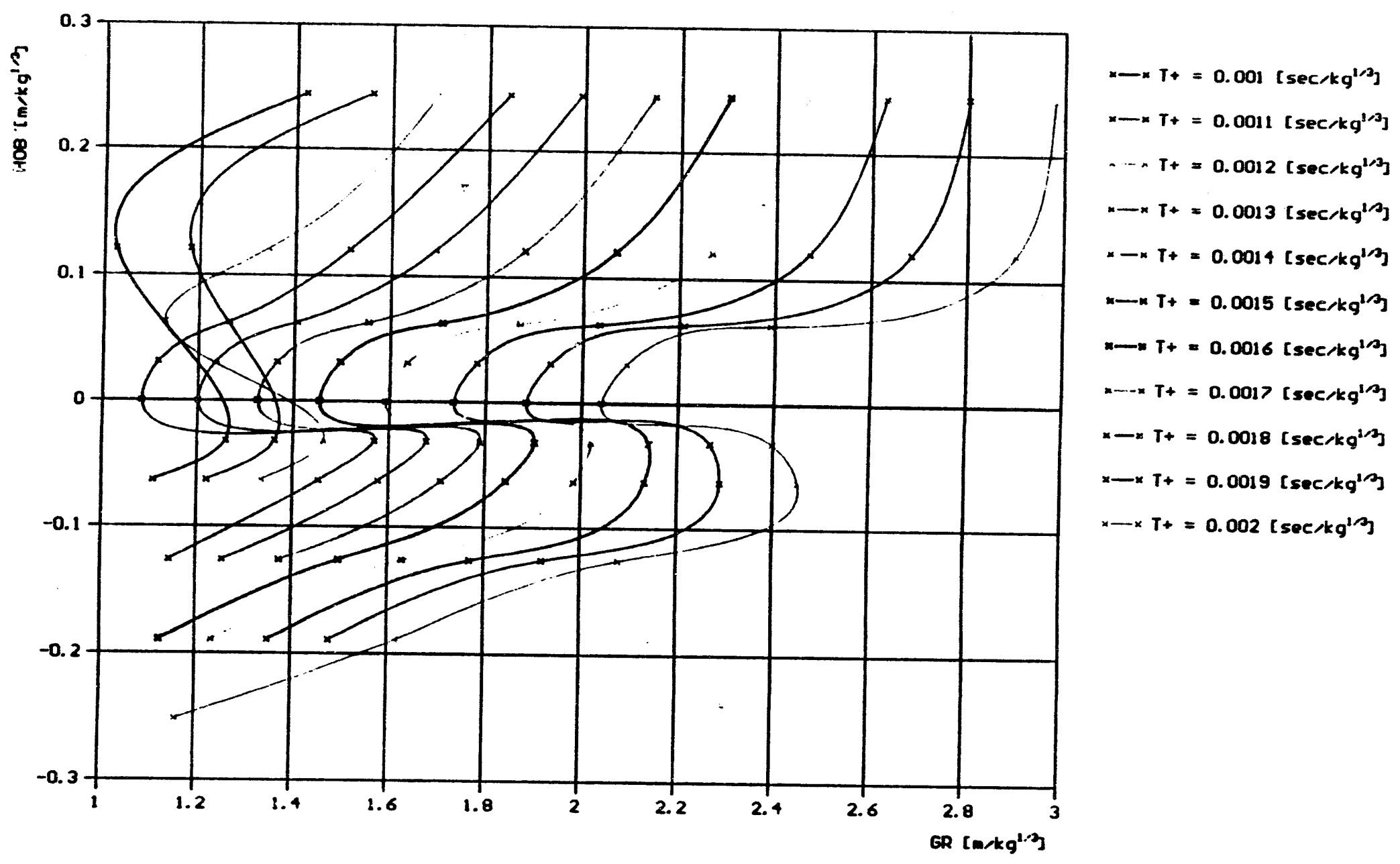

Figure 96 Constant duration DOB-curves for dry aerated grout (dry YTONG). 


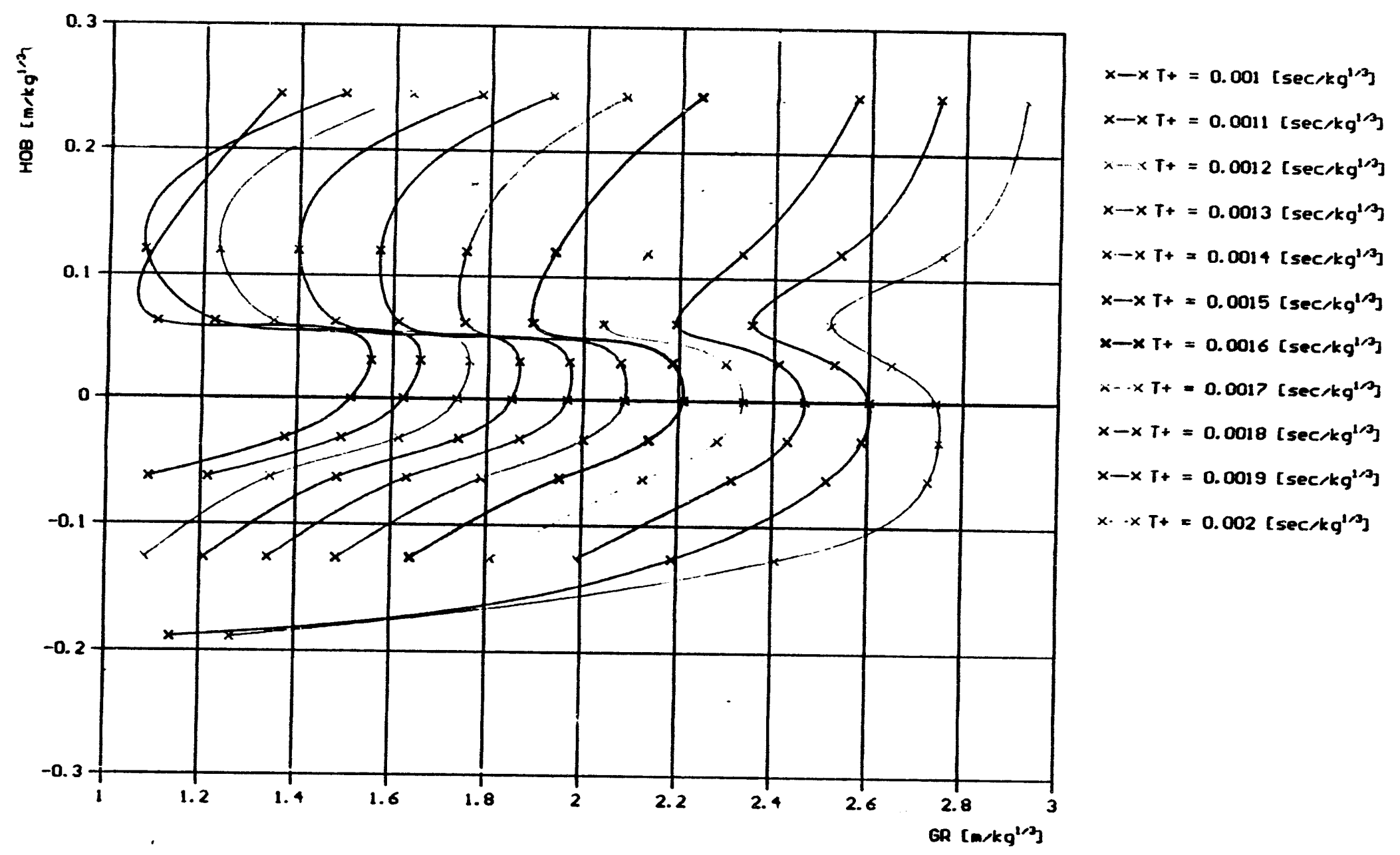

$\bar{\omega}$

Figure 97 Constant duration DOB-curves for water saturated grout (wet YTONG). 


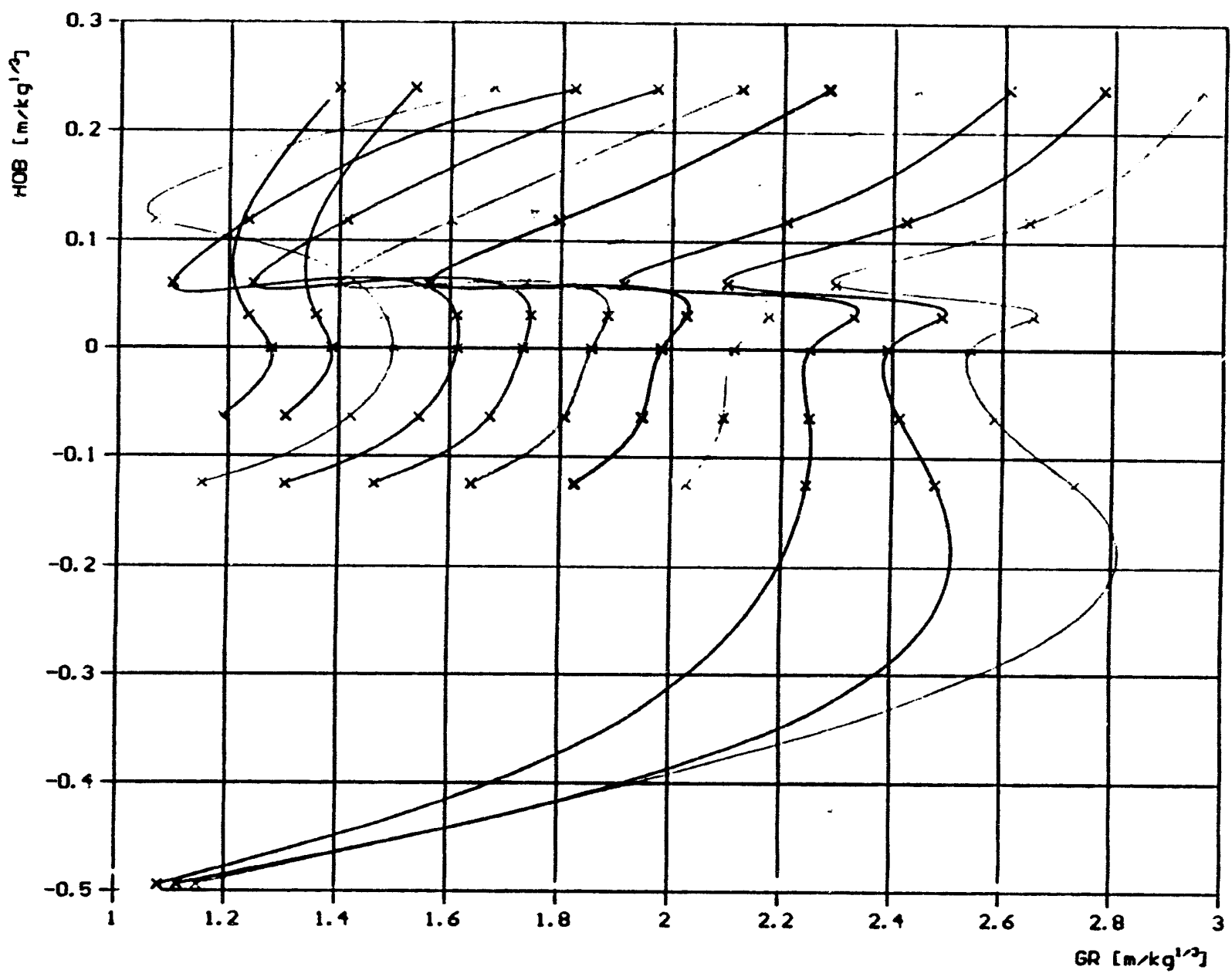

$x-x T_{+}=0.001\left[\sec / k^{1 / 3}\right]$

$x-x T+=0.0011\left[\sec / k^{2 / 3}\right]$

$n-、 T+=0.0012\left[\sec / k^{1 / 3}\right]$

$x-x T+=0.0013\left[\sec / k g^{1 / 3}\right]$

$x-x T_{+}=0.0014\left[\sec / \mathrm{kg}^{1 / 3}\right]$

$x-x T+=0.0015\left[\sec / k g^{1 / 3}\right]$

$x-x T_{+}=0.0016\left[\sec / k^{2 / 3}\right]$

$x--x T+=0.0017\left[\sec / k g^{1 / 3}\right]$

$x-x T_{+}=0.0018\left[\sec / \mathrm{kg}^{1 / 3}\right]$

$x-x T_{+}=0.0019\left[\sec / \mathrm{kg}^{1 / 3}\right]$

$x . \times T_{+}=0.002\left[\sec / \mathrm{kg}^{1 / 3}\right]$

Figure 98 Constant duration DOB-curves for clay/loam. 


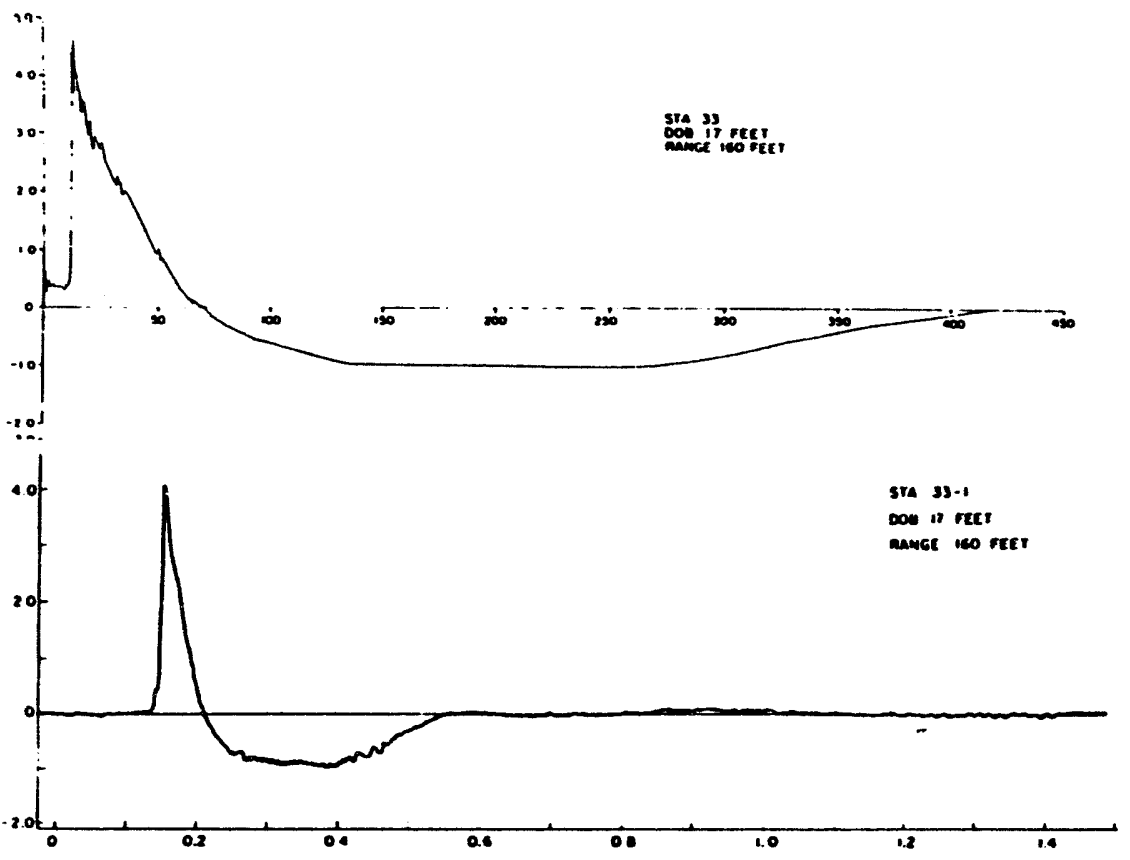

$=1$
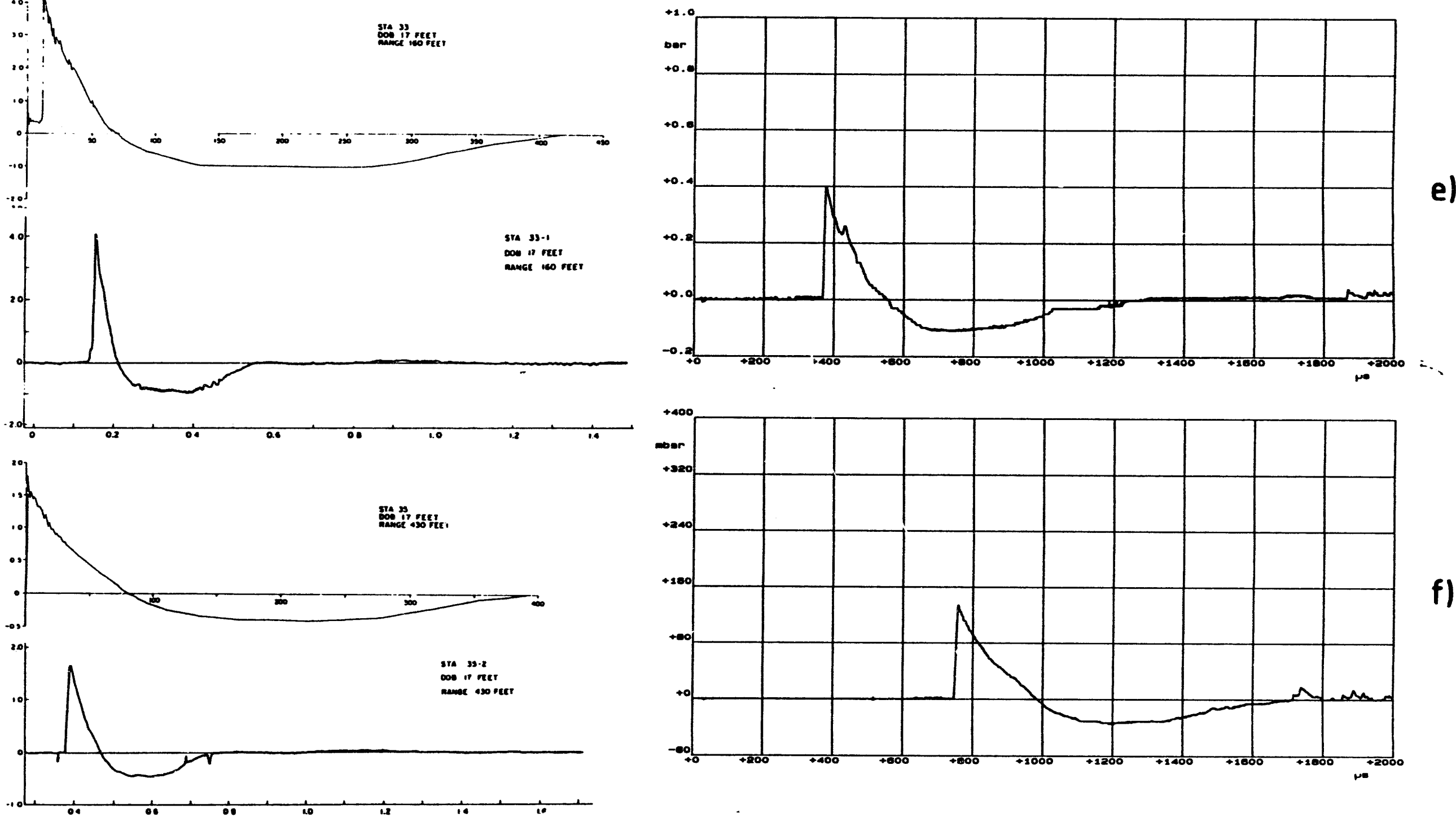

e)

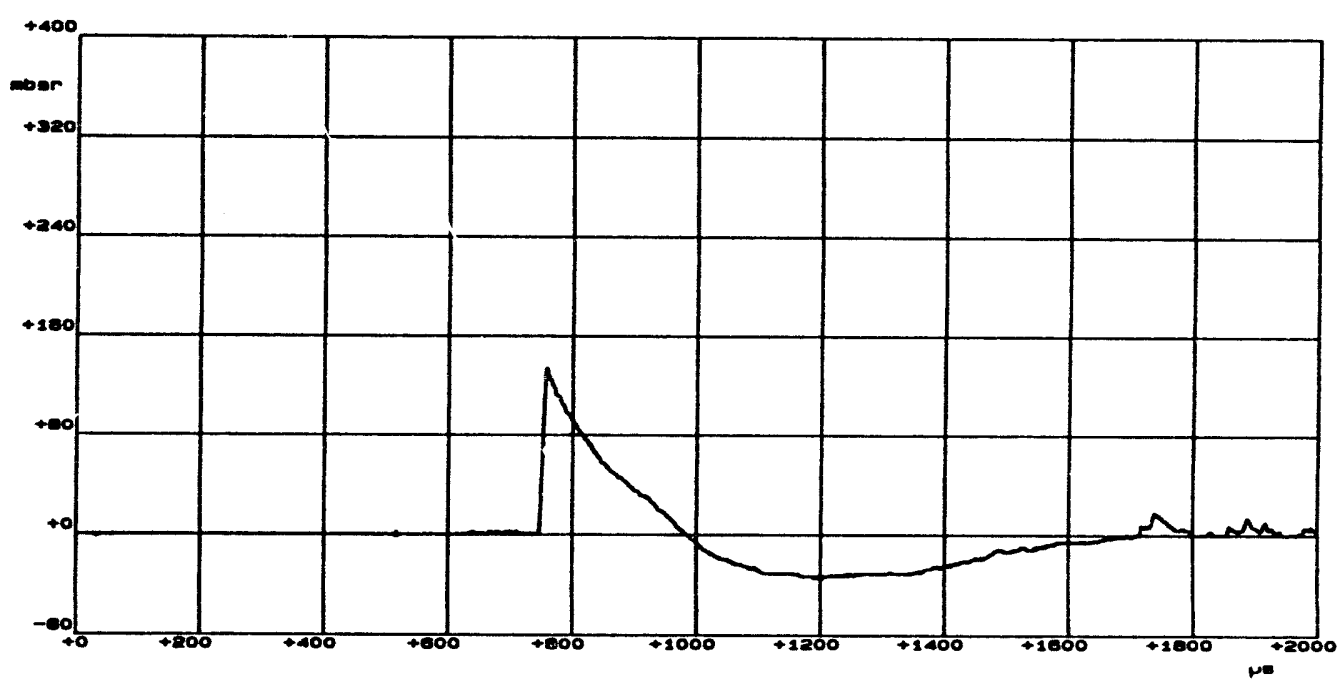

Figure 99 Comparison with wave forms from Ref. [12].
a) BRL $\{\mathrm{DOB}=17 \mathrm{ft} ; \mathrm{GR}=160 \mathrm{ft}$
b) $\mathrm{NOL}\left\{\simeq 0.20 \mathrm{~m} / \mathrm{kg}^{1 / 3} ; \simeq 1.86 \mathrm{~m} / \mathrm{kg}^{1 / 3}\right.$
c) $B R L\{D O B=17 \mathrm{ft} ; \mathrm{GR}=430 \mathrm{ft}$
d) NOL $\left\{\simeq 0.20 \mathrm{~m} / \mathrm{kg}^{1 / 3} ; \simeq 5.0 \mathrm{~m} / \mathrm{kg}^{1 / 3}\right.$

e) EMI DOB $=1.5 \mathrm{~cm} ; \mathrm{GR}=15 \mathrm{~cm}$ $\simeq 0.19 \mathrm{~m} / \mathrm{kg}^{1 / 3} ; \simeq 1.89 \mathrm{~m} / \mathrm{kg}^{1 / 3}$

f) EMI DOB $1.5 \mathrm{~cm} ; \mathrm{GR}=39 \mathrm{~cm}$ $\simeq 0.19 \mathrm{~m} / \mathrm{kg}^{1 / 3} ; \simeq 4.9 \mathrm{~m} / \mathrm{kg}^{1 / 3}$ 


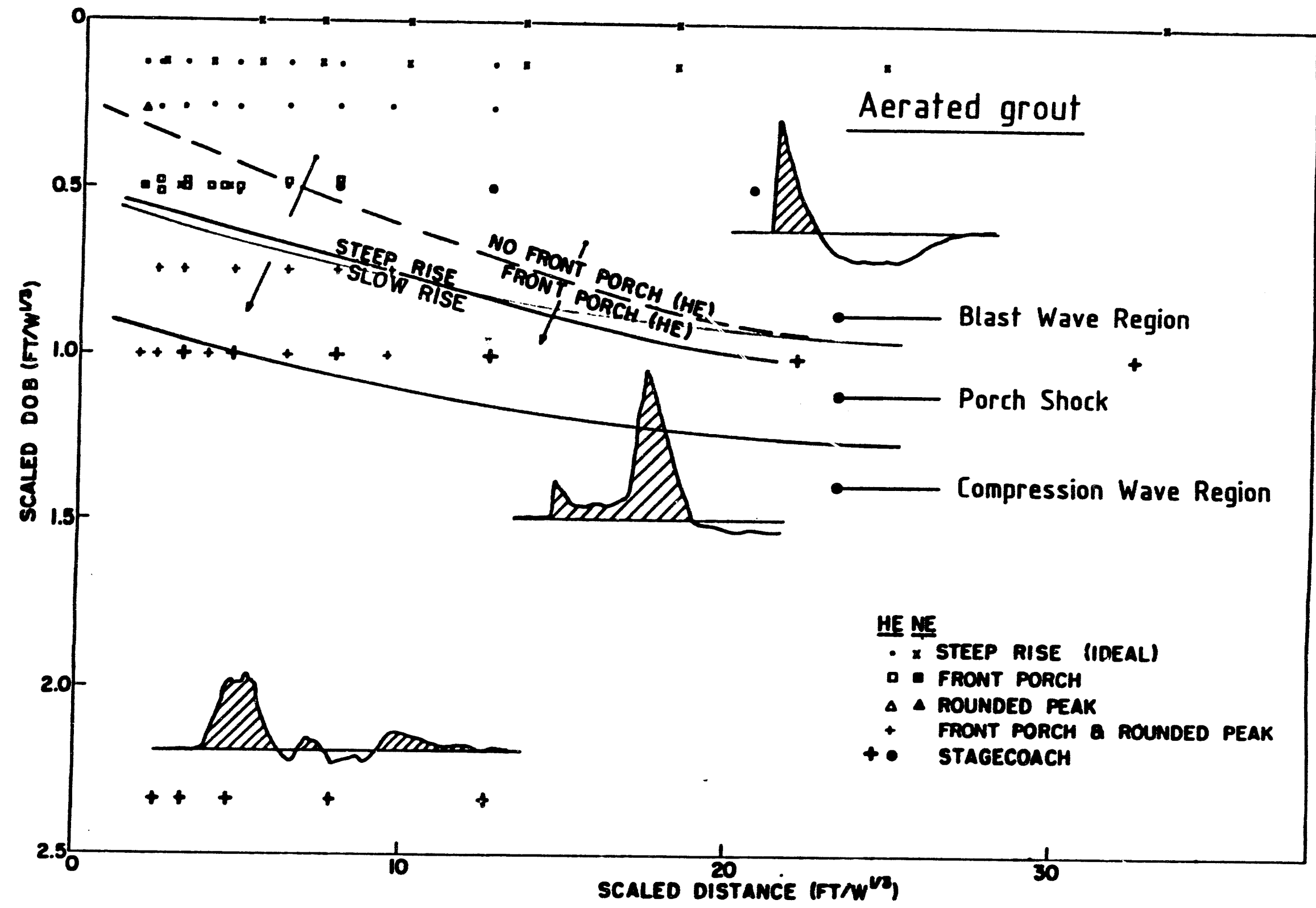

Figure 100 Comparison of wave form transitions for desert alluvium [from Ref. 12] and dry aerated grout (dry YTONG). 


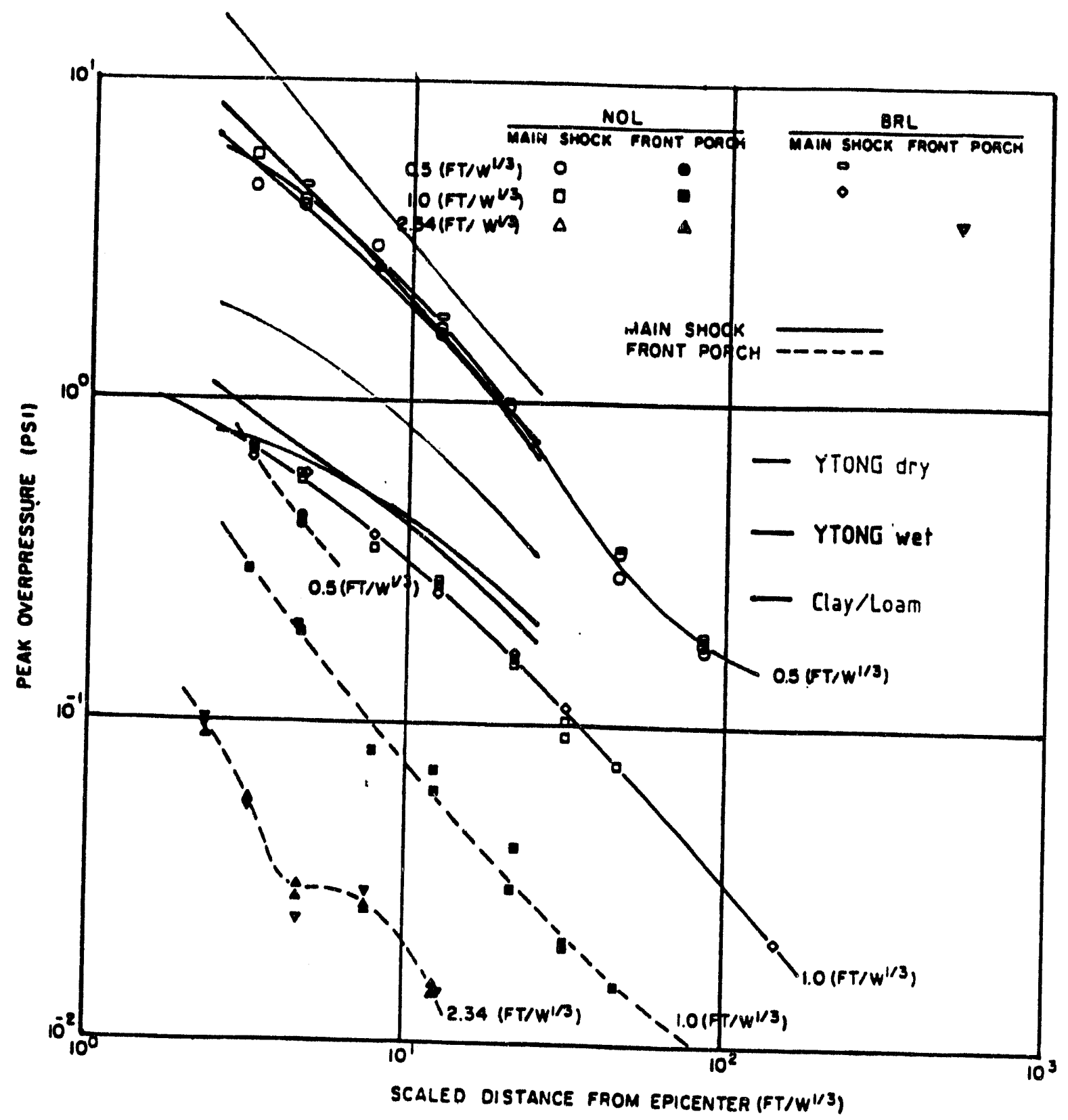

Figure $101 \quad \begin{aligned} & \text { Peak overpressure vs ground range for desert alluvium [Ref. 12] compared } \\ & \text { with results for aerated }\end{aligned}$ with results for aerated grout, water saturated grout and clay/loam. 


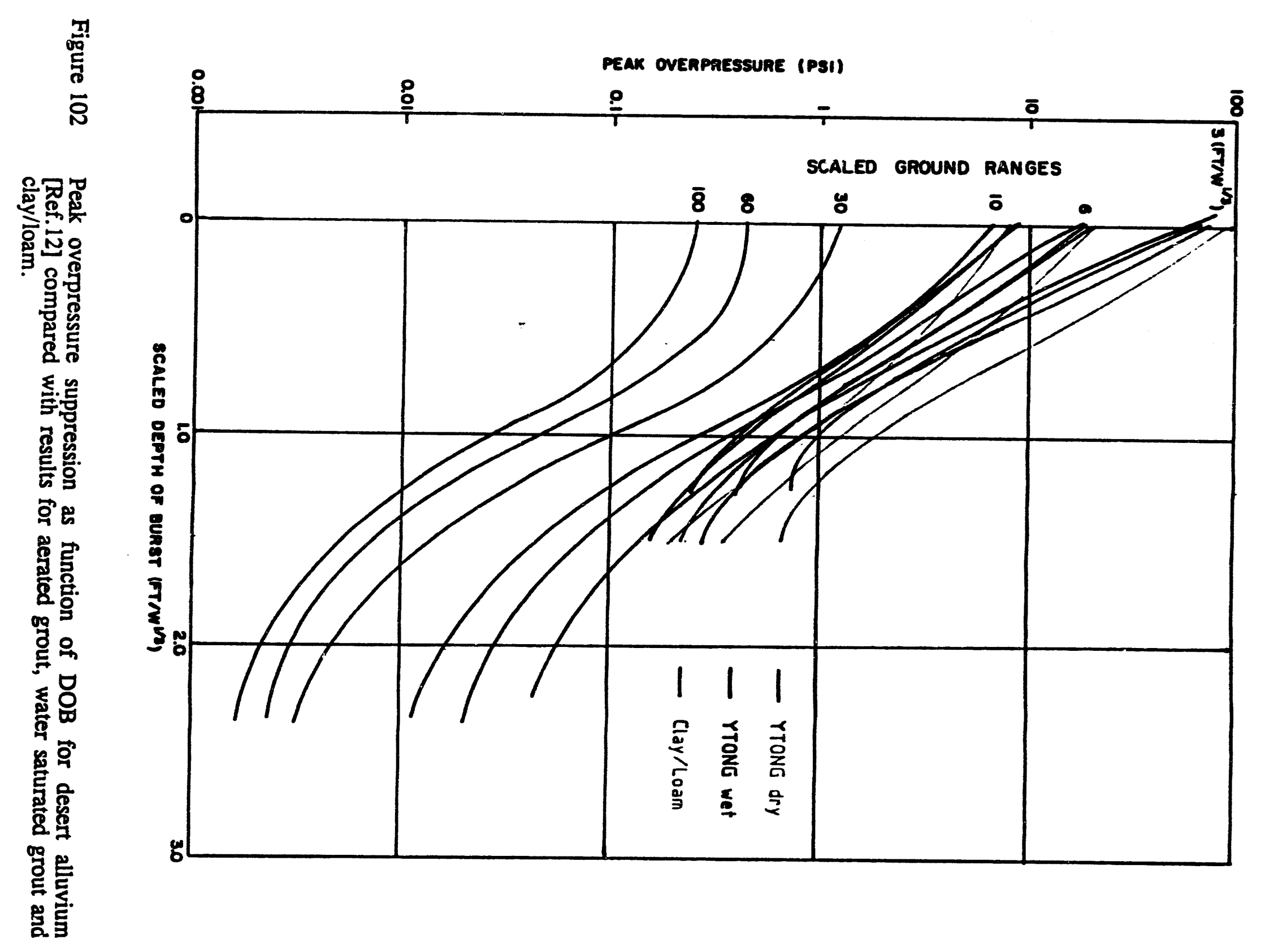

ธ్ํํ 

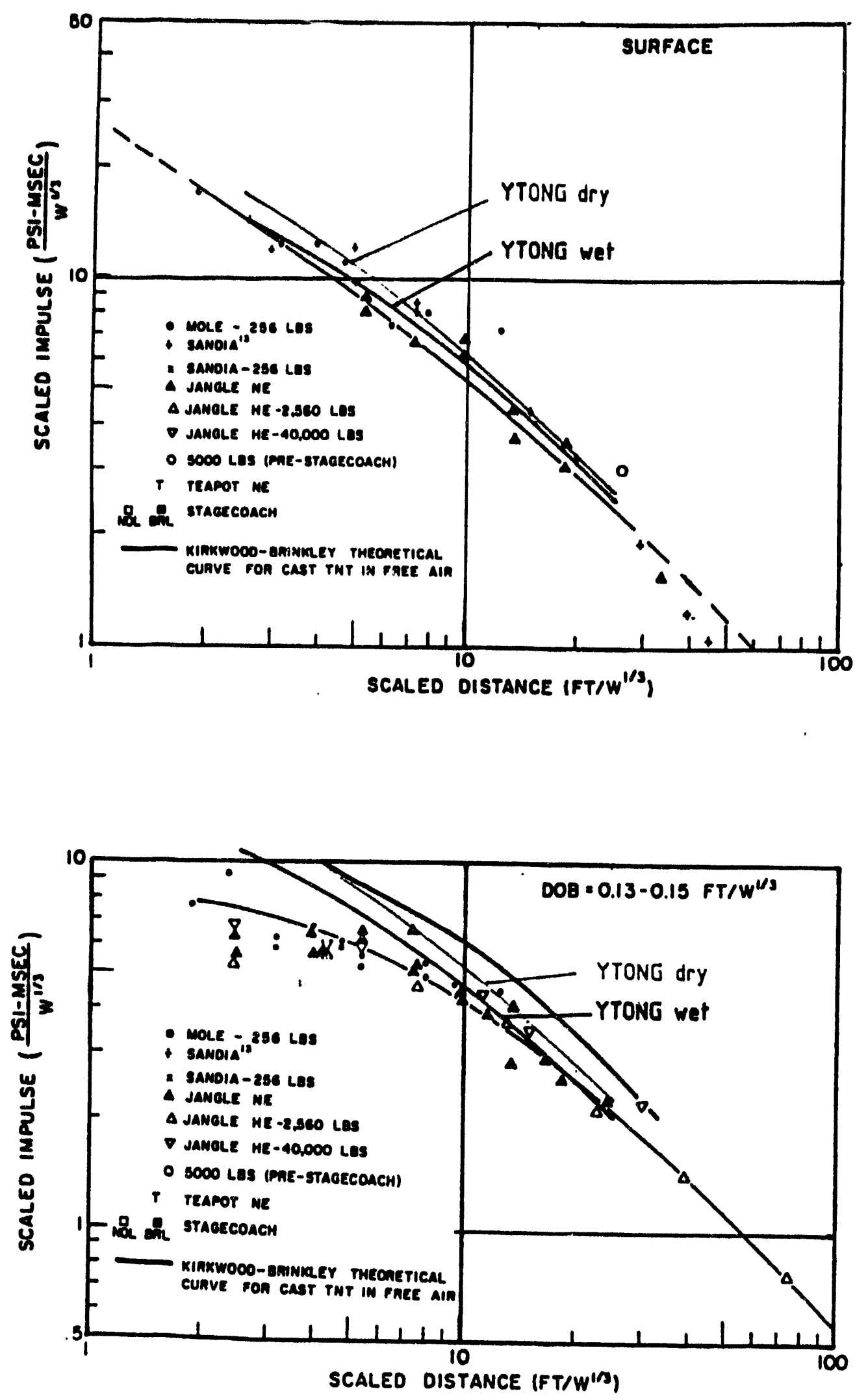

Figure 103 Impulse vs ground range for all charges fired in NTS desert alluvium [Ref. 12] compared with results for aerated grout and water saturated grout. 
161
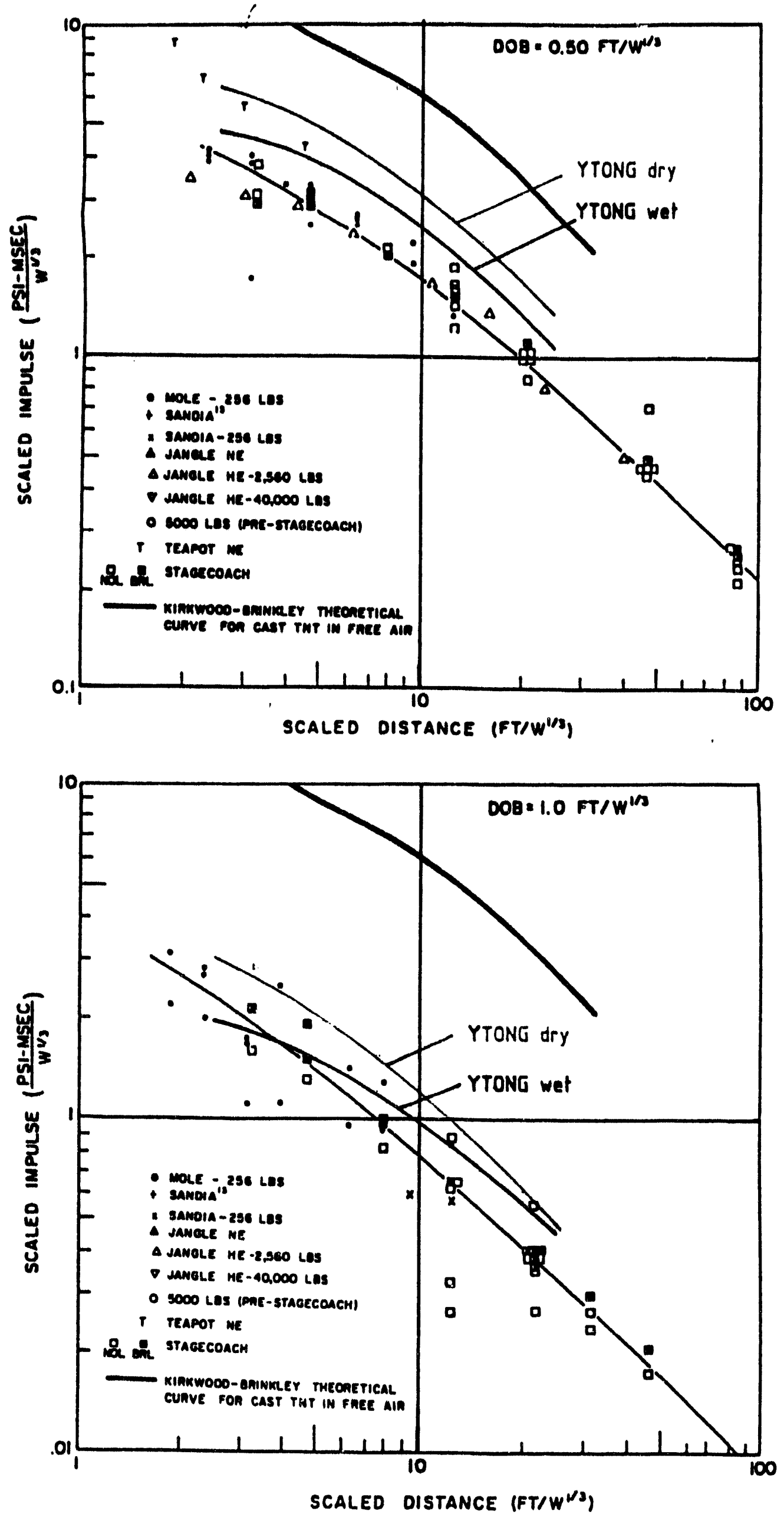


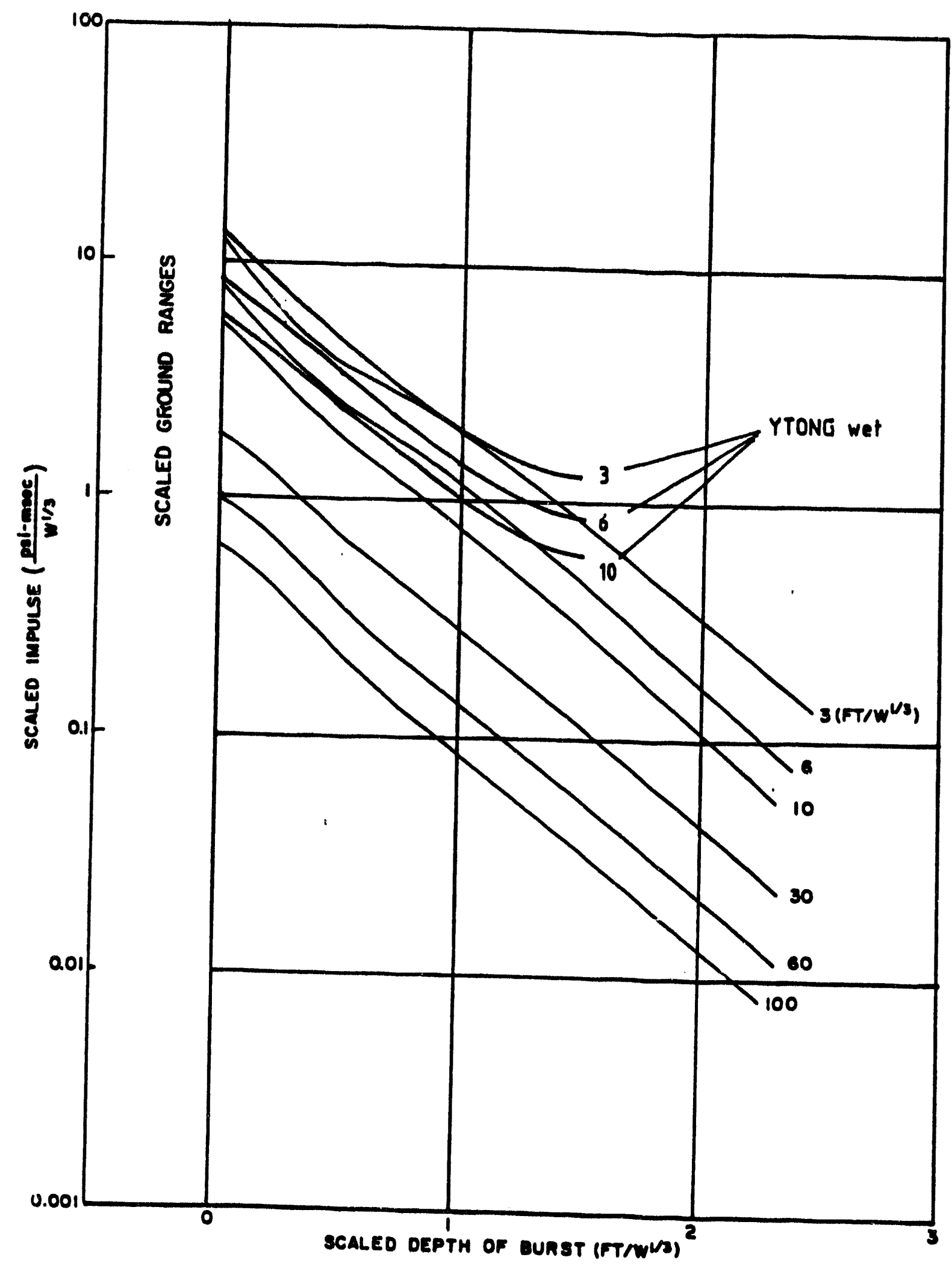

Figure 104 Suppression of blast impulse as function of DOB for desert alluvium [Ref. 12] compared with results for water saturated grout. 


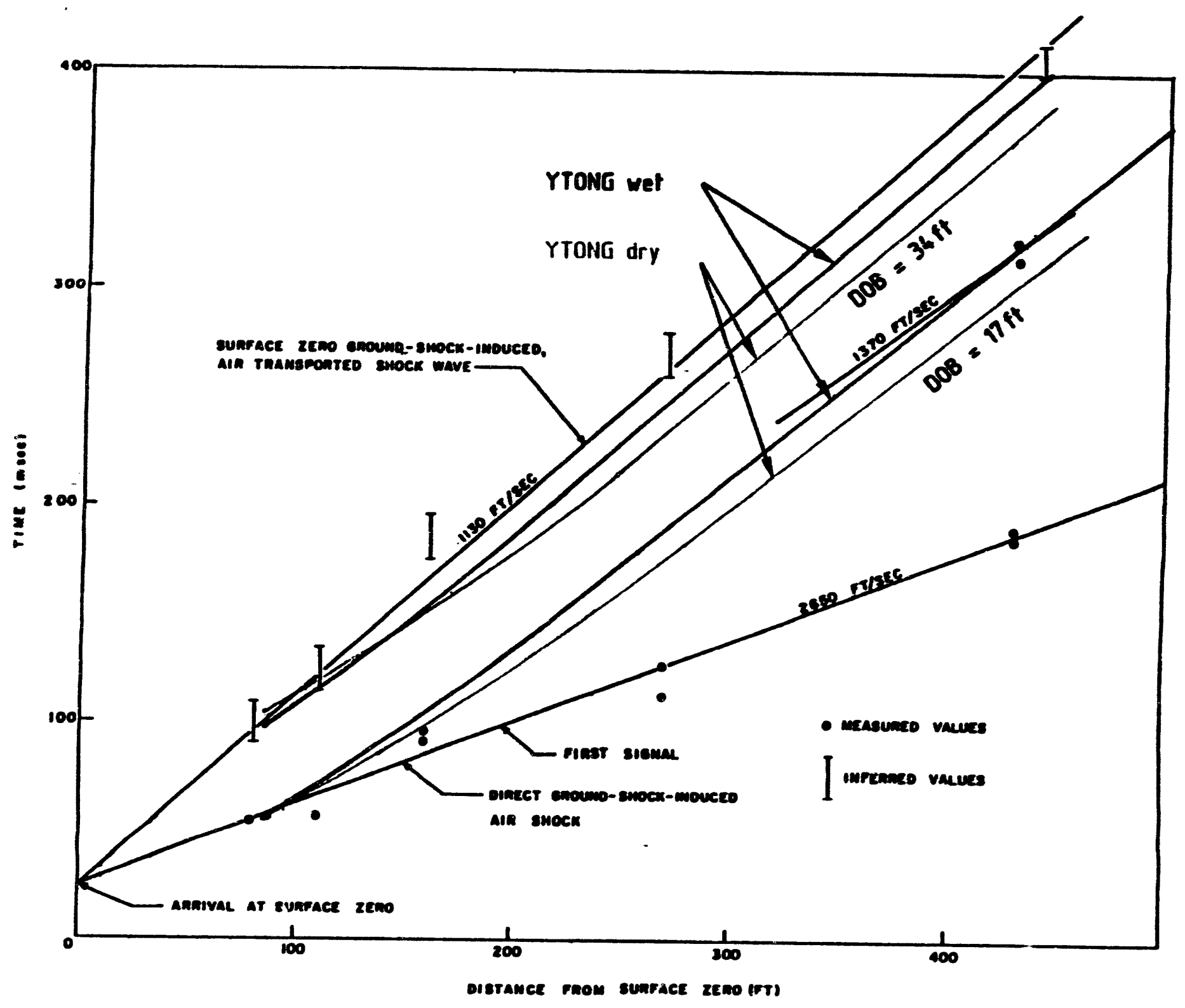
water saturated gout, resp. 

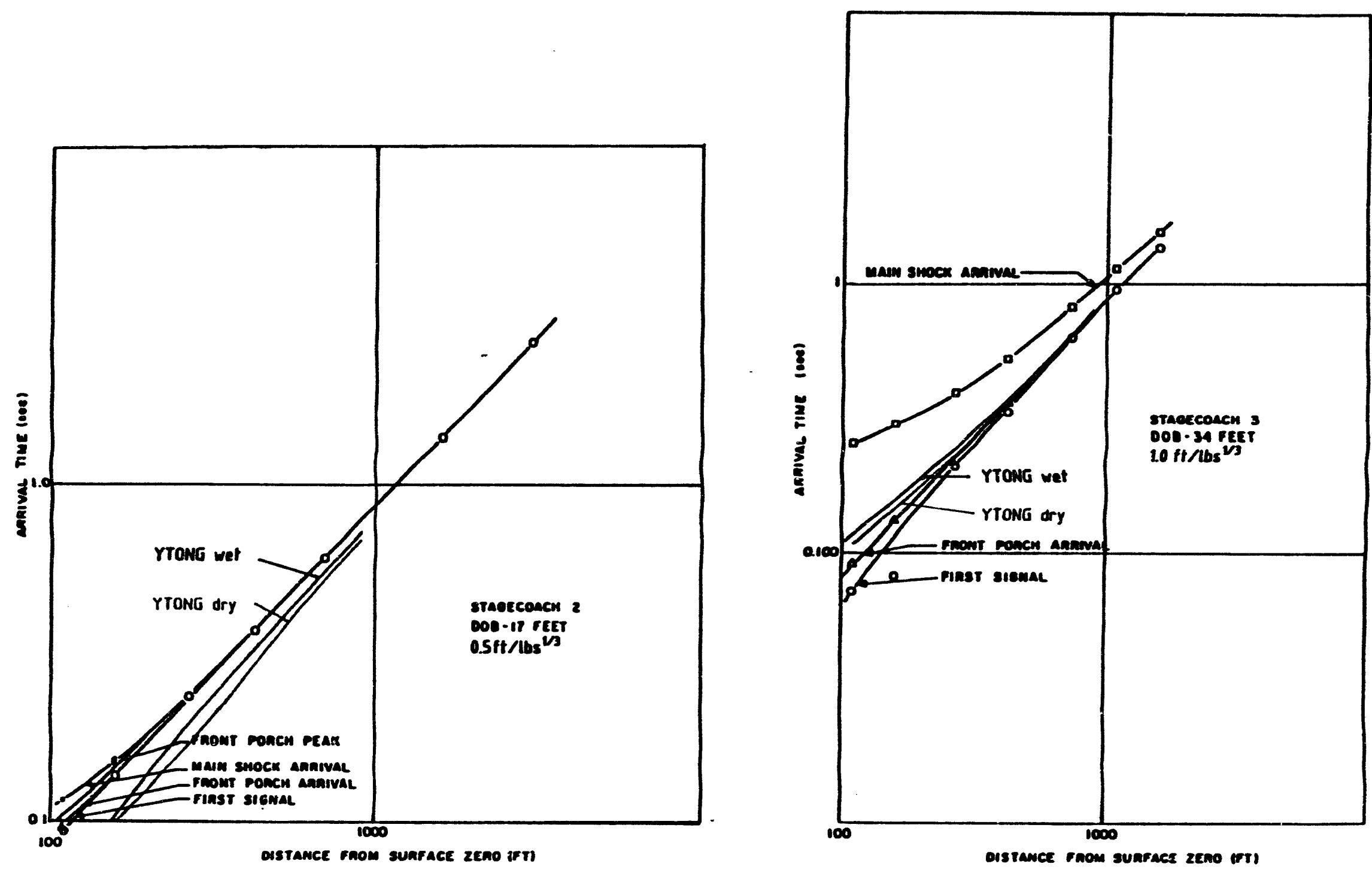

$\overline{8}$

Figure 106 Arrival time vs ground range for DOB $=0.5[\mathrm{ft} / \mathrm{lbs} / / 3](=17 \mathrm{ft})$ and DOB $=1.0\left[\mathrm{ft} / \mathrm{lbs} s^{1 / 3}\right](=34 \mathrm{ft})$ [Ref. 12] compared with results for aerated grout and water saturated grout, resp. 


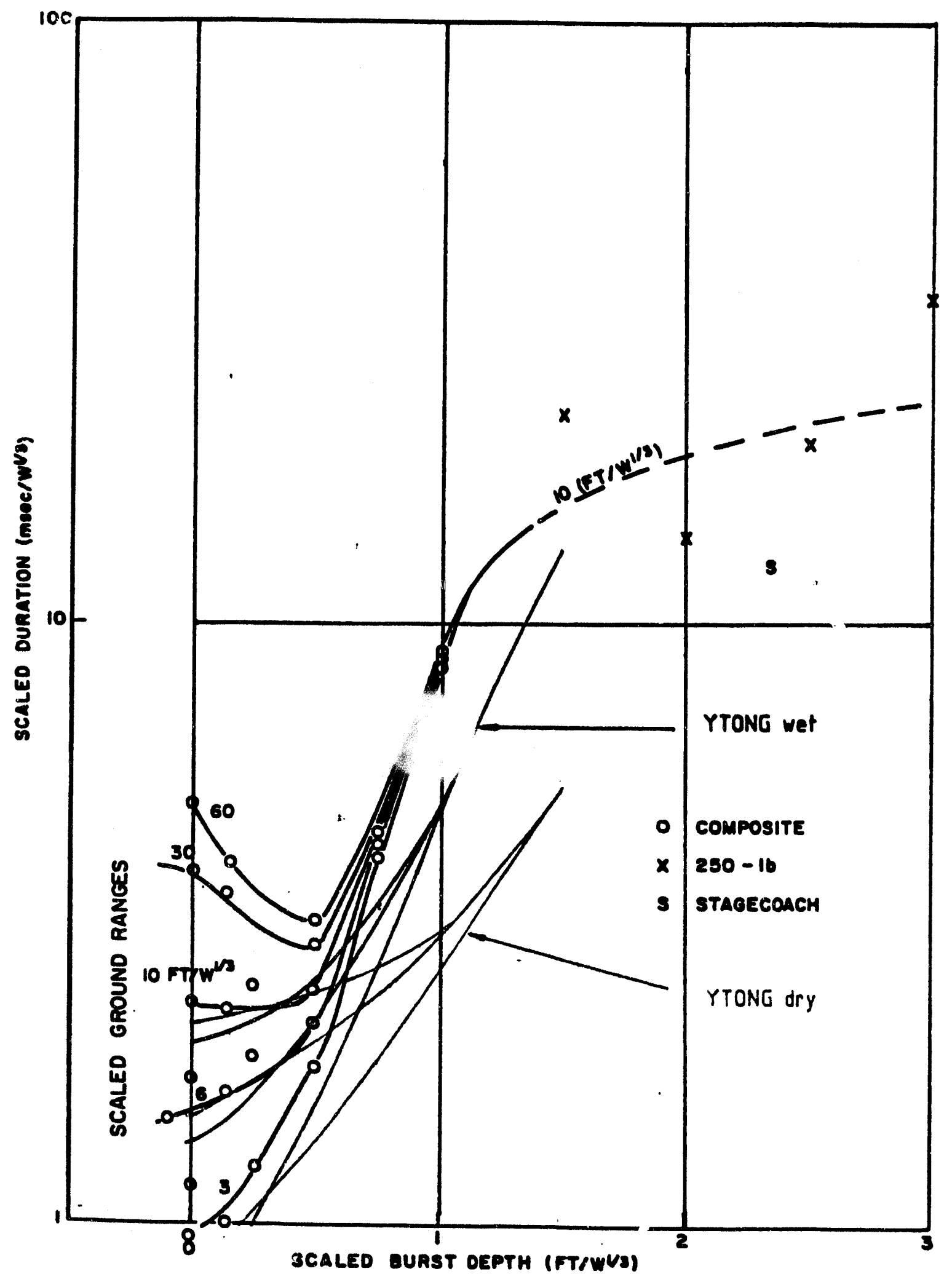

Figure 107 Effect of charge burial in desert alluvium on positive phase duration [Ref. 12] compared with results for aerated grout and water saturated grout, resp. 

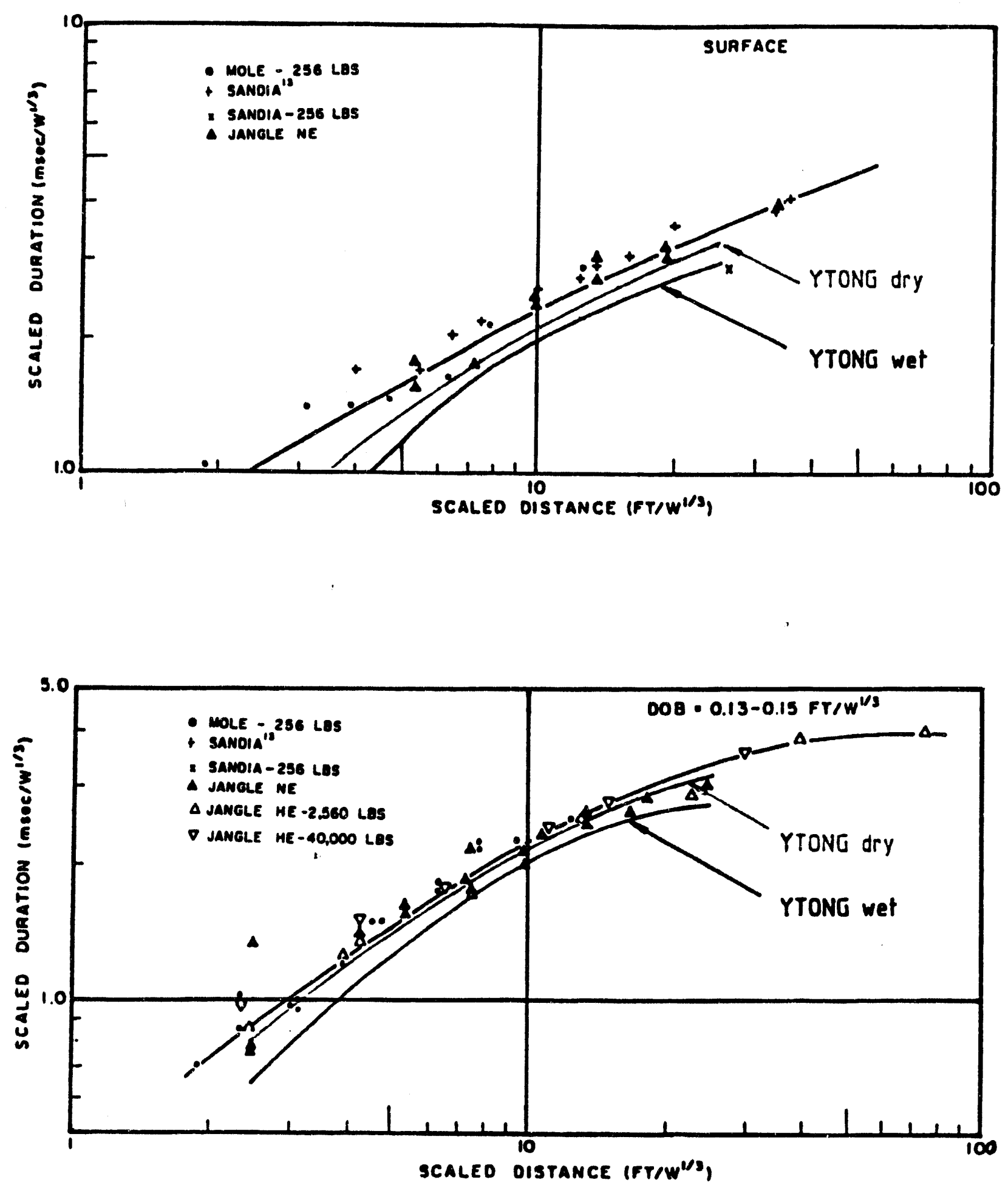

Figure 108 Positive phase duration vs ground range for all charges fired in desert alluvium [Ref. 12] compared with results for aerated grout and water saturated grout, resp. 

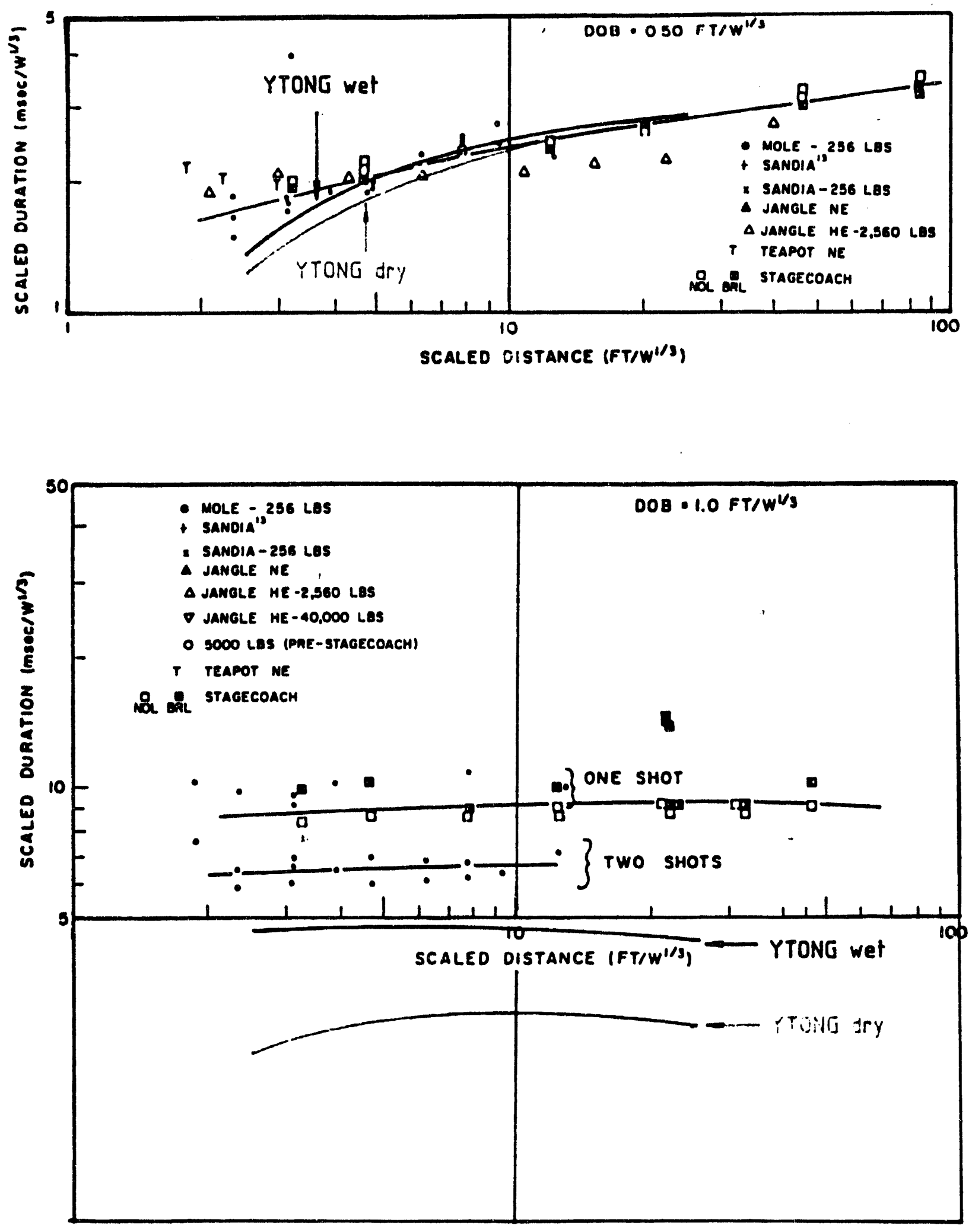

Figure 108 Continued. 


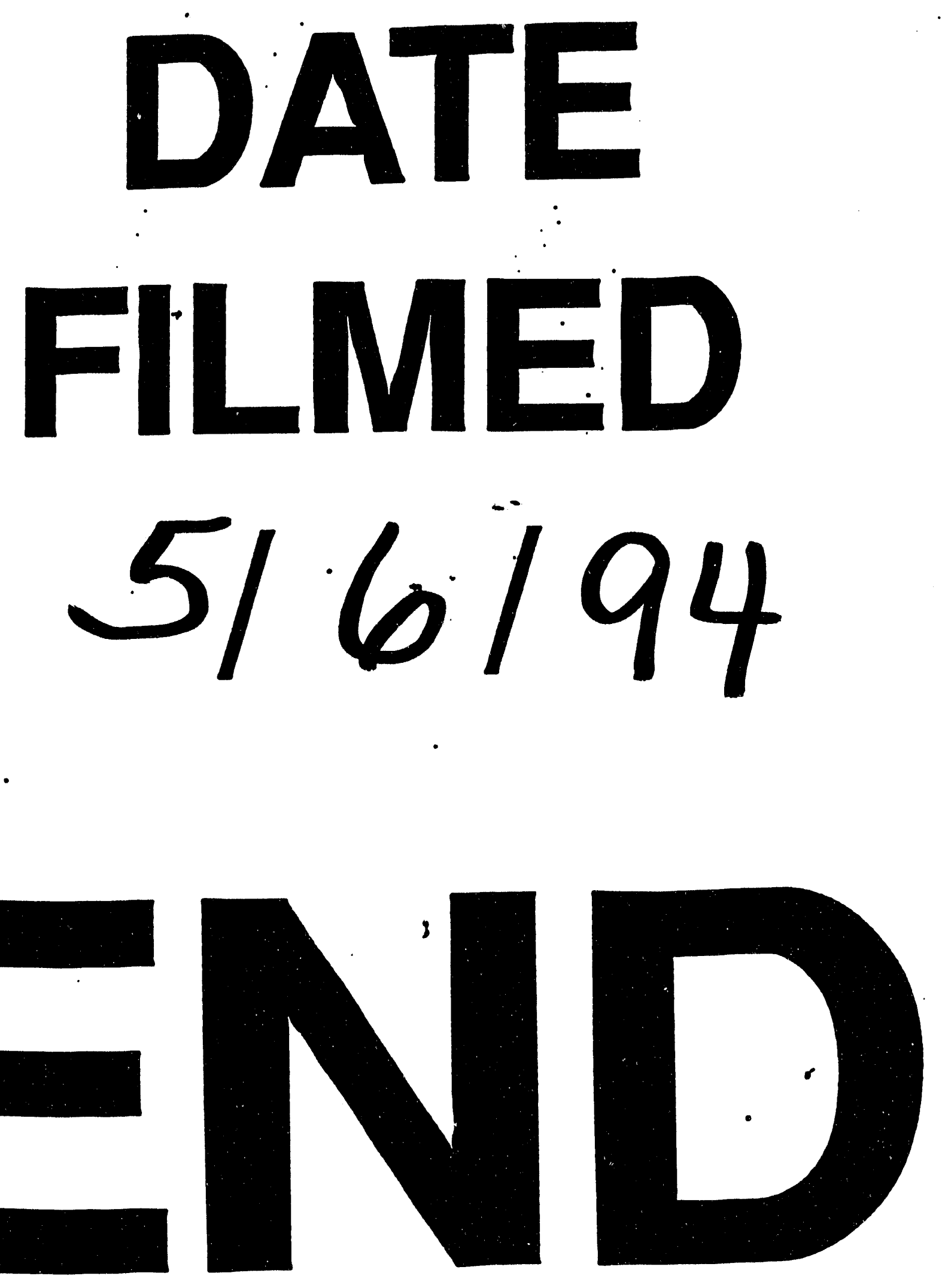


$6-1-2+2-2+2$ 